\title{
Referential properties of Serbian possessive modifiers
}

\author{
Inauguraldissertation \\ zur Erlangung des Grades eines Doktors der Philosophie \\ im Fachbereich Neuere Philologien \\ der Johann Wolfgang Goethe-Universität \\ zu Frankfurt am Main
}

vorgelegt von

Sanja Srdanović

aus

Novi Sad, Serbien

Einreichungsjahr: 2021

Erscheinungsjahr: 2022 
1. Gutachter: Prof. Dr. Esther Rinke

2. Gutachter: Prof. Dr. Petra Schulz

Tag der mündlichen Prüfung: 10. Juni 2021 


\section{Acknowledgements}

Undertaking this $\mathrm{PhD}$ has been a life-changing experience for me and I could not imagine succeeding in it without the support and guidance that I received from many people to whom I owe immense gratitude.

First of all, I would like to thank my supervisors, Prof. Dr. Esther Rinke and Prof. Dr. Petra Schulz, from whom I benefited a lot during these years. Dear Esther, thanks a lot for all your constructive feedback and discussions. You were there for me whenever I needed you, and without your guidance and support, this process would be much more difficult. Thank you for being so thoughtful and for believing in me. It has been an honour to have you as my first supervisor, I couldn't imagine a better and nicer person for this role! Dear Petra, I learned a lot about experimental methods from you, and I appreciate all the feedback you gave me. Even though I am not directly related to the acquisition, I enjoyed being a part of your Colloquium and sharing ideas and discussions about experiments with other colleagues.

I would like to thank all members of the Graduate school 'Nominal Modification', including all the PIs who have been always ready to help and give their feedback, especially during our GK Colloquium and Retreats.

Special thanks go to my GK colleagues, you're the reason why I have never felt alone in this process. After almost a year of the home office, I appreciate our offices at the campus and the time we spent together even more. I will miss the celebrations and spontaneous gatherings in the middle office and our cosy coffee sessions. I am grateful for meeting such good people, who were not only my colleagues, but became my real friends: Abby, Lydia, Astrid, Fenna, Melly, Lai, Ruby, Priscilla, Emine, Sebastian, Ahmad, Caro, Yranahan and Eu. I was so lucky to have the nicest office mates with whom I could talk not only about work, but also about personal matters - Lydia and Abby. A big thank you to Astrid, my statistics co-fighter, I appreciate all the discussions and your proofreading, and of course help with German translations.

It was also nice having someone who has already gone through the process of getting their $\mathrm{PhD}$, and from whose experience I learned a lot - Zheng, Heidi and Derya, you were my role models and I learned a lot from each of you! I am also very grateful to people from the Goethe Welcome Center, and especially to Birgit and Elke who made all the 
bureaucracy much easier.

I would have never become a linguist if it weren't for the Novi Sad Linguistic Colloquium group and professors (Tanja, Nataša and Sabina) who sparked my interest in syntax, and where I met my dear colleagues Isidora and Anja. I would like to thank the audience at the conferences I attended in the past years for their valuable feedback. And of course, I owe a special thank you to all the participants of my experiments.

I could have never dreamed of ending up in Frankfurt, but I am thankful for all the people I met, and for all the opportunities that were given to me here. I would like to thank the people who helped me the most when I moved to Germany. Dear Radmila, Julius, Mareen, Branka and Rade, I will never forget what you did for me and I will always be grateful that there are such good people like you on this planet. Dragana, the world is so small, and I am so happy to have a cousin here.

I am indebted to all my friends and family in Serbia, who were my first 'participants'. Thank you for putting up with me and all my experiments, I know that all the animals, managers, ga and njega etc. were sometimes overwhelming, but you helped me a lot with your judgments. My heart was full every time I came home and I tried spending as much time as possible with each of you. Pajo, I'm glad I could be there for your wedding. Kuma Branka (kuma Hana misses Damjan a lot) and Mima, I was happy each time we met and made our traditional photo. Sanje, I think we meet now more often, because you lived so far away from me when I was in Futog :D Isi, my initiator, you will always get an HP gift od tvoje teDke iz Frankfurta. Dragana, Jelena\&Jelena, we do keep gossiping via Viber but it's not the same as in person. Vanja, Grco, Veko and Malina (my DE support), I will never forget our gatherings at Korzo and of course we would always order something to eat. Now that we are all in DE (NL), Vanja, we are only waiting for you to come to Germany so we can gather here. Danka, teta Milada, thanks for your support!

I owe my deepest debt of love and thanks to my husband Igor, who moved to Germany because of me and has been always by my side throughout this process. I know it wasn't always easy, but we go through everything together! Thank you for drawing the pictures for my experiment, you're my artist. $<3$

Last but not least, I'd like to thank my family for believing in me. Mama, tata and Nikola, it has been difficult being apart from you, but you've always been there for me, no matter what, and I couldn't make it without your support, I love you so much! 


\section{Table of Contents}

1 Introduction 1

1.1 Object of investigation and research questions . . . . . . . . . 3

1.2 Thesis outline . . . . . . . . . . . . . . . . . . 11

2 Prenominal possessive modifiers $\quad 12$

2.1 Prenominal possessive modifiers cross-linguistically $\ldots \ldots \ldots$

2.1.1 Categorial status of possessives cross-linguistically: the DG/AG

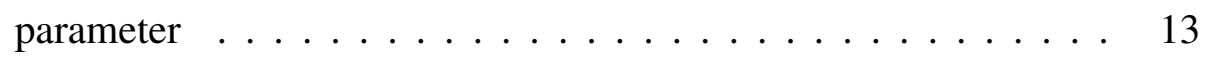

2.1.2 Position of possessives within the DP $\ldots \ldots \ldots 18$

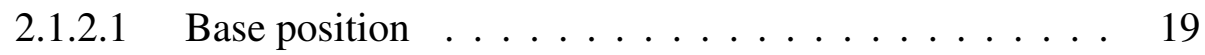

2.1.2.2 Derived positions ............... 22

2.1.3 Consequences of categorial status and syntactic position for binding cross-linguistically . . . . . . . . . . . . 28

2.2 Prenominal possessive modifiers in Serbian . . . . . . . . . . . 31

2.2.1 Characteristics of Serbian prenominal modifiers . . . . . . . 31

2.2.2 Morphology of Serbian possessives . . . . . . . . . . . 35

2.2.3 The categorial status of possessives in Serbian . . . . . . . . 39

2.2.3.1 Categorial status of possessives: adjectives? . . . . . . 41

2.2.3.2 Categorial status of possessives: exponents of D? . . . 42

2.2.4 Syntactic position of possessives in Serbian . . . . . . . . . . . 48

2.2.5 'Possessive binding' in Serbian . . . . . . . . . . . . . . . 52

2.3 Chapter summary . . . . . . . . . . . . . . . . . . 60

3 Study I - Binding of pronouns/ Binding Principle B 61

3.1 The role of different pronominal object forms in binding . . . . . . . . 61 
3.2 Experiment 1 - Principle B: Picture Selection Task . . . . . . . . . . . 72

3.2 .1 Methodology . . . . . . . . . . . . . . . . 73

3.2.1.1 Participants .................. 73

3.2.1.2 Design and Stimuli $\ldots \ldots \ldots \ldots$

3.2 .1 .3 Procedure ................. 75

3.2 .2 Results ........................ 77

3.3 Discussion . . . . . . . . . . . . . . . . . . . 79

3.4 Chapter summary . . . . . . . . . . . . . . . . 82

4 Study II - Binding of R-expressions/ Binding Principle C 83

4.1 Cataphoric dependencies and Condition $\mathrm{C}$ effect . . . . . . . . . . . . . 84

4.2 Previous psycholinguistic studies . . . . . . . . . . . . 86

4.3 The study: two experiments investigating the Principle C effect in Serbian 91

4.3.1 Experiment 2 - Principle C: an offline study _. . . . . . . . 94

4.3.1.1 Methodology ................ 95

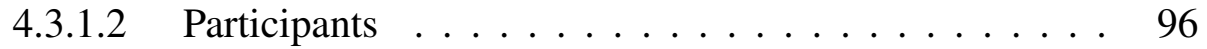

4.3.1.3 Design and Stimuli . . . . . . . . . . . 96

4.3.1.4 Procedure .................. 100

4.3.1.5 Results .................... 100

4.3.2 Experiment 3 - Principle C: an online study . . . . . . . . . 103

4.3.2.1 Methodology . . . . . . . . . . . . . . 104

4.3.2.2 Participants . . . . . . . . . . . . . 104

4.3.2.3 Design and Stimuli . . . . . . . . . . . . 105

4.3.2.4 Procedure ................... 109

4.3.2.5 Results . . . . . . . . . . . . . 110

4.3.3 Summary of the results of Experiments 2 and $3 \ldots \ldots 117$

5 General discussion $\quad 120$

5.1 Coming back to the categorial status of possessives $\ldots \ldots \ldots 121$

5.2 The non-c-commanding position of possessives within the nominal phrase 123

5.3 DP or NP in Serbian? . . . . . . . . . . . . . . . . . . 127

5.4 The explanation of the variability of coreference and non-coreference . . 129 
6 Conclusion

135

Appendix A Experiment 1

Appendix B Experiment 2

Appendix C Experiment 3 


\section{List of Figures}

3.1 The general context of Experiment $1 \ldots \ldots \ldots 76$

3.2 Screen 1. An introductory sentence and picture (Experiment 1) . . . . 76

3.3 Screen 2. Test item and picture choice $($ Experiment 1) $\ldots \ldots$. . . . . . 77

3.4 Choice of coreferent/non-coreferent interpretation with clitic/strong pronoun in percentages $($ Experiment 1$) \ldots \ldots \ldots$. . . . . . . . 78

4.1 Choice of coreferential/non-coreferential interpretation in 4 conditions . . 101

4.2 Choice of coreferential/non-coreferential interpretation for fillers . . . . 102

4.3 Self-paced reading task procedure . . . . . . . . . . . . . . . 110

4.4 Average reading times on the critical word per condition (N1) . . . . . . . 114

4.5 Average reading times at the spillover region per condition (N2) . . . . . 117 


\section{List of Tables}

1 List of Abbreviations $\ldots \ldots \ldots \ldots \ldots \ldots \ldots$

2.1 Properties of DPs in AG vs. DG languages (Schoorlemmer 1998:62) . . . 17

2.2 Serbian pronominal possessives . . . . . . . . . . . 36

3.1 A sample of test items in Experiment $1 \ldots \ldots$. . . . . . . . . . 74

3.2 A sample of control items in Experiment $1 \ldots \ldots$. . . . . . . . . 75

3.3 Experiment1. Generalized Linear Mixed-Effects Regression for the likelihood of coreferential interpretation . . . . . . . . . . . 78

4.1 Conditions from the self-paced reading task (Experiment 3) by Kazanina et al. $(2007: 401) \ldots \ldots \ldots \ldots \ldots \ldots$

4.2 Conditions from the offline task (Experiment 3) by Kazanina et al. (2007) 89

4.3 A sample of test items for Experiment 2 . . . . . . . . . . . . . . . . 97

4.4 A sample of filler items for Experiment 2 . . . . . . . . . . . . . . . . 98

4.5 Experiment2. Generalized Linear Mixed-Effects Regression for the choice of coreferential interpretation . . . . . . . . . . . . . 101

4.6 The distribution of non-coreferential responses: another referent vs. somebody else ......................... 103

4.7 A sample of test items for Experiment 2 . . . . . . . . . . . . 106

4.8 A sample of filler items - Experiment $3 \ldots \ldots$. . . . . . . . . . . 107

4.9 A sample of comprehension questions - Experiment 3 . . . . . . . . 108

4.10 Linear Mixed-Effects Regression - the final model at the critical word

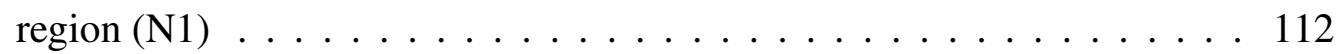

4.11 The role of C-command on each Gender level (N1) . . . . . . . . . 113

4.12 The role of Gender on each C-command level (N1) . . . . . . . . . . 113 
4.13 Linear Mixed-Effects Regression - the final model at the spillover region

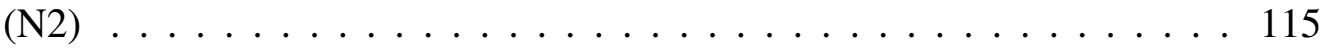

4.14 The role of C-command on each Gender level (N2) . . . . . . . . . . . 115

4.15 The role of Gender on each C-command level (N2) $\ldots \ldots$. . . . . . . . 116

A.1 Experiment 1: Intro sentences and pictures . . . . . . . . . . . . . . . . 149

A.2 Experiment 1: Test sentences and pictures $\ldots \ldots \ldots \ldots$

A.3 Experiment 1: Control sentences and pictures . . . . . . . . . . . 157

A.4 Experiment 1: Practice sentences and pictures . . . . . . . . . . . . 158

B.1 Experiment 2: Practice items . . . . . . . . . . . . . . . . . . . . 159

B.2 Experiment 2: Test items with questions $\ldots \ldots \ldots \ldots$

B.3 Experiment 2: Filler items with questions . . . . . . . . . . . . 167

C.1 Experiment 3: Practice items . . . . . . . . . . . . . . . . 176

C.2 Experiment 3: Test items and comprehension questions . . . . . . . . . 177

C.3 Experiment 3: Filler items and comprehension questions . . . . . . . . 183

C.4 The post-hoc Tukey Test - Pairwise comparison at the critical word region

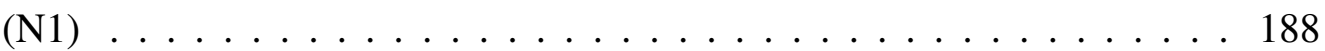

C.5 The post-hoc Tukey Test - Pairwise comparison at the spillover region (N2) 189 


\section{List of abbreviations}

Table 1: List of Abbreviations

\begin{tabular}{|c|c|}
\hline Abbreviation & Meaning \\
\hline $1,2,3$ & first, second, third person \\
\hline $\mathrm{ACC}$ & accusative \\
\hline ADJ & adjective \\
\hline $\mathrm{AG}$ & adjectival genitive \\
\hline AgrP & agreement phrase \\
\hline AUX & auxiliary \\
\hline CONJ & conjunction \\
\hline CL & clitic \\
\hline $\mathrm{CP}$ & complementizer phrase \\
\hline DAT & dative \\
\hline DEF & deficient \\
\hline$+/-$ def & definite/indefinite \\
\hline DERIV & derivational \\
\hline Det & determiner \\
\hline DG & determinative genitive \\
\hline DP & determiner phrase \\
\hline DEM & demonstrative determiner \\
\hline EPP & Extended Projection Principle \\
\hline $\mathrm{F}$ & female \\
\hline FP & functional phrase \\
\hline FUT & future \\
\hline GEN & genitive \\
\hline INFL & inflectional \\
\hline IP & inflectional phrase \\
\hline INST & instrumental \\
\hline LF & Logical Form \\
\hline M & mean \\
\hline $\mathrm{ms}$ & milliseconds \\
\hline
\end{tabular}




\begin{tabular}{ll} 
Abbreviation & Meaning \\
NEG & negative \\
NP & noun phrase \\
NOM & nominative \\
nP & little NP \\
NumP & number phrase \\
PL & plural \\
POSS & possessive \\
PossP & possessive phrase \\
PP & prepositional phrase \\
QP & quantificational phrase \\
RT & reaction time \\
R-expression & referential expression \\
SG & singular \\
Spec & specifier \\
STR & strong pronoun \\
t & trace \\
VP & verb phrase \\
vP & little VP \\
VoiceP & voice phrase \\
\hline
\end{tabular}


To my family 



\section{Chapter 1}

\section{Introduction}

Based on the parallels that have been drawn between sentences and noun phrases, Abney (1987) proposed that noun phrases are DPs and not NPs. The underlying assumption of the DP hypothesis is that analogously to verbs that are a part of a larger structure, i.e. dominated by functional material, nominal expressions are a part of a larger functional complex too, and this is a DP. According to the Universal DP Hypothesis (UDPH), it is claimed that all languages have the DP regardless of the presence or the absence of articles. Thus, it is believed that even articleless languages, such as Serbian, ${ }^{1}$ project a D head, although it is not pronounced (Bašić 2004; Progovac 1998; Stanković 2013). On the other hand, it has been proposed that the DP structure does not hold for articleless languages. A group of authors observed that languages with and without articles exhibit severely different possibilities and characteristics (Baker 2003; Bošković 2005, 2008; Chierchia 1998; Zlatić 1997, 1998). For instance, they differ in the aspect of leftbranch extraction, adjunct extraction, scrambling, clitic doubling, etc. (Bošković 2005, 2008). One more piece of evidence in the favour of no-DP analysis is that Serbian and English differ in binding possibilities (Despić 2011, 2013). In this thesis, I will focus on the structure and binding properties of possessive noun phrases in order to contribute to a better understanding of how noun phrases work in Serbian and to contribute to the briefly introduced DP debate.

In order to find out more about the referential properties of possessive noun phrases, one should firstly have a closer look at the characteristics and behaviour of possessives. Possessives differ across languages in terms of their features, surface word ordering, and types of possessives etc. Lyons (1986) and Giorgi and Longobardi (1991) distinguish

\footnotetext{
${ }^{1}$ The language of investigation is referred to as Serbian, and not as Serbo-Croatian (SC) or Bosnian/Serbian/Croatian (BSC), which are the common labels in the literature, because only native speakers of the Serbian variety participated in the experiments. Therefore, it might be inaccurate to generalize the findings for all varieties, as it might be the case that speakers of the Croatian or Bosnian variety would not share the judgments or allow for the coreference in the same cases as consulted speakers of the Serbian variety did. This phenomenon may behave the same in all varieties, but in order to be certain, the findings should be replicated with a group of native speakers of Croatian and Bosnian in future empirical studies.
} 
between two types of languages: (1) 'determiner genitive' (DG), in which possessors function like determiners and in (2) 'adjectival genitive' (AG) languages, possessors pattern with adjectives and have a modifier function. As for Serbian, it is a matter of debate to which group the language belongs.

Secondly, the internal make-up of a nominal phrase, as well as patterns and restrictions of word order with respect to possessives in combination with other prenominal modifiers should be observed. In DG languages, possessors seem to occupy a position in $\mathrm{D}$ or SpecD, while in $\mathrm{AG}$ languages possessors are in lower specifier positions than $\mathrm{D}$ (e.g. SpecAgrP or SpecnP) (Alexiadou et al. 2007). However, Kayne (1994) proposes that the prenominal possessor in English should also occupy a lower specifier position, namely the SpecPossP, dominated by a DP with a null D head. The difference between the approaches concerning the position of possessives pertains to the question of whether possessives can c-command out of their phrase and violate binding principles.

Possessives seem to be very intriguing when it comes to their binding possibilities. Namely, the referential properties of possessives modifying a noun in subject position seem to behave differently from nouns that are not modified with possessives when it comes to binding of a pronoun in object position. Example (1) can never be grammatical with a coreferential interpretation between 'John' and 'him'. In order to make (1) grammatical, an anaphora sebe/se, 'himself' should be used (example (2)).

(1) ${ }^{*} \operatorname{Jovan}_{i} \operatorname{ga}_{i}$ je udario. / $* \operatorname{Jovan}_{i}$ je udario njega $i$.

Jovan him.CL AUX hit. / Jovan AUX hit him.STR.

*'John ${ }_{i}$ hit him $_{i}$ ',

(2) $\operatorname{Jovan}_{i} \mathrm{se}_{i} \quad$ udario. / Jovan $i$ je udario sebe ${ }_{i}$.

John himself.CL hit. / John AUX hit himself.STR

' $\mathrm{John}_{i}$ hit himself ${ }_{i}$ ',

However, if the anaphor was used instead of the pronoun in an example with possessives, the interpretation gets completely different, see (3). The coreference can be only established with the subject konj, 'horse', and not with the possessive Jovanov, 'John's' anymore.

Jovanov $_{* i} \operatorname{konj}_{i} \operatorname{se}_{i} \quad$ udario. $/$ Jovanov $_{* i} \operatorname{konj}_{i}$ je udario sebe ${ }_{i}$.

Jovan's horse himself.CL hit. / Jovan's horse AUX hit himself.STR.

'John ${ }_{\star i}$ 's horse ${ }_{i}$ hit himself $i$.'

The data in (3) are uncontroversial. However, it is not clear whether the binding properties of possessive constructions always differ from unmodified noun phrases. For English, this 
seems to be the case undeniably $\left({ }^{*} \mathrm{John}_{i}\right.$ hit $\operatorname{him}_{i} . / \mathrm{John}_{i}$ 's horse hit him ${ }_{i}$ ). For languages such as Serbian, it has been claimed that a coreferential interpretation between a possessive in subject position and a bound element in object position is not allowed (Despić 2013).

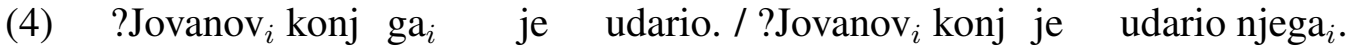
John's horse him.CL AUX hit. / John's horse AUX hit him.STR 'John ${ }_{i}$ 's horse hit him $i$ ',

The overall goal of this dissertation is to determine the role of prenominal possessives modifying a noun in subject position in binding constructions as in previous examples, and to investigate whether it is actually possible to get coreference in such configurations in Serbian. Since the categorial status and structural position of possessives can have consequences for the process of binding, the categorization of Serbian possessives according to the DG/AG parameter, as well as the structure of the nominal phrase are re-examined. Moreover, the purpose of my research is to provide empirical evidence that would support theoretical assumptions, and to show that, contrary to existing claims, possessives can indeed corefer with pronominal objects or R-expressions in Serbian, which is corroborated by two experimental studies.

\subsection{Object of investigation and research questions}

Who has been bitten in the sentence in (5) and whose parrot has bitten John in the sentence in (6)? These are the questions of great significance for this dissertation.

?Jovanov $_{i}$ papagaj ga $_{i}$ je ugrizao.

Jovan's parrot him.CL AUX bitten

'John ${ }_{i}$ 's parrot has bitten $\operatorname{him}_{i}$ '.

(6) ?Njegov $_{i}$ papagaj je ugrizao Jovana ${ }_{i}$.

His parrot AUX bitten John

'His $i$ parrot has bitten $\mathrm{John}_{i}$.'

It has been claimed in the literature that it is impossible to get a coreferential interpretation between Jovanov, 'John's' and ga, 'him.CL', and njegov, 'his' and Jovana, 'John. ACC' respectively (Despić 2013). However, corresponding English sentences are perfectly acceptable with the coreferential interpretation (Despić 2011, 2013).

In English, object pronouns or R-expressions can be coreferential with a possessive modifier modifying a noun phrase in subject position within the same sentence, see example (7) from Despić (2013:243). 
a. $\operatorname{His}_{i}$ father considers $\operatorname{John}_{i}$ highly intelligent.

b. $\mathrm{John}_{i}$ 's father considers him ${ }_{i}$ highly intelligent.

Despić (2013) rules out such constructions in Serbian, where a possessive name or a possessive pronoun modifies a noun in subject position, and a pronoun or an R-expression is in object position, see examples (8) and (9) from Despić (2013:245).

a. *Kusturicin ${ }_{i}$ najnoviji film je zaista razočarao njega . $_{\text {. }}$ Kusturica's latest film AUX really disappointed him.STR 'Kusturica ${ }_{i}$ 's latest film really disappointed him $_{i}$.'

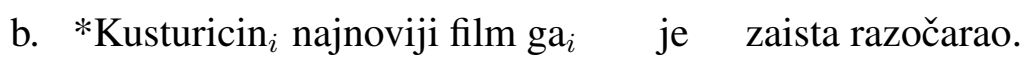
Kusturica's latest film him.CL AUX really disappointed 'Kusturica ${ }_{i}$ 's latest film really disappointed him $_{i}$.'

(9) $*$ Njegov $_{i}$ najnoviji film je zaista razočarao Kusturicu ${ }_{i}$. His latest film AUX really disappointed Kusturica.ACC 'His ${ }_{i}$ latest film really disappointed Kusturica ${ }_{i}$ '

According to Despić (2013), the possessive name Kusturicin, 'Kusturica's' (8) and possessive pronoun njegov, 'his'(9) cannot corefer to the object pronoun ga/njega, 'him' (8) and proper name Kusturica (9) respectively (Despić 2013). Despić (2011) follows LeeSchoenfeld's (2008) proposal that a phase corresponds to the so-called Binding Domain and assumes that DPs are phases, while NPs are not. Assuming that Serbian does not project DPs, but has traditional NPs, Kusturicin najnoviji film, 'Kusturica's latest film' in (8) and Njegov najnoviji film, 'His latest film' in (9) are not phases according to Despić (2011). He argues that the possessor has the ability to bind the pronoun/R-expression and therefore violates Binding Principles B and C accordingly. Despić (2011) concludes that the data provide evidence in favour of the no-DP analysis. Assuming that the possessor is NP-adjoined, and predicting that DP is not projected above the noun phrase, there is then no element to block the c-command of a possessor out of the NP.

Despić's argumentation shows that the binding properties of possessive noun phrases are closely related to their internal structure. The internal structure of possessive noun phrases, in turn, relates to the grammatical properties of possessives. Therefore, the first major issue for binding arises from the categorial status of possessives. There has been a long dispute on the categorial status of possessives in Serbian. Although the proponents of NP analysis (Bošković 2005; Despić 2011; Zlatić 1997) claim that possessives should be analysed as adjectives, the opposing view is that they should be treated as exponents of D (Bašić 2004; Šarić 2018).

According to Zlatic (1998), possessives exhibit the behaviour of both nouns and adjectives, because they show adjectival behaviour concerning morphological agreement, 
since they agree with the head noun in case, gender and number, as illustrated in (10) (Bošković 2009:192).
a. mojim
nekim
visokim devojkama
my.POSS.PL.INST some.F.PL.INST tall.F.PL.INST girls.F.PL.INST
b. mojih
nekih
visokih
devojaka
my.POSS.PL.GEN some.F.PL.GEN tall.F.PL.GEN girls.F.PL.GEN

Additionally, demonstratives and adjectives that precede a possessor, such as ovaj, 'this' in example (11) from Despić (2013:247) do not constrain its c-command domain, under the assumption that they are also NP-adjoined (Bošković 2008, 2012; Despić 2011, 2013).
a. *Ovaj Kusturicin najnoviji film ga $_{i}$ je zaista razočarao.
This Kusturica's latest film him.CL AUX really disappointed

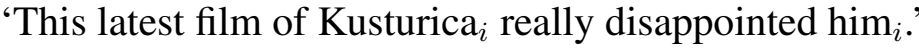
b. *Ovaj njegov ${ }_{i}$ najnoviji film je zaista razočarao Kusturicu $_{i}$ This his latest film AUX really disappointed Kusturica.ACC 'This latest film of his ${ }_{i}$ really disappointed Kusturica ${ }_{i}$.'

Zlatić (1997), Despić (2011), and Bošković (2012) postulate that the demonstrative in (11) does not block c-command because, like possessives and adjectives agreeing with a noun, they are multiple adjuncts or multiple Specs of the same position in Serbian.

However, even though possessives show morphological agreement with nouns and bear other properties that equate them to adjectives, there are numerous convincing counterarguments that fully support the claim that they behave like DPs (such as coordination and binding). When it comes to binding, possessives display nominal properties. Bašić (2004:20) uses Zlatić's (1998) example to show that possessives are able to bind anaphors as illustrated in (12). ${ }^{2} 3$

\footnotetext{
${ }^{2}$ The following pronouns are used to express reflexivity in Serbian: the reflexive pronoun sebe, the clitic reflexive pronoun $s e$, and the possessive reflexive $s v o j$.

(i) $\operatorname{Petar}_{i}$ je dao Mariji svoju knjigu.

Peter AUX gave Mary self's book

'Peter gave Mary his $_{i}$ book.'

Serbian reflexives are subject-oriented, which means that they select clausal subjects as their antecedents (Bašić 2004:21).

${ }^{3}$ The noun opisivanje, 'description' in (12) is a complex nominal according to Grimshaw (1990). Following previous literature (Alexiadou 2001; Schoorlemmer 1998), complex nominals have embedded verbal functional layers, where possessives behave as subjects. This indicates that possessives can bind reflexives, given that they function as subjects at some level of derivation within Serbian nominals.
}

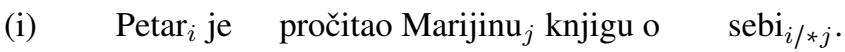

Peter AUX read Mary's book about self

'Peter read Mary $_{j}$ 's book about himself $i / * j$ ' 


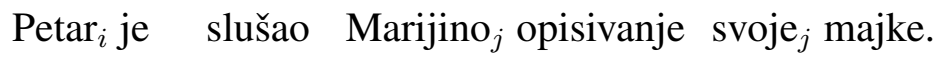

Peter AUX listened Mary's description self's mother

'Peter ${ }_{i}$ listened to Mary ${ }_{j}$ 's description of her ${ }_{j}$ mother.'

Moreover, according to Šarić (2018:176) following Rappaport (2000), possessives can bind anaphoric pronouns, while adjectives cannot, as shown in (13).

a. Htela sam da pozajmim Aninu $_{i}$ haljinu, ali ona ${ }_{i}$ nije htela da mi je Wanted.I AUX to borrow Ana's dress but she not want to me it da. give

'I wanted to borrow Anna ${ }_{i}$ 's dress, but she ${ }_{i}$ wouldn't give it to me.'

b. *Kupila sam italijanske ${ }_{i}$ cipele. Jesi li nekad bio $\operatorname{tamo}_{i}$ ? bought.I AUX italian shoes. have AUX ever been there 'I bought a pair of Italian shoes. Have you ever been there?'

If possessives were indeed adjectives, then their binding behaviour could not be accounted for (Bašić 2004; Šarić 2018). To accommodate these facts, the authors propose that possessives in Serbian should be analysed as exponents of D.

The brief summary shows that the categorial status of possessives has immediate consequences for their binding properties. Because the binding properties of possessives - beyond the binding of reflexives as discussed above - are the main focus of my dissertation, the nature of possessives is of particular interest to my analysis. Therefore, I will examine more arguments in favour of both analyses and discuss what consequences they have in a literature overview of the categorial status of Serbian possessives presented in Chapter 2.

Even though Despić (2013) asserts that non-coreferential reading is the only interpretation, regardless of whether a strong or a weak pronoun is used in object position as in example (8a) vs. (8b), I expect that there should be at least some differences, given the nature and distribution of weak and strong pronouns in Serbian.

It is well known that there are different types of pronouns cross-linguistically, which differ in morphological, phonological, syntactic, semantic and pragmatic aspects. Therefore, using a strong pronoun in languages that allow for different types of pronominal forms in an environment such as in the previous examples, where a clitic would be rather used, turns out to be quite unexpected. Franks (2019) noticed this for Macedonian and Bulgarian after re-evaluating the examples from LaTerza (2016). Because Serbian also distinguishes between two different types of pronominal objects as Macedonian and Bulgarian do, I will investigate whether there are any differences concerning the acceptability of coreferential interpretation when a clitic or a strong pronoun is used in object position.

However, with simple nominals as in (i), the reflexive must be bound by the clausal subject (Bašić 2004:21). 
Further theoretical justifications for the experiment, and previous studies for Serbian, Bulgarian and Macedonian Condition B-like structures, and my own experimental study (Experiment 1) are provided in Chapter 3. Experiment 1 will not only outline the characteristics of Serbian possessives, but also indicate that the picture is not simply black and white, and that it does not have to mean that the structures in question allow either for the coreferential or non-coreferential reading exclusively. Even though the structure must allow for a potential coreferential interpretation, it does not have to be always employed. Some other circumstances or principles could affect the coreferential reading, and one of them is the type of pronoun used in object position. Other principles will be discussed later in Chapter 3.

In order to better understand the possible cross-linguistic difference in binding, it is also crucial to investigate the structural position of possessives within the noun phrase. This is related to the notion of c-command, given that the main argument for the unacceptability of coreference in Serbian, as shown above, is the claim that Serbian possessives c-command out of their phrase, unlike their English counterparts. This matter will be addressed in more detail in Chapter 4, but I will briefly lay out how it relates to the possessive binding.

Accepting the NP analysis would mean that structures in (14) and (15) do not differ in binding possibilities, and that the same constraints (c-command) refer to both structures below.

(14) $* \mathrm{On}_{i}$ je pričao sa fanovima dok je $\operatorname{Jovan}_{i}$ potpisivao autograme. he AUX talked to fans while AUX John signed autographs *' $\mathrm{He}_{i}$ was talking to fans while $\mathrm{John}_{i}$ was signing autographs.'

?Njegov $_{i}$ menadžer je pričao sa fanovima dok je $\operatorname{Jovan}_{i} \operatorname{potpisivao~}$ his manager AUX talked to fans while AUX John signed autograme. autographs 'His ${ }_{i}$ manager was talking to fans while $\mathrm{John}_{i}$ was signing autographs.'

According to previous studies (Despić 2013; LaTerza 2016), there should be no difference between a pronoun and a possessive modifying a noun in subject position, i.e. in both sentences only a non-coreferential reading would be possible.

Contrasting with the claims made in the literature for Serbian, a number of psycholinguistic studies investigating these constructions in various languages, e.g. in English, German, Dutch, and Russian etc. have clearly shown that coreference between possessives and R-expressions (as in (16b)) is possible cross-linguistically, while the coreference between pronouns and R-expressions (as in (16a)) is rejected (see Kazanina et al. 2007; Kazanina and Phillips 2010; Drummer and Felser 2018). These studies show that a search 
for an appropriate antecedent is constrained by Binding Principle $\mathrm{C}$, which restrains coreference between a cataphoric pronoun and an R-expression within its c-command domain.

Even though backward anaphora is productive and completely acceptable in English and German, it is constrained in constructions where a pronoun c-commands its antecedent, as in the example in (16a), in which the subject pronoun er, 'he' is located in an argument position and c-commands 'Daniel' in the adjunct when-clause. As referential expressions are not supposed to be bound, coreference between the two elements should be rejected. Thus, example (16a) is ungrammatical, because it violates the constraint Binding Principle C (Chomsky 1981) which prohibits referential relations in which the pronoun structurally c-commands the antecedent. On the other hand, it is assumed that possessives do not c-command antecedents, i.e. upcoming potential referents, and there is no such constraint. In example in (16b), the possessive adjective sein, 'his' is a modifier of the noun Freund, 'friend' and does not c-command the name, thus coreference is allowed (Drummer and Felser 2018:105).

a. $\quad \mathrm{Er}_{* i}$ fütterte die Tiere, als Daniel $_{i}$ ein lautes Geräusch hörte, und der he fed the animals when Daniel a loud noise heard and the Zoowärter wusste, woher der Lärm kam. zookeeper knew where.from the noise came *' $\mathrm{He}_{i}$ was feeding the animals when Daniel $_{i}$ heard a loud noise, and the zookeeper knew where the noise was coming from.'

b. $\operatorname{Sein}_{i}$ Freund fütterte die Tiere, als Daniel $_{i}$ ein lautes Geräusch hörte, his friend fed the animals when Daniel a loud noise heard und der Zoowärter wusste, woher der Lärm kam. and the zookeeper knew where.from the noise came 'His ${ }_{i}$ friend was feeding the animals when Daniel ${ }_{i}$ heard a loud noise, and the zookeeper knew where the noise was coming from.'

Following the psycholinguistic studies by Kazanina et al. (2007) and Drummer and Felser (2018), I will provide experimental evidence in order to investigate whether R-expressions can be coreferential or not with pronominal possessives in Serbian, and whether coreference is indeed rejected with pronouns. If Serbian behaves similarly to German and English, possessives should not c-command the R-expression, assuming that they are not adjoined, but located lower in XP/DP. In contrast, pronoun subjects would c-command out of the phrase and bind the proper name/R-expression. If this difference between pronouns and possessive modifiers was found in Serbian, it would mean that Serbian patterns with typical DP languages in this respect. More on Binding Principle C is addressed in Chapter 4.

To sustain the alleged difference between Serbian and English, Despić (2013) assumes some additional principles beyond Principle B and $\mathrm{C}$ that will be addressed in 
more detail in the coming chapter. This already suggests that the facts might not be as straightforward as they appear at first sight, and that more empirical evidence is needed to shed light on this phenomenon. In spite of that, I will introduce some potential problems for the current analysis of possessive binding in Serbian, together with my research questions and hypotheses.

The first level of questions concerns the categorial status and structural position of possessives within the extended nominal phrase. The second level concerns the interpretation of possessives, e.g. the grammatical and (pragmatic) principles that (dis)allow coreferential interpretation or restrict coreference.

The more general questions I would like to answer in the dissertation are the following:

\section{Based on their properties, what is the categorial status of possessive modifiers in Serbian? Should they be treated as adjectives or exponents of D?}

As shown in the introduction, the categorial status of Serbian possessives has been controversially discussed in the literature. Many researchers debated whether they should be analysed as adjectives or exponents of D. Because possessives share certain characteristics with adjectives, in Zlatić's (1998) and Despić's (2013) analysis, they have been treated on a par with adjectives, and it has been believed that they are adjoined as one of the multiple specifiers of NP. However, there are also a lot of characteristics that differentiate possessives from adjectives, which provides evidence that possessives should be treated as exponents of D (Bašić 2004; Šarić 2018). Based on the arguments from both views, I will argue that possessives in Serbian are not adjectives, they are not typical D-elements (as articles) nor simple pronouns, which also casts doubt on the DG/AG parameter. Hence, possessives are quite a peculiar category, and I label them as Poss, but what is syntactically relevant are the properties and features of the element. Given that they are represented either by nouns or pronouns, I will analyse them as DPs.

\section{What is the syntactic position of possessives within the extended nominal} phrase?

The syntactic position of possessive modifiers is extremely important for the question of whether they are able to c-command out of the noun phrase and therefore for binding itself. As already mentioned in the previous section, Despić (2013) has argued that possessives - as specifiers of NP - c-command out of their NP, and this is why they violate binding principles. However, based on Bašić's (2004) argument that the word order within the noun phrase is not as free as assumed, possessives cannot easily precede 
demonstratives without changing the meaning. This further suggests that possessives are generally located lower in the noun phrase (below demonstratives), in a position from where they do not c-command. I hypothesise that they are base-generated in the SpecPossP, and then they move to a higher specifier position, but below the highest functional layer. Following previous literature cross-linguistically, the landing site of possessives could be an intermediate position within the nominal phrase - SpecAgrP. Consequently, such a structural configuration would not exclude the possibility of coreference in Serbian.

\section{Is coreferential interpretation indeed disallowed between possessive modi-} fiers (modifying a noun in subject position) and an object in Serbian?

As already discussed, it has been claimed by Despić (2013) that coreference between possessive modifiers and objects is disallowed in Serbian. However, Despić (2013) himself mentions a number of exceptions where binding is indeed possible (e.g. when a nominal possessive modifier occurs in subject position and a full noun phrase in object position). This already suggests that the facts might not be as straightforward as they appear on the surface. More empirical evidence is needed and especially data from controlled experiments in order to confirm these judgements. One aim of this dissertation is to provide innovative empirical evidence on possessive binding in Serbian.

In an attempt to systematically address one of the factors that may contribute to coreferential possibilities, namely the type of pronominal object (as argued by Franks 2019), I will also discuss the following question:

3.a. If coreference between lexical possessives and pronominal objects is indeed possible in Serbian, are there any differences between different types of pronouns in object position, i.e. clitics vs. strong pronouns?

The second study addresses the issue of the role of c-command concerning binding more closely by comparing the structure of a subject (pronominal possessives modifying a noun vs. pronouns in subject position) aiming to answer the next question:

3.b. Is binding of an R-expression by a pronominal possessive modifying a noun in subject position possible in Serbian?

These experimental studies will in turn be related to questions (1) and (2), and so contribute to the bigger picture about the nature and structure of Serbian prenominal possessives. 


\subsection{Thesis outline}

This dissertation is composed of six chapters. Chapter 2 addresses the general properties of prenominal possessive modifiers, first cross-linguistically in Section 2.1 and then in Serbian in Section 2.2, with a focus on their categorial status and syntactic structure, and what consequences they have on binding.

Chapter 3 represents the first part of the study, and that is the binding of pronouns, i.e. configurations that have been claimed to violate Binding Principle B. This section briefly summarizes Despić's analysis according to which the impossibility of coreferential reading in such structures has been a piece of evidence in favour of the NP analysis of Serbian noun phrases. Some difficulties of this analysis are also discussed. Based on Franks (2019), this section provides arguments that different types of pronouns can be one factor influencing the (im)possibility of coreferential interpretation. This leads to the first experiment reported in Section 3.2. The section reveals the results of a Picture Selection Task dealing with the coreferential possibilities between lexical possessives and different types of pronouns (Binding Principle B): clitics and strong pronouns.

Chapter 4 focusses on Binding Principle $\mathrm{C}$ effect, i.e. cataphoric dependencies in Serbian. The role of c-command in a different structure of the binder is examined in Section 4.1, followed by the overview of previous psycholinguistic studies in Section 4.2. Section 4.3 outlines the Study II that consists of two experiments: In Section 4.3.1 Experiment 2 - an offline study is presented, and in Section 4.3.2 Experiment 3 - an online study.

Chapter 5 connects all the dots together by discussing the overall research questions and how my experiments contribute to the bigger picture. Put differently, I will discuss what the availability of coreference in the constructions under scrutiny reveals about the categorial status and the structure of possessives in Serbian.

Finally, Chapter 6 will conclude the thesis and bring all the conclusions together. Moreover, some ideas for further research are suggested. 


\section{Chapter 2}

\section{Prenominal possessive modifiers}

This thesis focuses on prenominal possessive modifiers, especially the constituents that express possessor relation, including both lexical DPs and pronominal possessives. This chapter encompasses two parts: the first one deals with possessive modifiers crosslinguistically (Section 2.1), and the second one focuses on prenominal possessive modifiers in Serbian (Section 2.2).

Subsection 2.1.1 addresses the traditional discussion on the categorial status of possessives cross-linguistically taking into account the DG/AG parameter. From the categorial status, I will proceed to the position of possessives within the DP and provide an overview of analyses concerning the base and derived syntactic positions of possessives across languages (Subsection 2.1.2). In Subsection 2.1.3 some alternative analyses for the syntactic position of possessives are presented in order to clarify how the position influences binding with respect to c-command.

Then, I will turn specifically to Serbian prenominal modifiers in Section 2.2 and discuss their distribution and characteristics (Subsection 2.2.1), and specifically the features of Serbian prenominal possessives and their interaction with other elements in this domain (Subsection 2.2.2) in order to reveal the peculiar nature of Serbian prenominal possessives. In Subsection 2.2.3 the categorial status of Serbian possessives is discussed. More specifically, there has been a dispute on the categorial status of Serbian possessives in the literature and the arguments for both views will be examined in order to reach the conclusion of which analysis fits better. Following previous work, Subsection 2.2.4 discusses the structural position of possessive modifiers in Serbian, assuming that they occupy a specifier projection below D/DP and higher than NP. Furthermore, Section 2.2.5 addresses Despić's (2013) analysis of possessive binding, including both restrictions and additional principles that endorse coreference in Serbian. I will also lay out the consequences and predictions of categorial status and syntactic position for the binding with possessives in Serbian. Finally, Section 2.3 sums up the main points and the predictions for the experimental part. 


\subsection{Prenominal possessive modifiers cross-linguistically}

Possessive modifiers can occur in prenominal or postnominal positions crosslinguistically. For instance, in English, the possessor relation is established by using prenominal genitive DPs or possessive pronouns as in (1a), or with postnominal of -PPs as in $(1 b){ }^{1}$

(1) a. Mickey's/his backpack is on the chair.

b. The beautiful red car of a famous actor was stolen in Manhattan last week.

The same is true in Serbian, see corresponding examples for prenominal possessives in (2a) and for postnominal possessives in (2b).
a. Mikijev/njegov ranac je na stolici.
Mickey's/his backpack AUX on chair 'Mickey's/his backpack is on the chair.'

b. Prelepi crveni auto (od) poznatoga glumca ukraden je na Beautiful.def red.def car (of) famous actor stolen AUX in Menhetnu prošle nedelje.

Manhattan last week

'The beautiful red car of a famous actor was stolen in Manhattan last week.'

The main interest of my thesis are prenominal possessives as in (2a) that express a possessor relation, but other types of possessives (such as postnominal possessives, or prenominal possessives involving deverbal nominals) will be also briefly mentioned for a better understanding of the syntactic position of the possessors under investigation.

\subsubsection{Categorial status of possessives cross-linguistically: the DG/AG parameter}

The behaviour of possessives, as well as their categorial status and their syntactic position, is not the same across languages. Cross-linguistically, it has been proposed that posses-

\footnotetext{
${ }^{1}$ Two types of possession can be distinguished: alienable possession (ia) vs. inalienable possession (ib).
}

(i) a. Mike's car, Mary's bag, the house of a famous singer

b. Mike's leg, Anne's mother, the top of the hill

Both types of possession bring two entities in a relation, a possessor and the entity which they possess - a possessum. The main difference is that in the case of inalienable possession, the two entities are semantically dependent, e.g. body parts and kinship terms as in (ib). On the other hand, an alienable possession denotes a possessor who is involved in acquiring the possessum, with no intrinsic relation. However, I will not go into the differences between alienable and inalienable possession in this work. 
sive pronouns behave either like determiners or like adjectives (Lyons 1986; Giorgi and Longobardi 1991). Lyons (1986) distinguishes between two types of languages depending on the function possessives perform in a language: (1) 'determiner-genitive' (DG) and (2) 'adjectival-genitive' (AG) languages. In the former, genitives or possessive pronouns have a determiner function, while in the latter they behave like adjectives, performing a modifier function.

Based on this division, English for instance belongs to the group of DG languages: genitives in determiner function realise a definite interpretation, see $(3 a, b)$, whereas a prepositional construction has to be employed to express indefiniteness (3c).
a. John's/his car
b. the car of John's/him
c. a car of John's/his

In the prenominal position, it is not possible to combine any of the determiner elements with a possessive, assuming that the possessive or genitive is itself located in determiner position (Lyons 1986).

(4) *the/a/this John's/his house

Italian is a representative of AG languages: possessives are not located in determiner position as in the aforementioned cases, but rather occupy a modifier position. Thus, the co-occurrence of possessives is possible with both definite (5a) and indefinite articles (5b).
a. il mio libro (Italian)
'my book'
b. un suo amico
'a friend of his'

However, there is also some variation across languages and it has to do with the type of possessive pronouns. In some languages, possessives seem to show more peculiar behaviour and are seen to be in between of these two groups. For instance, Spanish is in between a DG and an AG language, depending on the position of a possessive within the DP. When prenominal, they function as determiners $\left(\left(* l a / *^{*} u n a\right)\right.$ su casa) and when postnominal they pattern with modifiers (la/una casa suya, with the long form of the pronoun as opposed to the prenominal short form). From this example, it can be observed that possessives can have different forms within one and the same language.

As in the tripartite strong-weak-clitic division of personal pronouns in Cardinaletti 
and Starke (1999), Cardinaletti (1998) proposes a similar division for possessive pronouns, too. She identifies three types of possessive pronouns: strong, weak and clitic possessive pronouns. ${ }^{2}$

French and Bulgarian belong to languages that have clitic possessive pronouns. If we have a look at Bulgarian, which has both clitic and non-clitic possessors, we will notice that full form possessors precede the noun (see (6a)), and may get an article (-ta) cliticized to them. On the other hand, clitic possessive pronouns are attached together with the clitic to the preceding element $($ see $(6 \mathrm{~b}, \mathrm{c})) .^{3}$

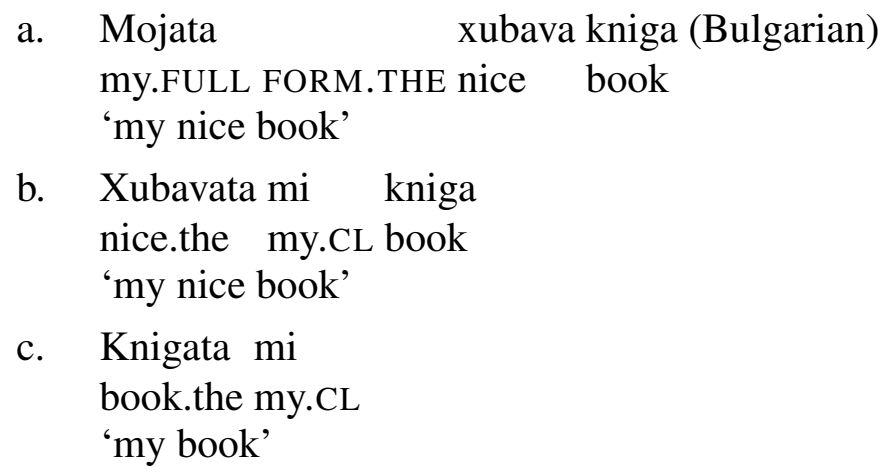

Another systematic distinction between AG and DG languages is the (non-)existence of a special elliptical form of the possessor (Schoorlemmer 1998). DG languages show morphological effects of ellipsis: there are different forms of the possessors in elliptical and non-elliptical possessive DPs in these languages. An example for English is given in (7) (Schoorlemmer 1998:61).
a. my book
b. your book, not mine

On the other hand, AG languages such as Bulgarian have only one form in both elliptical and non-elliptical environments (Schoorlemmer 1998:62).
a. Tvojata kniga (Bulgarian) your.the book
b. "Čija tetradka šte vzemeš?" "Tvojata." whose notebook will.you take.2sg? Your.the

As already illustrated, Bulgarian has all the properties of an AG language in the sense that

\footnotetext{
${ }^{2}$ All the types of pronominal possessives are merged in the lexical domain of the NP. Pronouns expressing strict possession are said to be base-generated in the specifier of SpecnP/SpecPossP, thematic possessive pronouns that express an argument of the head $\mathrm{N}$ are base-generated in a thematic position (Alexiadou et al. 2007)

${ }^{3}$ An article cliticizes to the leftmost head in the DP to mark definiteness in Bulgarian. The absence of the article indicates indefiniteness (Schoorlemmer 1998).
} 
it allows for the co-occurrence of determiners and possessives, and the same form occurs in both elliptical and non-elliptical contexts. However, when it comes to clitic possessive pronouns, they can occur in definite DPs only. See (9) from Dimitrova-Vulchanova and Giusti (1995:62).
a. *Knigami (Bulgarian) book.my.CL 'a book of mine'
b. Moja kniga my.FULL FORM book 'a book of mine'

Following Chomsky's (1995) assumption of clitics being simultaneously maximal projections and heads, together with Cardinaletti and Starke's (1994) assumption that they must raise to an $\mathrm{F}^{\circ}$ position in the extended projection of $\mathrm{N}$, Schoorlemmer (1998:78) proposes the following structure in (10). She assumes that the clitic moves up to SpecPossP in order to be licensed as a possessor. Afterwards, it undergoes movement to $\mathrm{D}$, as to be licensed as a clitic. More on the syntactic position of clitic and other types of possessors will be discussed in the next section as well.

$$
\text { [DP Possessor [PosP } \left.\left.\mathrm{t}_{\text {Possessor }} \mathrm{N}+\mathrm{Pos}\left[\mathrm{NP} \mathrm{t}_{\text {Possessor }} \mathrm{t}_{N}\right]\right]\right]
$$

Clitic possessive pronouns are always definite. One might wonder how it is possible to have both a clitic possessor and an article in D then. It has been discussed that the Bulgarian definite article is an affix expressing agreement with a definite $\mathrm{D}$. This is supported by the fact that it can co-occur with demonstratives in some cases (Halpern 1995). According to Dimitrova-Vulchanova and Giusti (1995), some constituents move to SpecDP, whose head is affixed with the article as agreement with $\mathrm{D}[+\mathrm{def}]$. The agreement is expressed by the head of the entire structure as a last resort (knigata mi, 'book.the my.CL'). Then, the possessor moves up to D and cliticizes to the head of the constituent located in SpecDP (Schoorlemmer 1998). Based on the presented data, Schoorlemmer (1998:62) sums up the following properties of DPs in AG vs. DG languages, outlined in Table 2.1. 
Table 2.1: Properties of DPs in AG vs. DG languages (Schoorlemmer 1998:62)

\begin{tabular}{c|l|c|c}
\hline & Property & AG languages & DG languages \\
\hline 1. & an article in possessive constructions & + & - \\
2. & a definite possessor occurs in indefinite DP & + & - \\
3. & a special elliptical form of possessor & - & + \\
\hline
\end{tabular}

The table by Schoorlemmer (1998:62) shows a generalization that there is no language that can combine properties 1 and 2, i.e. DG and AG languages behave in the opposite way in all three features:

1. possessors freely co-occur with overt articles

2. a possessive construction with a definite possessor may be indefinite

3. a special form of the possessor is used in elliptical DPs

The data from Bulgarian in the previous examples show that this Slavic language belongs to the group of AG languages. Other Slavic languages such as Czech and Russian, also have all the properties of AG languages, they only lack articles. However, the possessive can be combined with article-like elements, such as demonstratives as in (11a) or with one/such in (11b).
a. Eta moja kniga (Russian) this my book 'this book of mine'
b. Odna/tokaja moja kniga one/such my book
c. Eto tvoja kniga, ne moja
this (is) your book, not mine

The same holds for Serbian. This language also lacks articles, but it behaves as an AG language, see corresponding examples in (12).
a. Ta moja knjiga (Serbian)
this my book 'this book of mine'
b. jedna/takva moja knjiga one/such my book
c. To je tvoja knjiga, ne moja this is your book, not mine

Even though it appears like an AG language on the surface, the categorial status of posses- 
sive has been widely discussed among the researchers (Bašić 2004; Šarić 2018; Bošković 2009; Despić 2011). I will devote Section 2.2.3 to discuss the opposing views on the category of possessives in Serbian.

The following section provides more discussion on cross-linguistic variation and the positions of possessives, including the base and derived position of different types of possessives in a language.

\subsubsection{Position of possessives within the DP}

It is assumed that different types of prenominal genitives in English occupy the same position as determiners. The assumption follows from the fact that prenominal possessives are incompatible with the article or demonstrative as illustrated in the examples below from Alexiadou et al. (2007:549).

a. *The John's/his books are on the table.

b. *Johns/his the books are on the table.

a. *The Belushi's/his mixing of drugs led to his demise.

b. *Belushi's/his the mixing of drugs led to his demise.
a. *these the barbarians'/their destruction of the city
b. *the barbarians'/their the destruction of the city
c. *that the city's/its destruction
d. *the city's/its that destruction

Given that possessives and demonstratives express definite interpretation, they are often tied closely together to the definite article. Even though they might be actual exponents of $\mathrm{D}$, too, their position in DP is derived via movement from their base positions below the DP whereas the definite article is merged directly as a D head (Alexiadou et al. 2007).

For English, it is assumed that prenominal genitives and prenominal possessive pronouns can have a possessor or a thematic relation to the head noun. Regardless of their interpretation, the same surface position is assumed (as they occupy the same position as determiners, i.e. articles and demonstratives, which results in their incompatibility in English as in (15)) (Alexiadou et al. 2007).

The next subsection overviews the typical positions assumed to be base-generated positions of possessives, and in the subsection afterwards, their derived positions are discussed. 


\subsubsection{Base position}

One piece of evidence for the clausal nature of the internal structure of noun phrases is the subject-like behaviour of possessive modifiers. Whereas complex event nominals have specific theta relations with their arguments, possessors do not, and they are rather seen as subject-like instead of being complements (Alexiadou et al. 2007). As it is not necessary for subjects to have a thematic relation with the verb that they are the subject of in the clausal domain, prenominal genitives correspondingly do not realize a specific argument of the noun, e.g. in John's book.

Hungarian data support the claim that possessives behave like subjects, as they also have possessives in nominative, and nominative case is typically associated with subjecthood. The Hungarian prenominal possessor may either follow the determiner, and it bears nominative case, see (16a), or it may precede the determiner, whereby it has dative case, see (16b).
a. a Mari kalap-ja
the Mari.(NOM) hat-POSS.3SG
b. Mari-nak a kalap-ja
Mari.(DAT) the hat-POSS.3SG
'Mari's hat'

Given the arguments above, Alexiadou et al. (2007) assume that prenominal possessors and prenominal arguments of $\mathrm{N}$ occupy the same structural position, a position which is to the nominal projection what the canonical subject position is to the clause. The subject position in the clause is the highest specifier in the functional domain - SpecIP (SpecAgrP, SpecTP).

Given the apparent symmetry across categories between the syntactic structure of clauses and DPs, it is often assumed that the structure of noun phrases should correspond to the complex internal structure of verb phrases, consisting of an outer vP shell headed by an abstract light verb ('v') and an inner VP headed by a lexical verb (V) (Chomsky 1995). More precisely, this would lead to the assumption that DPs also involve an external $\mathrm{nP}$ shell headed by a light noun and an inner NP headed by a lexical noun. The external $\mathrm{nP}$ shell is seen as the complement of a higher functional head, e.g. number or gender (Alexiadou et al. 2007).

According to Radford (2000), the evidence for the existence of the specifier of light $\mathrm{n}$ comes from complex event nominals in English, as in example (17a) (Alexiadou et al. 2007:561).
a. the enemy's destruction of the city
b. [nP the enemy ${ }_{k}\left[\mathrm{n} \mathrm{destruction}_{j}\right]\left[\mathrm{NP}\left[\mathrm{N} \mathrm{t}_{j}\right]\right.$ of the city $\left.]\right]$ 
c. [DP the enemy's ${ }_{k}[\mathrm{D} 0]\left[\mathrm{nP} \mathrm{t}_{k}\left[\right.\right.$ destruction $\left._{j}\right]\left[\mathrm{NP}\left[\mathrm{N} \mathrm{t}_{j}\right]\right.$ of the city $\left.\left.]\right]\right]$

Radford's (2000) idea is that the Agent DP 'the enemy' is merged outside of NP, namely in SpecnP. $\mathrm{N}$ raises to $\mathrm{n}$ (analogously as $\mathrm{V}$ raises to $\mathrm{v}$ ), see (17c). In the same fashion as the subject of the clause raises out of $\mathrm{vP}$ to satisfy the EPP features, the Agent DP the enemy undergoes an analogous movement, as illustrated in $(17 \mathrm{~b}, \mathrm{c}) .{ }^{4}$ Radford assumes that the Agent DP moves up to the specifier of D.

Another analysis of the syntactic position of possessors modifying complex event nominals comes from Borer (1993). In (18) the argumental subject the vandals' is situated in SpecDP and is interpreted pragmatically as the suppressed subject of the passivized VP (Borer 1993).

$$
\text { the vandals' destruction of Rome }
$$

The prenominal genitive is taken to be generated in SpecDP, but it is thematically interpreted as an Agent, because in English SpecDP can function as an A-position.

According to Alexiadou et al. (2007), although Radford's analysis in (17) accounts for the enemy as the Agent of the $\mathrm{N}$ destruction, it is not compatible with the claims concerning the structure of deverbal noun (in lines of Borer's analysis). However, the authors claim that some aspects of his analysis could be adopted for the syntax of possessors. Correspondingly, Alexiadou et al. (2007) assume that external arguments of V receive their thematic role in the specifier of $\mathrm{vP}$ (or of VoiceP) and afterwards, they raise to a higher functional position. In the same manner, (alienable) possessors seem to obtain their possessor role in the specifier of $\mathrm{nP}$ and move up higher - to the specifier position of the nominal IP - AgrP (corresponding to the way clausal subject moves to the highest specifier of IP). ${ }^{5}$ The movement to IP is an intermediate step and the final position will be presented later. Alexiadou et al. (2007:562) assume the following structure which accounts for the cross-categorial symmetry between the clause and the extended NP.

$$
\begin{aligned}
& \text { a. John's book } \\
& \text { b. [nP John's } \left.\left[\text { book }_{j}\right]\left[\mathrm{NP}\left[\mathrm{N} \mathrm{t}_{j}\right]\right]\right] \\
& \text { c. [IP John's } \left.{ }_{k}[\mathrm{I}]\left[\mathrm{nP} \mathrm{t}_{k}\left[\mathrm{n} \mathrm{book}_{j}\right]\left[\mathrm{NP}\left[\mathrm{N} \mathrm{t}_{j}\right]\right]\right]\right]
\end{aligned}
$$

Alternatively, Alexiadou et al. (2007) state that $\mathrm{nP}$ in possessor constructions could be also labelled as PossP.

$$
\text { a. [PossP John's [Poss book } \left.\left.\text { b }_{j}\right]\left[\mathrm{NP}\left[\mathrm{N} \mathrm{t}_{j}\right]\right]\right]
$$

\footnotetext{
${ }^{4}$ Radford assumes that even nominals need to check the EPP features.

${ }^{5}$ Alexiadou et al. (2007) first label it as IP, and later as AgrP. In my analysis, I will adopt the label AgrP.
} 
b. [IP John's $s_{k}[\mathrm{I}]\left[\right.$ Poss $_{k}\left[\right.$ Poss book $\left.\left.\left._{j}\right]\left[\mathrm{NP}\left[\mathrm{N} \mathrm{t}_{j}\right]\right]\right]\right]$

The possessor relation between the possessor and the head noun is established structurally, and is mediated by a head - either $n$ in $(19 b, c)$ or Poss in $(20 a, b)$. What is important is that the possessor is located outside the lexical projection of the head noun. Even though the possessor DP is external, it forms a constituent PossP/nP with the noun (Alexiadou et al. 2007:563).

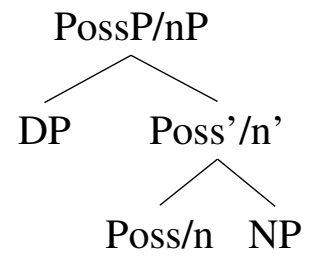

In my analysis for Serbian later on, I will follow Alexiadou et al. (2007), but considering the fact that according to UTAH, possessors cannot be merged as a specifier of $n$, because this position is reserved for a specific theta role (Agent) that possessor does not have. In this position, $\mathrm{nP}$ agents of complex event nominals are base-generated because here they receive their theta-role. I will thus assume that the additional optional category PossP is present. This category introduces a semantic relation between the element in its specifier and the $\mathrm{nP}$, and possessors are merged in SpecPossP.

There are also some alternative hypotheses that concern the base position of possessors, such as a small clause structure. Such hypotheses analyse the possession relation in a way that the possessor and the possessum comprise a maximal projection together.

One analysis, built on proposals for the analysis of the double object construction (Kayne 1984; Guéron 1985), proposes that the relation of possession is a predication relation between the possessor and the possessum. The possessor functions as the subject of the predication, and the possessum as the predicate nominal. The proposed structure is given in (22) (Alexiadou et al. 2007:563).

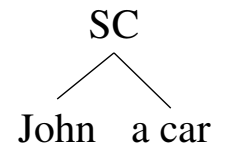

There is also another small clause hypothesis, but the elements have a reversed relation, i.e. the possessor has a function of the predicate of the small clause and the possessum is a subject. A PP, the dative marker to, or the genitive marker of can assign the possessor role (see Hoekstra 1994; den Dikken 1995, among others). This hypothesis is substantiated by data from several languages, including Latin, in which a copula is used to express the possessor relation and the possessor bears a dative/genitive case, see (23) (Alexiadou et al. 2007:563). 
(23)

Liber est Marco.

book is Marcus.DAT

In (24), two syntactic structures are illustrated to represent this analysis (den Dikken 1995; Larson and Cho 2003).

a.

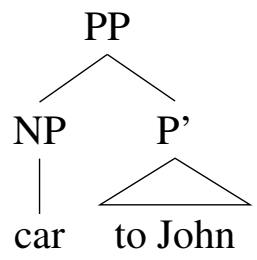

b.

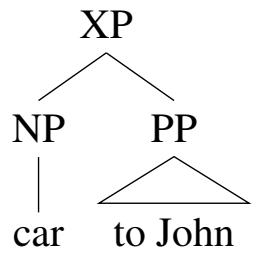

In all the aforementioned proposals, it can be noticed that possessors mostly appear relatively high within the DP, giving a hint that there is some kind of a DP-internal movement. More on the exact derived position of possessives is presented in the following subsection.

\subsubsection{Derived positions}

As has been noted, in many languages possessors are associated with D given their complementary distribution with determiners. In (25) it is illustrated that in English, the prenominal possessives, either possessive names or pronouns, are incompatible with articles or demonstratives.

*Mickey's/his the car is parked in front of the house.

In order to account for this complementary distribution, it has been proposed that possessors are located in SpecDP, see (26) following Radford's (2000) explanation for complexevent nominals reported in Alexiadou et al. (2007:566). ${ }^{6}$

$$
\text { [DP John's } \left.{ }_{k}\left[\mathrm{D} \text { 0] [nP t } \mathrm{n}_{k}\left[\mathrm{nbook}_{j}\right]\left[\mathrm{NP}\left[\mathrm{N} \mathrm{t}_{j}\right]\right]\right]\right]
$$

\footnotetext{
${ }^{6}$ Some authors (including Radford 2000) analyse 's as a spell out of D in English. (i) $\left[\mathrm{DP} \mathrm{John}_{k}\left[\mathrm{D}\right.\right.$ 's] [nP t$\left.k\left[\mathrm{nbook}_{j}\right]\left[\mathrm{NP}\left[\mathrm{N} \mathrm{t} \mathrm{t}_{j}\right]\right]\right]$

According to Alexiadou et al. (2007:566), such an assumption is not consistent with the Doubly filled Comp Filter as illustrated in (25), because both D ('s) and SpecDP (the possessor) are filled, therefore, they assume that D is empty, and that John's is located in SpecDP.
} 
Following Chomsky and Lasnik's (1977) Doubly filled Comp Filter, it is impossible to have both the specifier of $\mathrm{CP}$ and $\mathrm{C}$ filled at the same time. This restriction is shown in (27) for English.

$$
\text { I wonder [CP who [C(*that)] [ they will invite]]. }
$$

Similarly, the assumption that possessors occupy SpecDP and that there is a similar restriction on filling D and SpecDP at once, gives an explanation for excluding examples as in (23), in which the possessor in SpecDP co-occurs with the article in D (Alexiadou et al. 2007).

However, if all possessors were as high as in D/DP, they should never co-occur with determiners. Yet, this is not the case, as already mentioned in Section 2.1. Articles can be combined with possessives in some languages, see examples from Italian and from Portuguese below.

$$
\begin{aligned}
& \text { a. il mio libro (Italian) } \\
& \text { the my book } \\
& \text { b. o meu livro (Portuguese) } \\
& \text { the my book }
\end{aligned}
$$

Previous examples do not seem to dispute the ban on doubly filling D. If determiners occupy $\mathrm{D}$, then the specifier of $\mathrm{D}$ should be to its left, which further leads to the assumption that possessors are higher than $\mathrm{N}$ but somewhere lower than $\mathrm{D}$ in these languages.

As explained in Section 2.1.1 languages vary depending on the function possessives perform in a language: pronominal possessors in DG languages are determiners, while pronominal possessives in AG languages are adjectival in nature. This also has consequences for their structural position within the DP: adjectival possessives are located in the specifier position of a projection which is lower than D. A general syntactic structure for AG languages is given in (29) (Alexiadou et al. 2007:568).

$$
\text { [DP il [IP } \left.\left.\operatorname{mio}_{i}\left[\ldots \mathrm{t}_{i} \text { libro }\right]\right]\right]
$$

The structure proposes that the possessor starts out in SpecnP, where it gets the possessor role, and then it moves to the subject position (SpecIP in the nominal system). ${ }^{7}$ In (29) the possessor does not raise up to D as it is the case in DG languages, cf. (30) where the possessor moves up to adjoin to $\mathrm{D}$ (this move is seen as a form of cliticization) (Alexiadou et al. 2007:568).

\footnotetext{
${ }^{7}$ Sabina Halupka Rešetar points out how this structure might be problematic for UTAH and A-structure of deverbal nominals, provided that the structural position in which an item is merged determines the thetarole it receives, and this position is reserved for $\mathrm{nP}$ agents.
} 


$$
\left[\mathrm{DP}\left[\mathrm{D} \mathrm{my}{ }_{i}\right]\left[\mathrm{IP} \mathrm{t}_{i}\left[\mathrm{np} \mathrm{t}_{i}\left[\mathrm{n} \mathrm{book}_{k}\left[\mathrm{NP} \mathrm{t}_{k}\right]\right]\right]\right]\right]
$$

As already mentioned in the previous section, three types of possessive pronouns can be distinguished (Cardinaletti 1998). Depending on their typology, the possessive pronouns either move (deficient pronouns) or stay in situ (strong pronouns). The clitic possessive pronouns and the weak possessive pronouns raise to a higher position in the DP. What is specific for clitics is that they move to the highest position of all three types of possessive pronouns and incorporate to $\mathrm{D}$. Their head-movement to $\mathrm{D}$ explains why they cannot cooccur with articles in this position. Weak possessors also move, but to a lower position, namely SpecIP or a similar position below D. On the other hand, strong possessive pronouns can remain in their base position. In case $\mathrm{N}$ moves, then strong possessive pronouns will be postnominal as in Italian examples (il libro mio, 'the book my'). (31) illustrates all the different types of syntactic positions inside the DP, whereby (31b) illustrates the position of a clitic possessive pronoun, (31c) of a weak pronoun, and (31d) involves a strong possessive pronoun (Alexiadou et al. 2007:569).

$$
\begin{aligned}
& \text { a. [DP [D clitic] [IP weak [np strong [n N [NP t } \left.\left.\left.\left.\mathrm{N}_{k}\right]\right]\right]\right] \\
& \text { b. [DP [D ma } \left.\left.{ }_{i}\right]\left[\mathrm{IP} \mathrm{t}_{i} \text { voiture }_{k}\left[\mathrm{np} \mathrm{t}_{i}\left[\mathrm{n} \mathrm{t}_{k}\left[\mathrm{NP} \mathrm{t}_{k}\right]\right]\right]\right]\right] \\
& \text { c. [DP la [IP mia } \left.\left.{ }_{i} \ldots\left[\operatorname{macchina}_{k}\left[\mathrm{npt}_{i}\left[\mathrm{nt}_{k}\left[\mathrm{NP} \mathrm{t}_{k}\right]\right]\right]\right]\right]\right] \\
& \text { d. [DP la [IP ... [macchina } \left.\left.{ }_{k}\left[\mathrm{np} \mathrm{MIA}_{i}\left[\mathrm{nt}_{k}\left[\mathrm{NP} \mathrm{t}_{k}\right]\right]\right]\right]\right]
\end{aligned}
$$

Cross-linguistic data and the fact that in some languages different types of possessors exist, indicates that possessors can have several different DP-internal positions. Alexiadou et al. (2007:571) give three different positions when it comes to the derived vs. nonderived status of possessors in (32). Namely, $\mathrm{nP}$ represents the domain in which the possessor relation is assigned, FP corresponds to an inflectional projection (comparable to the clausal IP) and DP is a superficies of the nominal projection.

$$
\text { [DP derived [FP derived [nP ... POSSESSOR ]]] }
$$

Generally, when a possessor occurs postnominally it is seen to be found in its thematic position. Thus, the surface order is an outcome of a leftward movement of N or NP across the possessor. The first instantiation of an XP movement is a movement of possessives to SpecFP, as it is the case in Italian examples. In (33) the possessor mio, 'my' sits in the lower derived position in FP (Alexiadou et al. 2007:571).

[DP il [FP mio [nP libro ]]]

When it comes to the higher derived position in the DP layer, it is either SpecDP, for lexical DPs, e.g. John's in English example (34a), or D, e.g. French pronoun mon, 'my' 
(Alexiadou et al. 2007:571), which is another XP movement.
a. [DP John's [D ] [FP [nP book ]]]
b. [DP [D mon ] [FP [nP livre ]]]

It is believed that possessors necessarily move to the domain of $\mathrm{D}$ in languages in which there is a competition between the possessor and the determiner for the same syntactic position. However, this would contradict the earlier proposal of Alexiadou et al. (2007) (repeated in (35)) that the possessor is in the nominal SpecIP, which is lower than one in the previous structure in (34a) (Alexiadou et al. 2007:571).

$$
\begin{array}{ll}
\text { a. } & {\left[\mathrm{IP} J o h n ' \mathrm{~s}_{k}[\mathrm{I}]\left[\mathrm{nP} \mathrm{t}_{k}\left[\mathrm{n} \mathrm{book}_{j}\right]\left[\mathrm{NP}\left[\mathrm{N} \mathrm{t}_{j}\right]\right]\right]\right]} \\
\text { b. } & {\left[\mathrm{IP} \mathrm{John}_{k}[\mathrm{I}]\left[\text { Poss t }_{k}\left[\text { Poss book }_{j}\right]\left[\mathrm{NP}\left[\mathrm{N} \mathrm{t}_{j}\right]\right]\right]\right]}
\end{array}
$$

Thus, Alexiadou et al. (2007) bring the two assumptions together by suggesting that (35) represents an intermediate step in the derivation to (34a), observe (36) (Alexiadou et al. 2007:572).

$$
\begin{array}{ll}
\text { a. } & {\left[\mathrm{DP} \mathrm{John's} \mathrm{s}_{k}\left[\mathrm{IP} \mathrm{t}_{k}[\mathrm{I}]\left[\mathrm{nP} \mathrm{t}_{k}\left[\mathrm{n} \mathrm{book}_{j}\right]\left[\mathrm{NP}\left[\mathrm{N} \mathrm{t}_{j}\right]\right]\right]\right]\right]} \\
\text { b. } & {\left[\mathrm{DP} \mathrm{John}_{k}\left[\mathrm{IP} \mathrm{t}_{k}[\mathrm{I}]\left[\operatorname{Poss}_{\mathrm{P}} \mathrm{t}_{k}\left[\operatorname{Poss~book}_{j}\right]\left[\mathrm{NP}\left[\mathrm{N} \mathrm{t}_{j}\right]\right]\right]\right]\right]}
\end{array}
$$

In languages where the determiner is followed by a possessive pronoun, like Italian, the possessor should be below D but in a rather high position within the DP. This can be shown by examples that include a prenominal adjective and a possessive pronoun. As shown in (37), the possessor will come before the adjective. This shows that the possessor raises to an $\mathrm{N}$-related inflectional projection dominating the projections hosting adjectives (Alexiadou et al. 2007:572).
a. la loro brutale invasione (Italian) the their brutal invasion
b. *la brutale loro invasione

In the structure in (38), the AP brutale, 'brutal' is located in the SpecNumP, but what kind of position does the prenominal possessor loro, 'their' occupy? The first possibility would be that it is in an adjoined position as in (38) (Alexiadou et al. 2007:572).

$$
\text { [DP [D la] [NumP loro [NumP brutale [Num [N invasione]] [nP [NP t]]]]] }
$$

However, this is problematic because of the parallelism between possessors and subjects proposed in Alexiadou et al. (2007): an adjoined position does not seem to entitle for being a canonical subject position. This shows that it is more adequate to assume that the 
possessor is in the specifier of a functional projection.

An additional argument comes from languages in which the prenominal possessor moves to a position after the determiner in order to get its case. The Hungarian example in (39) is an instance of the post-determiner possessor, which gets the nominative case (Alexiadou et al. 2007:573)

$$
\begin{aligned}
& \text { a. az én kalap-om (Hungarian) } \\
& \text { the I(NOM) hat-POSs.1SG } \\
& \text { 'my hat' } \\
& \text { b. az én kalap-ja-i-m } \\
& \text { the I(NOM) hat-POSS-PL-1 SG } \\
& \text { 'my hats' }
\end{aligned}
$$

In addition to this position, possessives in Hungarian can occupy a position to the left of $\mathrm{D}$ when they bear dative case, see (40). This example speaks in favour of the possessive (Marinak) occupying SpecDP.

$$
\begin{aligned}
& \text { Marinak a kalapja } \\
& \text { Mary(DAT) the hat-Poss.3SG } \\
& \text { 'Mary's hat' }
\end{aligned}
$$

The fact that the possessor gets its case in the prenominal position also speaks against the assumption that the possessor is in an adjoined position because adjoined positions are not usually seen to be case positions. Therefore, an analysis should be preferred according to which the possessor is in the specifier of a functional projection, see (41). What kind of projection could this be? If we assume that the prenominal possessor is in the SpecNumP rather than being adjoined to NumP, this would mean that the prenominal adjective is a specifier of a different projection below (Alexiadou et al. 2007:573).

$$
\text { [DP [D la] [NumP loro [FP brutale [F [N invasione }]] \text { [nP [NP t]]]]] }
$$

Alternatively, it could be assumed that prenominal adjectives occupy NumP, and the prenominal possessor occupies a higher customized projection FP, see (42).

$$
\text { [DP [D la] [FP loro [NumP brutale [Num [N invasione]] [nP [NP t]]]]] }
$$

Again, the Hungarian example in (43) adds evidence that goes in favour of (42) rather than the previous proposal in (41).

$$
\begin{aligned}
& \text { a. a te } \quad \text { kalap-od (Hungarian) } \\
& \text { the you(NOM) hat-POSS.2SG }
\end{aligned}
$$




\section{b. a te kalap-ja-i-d \\ the you(NOM) hat-POSS-PL-2SG}

Example (43) illustrates that there are two different agreement morphemes in Hungarian: (1) the prenominal possessor te, 'you' agreeing with the $\mathrm{N}$ in person and number; (2) the head N kalap-ja-i-d varies for number on its own. Consequently, two functional projections are necessary, namely one for $\mathrm{N}$-number, and another one for the possessors. Examining the form of the noun N kalap-ja-i-d and the possessor te in (43b) more closely, it can be observed that the plural morpheme of the noun $-i$, is closer to the stem kalap than the morpheme $d$ (2.Sg), which agrees with the possessor. This suggests that the structure in (42) is more adequate, since the projection hosting the possessor dominates NumP, responsible for the encoding of the number of nouns. In Hungarian, the prenominal possessor following the determiner bears nominative case (cf. én in (37) and te in (40)). In the clausal projection, nominative DP is typically located in the non-thematic specifier position of the highest functional projection of the inflectional domain, namely AgrP or TP. Based on the similarity between the post determiner possessor in the Hungarian DP and the clausal subject, and the fact that possessors agree with $\mathrm{N}$, it has been assumed that the prenominal possessor occupies the upmost specifier position in the functional domain dominating NP. Thus, they renamed the projection FP in (42) as AgrP given that the projection has to do with possessor agreement (Alexiadou et al. 2007). (44) illustrates the functional structure of the noun phrase.

$$
\mathrm{DP}>\text { AgrP }>\text { NumP }>\text { GenP }>\text { nP }>\text { NP }
$$

Against the backdrop of what has been discussed in this chapter, (45) summarizes the cross-linguistically proposed derived positions of possessives within the noun phrase for English, French, Hungarian and Italian. Given that non-pronominal possessors in Hungarian may also bear nominative case, it is assumed that they also raise to SpecAgrP. Lastly, it is assumed that English prenominal possessor DPs occupy SpecDP (cf. (45d)) and French possessive pronouns cliticize to D (cf. (45e)) (Alexiadou et al. 2007:574,575).

$$
\begin{aligned}
& \text { a. [DP [D la] [AgrP loro [NumP brutale invasione... ]]] (Italian) } \\
& \text { the their brutal invasion } \\
& \text { b. [DP }[\mathrm{D} \text { a] [AgrP te [NumP kalapod ]]] (Hungarian) } \\
& \text { the you-NOM hat-POSS.2SG } \\
& \text { c. [DP [D a] [AgrP Mari [NumP kalapja ]]] (Hungarian) } \\
& \text { the Mari hat-POSS.3SG } \\
& \text { d. [DP John's [D 0] [AgrP t [NumP ... book... ]]] (English) } \\
& \text { e. }[\mathrm{DP} \quad[\mathrm{D} \quad \mathrm{son}][\text { AgrP t } \quad[\text { NumP... livre... }]]] \text { (French) } \\
& \text { his } \\
& \text { book }
\end{aligned}
$$


The tree in (46) illustrates the structure of DP and all the positions possible for possessives to occur depending on a type of possessor and a language they belong to (Alexiadou et al. 2007:575).

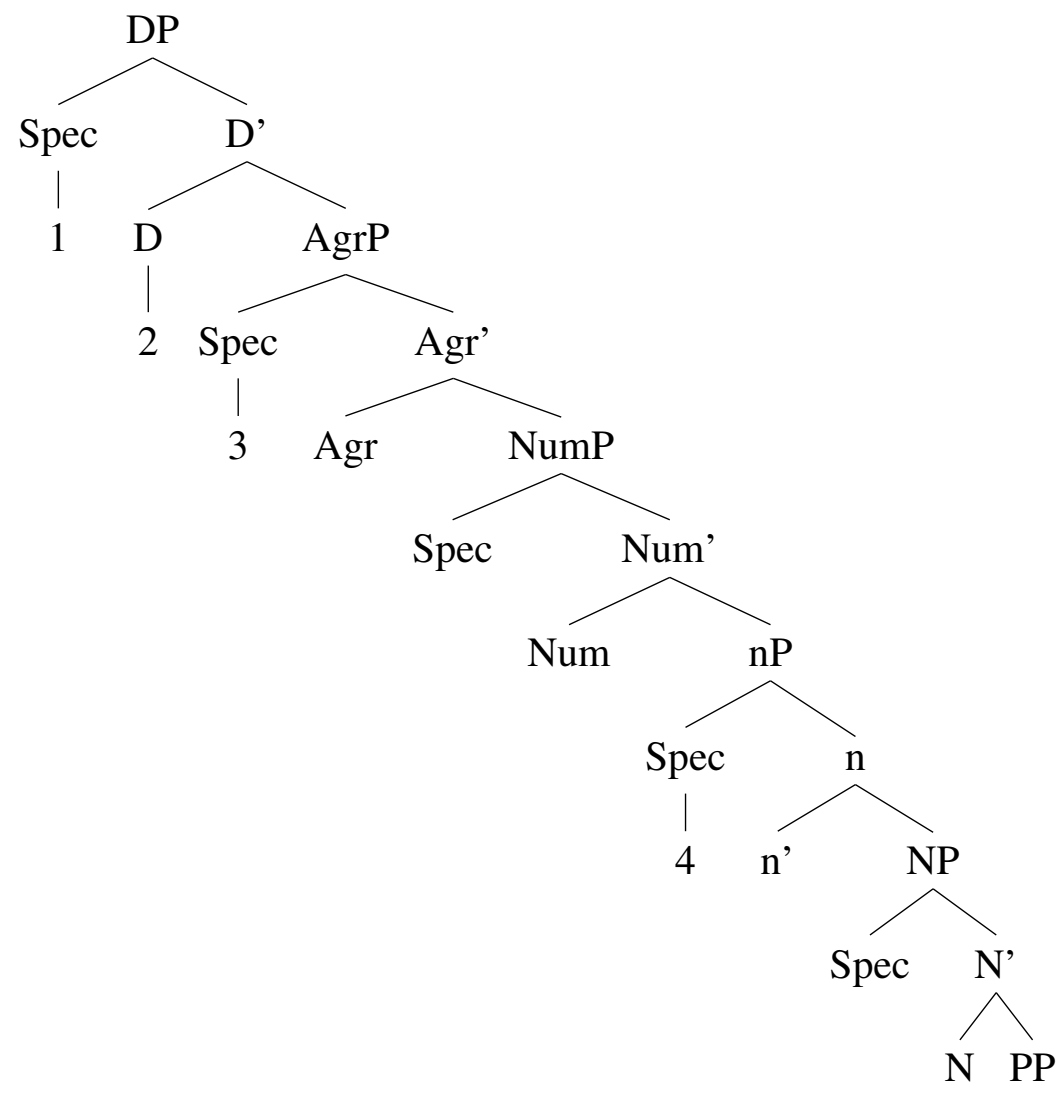

We have seen the difference between AG and DG languages and various corresponding positions for possessives across languages. However, to account for the binding facts in English, Kayne (1994) following Szabolcsi (1981, 1983), proposed that possessives in English should actually be lower than D. The alternative analysis is discussed in Section 2.1.3.

\subsubsection{Consequences of categorial status and syntactic position for binding cross-linguistically}

In the previous section, we have seen that according to Alexiadou et al. (2007), depending on which type of language they belong to, possessives can occupy different positions within the DP spine. For DG languages, possessives can either occupy SpecDP (lexical possessives) or D (clitic possessives). On the other hand, possessives are located below D/DP in AG languages, namely in specifier positions such as SpecAgrP or SpecnP. For some AG languages, it has been discussed that possessives do not actually have typical adjectival behaviour, or are seen to express features of both AG and DG languages. More- 
over, it appears that the situation is not so clear even for DG languages such as English if phenomena such as binding are considered.

As already mentioned in the introduction, English examples such as $(47 a, b)$ are both accepted with coreferential reading.
a. $\operatorname{His}_{i}$ father considers $\mathrm{John}_{i}$ highly intelligent.
b. $\mathrm{John}_{i}$ 's father considers him ${ }_{i}$ highly intelligent.

As previously shown in (45d), it is assumed for DG languages like English that possessives like his and John's are located in the specifier of DP.

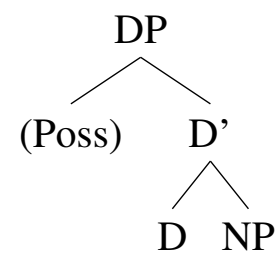

However, this assumption poses a problem for the binding facts presented in (47). Namely, if we follow Kayne's (1994) Antisymmetry approach, specifiers are adjuncts and following the definition of c-command in (49), they c-command out of the category they are specifiers of.

\footnotetext{
"X c-commands $\mathrm{Y}$ iff $\mathrm{X}$ and $\mathrm{Y}$ are categories, $\mathrm{X}$ excludes $\mathrm{Y}$, and every category that dominates $\mathrm{X}$ dominates $\mathrm{Y}$. (X excludes $\mathrm{Y}$ if no segment of $\mathrm{X}$ dominates $\mathrm{Y}$.)" (Kayne 1994:16)
}

Following this definition, and assuming the structure in (48), examples $(47 \mathrm{a}, \mathrm{b})$ would be wrongly ruled out, since from this position his and John's do c-command John and him respectively, which would result in violating Binding Principles $\mathrm{C}$ and B. However, these structures are perfectly grammatical in English. To resolve this issue, Kayne (1994) makes the following assumptions. Based on Szabolcsi's (1983) analysis of Hungarian possessives, he assumes that there is an independent $\mathrm{D}$ above the possessor, like in Italian (see (45a)).

Hence, Kayne's (1994) proposal is that English possessives should not be located in the upmost specifier position - SpecDP as it was previously assumed, but rather below, in a position from where they do not c-command out of the DP. He assumes this position to be the specifier of a PossP, which is dominated by a DP with a null D head, as illustrated in the tree in (50). 
(50)

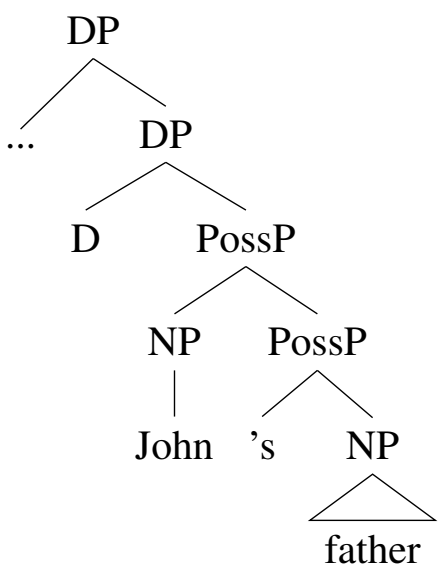

This structure would account for the acceptability of examples such as (47a,b). Assuming the additional - null DP - projection above the possessor prevents the violation of Binding Principles B and C. More precisely, the possessives his and John's do not c-command the coindexed elements outside their DP.

I find the arguments presented by Kayne (1994) extremely important for the notion of binding since they account for the no c-command of possessives out of their DP. This explains why there is no violation of Binding Principles $\mathrm{B}$ and $\mathrm{C}$ in these sentences. Following Kayne (1994), I assume that possessives should occupy a position lower than D/DP. Both lexical and pronominal possessives should be hosted in a lower position, given that the outcome is the same in both Binding Principles $\mathrm{B}$ and $\mathrm{C}$ constructions. This assumption has an interesting consequence for the typology of possessives crosslinguistically, because the position Kayne assumes for English (which is a typical DG language) is similar to Alexiadou et al.'s (2007) structure for AG languages. This could actually cause a problem for the assumption of the DG/AG parameter. However, data from different languages, including Serbian also challenge the DG/AG parameter, as we will see in the upcoming sections.

An analysis for English that could bring together the important aspects of both Alexiadou et al.'s (2007) and Kayne's (1994) accounts is a structure proposed by Bernstein and Tortora (2005). Firstly, with their proposal in (51), Bernstein and Tortora (2005) account for the difference between lexical and pronominal possessives in English, as the structure accommodates the fact that pronominal possessives are lower than lexical ones (cf. Alexiadou et al. 2007). ${ }^{8}$ Secondly, they suggest that possessives in English occupy positions lower than D, in the vein of Kayne's (1994) approach.

\footnotetext{
${ }^{8}$ Additionally, with such a structure Bernstein and Tortora (2005) explain the contrast in (i).

(i) a. Mary's/the woman's friend

b. *their's friend

(ib) is not plausible given that the pronominal possessive their is lower than 's.
} 


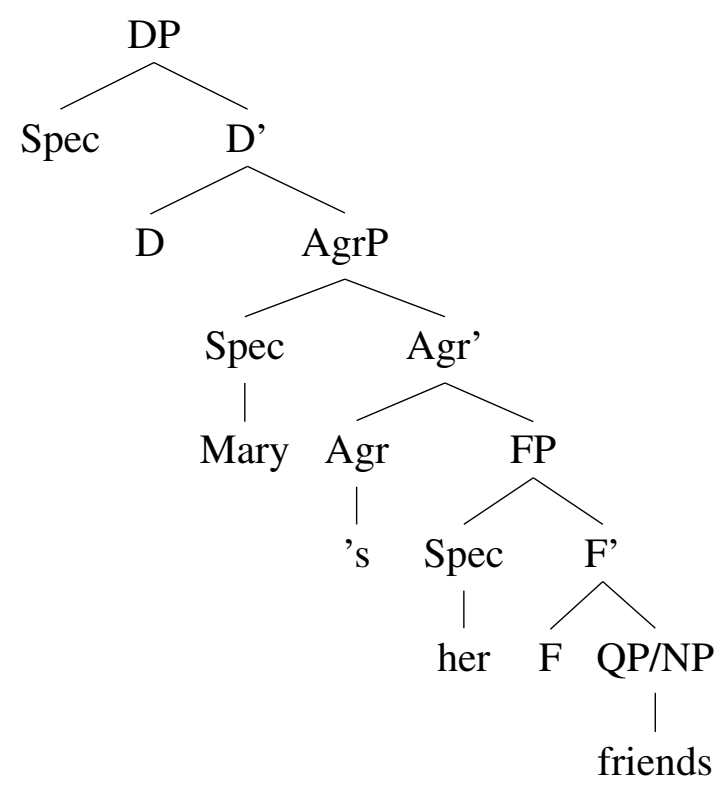

To sum up, I adopt the suggestion that possessives are base-generated in the SpecnP or SpecPossP, and then they can move up to the specifier of AgrP (cf. Alexiadou et al. 2007; Bernstein and Tortora 2005) under certain conditions depending on the properties of the languages such as for example definiteness in Portuguese, or defocalization in Italian etc. (Kupisch and Rinke 2011). In addition, to accommodate the binding facts, the possessives should occupy a lower position than D from where they do not c-command in DG languages as well, contra Alexiadou et al. (2007) but in line with Kayne (1994) and Bernstein and Tortora (2005).

\subsection{Prenominal possessive modifiers in Serbian}

Given all the above, I will compare Serbian to other languages in order to observe what the similarities and differences between Serbian possessive modifiers and those of other languages in terms of their categorial status and structural position are. As already mentioned in the introduction, some authors have claimed that possessives behave like adjectives in Serbian, others have argued that they behave like exponents of D, so the arguments of both groups will be discussed. Before that, I will present a general description of Serbian prenominal modifiers and their distribution, specifically focussing on the prenominal possessives.

\subsubsection{Characteristics of Serbian prenominal modifiers}

The following elements can occupy the prenominal position in Serbian: quantifiers (52a), demonstratives (52b), possessives (52c) and attributive adjectives (52d). All prenominal modifiers agree with the head noun in case, number and gender. 
(52)
a. sve igračke
all-NOM.F.PL. toys-NOM.F.PL. 'all toys'
b. ova igračka
this-NOM.F.SG. toy-NOM.F.SG.
'this toy'
c. Milanova igračka
Milan's-NOM.F.SG. toy-NOM.F.SG.
'Milan's toy'
d. šarena igračka
colourful-NOM.F.SG. toy-NOM.F.SG. 'colourful toy'

The neutral word order is shown in (53) (Bašić 2004:12).

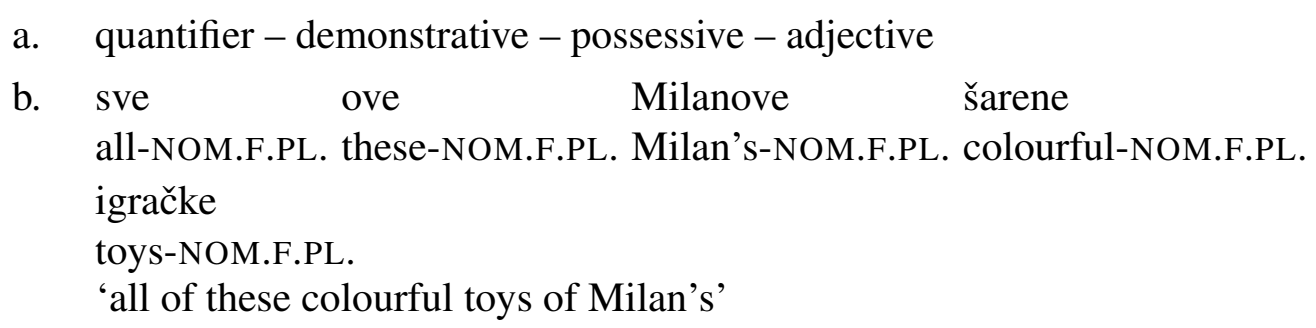

Even though Serbian has relatively free word order, there are still some restrictions. Some universal quantifiers such as svi, 'all', and svako, 'each/every' mostly occupy the initial position in prenominal modifier constructions, but there are other quantificational expressions such as nekoliko, 'several', mnogo, 'many/much', and numerals higher than pet, 'five' with a more flexible distribution. These elements impose the genitive plural form on the noun and the other modifiers preceding the nouns, see (54).
a. tih nekoliko kutija
those-GEN.PL. several boxes-GEN.PL. 'those several boxes'
b. mnogo plišanih igračaka many stuffed-GEN.PL. toys-GEN.PL. 'many stuffed toys'
c. pet mojih drugova five my-GEN.PL. friends-GEN.PL. 'five friends of mine'

With these elements, the distribution is less strict. ${ }^{9}$

\footnotetext{
${ }^{9}$ Although this word order with mnogo, 'many' in example (55b) is not acceptable according to some native speakers.
} 

a. nekoliko tih kutija
several those-GEN.PL. boxes-GEN.PL.
b. plišanih mnogo igračaka
stuffed-GEN.PL. many toys-GEN.PL.
c. mojih pet drugova
my-GEN.PL. five friends-GEN.PL.

As illustrated in the previous examples, we can play around with the position of quantifiers, but this leads to different semantic interpretations with respect to exhaustive vs. non-exhaustive reading. For instance, if quantifiers come before demonstratives, we obtain the partitive interpretation, as illustrated in example (56) below from Bašić (2004:14).
a. Prodao je nekoliko ovih knjiga. sold AUX several these books 'He sold several of these books.'
b. Prodao je ovih nekoliko knjiga. Sold AUX these several books 'He sold these several books.'

In other cases, word order is much more rigid. Namely, demonstratives (including the indefinite determiners jedan/neki, 'one/some' in (57c)) cannot swap positions with possessives (57a) and adjectives (57b).
a. *Igorovi oni drugovi Igor's those friends 'Igor's those friends'
b. *smešni oni drugovi funny those friends 'funny those friends'
c. *njegov jedan/neki drug his one/some friend 'his a/some friend'

Possessives do generally precede adjectives in the noun phrase:

$$
\begin{aligned}
& \text { Igorovi smešni drugovi } \\
& \text { Igor's funny friends } \\
& \text { 'Igor's funny friends' }
\end{aligned}
$$

They can only switch positions when an adjective bears a contrastive topic as shown in (59), which results in a different interpretation, meaning that not all of his friends are 
funny, so this represents just a subset of his friends, whereas Igorovi smešni drugovi, 'Igor's funny friends' in (58) represents an exhaustive set.

smešni Igorovi drugovi

funny Igor's friends

'Igor's funny friends'

Concerning word order and morphological agreement in case, number and gender with nouns they modify, lexical possessives and pronominal possessives behave the same, cf. (57), (58) and (59) in comparison to (60). When an adjective precedes the pronominal possessive as in (60b), the adjective has to bear a contrastive topic, same as in (59). (60c) and (60d) illustrate that it is not possible to reverse the order of demonstratives and prenominal possessives, as it is the case with lexical possessives (57a).

$$
\begin{aligned}
& \text { a. njegovi smešni drugovi } \\
& \text { his funny friends } \\
& \text { 'his funny friends' } \\
& \text { b. smešni njegovi drugovi } \\
& \text { funny his friends } \\
& \text { 'his funny friends' } \\
& \text { c. oni njegovi drugovi } \\
& \text { those his friends } \\
& \text { 'those friends of his' } \\
& \text { d. *njegovi oni drugovi } \\
& \text { his those friends } \\
& \text { 'his those friends' }
\end{aligned}
$$

In general, adjectives immediately come before the noun they modify. Moreover, there are regularities concerning their word order with respect to each other. These ordering constraints are to some extent similar across languages, but they may also vary crosslinguistically. The partial ordering (consisting of most common types of adjectives) suggested by Sproat and Shih (1991), and adopted by Cinque (1994) is given in (61):

$$
\text { evaluating (quality) - size - colour }
$$
a. English
beautiful big red ball
b. German
schöner großer roter Ball

The same ordering patterns and restrictions apply to Serbian. More precisely, adjectives denoting size must precede the adjectives denoting colour, whereas the evaluating ad- 
jectives precede both classes. All of these classes are followed by referential adjectives, such as srpska, 'Serbian' in (62). Other adjectives that immediately precede the noun are denominal adjectives, such as svadbena, 'wedding-adj' (Bašić 2004:15).

ogromna bela srpska svadbena torta

huge white Serbian wedding cake

In comparison to example (62) where the neutral order of adjectives is shown, reordering of adjectives as in (63) causes an irregular outcome.
a. *svadbena bela torta
wedding-adj white cake
b. *srpska ogromna torta
serbian huge cake

On the basis of these restrictions, Bašić (2004) concludes that the ordering patterns of prenominal modifiers in Serbian noun phrases are more restricted than previously assumed. She interprets her findings as evidence for a DP analysis for the Serbian nominal phrase.

After having presented the general properties and ordering of prenominal modifiers, in Section 2.2.2 I focus more closely on the possessives in Serbian.

\subsubsection{Morphology of Serbian possessives}

Serbian possessor nouns are formed by adding the suffix -in (feminine) or -ov (masculine, neuter) to the stem of the noun which is in turn followed by an additional inflectional agreement suffix, as shown in (64a) and (64b).

$$
\begin{aligned}
& \text { a. Jovan - ov - a mačka je crno-bela. } \\
& \mathrm{Jovan}_{\text {stem.m.sg. }}+\mathrm{ov}_{\text {poss }}+\mathrm{a}_{\text {agr fornom.f.sg }} \text {. cat.F.SG.NOM. AUX black-white } \\
& \text { 'Jovan's cat is black and white.' } \\
& \begin{array}{l}
\text { b. Brank }- \text { in }-\mathrm{u} \quad \text { mačku je uplašio auto. } \\
\text { Brank }_{\text {stem.f.sg. }}+\mathrm{in}_{\text {poss. }}+\mathrm{u}_{\text {agrforacc.f.sg. }} \text {. cat.F.SG.ACC. AUX scared car } \\
\text { 'Branka's cat got scared by a car.' }
\end{array}
\end{aligned}
$$

Pronominal possessives are also derived by adding the suffix -ov or -(i)n to the pronoun, but there is a substantial amount of suppletion (see Table 2.2), which is common for pronouns cross-linguistically. 
Table 2.2: Serbian pronominal possessives

\begin{tabular}{c|l|c|c}
\hline p. & Singular & p. & Plural \\
\hline 1. & moj 'my' & 1. & naš 'our' \\
2. & tvoj 'your' & 2. & vaš 'your' \\
3. & njegov 'his' & 3. & njihov 'their' \\
& $\begin{array}{l}\text { njen 'her' } \\
\text { njegov 'its' }\end{array}$ & & \\
\hline
\end{tabular}

In the same fashion as lexical possessives get an additional inflectional agreement suffix, pronominal possessives also agree in number, gender and case with the noun they modify, as illustrated in (65).
a. njeg
- ov $\quad-$ a
mačka
je crno-bela.
njeg $_{\text {stem.m.sg. }}+\mathrm{ov}_{\text {poss }}+\mathrm{a}_{\text {agrfornom.f.sg }}$. cat.F.SG.NOM. AUX black-white 'His cat is black and white.'
b. Nje $-\mathrm{n}-\mathrm{u}$ mačku je uplašio auto. nje $\mathrm{stem.f.sg.}+\mathrm{n}_{\text {poss. }}+\mathrm{u}_{\text {agr foracc.f.sg }}$. cat.F.SG.ACC. AUX scared car 'Her cat got scared by a car.'

Corbett (1987) argues that possessives in Slavic languages are problematic for morphological theories because the Serbian possessive suffix shows a dual behaviour: When it comes to syntax (e.g. binding, see example (66)), it functions like an inflectional morpheme, whereas in other respects (e.g. class membership change) it acts like a derivational one.
a. $\quad$ predsednikovo $_{i}$ predstavljanje sebe $_{i} \quad /$ svoje $_{i}$ kampanje president.POSS presentation himself/ his.own campaign 'president's presentation of himself/ his own campaign'
b. ${ }^{*} \operatorname{srpsko}_{i}$ predstavljanje sebe $_{i}$ serbian presentation themselves intended: 'Serbians' presentation of themselves'

Example (66) illustrates that possessives exhibit a noun-like behaviour, since the possessive modifier in (66a) can bind an anaphor, unlike the adjective in (66b). On the other hand, possessives display concord with the noun, indicating towards the class membership change from nominal to adjectival.

Zlatić (2000) provides an explanation for such a binary behaviour of Serbian possessives assuming that they are syntactically adjectives, but semantically nouns. More- 
over, Wechsler and Zlatić (1998, 2000) argue that nominals are specified with two sets of agreement features: morphosyntactic - concord features and semantic - referential index features. Concord is the feature of the syntactic head, while index concerns the semantic content of the noun. For example, a noun like mačka, 'cat' is a referring expression, and it is specified with both concord and index features.

CONCORD: number [1]sg, gender[2]f and case:nom

INDEX: number[1], gender[2] and person:3rd.

Hence, the number and gender features for concord and index match in this instance, as is the case with most nouns (Zlatić 2000). On the contrary, non-referential elements like adjectives do not possess index features and only show morpho-syntactic concord features that are acquired from the noun that they modify. Zlatic (2000) proposes that referential behaviour of Serbian possessives means that they have both types of features, but that the values for these features - in contrast to those of nouns - do not match. She argues that possessives exhibit both nominal and adjectival behaviour and suggests that they are syntactically adjectives, but semantically nouns. To put it differently, possessives show concord with the noun that they modify in the same fashion as prenominal adjectives do, but additionally they entail a set of index features which they inherited from the noun that they are derived from. This mechanism is illustrated in the following example in (67) (Zlatić 2000:183).

Ovo su žen-in- $i_{i} \quad$ kaput-i. Ona ${ }_{i}$ ih je kupila juče. this are woman-POSS.M.PL coat-M.PL she.F.SG them AUX bought yesterday 'These are woman's coats. She bought them yesterday.'

In this example, the coreferential pronoun 'she' agrees with the index of the possessive noun phrase 'woman' but not with the concord features of the possessive (M.PL). More precisely, the possessive form ženini 'woman.POSS.M.' agrees with the masculine noun in plural kaputi 'coats', and accordingly bears a masculine and a plural concord feature, as well. However, the index features of the possessive form ženini are [feminine, singular] as the noun underlying the possessive form is žena, 'woman' which itself bears features [feminine, singular]. If the pronoun ona, 'she' agreed with the concord features of the possessive, its surface form would be oni, 'they.masculine' as the feature bundle would be [gender:masculine, number:plural]. ${ }^{10}$

Zlatic concludes that possessive formation in Serbian belongs to the derivational morphological processes whereby the corresponding possessive affix is combined with the noun producing an adjective as an output. Afterwards, the newly formed possessive adjective enters into further agreement relations characterized as instances of inflectional

\footnotetext{
${ }^{10}$ The masculine pronoun on, 'he' could be also used here, but it would not have any reference to the previous sentence, it would refer to some other extralinguistic entity.
} 
morphology. Zlatić (2000:188) illustrates the different morphological processes in the following manner, see (68).

[A [A [N noun stem] poss affix] infl agr affix]

Thus, possessive derivation comes before inflectional affixation. Evidence for such an order of morphological processes is also shown on indeclinable nouns like some foreign proper names in Serbian (Šarić 2018:164).
a. Razgovarala sam sa Anom.
Spoken.I AUX with Anna
'I spoke with Anna.'
b. Anina knjiga
Anna.POSs book
'Anna's book'
a. Razgovarala sam sa *Inesom/Ines Spoken.I AUX with Ines. 'I spoke with Ines.'
b. Inesina knjiga Ines.POSS book 'Ines' book'
c. Čitala sam Inesinu knjigu. Read.I AUX Ines.POSs book 'I read Ines' book.'

A proper name like Ines is indeclinable in Serbian, and has the same form in all cases, which means that it does not acquire any case morphology. Yet, once it gets possessive inflection and supposedly transforms into an adjective (70b), it is not indeclinable anymore (70c). Based on such instances, Zlatic (2000) concludes that the possessive suffix is not just a regular inflectional suffix, but rather a derivational one. Such a view is not peculiar at all, given that the possessive suffix does not attach to the whole phrase, but rather to the stem only.

Corbett (1995) had a similar proposal, namely that possessive affixation in Slavic languages is similar in nature to Suffixaufnahme. The defining characteristic of Suffixaufnahme is "for nouns in attributive relation to agree with their head noun in case" (Plank 1990). If it is true that possessive affixation is an instance of Suffixaufnahme, possessives would be then marked for (genitive) case as a result of their relation with the head noun. On top of that, the possessive gets additional case marking from the outside environment. This would suggest that the possessive gets double inflectional case marking. Corbett (1995:2712) takes Upper Sorbian as an example language. 


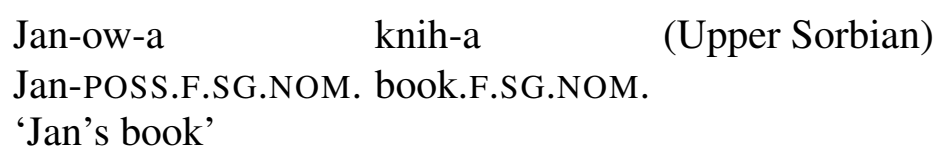

In the possessive Janowa the suffix - $a$ shows case agreement with the noun kniha. If we consider (71), Corbett's analysis seems to be correct with respect to marking of Nom of Jan because of kniha; however, his assumption of the possessive as genitive is questionable because the suffix -ow is actually not the standard (genitive) case marker, which is $-a$.

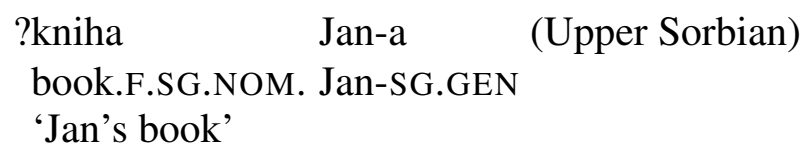

To put it differently, the possessive formation in Upper Sorbian is ambiguous between inflectional and derivational.

1. $\operatorname{Jan}_{N}-\mathrm{ow}_{I N F L}-\mathrm{a}_{I N F L}$

2. $\operatorname{Jan}_{N-R O O T}-\mathrm{ow}_{D E R I V}-\mathrm{a}_{I N F L}$

The same holds for Serbian, where the prenominal possessive agrees in case with the noun but the postnominal one shows genitive case.
a. Jovan-ov-a
knjig-a
John-POSS.F.SG.NOM. book-F.SG.NOM.
'John's book'
b. ?knjig-a Jovan-a
book-F.SG.NOM. John-SG.GEN

This raises some important questions about the status of the possessive marker and the morphological process to which possessive formation belongs: a derivational or inflectional process? This is immediately related to the issue of the categorial nature of possessives, i.e. whether they are nominal or adjectival. In the next subsection, the controversy concerning the categorial status of possessives is addressed.

\subsubsection{The categorial status of possessives in Serbian}

The discussion of the categorial status of possessives in Serbian is closely related to the analysis and internal make-up of nominal phrases in this language, which has split authors into two opposing camps, arguing either for an NP or a DP analysis for Serbian.

The categorial status of Serbian possessives has been related to this controversy: Proponents of an NP analysis (Bošković 2005; Zlatić 1997, among others) treat possessives parallel to adjectives as adjuncts of NP. They argue that Serbian has all the key properties 
as other Slavic languages (Russian, Czech) which belong to the group of AG languages. In contrast, the DP supporters believe that possessives should be treated as exponents of D, assuming they have their own functional projection DP (Progovac 1998; Bašić 2004).

Proponents of the NP analysis argue that prenominal elements modifying a noun and agreeing with it in case, number, and gender are adjoined to NP. They are treated as multiple specifiers to NP, as shown in (74) (Despić 2013:240, following Bošković 2005).

\section{[NP Demonstr [NP Poss [NP AP [NP N]]]]}

One of the most crucial arguments against applying the DP analysis to Serbian relates to the fact that this language does not have overt articles, which are typically seen to occupy the position $\mathrm{D}^{\circ}$ in article languages like English or German. In contrast, proponents of a DP-structure for Serbian (Bašić 2004; Progovac 1998; Stanković 2013) believe that the overtness of articles is not a convincing argument to conclude that Serbian lacks the DP layer because cross-linguistically, the existence of many covert categories has been proposed and argued for. Even for English or other typical DP-languages the existence of a null D is assumed in cases with plurals (movies in (75a)) or mass nouns (coffee in (75b)), when the presence of an overt article is not required, as exemplified in (75) below (see also Kayne's (1994) argumentation in Section 2.1.3).
a. My boyfriend doesn't like romantic movies.
b. Dragana drinks coffee with sugar.

Bašić (2004) argues against the NP analysis for Serbian, proposing that an element agreeing with the head noun does not need to be an adjunct to an NP projection, because agreement can be established in various ways: (a) by moving the elements in question through an agreement projection, or (b) by establishing the agreement relation between the noun and prenominal elements in their base positions, i.e. functional positions on top of NP (cf. Chomsky 2000, 2001). She sees the latter option as more plausible (cf. Julien 2002 who argues that agreement in Scandinavian DP is established in a similar fashion) and gives the tree structure for example (76) (Bašić 2004:25) in (77).

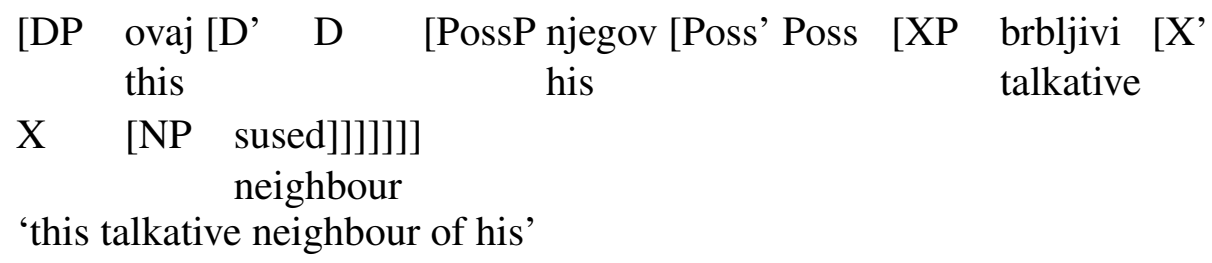


(77)

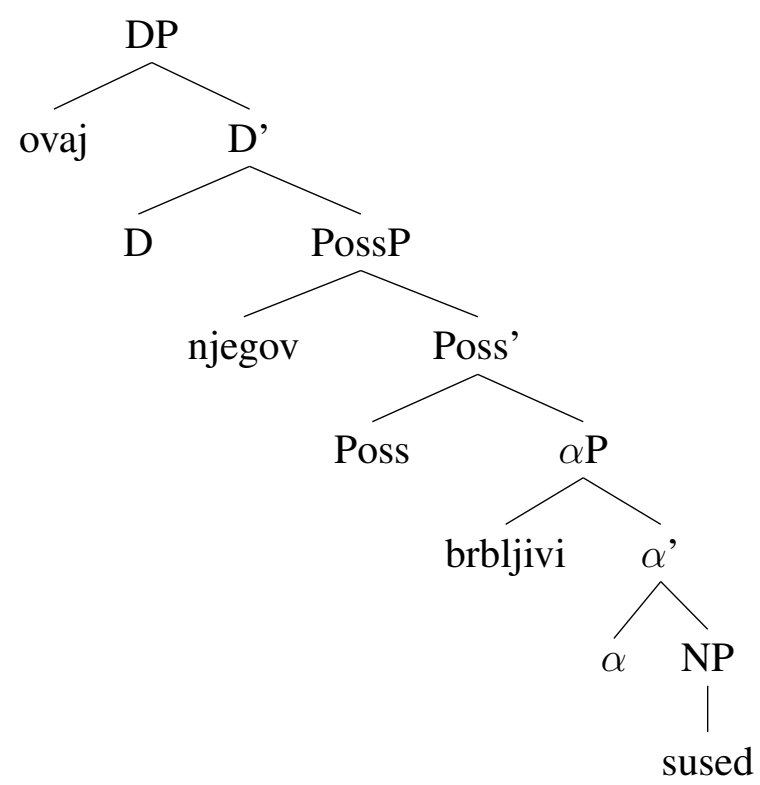

The different structures in (74) and (77) do not yet provide a clear answer concerning the categorial status of the possessive, which will be discussed in more detail in Subsections 2.2.3.1 and 2.2.3.2.

\subsubsection{Categorial status of possessives: adjectives?}

As shown in Section 2.1.1, cross-linguistically, possessive modifiers are typically analysed either as belonging to the category of D or to the category of adjectives. For Serbian, both categories have been proposed to hold. I will start by discussing the arguments in favour of an adjectival status.

Bošković (2005) and Zlatić (1997) argue that possessives should be treated as adjectives. Therefore, Serbian would belong to the group of AG languages according to the division proposed by Giorgi and Longobardi (1991) and Lyons (1986). One argument by Bošković (2005) and Zlatić (1997) is that possessives in Serbian show morphological agreement with the nouns they modify. Bošković (2009:192) shows that possessives, like adjectives, agree in number, gender and case with the head noun by giving a partial case paradigm as in example (78).
a. mojIM
nekIM
visokIM
devojkama
my.POSS.PL.INST. some.F.PL.INST. tall.F.PL.INST. girls.F.PL.INST.
b. mojIH
nekIH
visokIH
devojaka
my.POSS.PL.GEN SOme.F.PL.GEN. tall.F.PL.GEN. girls.F.PL.GEN.

Following Corver (1992), Bošković (2009) further supports this claim by showing that Serbian unlike English possessives can occur in a predicative position of copular constructions, which is a common environment for adjectives (79a). Assuming that possessives in 
English are exponents of D, the corresponding structures are ungrammatical in English as shown in (79b) (Bošković 2009:195).
a. Ova knjiga je moja. this book AUX my
b. *This book is $m y$.

Moreover, unlike in English, modifiers like demonstratives and possessives can be stacked in Serbian, which is another adjectival property.
a. ta moja knjga
that my book
b. *that my book

Further, the word order of prenominal modifiers in Serbian is relatively free in comparison to English as illustrated in (81) for Serbian and (82) for English (Bošković 2005:7).
a. Jovanova skupa slika John.POSS expensive picture
b. skupa Jovanova slika expensive John.POSS picture
a. John's expensive picture
b. *expensive John's picture

Finally, possessives cannot be modified by other possessives or adjectives. This is expected if we assume the adjectival analysis for possessives, given that it is impossible to modify adjectives by other adjectives (Bošković 2005:7).

$$
\begin{aligned}
& \text { *moj bratov prijatelj spava } \\
& \text { my brother's.POSs friend.POSs sleeps }
\end{aligned}
$$

To sum up, if we assume the adjectival analysis of possessives, i.e. that they are not exponents of $\mathrm{D}$, then possessives and adjectives do not require the DP projection to host them. Moreover, under the adjectival analysis, possessives do not require case assignment in the same way that nominal expressions do. The view that possessives are adjectives in Serbian has been challenged by the arguments provided in Section 2.2.3.2.

\subsubsection{Categorial status of possessives: exponents of $D$ ?}

Even though Serbian possessives do show certain adjectival properties, this does not necessarily mean that Serbian possessives are exponents of the category 'adjective'. On the contrary, if we take a closer look at the behaviour of prenominal modifiers, we will ob- 
serve that they should not be treated uniformly and that they actually occupy different positions in the prenominal domain.

First, Šarić (2018) makes a remark on Bošković's morphological argument, by comparing Serbian and German, in which articles overtly show phi-agreement with the noun, and they are not considered to be adjectives. Also, she claims that Serbian nouns take this adjectival morphology which is a property of all nominal elements and not solely adjectives, as illustrated in (84) (Šarić 2018:170).
a. neka
moja
nova
knjiga
some.F.PL.NOM. my.F.PL.NOM. new.F.PL.NOM. book.F.PL.NOM.
b. nekom
mojom
novom
knjigom
some.F.PL.INST. my.F.PL.INST. new.F.PL.INST. book.F.PL.INST.

In addition, possessives differ from adjectives since they do not show a definite/indefinite distinction. For instance, an adjective like plav, 'blue' has a long form plavi, marked with a suffix $-i$, which has been analysed as a marker of definiteness (plav auto, 'a blue car' vs. plavi auto, 'the blue car'). Possessives, however, cannot have long forms as adjectives can (Šarić 2018). Moreover, unlike adjectives, possessives do not have comparative and superlative forms, (e.g. plavlji, 'bluer', najplavlji 'the bluest' vs. *mojiji, 'myer', *najmojiji, 'the myest').

Furthermore, the argument regarding copular constructions that Bošković gives in favour of adjectival analysis might not be consistent. The fact that $m y$ is not allowed in predicative position in English does not necessarily mean that possessives are completely disallowed in this position. Instead, the difference between my and mine in English can be seen as a weak/strong opposition: Predicative positions require the strong form of a possessive 'mine', whereas the weak form 'my' is not possible (Cardinaletti 1998). LaTerza (2015) also questions Bošković's argument regarding copular constructions. She noticed that Bošković glosses the pronominal possessive moja as a possessive adjective 'my' and not as a possessive pronoun 'mine'. This is significant given that pronominal possessive adjectives and pronouns are syncretic in Serbian as shown in (85).
a. Ova knjiga je moja. this book AUX my 'This book is mine.'
b. Moja knjiga je na stolu. my book AUX on table 'My book is on the table.'

In contrast to Serbian, English shows a morphological difference between possessive adjectives and pronouns in the first person (e.g. my-mine, our-ours). This is the explanation 
why only mine can occur in the copular constructions (LaTerza 2015:91).
a. *This book is $m y$.
b. This book is mine.

However, in the case of 3. person masculine, English behaves just like Serbian and also exhibits syncretism between the possessive pronouns and the possessive adjective (LaTerza 2015).
a. This book is his.
b. His book is on the table.

This shows that - like English his (see (87)) - the Serbian possessive moja used in (84) may actually exhibit syncretism (LaTerza 2015). Another Slavic DP language - Macedonian also has syncretic pronouns and possessive adjectives (LaTerza 2015:91).
a. Ova knjiga e moja. (Macedonian) this book AUX my 'This book is mine.' my book AUX on table 'My book is on the table.'
b. Moja knjiga e na masata.

Hence, LaTerza (2015) concludes that based on the existing syncretisms, Bošković's argument based on copular constructions is unconvincing given that possessive elements in such constructions might be realized as possessive pronouns, which have a syncretic form with possessive adjectives.

As illustrated in the previous section, stacking of prenominal modifiers like demonstratives, possessives or adjectives is seen as another argument in favour of their categorial status as adjectives (see example (79)). However, Šarić (2018) finds this argument conflicting and argues that demonstratives and adjectives occupy different positions in the premodifier environment, given that one can only stack a demonstrative on top of an adjective. Furthermore, if possessives were analysed as adjectives in Serbian, it would be expected that it is allowed to have multiple possessives within one nominal expression, given the possibility of multiple adjectives modifying a noun. However, this is not possible as shown in (89) (Šarić 2018:173).
a. *Jovanova Markova devojka Jovan's Marko's girlfriend
b. visoka plava zelenooka devojka tall blonde green-eyed girl 
More evidence that diminish Bošković's argument concerning stacking comes from a number of DP languages which also permit modifier-stacking. For instance, demonstratives can co-occur with possessives in Hungarian (90a) (Abney 1987:173), Macedonian (90b) and Bulgarian (90c) (Dimitrova-Vulchanova and Tomić 2009:11).

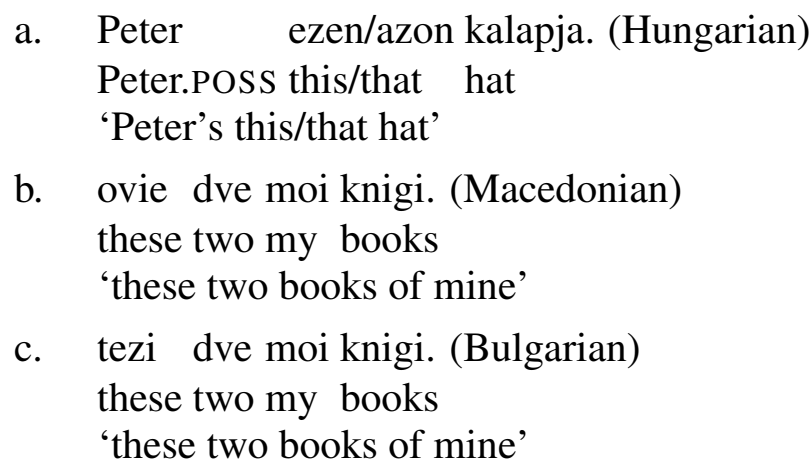

Concerning the argument that the relatively free word order of prenominal modifiers in Serbian is connected to the adjectival status of possessives, one should notice that even though Serbian has relatively free word order, there is only one default neutral word order, as already shown in Section 2.2.1. All the other combinations can alter the semantic interpretations, which implies that they are actually derived. For example, other orders can be prompted by some rules of information structure in order to express focus (Bašić 2004; Šarić 2018). Even though both (91a and b) are possible, example (91b) has a contrastive function.
a. Ona moja plava majica je oprana. that my blue T-shit AUX washed 'That blue T-shirt of mine is washed.'
b. Plava ona moja majica je oprana. blue that my T-shirt AUX washed 'That blue T-shirt of mine is washed (and not the pink one).'

According to Bošković (2005), another characteristic of possessives which speaks in favour of their adjectival status is the lack of modification. This observation, however, does not hold for all Slavic languages without articles. LaTerza (2015) gives examples from two articleless Slavic languages, namely Upper Sorbian (92a) and Slovak (92b) which permit the modification of their prenominal possessives. This is not in line with Bošković's claim that possessives in NP languages are adjectives and that their modification is therefore rejected.

$$
\begin{aligned}
& \text { a. mojeho mužova sotra (Upper Sorbian) } \\
& \text { my husband's sister } \\
& \text { 'my husband's sister' }
\end{aligned}
$$


b. našho dobrého susedova záhrada (Slovak)

our good neighbour's garden

'our good neighbour's garden'

That the existence or lack of articles does not correlate with the possibility of modifying a possessive is shown by a Serbian dialect which has articles, i.e. timočko-lužnički (classified as a DP language) which is predicted to allow for the modification of prenominal possessives but it does not allow it (Stanković 2013).

$$
\begin{aligned}
& \text { *moe drugarovo kuče } \\
& \text { my friend.POSs dog } \\
& \text { 'my friend's dog' }
\end{aligned}
$$

The data thus show that the modificational ability of possessives is not decisive to determine the categorial nature of these elements.

Concerning binding, Serbian possessives exhibit nominal properties. Zlatić (1997) notices that lexical possessives are able to bind anaphora as illustrated again by the following example (94a) (Bašić 2004:23). Binding of anaphora is also possible with pronominal possessives, see the same example with the corresponding pronominal possessive in (94b). ${ }^{11}$

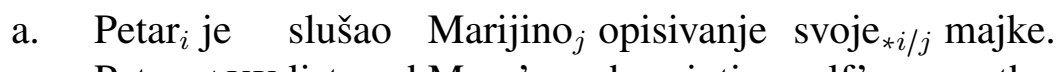
Peter AUX listened Mary's description self's mother
'Peter ${ }_{i}$ listened to Mary ${ }_{j}$ 's description of her ${ }_{* i / j}$ mother.'
b. $\operatorname{Petar}_{i}$ je slušao njeno ${ }_{j}$ opisivanje svoje $_{* i / j}$ majke.
Peter AUX listened her description self's mother

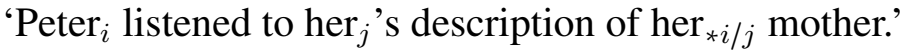

This also speaks against an adjectival status. Adjectives are not able to bind a reflexive in object position, not even referential ones. This contrast is shown in the example (95) (Šarić 2018:176).

$$
\text { a. John's destruction of himself }
$$

\footnotetext{
${ }^{11}$ This is also observed in Russian, see (i) from Rappaport (2000:17).
}
a. Ja videl [vaš $\check{ }_{i}$ portret $\operatorname{svoix}_{i}$ detej].
I saw your portrait your children

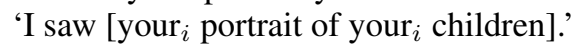
b. $\mathrm{On}_{i}$ rasskazal [amerikanskij ${ }_{j}$ anekdot pro sebja ${ }_{i / * j}$ ].
he told american joke about himself
'He told [an American joke about himself/*America].'

Pronominal possessives as in (ia) can be antecedents of reflexives contained in the same NP, unlike relational adjectives as in (ib). 
b. ??the American destruction of themselves

This is another significant difference between possessives and adjectives. Observe that the possessive in (96a) unlike the adjective (96b) cannot only bind the anaphor as in (93), but also be the antecedent of the anaphoric pronoun (Šarić (2018:176) following Russian examples from Rappaport (1998:17)). ${ }^{12}$

(96) a. Htela sam da pozajmim Aninu haljinu, ali ona nije htela da mi je da. wanted AUX to borrow Ana's dress but she not want to me it give 'I wanted to borrow Anna's dress, but she wouldn't give it to me.'

b. *Kupila sam italijanske cipele. Jesi li nekad bio tamo? bought.I AUX Italian shoes. have AUX ever been there 'I bought a pair of Italian shoes. Have you ever been there?'

Last but not least, Serbian patterns with Russian (Rappaport 2000) in the sense that an $\mathrm{NP}$ bearing genitive case can be coordinated with a possessive pronoun which shows that both are treated as syntactically parallel, see (97a). On the other hand, adjectives cannot be coordinated neither with genitives (97b) nor with possessives (97c) which would be expected if both would belong to the same syntactic category (Šarić's $(2018: 176,177)$ version of Rappaport's (2000: 13) Russian examples).
a. Ovo su moja i moje žene kola
This aux my.POSS and my.POSS.GEN wife.GEN car
'This is my and my wife's car.'
b. *Ovo su nemačka i moje žene kola.
this aux German and my.POSS.GEN wife.GEN car
c. *Ovo su nemačka i moja kola. this aux German and my.POSs car

From what we have seen, it is clear that possessives pattern with adjectives in some characteristics, mainly in morphological agreement with the noun they modify. However, the above presented arguments clearly indicate that they behave differently in many other aspects. Thus, it can be concluded that possessives and adjectives are different categories.

${ }^{12}$ This is also observed in Czech, see (i) (Veselovská 2014:116).

(i)
a. žena $i$ obvykle mluvi o sobe $_{i / * j}$
woman $_{i}$ usually talks about herself $i / * j$
b. Žen-in-o $i$ obvykle mluveni o sobe $_{i / * j}$
woman $_{i}$ 's usual talking about herself $_{i / * j}$
c. Žen-ske $i$ večne mluveni o sobe $_{\star i}$
female $_{i}$ 's permanent talking about ??self ${ }_{\star}$

Czech possessives behave as nominal elements, given that they are also able to bind an anaphor contrary to adjectives. 
Even though the arguments suggest that Serbian possessives can be analysed as exponents of $\mathrm{D}$, it is certain that they cannot be $\mathrm{D}$ in the sense of articles or demonstratives, and cannot occupy the same position as these elements. This is supported by examples such as (98), because the possessive co-occurs with d-like element $t a$, 'this'.

$$
\begin{aligned}
& \text { ta moja knjiga } \\
& \text { this my book }
\end{aligned}
$$

However, after considering all the arguments, I conclude that possessives are certainly not adjectives, but they are neither typical d-elements, nor typical pronouns. Because possessives are generally represented as pronouns or nouns, I will analyse them as full noun phrases DPs.

In the next section, I will discuss the structure of nominal phrases and show that these elements actually occupy different positions.

\subsubsection{Syntactic position of possessives in Serbian}

In the previous sections, I have discussed the categorial status and the distribution of possessives. We have seen that the word order of prenominal modifiers in Serbian is not as free as it seems at first sight. Specifically, in example (57) from Bašić (2004), it is shown that determiners cannot switch order with either possessives or adjectives. Following Bašić (2004), this further indicates that possessives in Serbian occupy the lower specifier position of the DP layer (as in the analysis of Scandinavian DPs in Julien (2002)).

Bašić (2004) claims that possessives appear in a SpecPossP, and that all other word orders are derived by movement. Furthermore, Bašić (2004) assumes that determiners, possessives and adjectives occupy specifier positions of different functional projections, given that possessives and determiners can co-occur. The fact that in many unrelated languages determiners and possessives do co-occur as well (such as in Norwegian, Hungarian, Italian, Modern Greek etc.) additionally supports this assumption.

Bašić's (2004) analysis is based on Szabolcsi's (1994) analysis of Hungarian. As already shown in Section 2.1.2 possessors in Hungarian can appear between determiners and nouns, triggering person and number agreement, expressed in the form of a suffix on the possessed NP, as shown in (99).

$$
\begin{aligned}
& \text { a. a te kalap-ja-i-d (Hungarian) } \\
& \text { the you hat-POSS.PL.2SG } \\
& \text { 'your hats' } \\
& \text { b. a Mary kalap-ja-i-0 } \\
& \text { the Mary-Nom hat-POSS.PL.3SG } \\
& \text { 'Mary's hats' }
\end{aligned}
$$


This suggests that Hungarian possessives are structurally positioned below D in the extended projection, namely in PossP. Given that the possessor bears nominative case further implies that PossP is a structural subject position, which coincides with the subject position in the finite clause. This way, a parallel can be drawn between D and C in the verbal domain.

Bašić (2004) adopts this analysis to Serbian possessors. She asserts that they appear in the SpecPossP, projected below the DP. As already mentioned, possessives have been treated as adjectives, together with other prenominal modifiers. Although possessives do pattern with adjectives in certain characteristics, this is not unique for articleless languages only, given that possessive forms behave as adjectives in certain aspects in languages in which they are analysed as D elements, as well. On the other hand, Serbian possessives can neither be D-elements as in English, given that they can co-occur with other d-like elements, they can have indefinite interpretation, etc. However, since possessives are formed out of nouns or pronouns, I rather analyse them as full noun phrases, namely DPs from a categorial point of view.

I assume that possessors in Serbian are merged in the specifier of PossP where they obtain their possessor role and move up higher - to the specifier position of AgrP (correspondingly how clausal subject moves to the highest specifier of IP). To account for the cross-categorial symmetry between the clause and the extended NP, Alexiadou et al. (2007) propose the following structure which I apply to Serbian examples below, with the difference that I assume that only possessives modifying complex event nominals are base-generated in SpecnP, but the possessives that have strict possessor role and are not $\mathrm{nP}$ agents are merged in SpecPossP.
a. Jovanov auto
John's car
b. [PossP Jovanov ... [n auto $\left.j]\left[\mathrm{NP}\left[\mathrm{N} \mathrm{t}_{j}\right]\right]\right]$
c. $\quad\left[\right.$ AgrP Jovanov $_{k}[$ Agr auto $j]\left[\right.$ PossP t $\left.\left._{k} \ldots\left[\mathrm{n} \mathrm{t}_{j}\right]\left[\mathrm{NP}\left[\mathrm{N} \mathrm{t}_{j}\right]\right]\right]\right]$

As already noted, Serbian should typologically belong to the AG group of languages. However, unlike Italian it does not have articles, so the $\mathrm{D}$ position would be empty, unless there is a d-like element such as a demonstrative that could occupy this head position.
a. moja knjiga
my book
b. [DP $\left[\right.$ AgrP $\operatorname{moja}_{i}\left[\ldots \mathrm{t}_{i}\right.$ knjiga $\left.\left.]\right]\right]$

Thus, following Alexiadou et al. (2007), the possessor in AG languages does not raise up to $\mathrm{D}$ as it is the case with DG languages. Rather, it should occupy one of the following positions: either (i) the SpecnP or SpecPossP or (ii) the SpecAgrP. The SpecPossP is a 
base-generated position of possessives and it is also reserved for postnominal possessives - such as strong possessives as in Italian (la casa MIA, 'my house'). When it comes to Cardinaletti's (1998) distinction of possessives, Serbian does not have three different types of possessives as some languages can have. In Italian, prenominal - weak possessors cannot be stressed, modified and coordinated unlike possessives in postnominal position - strong possessives. Unlike Italian, Serbian possessives can be coordinated, and they can be stressed. Therefore, I assume that Serbian possessives are strong, even though they are rather located prenominally. It is possible for possessives to appear in both prenominal and postnominal position in Serbian (and also in predicative position as shown above). However, the prenominal position is a neutral and preferred word order for possessives within the noun phrase, whereas the postnominal position is quite rare.
a. Slupao sam taj moj auto. crashed AUX that my car
b. Slupao sam taj auto moj. crashed AUX that car my 'I crashed that car of mine.'

If we compare Serbian and Italian, in Italian only postnominal possessives can be possible under the focus - la macchina MIA, 'the car MY'. Hence, in Italian, movement is triggered by defocalization (Kupisch and Rinke 2011). Although Serbian possessives are strong, they can be focused only prenominally - taj MOJ auto, and movement seems not to be related to information structure as in Italian. This might be due to some semantic reasons, i.e. taj auto, 'that car' already refers to a specific car and prosodically marking the low possessive in (102b), i.e. giving it a focused interpretation, appears to be infelicitous.

I assume that the adopted structure of Alexiadou et al. (2007) in (103) could account for Serbian data containing prenominal possessives.

$$
\begin{aligned}
& \text { [DP }\left[\mathrm { D } \text { taj] } \left[\text { AgrP } \operatorname { m o j } _ { i } [ \mathrm { Agr } \text { auto } _ { k } ] \left[\mathrm { PossP } _ { i } [ \mathrm { Poss } ] \left[\mathrm{nP}\left[\mathrm{nt}_{k}\right][\mathrm{NP}[\mathrm{N}\right.\right.\right.\right. \\
& \text { that my car } \\
& \left.\left.\left.\left.\left.\left.\mathrm{t}_{k}\right]\right]\right]\right]\right]\right]
\end{aligned}
$$

Moreover, I assume that there should be no differences between pronominal possessives and lexical possessives (possessive names) in Serbian, thus the same structure is assumed.

$$
\begin{aligned}
& \text { [DP [D taj] [AgrP Jovanov }{ }_{i}\left[\text { Agr } \text { auto }_{k}\right]\left[\text { PossP t }_{i}\left[\text { Poss ] [nP [n t } \text { t }_{k}\right][\mathrm{NP}\right. \\
& \text { that John's car } \\
& \left.\left.\left.\left.\left.\left[\mathrm{N} \mathrm{t}_{k}\right]\right]\right]\right]\right]\right]
\end{aligned}
$$


Also bearing in mind Kayne's (1994) argument with respect to the position of possessives and their binding possibilities concerning Binding Principles, one can notice that his structure in (50) repeated here as (105) resembles the structure Bašić (2004) proposed for Serbian in (77), here repeated as (106). They are similar in a significant way: they both assume a DP headed by a null D above the possessor. This projection plays a very important role in Kayne's (1994) approach, since it is essential for explaining examples as $(47 \mathrm{a}, \mathrm{b})$ with respect to the constraining of c-command out of their projections.

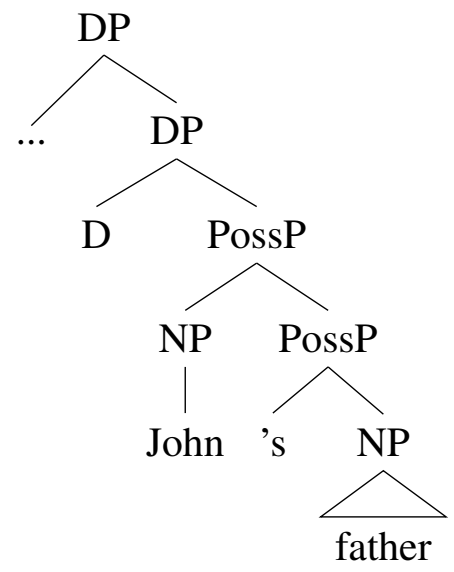

(106)

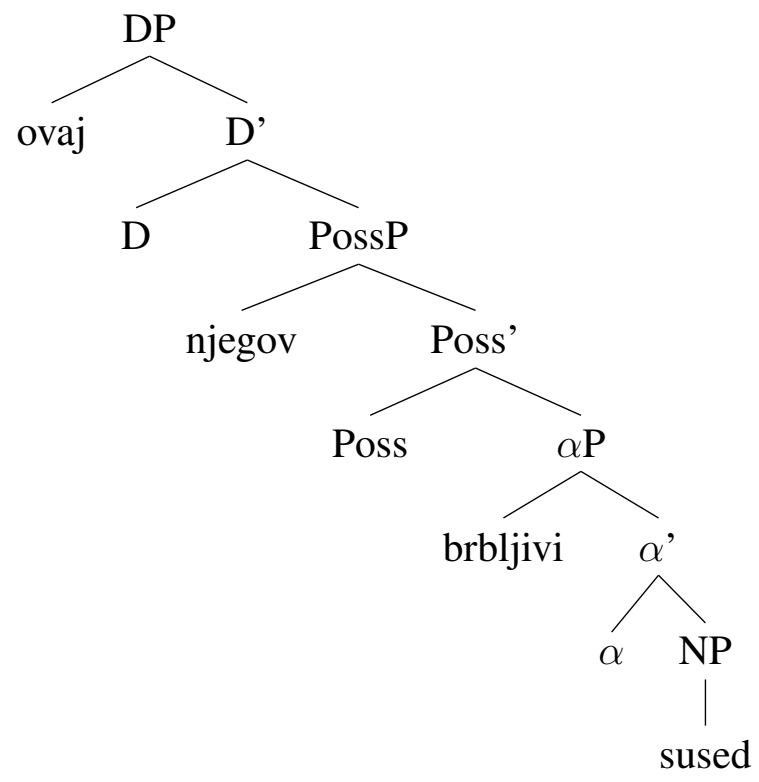

Taking all this into account, I suggest that it would be convenient to assume that Serbian also has a DP with a null D on the top of the nominal projection in line with Kayne's (1994) approach based on the argumentation related to binding. Alternatively, demonstratives such as taj, 'this' would occupy the D head when they are present. When it comes to the base position of the possessor, I follow Alexiadou et al. (2007), but provided that SpecnP is reserved for Agent theta role (e.g. for complex event deverbal nominals), I assume that there is a functional category PossP which introduces a semantic relation 
between the possessor and the nP. Thus, the possessor is merged in a specifier position of this functional category. Furthermore, I adopt Alexiadou et al.'s (2007) and Bernstein and Tortora's (2005) argument that the possessives' derived position is SpecAgrP, where they move to because of the agreement features. Finally, I suggest the structure for example (107) in (108) for Serbian.

(107) taj njegov/Jovanov auto that his/John's car 'That car of his/John's'

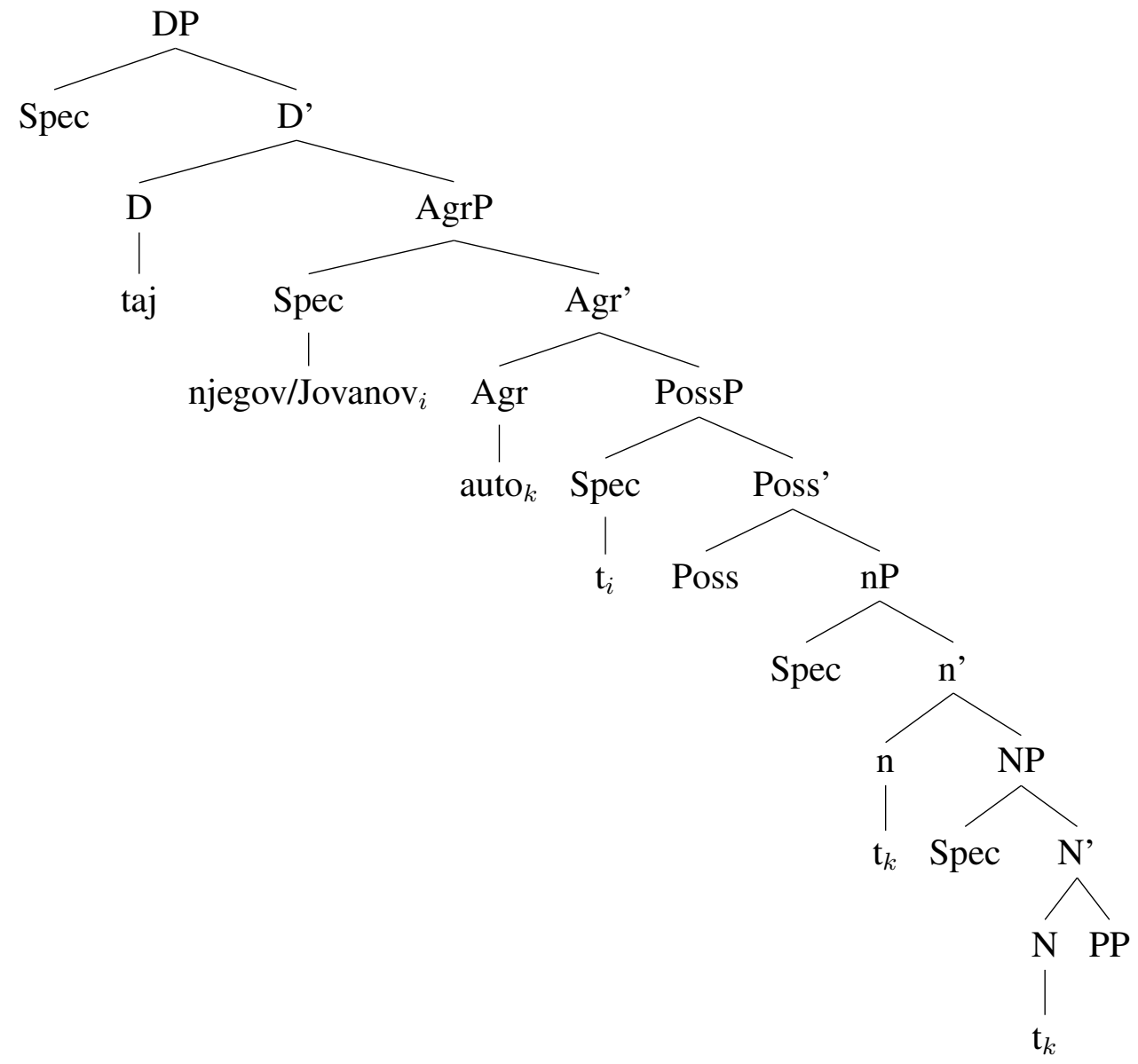

\subsection{5 'Possessive binding' in Serbian}

Given all the above, we have seen that possessives are quite peculiar elements and their features and functions may differ across languages with regard to their categorial status and position within the extended nominal projection. Also, some languages can have different types of pronominal possessives which occupy different structural positions accordingly. Based on the conclusions I reached in Sections 2.2.3 and 2.2.4, I will now turn to the assumptions how categorial status and structural position can affect binding in possessive constructions in Serbian. 
In Section 2.2.3, I questioned the DG/AG parameter for Serbian. Firstly, Serbian possessives are not articles/D-elements in the same sense as in English. This is clear based on the variability of their position in the prenominal domain, the combination with d-elements like demonstratives, and the possibility of receiving an indefinite interpretation etc. Hence, Serbian is typologically seen to belong to the group of AG languages. However, as argued in the previous section, this does not necessarily mean that Serbian possessives are adjectives. This shows that the DG/AG parameter is problematic, which is also true for other languages, where pre- and postnominal possessives are not behaving as typical adjectives or determiners, as it has been assumed (e.g. Spanish, which has different types of pre- and postnominal possessives). However, after reconsidering all the arguments and since they are represented by either pronouns or nouns, I will rather treat them as full noun phrases, namely DPs.

When it comes to Serbian, the structural position of possessives has an effect on binding possibilities, as in other languages as well. As discussed in Section 2.2.4, I follow Bašić (2004)'s argumentation that Serbian has only one default neutral word order in the noun phrase, although word order is relatively free. This further suggests that possessives are located in a specifier position lower within the DP-spine (below demonstratives). If possessives occupy SpecAgrP within the noun phrase, they cannot c-command out of it, as in English, and there should be no violation of Binding Principles B and C, contrary to what has been claimed by Despić (2013).

As already mentioned in the Introduction, according to Despić (2013), examples as in (109) and (110) are ruled out in Serbian. Their unacceptability goes in favour of the NP analysis, given that the assumed difference between English and Serbian is due to the absence of DP in Serbian.

?Jovanov $_{i}$ papagaj ga $_{i}$ je ugrizao.

Jovan's parrot him.CL AUX bitten

' $\mathrm{John}_{i}$ 's parrot has bitten $\operatorname{him}_{i}$.'

$$
\begin{aligned}
& \text { ?Njegov }_{i} \text { papagaj je ugrizao Jovana } \text {. } \\
& \text { His parrot AUX bitten John } \\
& \text { 'His } i \text { parrot has bitten } \mathrm{John}_{i} \text {.' }
\end{aligned}
$$

There have been some remarks on Despić's (2013) analysis supporting the Parameterized DP Hypothesis. LaTerza (2016) argues that these potential differences are not due to the absence/presence of DP by providing two arguments: (1) she considers Serbian possessive nominals which are further embedded within the subject as complements of some head, assuming that they should loose the constraints on coreference compared to the unembedded cases; (2) her premise is that Bulgarian and Macedonian - Slavic DP languages - should pattern with English, but rather they pattern with Serbian. 
To corroborate her first argument, LaTerza (2016) gives examples as in (111) and (112), in which relational nouns such as prijatelj, 'friend' take postnominal possessives as complements. She argues that in these examples, njegove, 'his' and Markove, 'Marko's' are neither adjuncts nor specifiers of the larger NP. Therefore, there is no c-command and thus, no violation of Binding Principles B and C. However, the same constraints are observed with unembedded possessives, i.e. the possessives and R-expressions/pronouns are not coreferential.

(111) * Prijatelj njegove ${ }_{i}$ majke je zagrlio Marka . $_{i}$ Friend his mother AUX hugged Marko 'His mother ${ }_{i}$ 's friend hugged $\mathrm{Marko}_{i}$.'

(112) *Prijatelj Markove majke je zagrlio njega $_{i}$.

Friend Marko's mother AUX hugged him.STR 'A friend of Marko $_{i}$ 's mother hugged him $i$.'

As her second argument, LaTerza (2016) takes into account Slavic languages which have a DP, namely Bulgarian and Macedonian. In the following examples (113) for Bulgarian and (114) for Macedonian, she shows that although they are DP languages, they unexpectedly behave in the same manner as Serbian, rather than as English.
a. *Negovijat ${ }_{i}$ papagal uhapa $\operatorname{Ivan}_{i}$ včera. (Bulgarian) his.the parrot bit Ivan yesterday

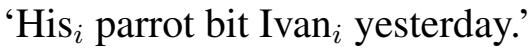
b. *Ivanovijat ${ }_{i}$ papagal nego ${ }_{i}$ uhapa včera. Ivan.POSS.the parrot him bit yesterday 'Ivan ${ }_{i}$ 's parrot bit him $_{i}$ yesterday.'

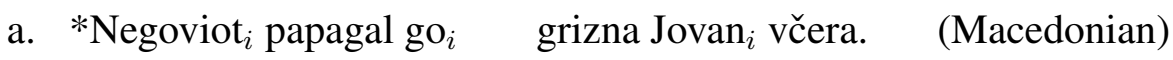 his.the parrot him.CL bit Jovan yesterday

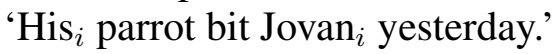

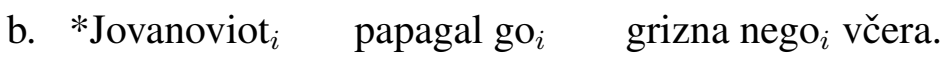 Jovan.POSS.the parrot him.CL bit him yesterday 'Jovan ${ }_{i}$ 's parrot bit $\operatorname{him}_{i}$ yesterday.'

This might be unexpected for Despićs analysis unless under the assumption that Serbian binding possibilities could be available in a DP language if the possessives were adjoined to a DP. DP languages differ in the word order of the possessives and the definiteness marking cross-linguistically. For instance, English definite articles are free-standing prenominal elements, as opposed to Bulgarian and Macedonian definite articles which are realized as postnominal suffixes, as in Jovanov-iot, 'Jovan.POSs.the'. However, LaTerza (2016) is uncertain about such a proposal because then, Bulgarian and Macedonian pos- 
sessives should be obliged to adjoin to DP instead of remaining in situ, and the question is what features would drive such a movement.

LaTerza (2016) concludes that some properties of Serbian (and therefore Bulgarian and Macedonian, as well) possessives might be responsible for the unacceptability of coreference in the aforementioned examples. She believes that possessives seem to behave as if they are located in a very high position from where they can c-command, even when they are embedded. LaTerza (2016) follows Szabolcsi's (1983) analysis of Hungarian dative possessors, which are able to raise to the edge position within their nominals. In a similar fashion, it might be assumed that Serbian, Bulgarian and Macedonian prenominal possessors uniformly raise at LF to the edge of their largest containing noun as in (115). From this position, they can c-command the rest of the clause, and that would explain why it is not possible to get a coreferential reading.

$$
\begin{aligned}
& \text { Markove }_{i} \quad \text { [prijatelj [Markove } \\
& \text { Marko.POSS friend majke]] je zagrlio njega }_{i} . \\
& \text { 'Marko }{ }_{i} \text { 's mother's friend hugged him }{ }_{i} \text {. }
\end{aligned}
$$

LaTerza (2016) also declares that (116) is acceptable because a PP is used, but native speakers I consulted disliked this construction, and given that it is not a prenominal possessive, such structures are not considered in my study.

Prijatelj od Marka Markovica je $_{\text {jegrlio njega }}$.

Friend of Marko Markovic AUX hugged him.STR 'A friend of Marko Markovic ${ }_{i}$ hugged him ${ }_{i}$.'

Even though LaTerza (2016) shows that the difference in binding between English and Serbian possessive sentences is not due to the presence vs. absence of DP in these languages, as proposed by Despić (2013), the picture is not that simple. As shown by Franks (2019), LaTerza's (2016) examples with Binding Principle B are problematic because they involve only strong pronouns in object positions. This matter will be further addressed in Chapter 3.

So far, LaTerza's (2016) arguments show that the cross-linguistic difference is not due to the DP layer, but she also supports Despić (2013) in claiming that such structures are not possible with coreferential reading in Serbian (Bulgarian and Macedonian). However, even though Despić (2013) rules out the examples such as $(109,110)$, he does mention that coreference is possible under certain conditions. For instance, he points out that non-agreeing quantifiers are a bit different. A non-agreeing, non-adjectival form of mnogi, 'many' behaves just like numerals, in the sense that it assigns the genitive of quantification. Such forms are introduced in a separate projection - QP, above an NP and they do constrain the c-command of possessives, which in these contexts allows for a 
coreferential relation with other elements without causing a binding violation. According to Despić (2011), the QP blocks the relevant c-command relation. Comparing sentences (117) and (118), Despić (2011) concludes that there is a difference between these two forms of 'many', because the agreeing quantifier behaves just as the demonstrative ovaj, 'this' causing binding violations, but the non-agreeing quantifier projects another phrase above an NP, and therefore it is possible to get the coreferential reading in (118).

$$
\begin{aligned}
& \text { *Mnogi Dejanovi } i_{i} \text { prijatelji su njega }_{i} \text { kritikovali. } \\
& \text { Many Dejan's friends AUX him.STR criticized } \\
& \text { 'Many of Dejan }{ }_{i} \text { 's friends criticized him }{ }_{i} \text {.' }
\end{aligned}
$$

$$
\begin{aligned}
& \text { Mnogo Dejanovih }{ }_{i} \text { prijatelja je kritikovalo njega }{ }_{i} \text {. } \\
& \text { Many Dejan's.gen friends AUX criticized him.STR } \\
& \text { 'Many of Dejan }{ }_{i} \text { 's friends criticized him } \text { h. }_{i}
\end{aligned}
$$

Moreover, Despić (2013:256) claims that the following example is also acceptable, although it would be expected to be a violation of Binding Principle C.

$$
\begin{aligned}
& \text { Jovanov }_{i} \text { papagaj je juče ugrizao Jovana } \\
& \text { John's parrot AUX yesterday bitten John } \\
& \text { 'John }{ }_{i} \text { 's parrot bit John }{ }_{i} \text { yesterday.' }
\end{aligned}
$$

In order to sustain the alleged difference between Serbian and English, and so as to account for the acceptability of examples as in (119), Despić (2013) assumes some additional principles beyond Principle $\mathrm{B}$ and $\mathrm{C}$ that will be addressed here briefly. Firstly, he adopts Safir et al.'s (2004) competitive principle - Form To Interpretation Principle (FTIP) (cited in (120)), which controls the distribution of reflexives, pronouns, and Rexpressions.

$$
\begin{aligned}
& \text { "If } \mathrm{x} \text { c-commands } \mathrm{y} \text {, and } \mathrm{z} \text { is not the most dependent form available in position } \\
& \mathrm{y} \text { with respect to } \mathrm{x} \text {, then } \mathrm{y} \text { cannot be directly dependent on } \mathrm{x} \text {." (Safir et al. 2004) }
\end{aligned}
$$

This principle also accounts for the grammaticality of apparent Principle B and Cviolations as in example (119) by assuming that more dependent elements like svoj and njegov are ungrammatical in the subject position for independent reasons, which is illustrated below in (121a) and (121b). ${ }^{13}$ In (121a) it is assumed that coreference cannot be

\footnotetext{
${ }^{13}$ The hierarchy of dependent elements in Serbian includes three elements: sebe, pronoun, R-expression (Despić 2013). The most highly dependent element is the reflexive sebe, 'self', which is local and subjectoriented. However, although it is prescribed by traditional grammars that reflexive sebe/svoj, 'self' should be used as in (ib), Serbian native speakers often produce sentences such as (ia) in everyday speech, with an intention to refer to the antecedent (both in spoken and written form) (Despić 2013).
}

(i) a. ??Jovan $i$ je udario njegovog $i$ prijatelja.

John AUX hit his friend 56


established, but the sentence in (121b) is completely ungrammatical and impossible to utter in Serbian.

a. *Njegov $i$ prijatelj je udario Jovana . $_{\text {. }}$ His friend AUX hit John

b. ${ }^{*}$ Svoj $_{i}$ prijatelj je udario Jovana . $_{\text {. }}$ Self's friend AUX hit John 'His ${ }_{i}$ friend hit $\mathrm{John}_{i}$ ',

Secondly, Despić (2013) offers arguments in favour of Lasnik (1989)'s definition of Condition C. Lasnik (1989) notices that Condition C differs cross-linguistically and he slightly modifies the condition, as cited in (122).

“An R-expression is pronoun free.” (Lasnik 1989)

Implementing this version of Condition C to Serbian, Despić (2013) yields to explain differences between the acceptability judgments of the upcoming set of examples. Given that sentences in question are ungrammatical with coreferential reading, it is expected that sentences like (119) repeated here as (123) behave in the same way, but it is not true.

Jovanov $_{i}$ papagaj je juče ugrizao Jovana ${ }_{i}$.

John's parrot AUX yesterday bitten John

'John ${ }_{i}$ 's parrot bit John $i$ yesterday.'

Despić (2013) explains the grammaticality of the previous example by employing Safir et al.'s (2004) FTIP, arguing that (123) is grammatical because all other alternatives, as exemplified in (124a), (124b) and (124c), are ungrammatical.

$$
\begin{aligned}
& \text { a. }{ }^{*} \operatorname{Jovan}_{i} \text { je juče ugrizao Jovana }{ }_{i} \text {. } \\
& \text { John AUX yesterday bit John }
\end{aligned}
$$

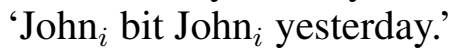

$$
\begin{aligned}
& \text { b. }{ }^{*}{ }^{*} \mathrm{On}_{i} \text { je juče ugrizao Jovana }{ }_{i} \text {. } \\
& \text { He AUX yesterday bit John } \\
& \text { 'He }{ }_{i} \text { bit } \mathrm{John}_{i} \text { yesterday.' } \\
& \text { c. }{ }^{*} * \operatorname{Jovan}_{i} \text { je juče ugrizao njega } \text {. } \\
& \text { John AUX yesterday bit him.STR } \\
& \text { 'John }{ }_{i} \text { bit him }_{i} \text { yesterday.' }
\end{aligned}
$$

b. $\operatorname{Jovan}_{i}$ je udario $\operatorname{svog}_{i}$ prijatelja.

John AUX hit self's friend

'John hit his $_{i}$ friend.'

However, this dichotomy is impossible in subject position, i.e. only the possessive 'njegov' can be used. 
Example (124a) is ungrammatical because it has (125) as a potential alternative, which involves the reflexive form sebe, 'self'. And examples (124b) and (124c) are even less acceptable because they violate not only Condition $\mathrm{C}$ and $\mathrm{B}$, but additionally, they also violate the FTIP.

$$
\begin{aligned}
& \text { Jovan }_{i} \text { je juče ugrizao sebe } \\
& \text { John AUX yesterday bit self } \\
& \text { 'John } \text { bit himself }_{i} \text { yesterday.' }
\end{aligned}
$$

Hence, Despić (2013:252) accounts for the grammaticality of examples as (123) by adopting Safir et al.'s (2004) FTIP, given that neither a reflexive, nor a clitic or strong pronoun are possible in this context.

Even though this principle sounds plausible for explaining pronoun choice in different pragmatic contexts (similar to other economy principles such as Cardinaletti and Starke (1999:92) Minimize structure Principle; Koster's (1997) Principle of Maximal Specialization, etc.), there are some issues. It is not clear how it can overrule a core structural configuration such as c-command and especially given the fact that the reflexive is clearly possible in this position (Srdanović and Rinke 2020). However, the meaning becomes different since it refers to the subject papagaj, 'parrot' instead (126).

$$
\begin{aligned}
& \text { Jovanov }_{* i} \text { papagaj }_{j} \text { je juče ugrizao sebe } \\
& * i / j \\
& \text { John's parrot AUX yesterday bitten self } \\
& \text { 'John }{ }_{* i} \text { 's parrot } \text { bit himself }_{* i / j} \text { yesterday.' }
\end{aligned}
$$

The grammaticality of (123) and the ungrammaticality of (126), follow without any additional assumption if one assumed that the possessive does in fact not c-command out of the noun phrase, indicating that Serbian patterns with DP languages with respect to binding.

Summarizing this chapter, we have seen that the process of binding is what restricts that pronouns are bound by a nominal phrase or vice versa, see (127).

$$
\begin{aligned}
& \text { a. }{ }^{*} \mathrm{He}_{i} \text { likes him }_{i} . \\
& \text { b. } * \mathrm{He}_{i} \text { likes John }_{i} . \\
& \text { c. } * \mathrm{Himself}_{i} \text { likes John }
\end{aligned}
$$

In these sentences, we can clearly observe that we deal with the ungrammaticality, since the pronoun binds another pronoun or R-expression that have to be free. In different words, here we have typical violations of binding principles and no additional principle could fix these sentences. However, when it comes to binding with possessives, this is not the case. Here we cannot talk about ungrammaticality in the same sense, but other 
pragmatic principles influence the likelihood of one or the other interpretation.

The second level that should be taken into account when discussing referential properties of (possessive) pronouns is the discourse structure or other factors. For instance, context can influence which interpretation is more likely. Other factors that can be at play are either related to (a) the antecedent: information structure/ topic shift/topic continuity or (b) to the pronominal object which can have different types in Serbian, i.e. clitic vs. strong pronoun (and also stressed strong pronouns).

In order to examine whether the coreferential interpretation is indeed possible in Serbian in these constructions and to shed more light on both of the levels concerned here, I conducted two experimental studies.

In Experimental Study 1, I wanted to find out whether Serbian native speakers accept coreferential interpretation in Binding Principle B constructions, between a possessive name modifying a noun in subject position and an accusative pronoun in object position. Moreover, I wanted to examine whether there is a difference between different types of pronouns that are used, i.e. strong pronouns and clitics, to see how other factors, such as the type of bound pronominal object, influence the coreference.

Then, in Experimental Study 2 I focus on the grammaticality itself in order to find arguments for the structural position of Serbian possessives. Following an experimental study for English (Kazanina et al. 2007) which compared personal pronouns and possessive pronouns, I wanted to observe whether the same difference exists in Serbian. The difference between personal pronouns which cannot be coreferential with an R-expression and possessives pronouns which can, would provide a good piece of evidence that opposed to personal pronouns, possessive pronouns do not c-command out of their phrase, further implying that these configurations do not violate Binding Principles B and C. The assumption that possessives are located in the SpecAgrP, would account for this.

My expectation is that both experimental studies will show that Principle B and $\mathrm{C}$ constructions with possessive modifiers in subject position are grammatical with coreferential reading, i.e. that coreference is likely and possible between both possessive names and possessive pronouns and pronouns and R-expressions respectively. If this is the case, I can assume that possessives actually do not c-command out of the phrase and we are not dealing with violation of binding principles at all, which fits the analysis on their syntactic position - that possessives are located in the SpecAgrP. Moreover, the availability of different types of pronouns in object position would show that other pragmatical factors should be taken into account when it comes to the analysis of possessive binding. 


\subsection{Chapter summary}

In this chapter, I have delivered an overview of the traditional view on the categorial status of possessives across languages. The AG and DG language groups have been addressed. This led to the cross-linguistic discussion on the syntactic position of possessives depending on their type.

Moreover, I have shown the distribution of Serbian prenominal modifiers and that the order of these elements is not as free as it seems at first, which suggests that possessives are located lower than demonstratives in the extended nominal phrase. This and other arguments presented in this chapter (such as coordination, binding, the impossibility of stacking etc.) further imply that even though possessives share some characteristics with adjectives, they should be distinguished and labelled as Poss. They are located in a specifier position lower than XP/ DP (such as SpecAgrP), rather than being adjoined to NP, which is crucial to account for their binding possibilities.

Assuming that the categorial status and position of possessives in Serbian influence the binding judgments significantly, my proposal is to re-analyse them in a more systematic way. This is why I conducted two experimental studies. In the first one, I examine whether coreferential interpretation is indeed possible in Serbian and pay attention to additional (pragmatic) principles that can play a role in determining the (non-)coreferential interpretation, more specifically the type of pronominal object. Therefore, Experimental Study 1 deals with constructions that have been claimed to violate Binding Principle B (Chapter 3). And Experimental Study 2 focuses on Binding Principle $\mathrm{C}$ configurations (Chapter 4) and examines the role of c-command with respect to syntactic constraints by comparing sentences with possessive pronouns modifying a noun vs. personal pronouns in subject position. 


\section{Chapter 3}

\section{Study I - Binding of pronouns/ Binding Principle B}

In this chapter, I will present and discuss the results of an experimental study focusing on the question of whether coreference is indeed possible between a lexical possessive modifier in subject position and a pronoun in object position, or whether violations of Binding Principle B arise in Serbian, as suggested by Despić (2013) (see Chapter 2).

Based on Franks' (2019) findings on Macedonian and Bulgarian - that the coreferential interpretation can vary depending on the type of pronoun used in object position I will also consider whether the type of object pronoun (clitic or strong) involved in the corresponding constructions plays a role in Serbian. Section 3.1 provides an overview of the typology of pronouns, and discuss how different pronominal forms influence pronoun resolution. Subsequently, the results from my first experiment - the Picture Choice task are reported in Section 3.2.

\subsection{The role of different pronominal object forms in binding}

LaTerza (2016) discusses Despić's (2013) analysis by comparing Serbian with Slavic article languages like Macedonian and Bulgarian (see Section 2.2.5). According to LaTerza (2016), these article languages also do not allow for the coreferential interpretation between the possessive modifier and the object pronoun and, therefore, do not pattern with English, but rather with Serbian. LaTerza (2016) explains the similarity between Serbian, Bulgarian and Macedonian by assuming that prenominal possessors uniformly raise at LF to the edge of their largest containing nominal, from where they c-command the rest of the clause, leading to a violation of Binding Principle B, see (1) and (2). 
(1)
a. *Ivanovijat papagal nego $_{i}$ uhapa včera. (Bulgarian) Ivan.POSS.the parrot him bit yesterday 'Ivan ${ }_{i}$ 's parrot bit him ${ }_{i}$ yesterday.'

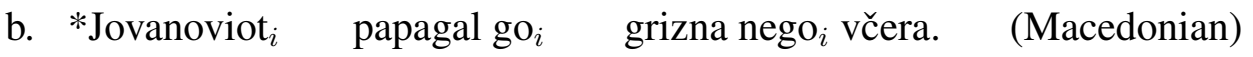 Jovan.POSS.the parrot him.CL bit him yesterday 'Jovan ${ }_{i}$ 's parrot bit him $i$ yesterday.'

Franks (2019) questions LaTerza's (2016) argumentation. According to the author, (Franks 2019:70) the ungrammaticality of LaTerza's (2016: 748) example (1a) in Bulgarian is not the outcome of the possessive Ivanovijat, 'Ivan's' c-commanding out of the noun phrase, but it rather arises from the infelicity of strong pronouns in such contexts, see (2).
(2) ?*Papagalât nego uxapa včera. (Bulgarian) parrot.DEF him bit yesterday 'The parrot bit him yesterday.'

Franks (2019) claims that the strong pronoun in (1a) is only plausible with contrastive focus. Still, focusing nego in (1a) would block a cataphoric interpretation and cause a non-coreferential reading between nego and Ivan independently of binding. On the other hand, if the clitic form of the object pronoun $(\mathrm{go})$ is used in the same contexts as in (1a), coreference is possible, see example (3) (Franks 2019:70).
(3) Ivanovijat $_{i} \quad$ papagal go ${ }_{i}$ uxapa včera. (Bulgarian)
Ivan.POSS.the parrot him bit yesterday
' $\operatorname{Ivan}_{i}$ 's parrot bit him $_{i}$ yesterday.'

A similar argumentation holds for embedded possessive structures such as prijatelj Markove majke, 'a friend of Marko's mother' in Serbian (LaTerza (2016), see Section 2.2.5). Franks (2019:76) assumes that replacing the strong pronoun with the clitic would allow for a coreferential interpretation (see (4b)), whereas the strong pronoun as in (4a) is not acceptable with a coreferential reading (Franks 2019:76).

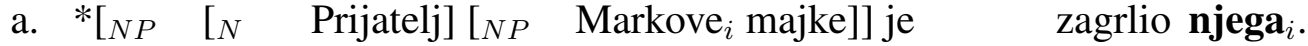 friend Marko's mother AUX3SG. hugged him.STR 'A friend of Marko $_{i}$ 's mother hugged him ${ }_{i}$.'
b. $\left[\begin{array}{lll}N P & {[N} & \text { Prijateljica }]\end{array}\left[\begin{array}{lll}N P & \text { Markove }_{i} \text { majke }\end{array}\right] \mathbf{g a}_{i} \quad\right.$ je female-friend Marko's mother him.CL AUX3SG. zagrlila. hugged 'A (female) friend of Marko $_{i}$ 's mother hugged him ${ }_{i}$ '


When it comes to Macedonian, the situation is slightly different, since clitic pronouns have developed into agreement markers in this language (Franks 2009). Consequently, the strong pronoun is available if doubled by the clitic. Contrary to the judgments provided by LaTerza (2016), Franks (2019) finds coreference to be possible in these contexts. Given that the non-coreferential reading is also available, he explains that the discrepancy between the judgments is based on preferences instead of binding principles.

$$
\begin{aligned}
& \text { Jovanoviot }_{i} \text { papagal go } \text { go }_{i / j} \text { grizna }\left(\text { nego }_{i / j}\right. \text { ) včera. (Macedonian) } \\
& \text { Jovan.POSS.the parrot him bit (him) yesterday } \\
& \text { 'Jovan }{ }_{i} \text { 's parrot bit him } i / j \text { yesterday.' }
\end{aligned}
$$

Given these observations, Franks (2019) dismisses LaTerza's (2016) analysis of LF movement of the possessive, and accepts Bošković's (2012) and Despić's (2013) parametrized DP/NP analysis for Serbian, i.e. that possessives are adjoined and c-command out of the subject NP. Even though I will diverge from this argumentation for Serbian, Franks' (2019) observations are of great significance for my study, because they reveal that when examining the referential possibilities in a language, one should pay attention not only to the syntactic structure, but also to other factors, such as the variability of pronominal forms available in the language.

Bearing this in mind, I will now look into different types of pronominal objects in order to compare their features and how they reflect on referential possibilities and binding.

Comparing different types of pronouns cross-linguistically shows that languages can have two (or more) distinct pronominal types that differ from each other at all linguistics levels (syntax, morphology, semantics and prosody). Cardinaletti and Starke (1994) discuss systematic differences between different pronoun types, and divide pronouns into two groups: strong and deficient. Within the group of deficient pronouns, they further distinguish between clitics and weak pronouns.

When it comes to their morphological form, deficient pronouns are reduced in comparison to strong ones, if there is a difference in form. For instance, the Slovak $3^{\text {rd }}$ person pronoun in singular has two distinctive forms - the deficient ho and the strong jeho, see (6) from (Cardinaletti and Starke 1994:5).
a. Vidím ho/ jeho. (Slovak) see.1.sg it/him.DEF /it/him.STR 'I see it/him.'
b. Vidím *ho/ jeho a tých druhých. see.1.sg it/him.DEF/ it/him.STR and these others 'I see it/him and these others.'


Unlike strong personal pronouns, deficient pronouns cannot occur at surface structure in $\theta$-/base positions, dislocations, cleft structures etc. They appear in a distinctive derived position. Also, deficient pronouns disallow c-modification, and coordination as shown in (7) (Cardinaletti and Starke 1994:7).
a. Anche/ Solo *essa / lei / Maria è bella. (Italian) also/ only *3.sg.F.DEF / 3.sg.F.STR / Mary is pretty 'Also/ Only she/ Maria is pretty.'
b. Lei e (d)*essa / lei / Maria sono belle. she and *3.sg.F.DEF/3.sg.F.STR / Mary are pretty 'She and she/ Maria are pretty.'

Concerning pronoun choice, Cardinaletti and Starke's (1994) generalisation is that the strong form is implausible where the deficient form is plausible, and that the strong form is possible if the deficient form is independently ruled out (by contrastive stress, an accompanying pointing gesture, coordination or c-modification). ${ }^{1}$ For instance, in (8) only the strong pronoun is acceptable since a new referent is introduced in the discourse, by pointing to a person (Cardinaletti and Starke 1994:7).

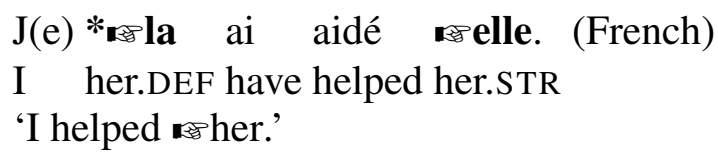

Furthermore, speaking of the semantic asymmetry, deficient personal pronouns must have an antecedent prominent in the discourse, whereas strong pronouns can be referential on their own (Cardinaletti and Starke 1994:8).

Strong pronouns refer to human entities only, while the deficient forms can refer to both human and non-human entities (Cardinaletti and Starke 1994:6).
a. Jean les
trouve belles. $<+$ human $>$; <-human $>$ (French)
John them.FEM.DEF
b. Jean trouve elles belles. <+human>
John finds them.FEM.STR pretty
'John finds them pretty.'

Moreover, deficient pronouns are possible in impersonal constructions, as expletives and non-referential datives. For instance, the non-argumental dative pronouns in French and Slovak in (10) do not have any referent (Cardinaletti and Starke 1994:11). In this manner, they resemble 'discourse-particles'. On the contrary, strong pronouns are not possible in

\footnotetext{
${ }^{1}$ Strong forms can have contrastive focus but deficient usually cannot, unless they refer to an entity prominent in the discourse (same holds true for ostension also).
} 
such a context, see (11).

a. Je vais te lui foutre une de ces claque! (French)

I will you him give one of such smack

b. Ja ti mu dám takú facku! (Slovak)

I you him give such smack

'By Joves, I'll give him a blow he'll remember!'

(11) a. *Je vais lui foutre une de ces claque à toi! (French)

b. *Ja mu dám takú facku tebe! (Slovak)

'I will him give such a smack to you!'

This is also true for Serbian, see (12). In this example, Bošković (2008) calls ti, 'you.CL.' ethical dative, which is a clitic that has no full form.

Ja sam ti se juče ceo dan odmarala.

I AUX CL. AUX yesterday whole day rested

'I was resting the whole day yesterday.'

When it comes to their prosodic features, deficient pronouns may prosodically restructure (e.g. liaison or reduction processes), which is not possible for strong pronouns. Contrary to strong pronouns and nouns (13a,b), deficient pronouns build a prosodic unit together with an adjacent lexical element (13c) (Cardinaletti and Starke 1994:14).
a. Jean voit Anna. (French)
'John sees Anna.'
b. Jean voit elle.
c. Jean la voit.
'John sees her.'

All different aspects taken together, the main idea of Cardinaletti and Starke's (1994) Minimise Structure principle is that clitics have a smaller structure than strong pronouns, and that the 'smaller structure' is chosen over a strong form whenever possible, which is illustrated by the following hierarchy: clitic $\leq$ weak $\leq$ strong.

What this means is that only if the smaller structure is independently ruled out, the bigger alternative is possible.

This is also the case in Serbian. As argued by Cardinaletti and Starke (1994), Zec (2002:243) also claims that strong pronouns can be referential on their own, while clitics must have an antecedent prominent in the discourse, see (14).

(14) What does she think of Peter? 


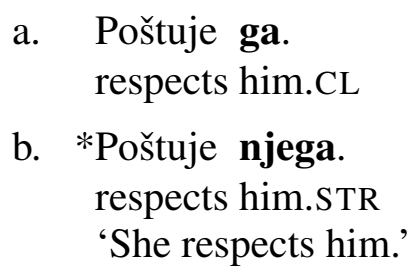

However, the strong pronoun is allowed when contrastively focused, as in (15a) because the clitic is not possible in such a context, see (15b).

What does she think of Peter and Maria?

a. $\quad$ Njega $_{F}$ poštuje ali ne i $\mathbf{n j u}_{F}$.

him.STR respects but not also her.STR

'She respects HIM, but not HER.'

b. *Ga poštuje ali ne i ju.

him.CL respects but not also her.CL

Clitics cannot be stressed, they build a single prosodic unit with an adjacent lexical element, unlike strong pronouns and lexical element that can be stressed on their own.

Moreover, we can observe that Serbian is not different from other languages when it comes to some structural asymmetries between the two forms, such as dislocation, coordination, etc. As illustrated in (15), we can notice that Serbian clitic forms are not allowed in coordination.

When it comes to their semantic features, examples (14) and (15) also show that clitic forms are 'less referential' than strong pronouns, in the sense that they cannot be referential on their own, but refer to an antecedent prominent in the discourse, which need not be the case for the strong pronouns. Also, (15b) shows that clitics cannot bear contrastive focus which is characteristic for strong pronouns (15a).

As in other languages that distinguish between these forms, strong pronouns can also refer to human entities only, see (16). ${ }^{2}$

\footnotetext{
${ }^{2}$ In his dissertation, Despić (2011) provides exceptions in which the strong pronoun can refer to both human and non-human entities, including inanimates modified by a focus operator. His prediction is that strong pronouns in focus are not restricted to refer only to human referents, because they are clitics underlyingly.

(i) Čuo sam čak i nju. <+human $>$; <-human>

Heard AUX even and her.DEF

'I heard even her.'

Despić (2011) analyses the pronoun as a 'morphological camouflage' for the deficient pronoun. What he means by this is that the deficient pronoun has to be pronounced as strong here because of the independent reasons (prosodic focus requirements), but it maintains its interpretative characteristics of referring to both human and non-human entities.
} 


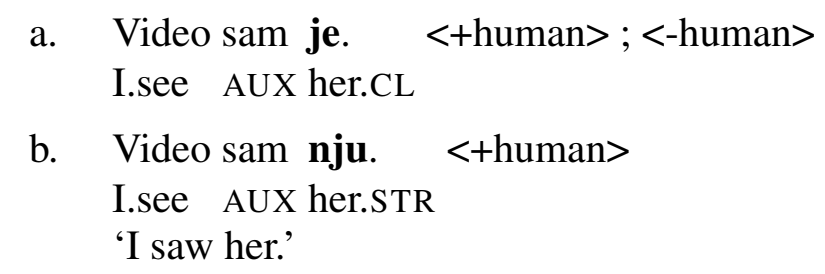

At the beginning of this section, I have presented Bulgarian and Macedonian data from Franks (2019), showing the differences between clitics and strong pronouns in object position with respect to binding. An interesting difference also arises in Serbian between deficient and strong pronouns in examples with a quantifier as in (17) and (18). Despić (2011) shows that in Serbian the deficient form - the clitic ga (17a) - is preferred with a coreferential interpretation with the subject, contrary to the strong pronoun njega in (17b) (Despić 2011:243).

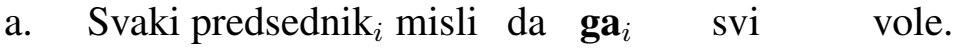 every president thinks that him.CL everyone loves 'Every president ${ }_{i}$ thinks that everybody loves him $_{i}$.'
b. Svaki predsednik misli da ??njega $_{i}$ svi vole. every president thinks that him.STR everyone loves 'Every president ${ }_{i}$ thinks that everybody loves him $_{i}$.'

A parallel can be drawn to pro-drop possibilities in subject position in Serbian, where either an overt subject or a non-overt pronoun (pro) can be used. In line with the previous example (17), Despić (2011) shows that there is a preference for the deficient form - pro referring to the subject (18a), whereas the overt, strong pronoun on, 'he', is ambiguous or preferably refers to somebody else (Despić 2011:243).

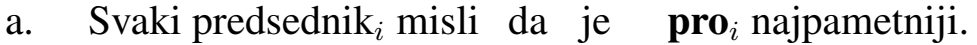
every president thinks that AUX pro smartest
'Every president ${ }_{i}$ thinks he ${ }_{i}$ is the smartest.'

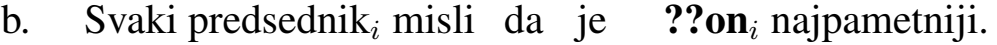
every president thinks that AUX he smartest
'Every president ${ }_{i}$ thinks he $_{i}$ is the smartest.'

In languages that are either pro-drop or allow for more than one type of a pronoun in the same position, there is usually a preference for one of the forms, which can be determined by various factors. Serbian also has the variability of pronominal forms in both subject and object positions. Following a number of pronoun choice principles (starting with Chomsky's (1981) Avoid Pronoun Principle, followed by Cardinaletti and Starke's (1994) Minimise structure principle, Montalbetti's (1984) Overt Pronoun Constraint principle among others), preference of choice of null pronouns over overt forms in pro-drop 
languages is assumed, or more generally, the deficient form is preferred over the strong pronominal form. Based on these principles, in Serbian example (18), in subject position, pro is chosen over the strong pronoun on, 'he' to refer to the subject of the main clause. The same happens in object position (17), where the deficient form - the clitic $g a$ - is chosen over the strong pronoun njega to refer to the prominent subject referent of the main clause.

Despić (2011) follows Montalbetti's (1984) examples on the Overt Pronoun Constraint principle regarding the bound variable interpretation in Spanish. In pro-drop languages such as Spanish, the overt pronominal subjects (19a) cannot function as bound variables, given that pro is also available in this language (19b). On the contrary, non-null subject languages such as English lack the null-overt variation, causing overt pronouns to function as bound variables, as it can be seen in the translation of the given examples (Montalbetti 1984:82).
a. Muchos estudiantes creen $_{\text {que ellos }}{ }_{* i / j}$ son inteligentes. (Spanish) many students believe that they are intelligent
b. Muchos estudiantes ${ }_{i}$ creen que pro $_{i / j}$ son inteligentes. many students believe that they are intelligent 'Many students ${ }_{i}$ believe that they $_{i}$ are intelligent.'

Moreover, Montalbetti (1984) assumes that similarly to the distinction between pro and the overt pronoun, the same asymmetry is visible between the clitic and the strong pronoun in (20). While the clitic can be used for the bound-variable interpretation (20a), the strong pronoun (20b) cannot (Montalbetti 1984:139).

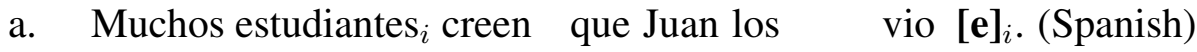 many students believe that John them.CL saw
b. *Muchos estudiantes ${ }_{i}$ creen que Juan los vio [a ellos] $]_{i}$. many students believe that John them.CL saw them 'Many students ${ }_{i}$ believe that John saw them $_{i}$.'

In summary, previous studies have shown that different types of pronouns - deficient and strong - differ at all linguistic levels. We have seen that this is also the case in Serbian. In particular, I am interested in pronominal objects - the clitic $g a$ and the strong pronoun njega, which also show the different interpretive behaviour as illustrated in other crosslinguistic studies.

Following Montalbetti (1984), Despić (2011) shows that Serbian, being a pro-drop language as well, patterns with Spanish both in case of pronoun choice in null subjects and more importantly for my study, the same preference applies to pronominal objects. This indicates that the distributional asymmetry between deficient (clitics) and strong pro- 
nouns holds for Serbian, too. When it comes to possessive constructions, Despić (2011) does not take into account the difference between different pronominal forms, explaining that his informants reject coreference nonetheless which of the two forms has been used. However, in the light of what has been found for Macedonian and Bulgarian, and given the fact that clitics and strong pronouns differ in various aspects in Serbian as in other languages, I find it important to look into the differences between the two forms more closely with respect to binding.

Jovović (2020) argues along these lines for possessive constructions in Serbian in binding configurations, as well. More precisely, she asserts that clitics and strong pronouns may behave differently, and if provided with the appropriate information structural context, coreference with both clitic and strong pronouns becomes grammatical in Serbian. Namely, old information (topic) on the subject is required for clitics (21) and new information (focus) on the subject for strong pronouns (22) (Jovović 2020:4). ${ }^{3}$

(21) A: Directors always admire their own films. Sijan likes all his movies. Dragojević isn't really happy with his recent movies. I don't know about Kusturica - is he more like Sijan or Dragojević?

B: Zapravo, Kusturičin ${ }_{i}$ najnoviji film ga $_{i} \quad$ je razočarao. Na ostale B: Actually, Kusturica's latest movie him.CL AUX disappointed. On rest je ponosan.

AUX proud.

'Actually, Kusturica $i$ 's latest movie disappointed him $_{i}$. He is proud of the others.'

(22) A: Who was disappointed by what?

\footnotetext{
${ }^{3}$ As pointed out by Sabina Halupka Rešetar, the $g a$ example is certainly better but by no means all right, not even with the context provided. The following sentences would be more appropriate for such contexts, see (i) and (ii) for examples (20) and (21) respectively.
}

(i) Zapravo, Kusturicu je razočarao njegov najnoviji film. actually Kusturica.ACC AUX disappointed his latest movie 'Actually, Kusturica was disappointed by his latest movie.'

(ii) Kusturica je razočaran svojim novim filmom.

Kusturica AUX disappointed his.own new movie

'Kusturica is disappointed by his own new movie.'

Fronting the object Kusturicu, 'Kusturica.acc' to the beginning of the sentence and using the pronominal possessive would better suit the context in (20), whereas using the 'self' form of possessive in object position would be more appropriate for (21). 

B: Kusturičin ${ }_{i}$ najnoviji film je razočarao njega $_{i}$.
B: Kusturica's latest movie AUX disappointed him.STR
'Kusturica ${ }_{i}$ 's latest movie disappointed him $_{i} . '$

Contrary to binding with possessives, which becomes admissible given the appropriate discourse context as in (21) and (22), the violation of typical Principle B as in (23) cannot be repaired in the same way (cf. Jovović 2020:6).

Who disappointed who?/ Who did Kusturica disappoint?

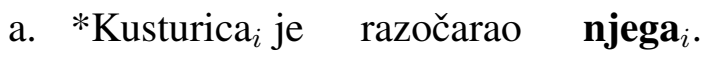 Kusturica AUX disappointed him.STR [intended] 'Kusturica disappointed himself.'
b. * Kusturica ${ }_{i}$ je razočarao NJEGA . $_{\text {. }}$ Kusturica AUX disappointed him.STR [intended] 'Kusturica disappointed himself.'

Furthermore, according to Jovović's (2020) argumentation, clitics are illicit when the antecedent is focused (new information) and strong pronouns are illicit when the antecedent is a topic (unless the strong pronoun is contrastively focused). Given these points, Jovović (2020) concludes that the ungrammaticality of these possessive structures is not a case of Condition B violation at all, but that it rather refers to the felicity of the clitic or strong form in the context. As much as I agree with the claim that preferences for a clitic or a strong pronoun depend on information structure, I strongly disagree with Jovović's (2020) conclusion that such possessive constructions are irrelevant for the issue of the categorial status of Serbian nominals as they do not represent grammatical restrictions, but are dependent on information structure only, i.e. on the appropriateness of the antecedent in the discourse. Based on what we know from theory, but also from empirical evidence, coreference has to be structurally allowed for, but even if it is plausible, it does not have to be always employed, and this is when we can talk about other (pragmatic) principles that affect the preferences for one or the other interpretation.

Jovović's (2020) finding can be captured by Ariel's (1990) Accessibility hierarchy. The Accessibility hierarchy determines to whom the referential expression refers depending on the degree of its accessibility (Ariel 1990). Namely, null pronouns refer to highly accessible referents, overt pronouns to slightly less accessible referents, and finally, full names or strong pronouns refer to referents of low accessibility. Thus, this means that in case both deficient and strong pronouns are available in a language, the strong pronoun receives lower accessibility than the deficient one (the clitic form in this case), which by rule takes up the more accessible referents.

A number of cross-linguistic experimental studies (Carminati 2002; Lobo and Silva 
2016; Portele and Bader 2016; Rinke and Flores 2018; Flores et al. 2020) have confirmed that the choice between different pronominal forms with respect to coreference both in subject and in object position is not only a reflex of the features of pronouns themselves, as discussed in the aforementioned pronoun choice principles (Avoid pronoun, Minimize structure, Overt pronoun constraint), but it also depends on how accessible the discourse referent is (Ariel 1990). There are different aspects of how the accessibility of antecedents can influence the pronoun resolution: adjacency, frequency, prominence, a grammatical role of the antecedent etc. (Ariel 1990; Arnold and Griffin 2007; Gundel et al. 1993; Smyth 1994).

One example is the usage of deficient and strong pronouns depending on topic continuity or topic shift. Generally speaking, in the case of subject position, the former refers to subject referents continuing the topic of a preceding sentence, whereas in the latter subject referents are inclined to shift to a new topic (Calabrese 1986; Tsimpli et al. 2004). According to several authors (Carminati 2002; Lobo and Silva 2016; Rinke and Flores 2018; Flores et al. 2020), the general preference is that a null subject continues the topic referent of the previous sentence, whereas an overt subject shifts the topic to the object of the previous sentence. Speaking of object position, in case of ambiguity, the pronoun is resolved in a similar fashion. Deficient forms (clitics) are generally preferred with the discourse topic - already given antecedents, whereas strong pronouns tend to refer to the discourse focus - new antecedents. Alternatively, the strong pronoun can also be used when the antecedent is the discourse topic, but then it must be contrastively focused. This cannot be the case for clitics, because they are illicit with a contrastive focus.

In my experiment I will not manipulate all the factors relating to discourse prominence as it would lead to a complex experimental design, but they will be discussed in more detail in the general discussion (Chapter 5).

Following the above-presented argumentation on the variability of different types of pronouns, we have seen that Serbian exhibits similar asymmetries between deficient forms - clitics and strong pronominal forms. Accordingly, it is expected that they show distinct interpretive behaviour in contexts where both may appear and it might also be a matter of preference which one to use, or the choice may be influenced by the accessibility of the discourse referent. More concretely, I assume that there should be a distinction between clitic and strong pronominal forms in object position with respect to their referential possibilities in possessive constructions in Serbian, which would affect the possibility of coreferential interpretation, similarly as in the corresponding structures in Macedonian or Bulgarian. Therefore, I examine the referential possibilities of the two pronominal forms in cases when there is a possessive modifier within the sentence.

Experiment 1 is a Picture Selection Task and investigates constructions involving Principle B, more specifically with possessive names as modifiers modifying a noun 
phrase in subject position and different types of pronouns in object position. Given that Serbian has clitics and strong object pronouns, and based on the assumption that these forms differ in various aspects (as discussed above), I test whether they allow for coreferential reading, and if there are any differences between them in this sense.

\subsection{Experiment 1 - Principle B: Picture Selection Task}

The central research questions of the present study are the following:

Q1. Is coreference between a possessive name in subject position and a pronoun in object position indeed admissible in Serbian?

Q2. If yes, are there any differences between sentences with the clitic and the strong pronoun in object position?

Based on the debate on the categorial status and syntactic position of Serbian prenominal possessives in Chapter 2, I concluded that prenominal possessives have referential features (index), and are located in a specifier position - SpecAgrP, from where they should not be able to c-command and bind the pronoun. This way, they do not violate any binding constraints, or the traditional Binding Principle B in this case. Hence, coreference between possessive names and pronouns is expected to be accepted in Serbian, as in DP languages like English.

However, even if coreference is possible, it does not have to be employed every time. As already discussed in Section 3.1 with respect to Jovović's (2020) work, there may be additional pragmatic principles that affect the interpretation of object pronouns in such structures leading to individual variation between the preferences of the speakers. The second research question (Q2) is aimed at investigating whether different types of pronominal objects can have an influence on the coreferential interpretation. Languages like standard German or English have only one pronominal form in object position - 'ihn' or 'him', while Serbian has two possibilities, either the clitic ga 'him.CL' or the strong pronoun njega 'him.STR' can be used. Based on the pronoun choice principles, and the accessibility of antecedents presented in Section 3.1 I hypothesize that using the clitic is preferred to express coreferentiality with prenominal possessives, given that it is a more deficient form, which always represents the unmarked choice. Moreover, since the referents are introduced in a short context, the possessive has a topic-like status, which is more easily taken by a weaker element, i.e. the clitic. This does not imply that coreference between the strong pronoun and the possessive modifier is completely unacceptable, but rather dispreferred. Hence, in an experimental setting like this one, the participants may accept coreference with a clitic pronoun more easily than coreference with a strong pronoun, but they may not categorically reject the latter option. 
A Picture Selection Task has been conducted to answer these questions and to evaluate native speakers' intuition on this matter in a controlled experimental setting.

\subsubsection{Methodology}

A picture selection task was chosen as a method because it enables to elicit preferences of participants who are asked to select a picture that fits better to the corresponding sentence. I decided to employ a preference task because it is an appropriate method to detect interpretation patterns which makes the choice even more convincing if chosen over an alternative that is a licit option. Such kind of task is especially suitable for this phenomenon, where a possessive modifier does not have to corefer after all with neither a strong pronoun nor the clitic. A more detailed description of the experiment is given in the following subsections.

\subsubsection{Participants}

Thirty-six native speakers of Serbian $(n=36)$, with normal or corrected-to-normal vision participated in this study. All of them gave their consent and agreed to participate in the study voluntarily. The group included both male and female participants ( 27 female and 9 male), aged between 19 and 33 years (mean age 26.2). The participants were non-linguists and all lived in Novi Sad, a city located in the northern part of Serbia. The majority of participants were highly educated, 31 had graduated from a university and 5 of them had finished high school.

\subsubsection{Design and Stimuli}

Given that my main research question concerned the possibility of coreference, coreferential/ non-coreferential reading (picture choice) was chosen as the dependent variable. Additionally, as the second research question was whether there existed a difference between the two pronominal forms used in object position, the independent variable was the type of the pronominal object in accusative: clitic ga 'him.CL' vs. strong pronoun njega 'him.STR'. The stimuli $(\mathrm{N}=24)$ consisted of test sentences with either the clitic or the strong pronoun, together with 10 control sentences. A sample of test items is shown in Table 3.1 and an example of control items in Table 3.2 below. All stimuli (together with pictures) are given in Appendix A. 
Table 3.1: A sample of test items in Experiment 1

\begin{tabular}{|c|c|}
\hline Condition & Item \\
\hline \multirow[t]{2}{*}{ Context } & Na slici su Petar, Petrov bik i Jovan. Pogledajte šta se desilo! \\
\hline & 'Here are Peter, Peter's bull and John. Look what happened!' \\
\hline \multirow[t]{3}{*}{ clitic ga 'him.CL' } & $\operatorname{Petrov}_{i}$ bik $_{\text {ga }}$ je povredio. \\
\hline & Peter's bull him.CL AUX hurt \\
\hline & 'Peter's bull has hurt him.' \\
\hline \multirow{3}{*}{$\begin{array}{l}\text { strong pronoun } \\
\text { njega 'him.STR' }\end{array}$} & Petrov $_{i}$ bik je povredio njega ${ }_{i}$. \\
\hline & Peter's bull AUX hurt him.STR \\
\hline & 'Peter's bull has hurt him.' \\
\hline
\end{tabular}

Note. The clitic and the strong pronoun are given in bold. Subscript indices indicate intended anaphoric dependencies.

All the test items were constructed in the same manner, namely, in subject position there was a lexical possessive, i.e. possessive name (Jovanov, 'John's or Petrov, 'Peter's') modifying a noun which was always an animal. Given that there were 24 items, both boys had 12 different animals each, so in half of the sentences it was John's animal and in the other half it was Peter's animal in order to counterbalance the stimuli. Verbs that were used were picked in a way that it was plausible that an animal can perform an action on a human and there were 24 different transitive verbs. The type of used verbs was balanced to avoid that preferences being made on the base of the verb meaning. This is necessary because the semantics of a verb can influence the choice, e.g. 'attack' vs. 'kiss' (it is more likely that my dog would attack somebody else but kiss me as the owner, even though the other options are possible, as well). ${ }^{4}$ To control that gender does not influence the results, and although no differences between male and female gender are expected only masculine possessive modifiers and male object pronouns were used.

${ }^{4}$ Despić's (2013) example with the verb 'disappoint' got some critics because a psych verb was used.

(i) *Kusturicin ${ }_{i}$ najnoviji film je zaista razočarao njega $_{i}$.

Kusturica's latest film AUX really disappointed him.STR

'Kusturica ${ }_{i}$ 's latest film really disappointed him $_{i}$.

Some people believe that it is difficult to get disappointed by your own work and this is why the noncoreferential interpretation is preferred in the sentence in (i) from Despić (2013:245) (with both pronominal forms). 
Ten sentences with an R-expression in object position were used as control items with the intention to make sure that participants are paying attention to the task. In these sentences there was no ambiguity, only one interpretation was possible because two names were used; one name was a possessive modifying a noun in subject position, as in the test items, and the other one was the object. An example of a control item is illustrated below in Table 3.2.

Table 3.2: A sample of control items in Experiment 1

\begin{tabular}{l|l}
\hline Context & $\begin{array}{l}\text { Na slici su Jovan, Jovanov bik i Petar. Pogledajte šta se desilo! } \\
\text { 'Here are John, John's bull and Peter. Look what happened!' }\end{array}$ \\
\hline R-expression & $\begin{array}{l}\text { Jovanov }_{i} \text { bik je jurio Petra } \\
\text { John's bull AUX chased Peter } \\
\text { 'John's bull has chased Peter.' }\end{array}$ \\
\hline
\end{tabular}

Note. The R-expression is given in bold. Subscript indices indicate that only non-coreferential reading is possible.

In order to introduce the characters of an action, there was a short introductory sentence before each test and control item, as shown in Tables 3.1 and 3.2. The sentence was simple and always the same for each item, only the 'possessive + animal' part differed across the sentences. This was done on purpose in order to have an identical context, given that different contexts could also have an effect on pronoun resolution and would introduce additional conditions turning the experiment too complex. The role of different discourse contexts is left for further experimental studies, but nevertheless, it will be briefly discussed in the overall discussion part.

\subsubsection{Procedure}

The procedure of the experiment is described in this subsection. The participants were first asked to fill in their personal information, and they were informed about data privacy. All the participants gave their consent. Then, they heard and read about the description of the experiment and were instructed how to do it. The presentation of the items was both visual and auditory in order to control for neutral stress on the pronoun. First, a general context of the story was presented to the participants, with a picture showing two boys with their animals. 
Figure 3.1: The general context of Experiment 1

John and Peter are brothers and both of them have a lot of animals. The animals love them both because they spend a lot of time together. The boys get into very unusual and interesting situations with their own and their brother's animals on a daily basis. You will now see some of the situations and help us figure out what happened to whom. Two practice examples are following.
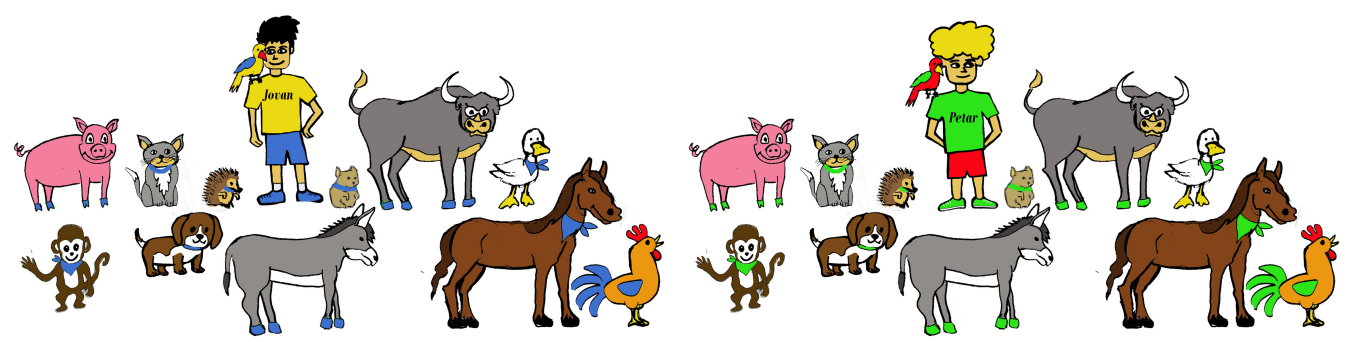

Note. All John's animals had some kind of a blue feature, and Peter's a green one in order to make it more distinctive to whom they belong.

Before the actual experiment, there were two practice items that were excluded from the analysis. After it was made sure that participants understood the task, they clicked on the button 'Start with the task'. The experiment started and the participants first heard a 1 -sentence context and saw an introductory picture on the first screen. Consequently, on the second screen, they heard a test sentence (see Table 3.1) and saw two pictures, one expressing a coreferential reading, the other a non-coreferential reading. The position of pictures was randomized to ensure that participants do not expect one interpretation appearing always at the same place. This way, they would be more attentive and concentrated on their task, i.e. to choose which of the two pictures (coreferential vs. noncoreferential) matched the corresponding sentence. The participants were instructed to click on the picture they thought fitted better if both options were possible. The procedure is illustrated in Figures 3.2 and 3.3 below where a test item is exemplified.

Figure 3.2: Screen 1. An introductory sentence and picture (Experiment 1)

Context: Na slici su Petar, Petrov bik i Jovan. Pogledajte šta se desilo!

'Here are Peter, Peter's bull and John. Look what happened!'

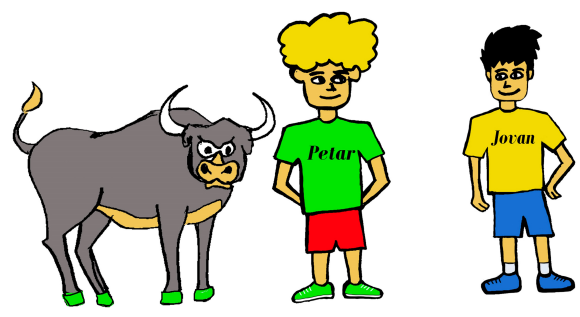


Figure 3.3: Screen 2. Test item and picture choice (Experiment 1)

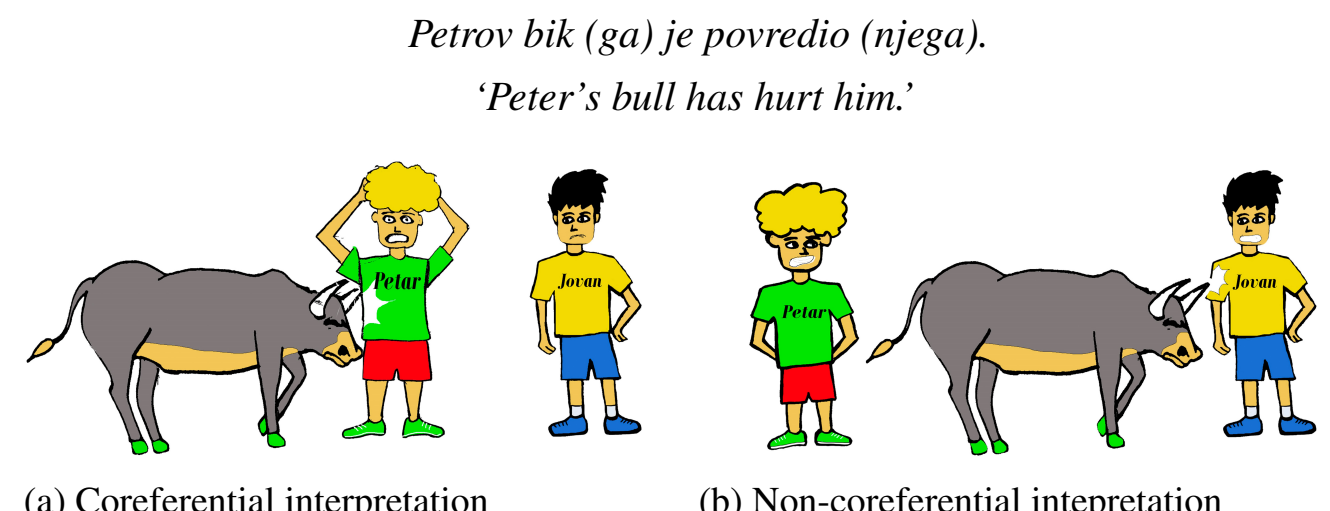

(a) Coreferential interpretation

(b) Non-coreferential intepretation

For each participant to see only either the clitic or the strong pronoun version of an item, the stimuli were divided into two lists. Each participant saw 12 sentences with clitics and 12 sentences with strong pronouns. Moreover, 10 sentences with R-expression, where only one reading was possible, were included as control items in order to check if participants paid attention to the stimuli and if they clicked on pictures randomly or not. Therefore, each participant saw 34 items altogether. The stimuli were presented to the participants in a randomized order.

A native speaker read the sentences to control for the neutral stress, i.e. that there was no emphatic stress on the strong pronoun, which could elicit the coreferential interpretation, since it would have a contrastive role, e.g. 'Peter's dog bit HIM, not John'. After they had concluded the experimental task, the experimenter asked the participants to explain their choices and to report on their impressions of the task.

In total, the experiment lasted around 15 minutes. The task was constructed in the online software IBEX farm, using PennController (Zehr and Schwarz 2018), but it was conducted in person, to ensure that participants pay attention to the task.

\subsubsection{Results}

The thirty-six participants produced an overall number of 360 control items and 864 test items. For the control items, which only allowed for non-coreferential interpretation (see Table 3.2), the participants chose the non-coreferential picture with $100 \%$ accuracy. This shows that they understood the test and paid attention. The results for the test items indicate that participants chose the picture expressing a coreferential reading in $55 \%$ of the examples if the clitic pronoun was used ( 240 out of 432 items). Coreference with the strong pronoun was slightly less chosen in $40 \%$ of the examples (177 out of 432 items). The percentages of (non-)coreference for the clitic and the strong pronoun are illustrated in Figure 3.4. 
Figure 3.4: Choice of coreferent/non-coreferent interpretation with clitic/strong pronoun in percentages (Experiment 1)

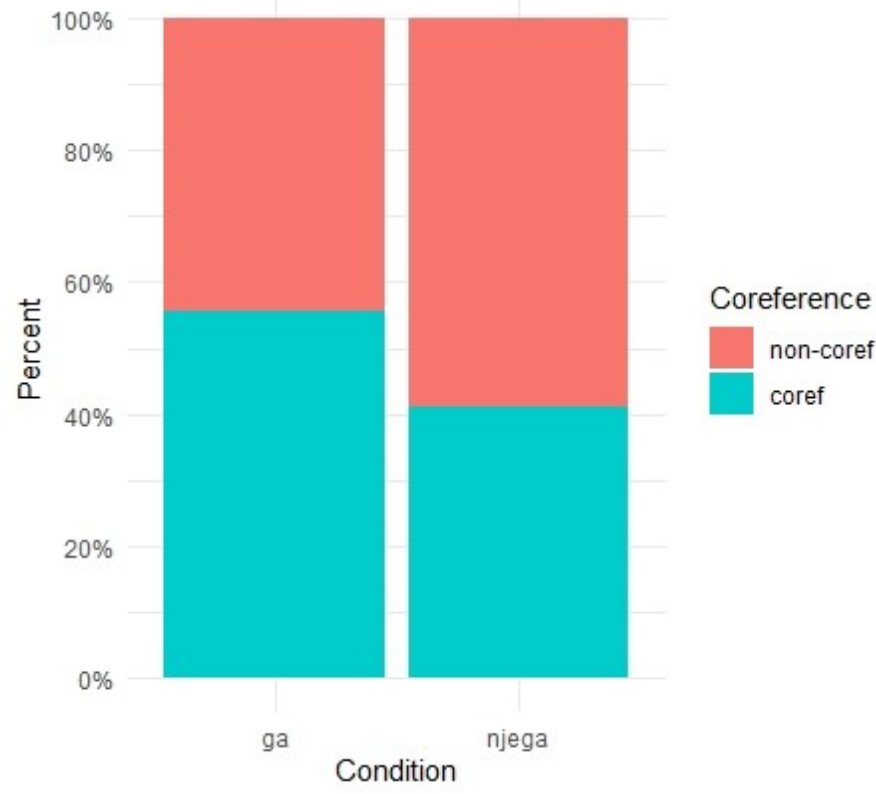

The analysis was carried out in $\mathrm{R}$ (Team 2013). For the statistical analysis, the results were introduced in a Generalized Linear Mixed-Effects Regression (GLMER), using the lmer package (Bates et al. 2014) with choice (coreference/non-coreference) as the dependent variable and condition (strong vs. clitic pronoun) as the independent variable. Participants and stimuli were included as random factors in the final GLMER model (Formula: Answer $\sim$ poly (TrialOrder, 2) $+I V+(1 \mid$ Participants $)+(0+$ poly(TrialOrder, 2$)$ | Participants $)+(1 \mid$ Stimuli $))$. The trial order was included into the statistical model as a numerical co-variable. The results of the final GLMER are summarized in Table 3.3.

Table 3.3: Experiment1. Generalized Linear Mixed-Effects Regression for the likelihood of coreferential interpretation

\begin{tabular}{lcccc}
\hline Fixed effects & & & & \\
\hline & Estimate & Std. Error & $\mathrm{Z}$ value & $\operatorname{Pr}(>|\mathrm{z}|)$ \\
\hline (Intercept) & -0.563 & 0.283 & -1.99 & $0.046 *$ \\
Trial Order (order of presentation) & 3.432 & 3.341 & 1.03 & 0.304 \\
Condition & 0.917 & 0.172 & 5.32 & $0.000 * * *$ \\
(ga vs. njega) & & & & \\
\hline
\end{tabular}

Note. $* \mathrm{p}<.05 ; * * * \mathrm{p}<.001$.

The results indicated that there was only a significant effect of the condition $(\mathrm{p}<$ .001). There was no statistically significant effect of trial order. 
Even though the GLMER model already takes into account the effects of participants as a random factor, there still exists some individual variation among participants. Only two speakers always opted for either coreference (1), or non-coreference (1). Although, some participants preferred coreferential (8) and some non-coreferential (6) ${ }^{5}$ reading in both conditions, the overall picture indicates that it is a question of preference: for most speakers, both coreference and non-coreference were an option with the clitic and the strong pronoun. For instance, 12 participants preferred the coreferential reading with the clitic, but non-coreferential with the strong pronoun and only two did the opposite. Additionally, some participants preferred non-coreference with the strong pronoun, while they almost equally allowed for both readings with the clitic.

After looking at the binomial distribution, the participants were above chance if they responded correctly to 9 or more out of the 12 test items. For the condition with the clitic, it was expected by the hypothesis that participants should prefer coreference and 14/36 individuals were above chance (and 8 of them were at chance). When it comes to the strong pronoun condition, the expectancy was that the participants would choose the noncoreferential answer and even more participants were above chance, namely 19 out of 36 individuals ( 5 were at chance). This might imply that it was easier to match the strong pronoun njega with the non-coreferential interpretation, as this form of the pronoun is clearly dispreferred in such a context with a coreferential reading. On the other hand, the clitic seems to be more ambiguous, as some of the participants equally chose both options, and some of them changed their pattern along with the items, but still, more than half of participants opted for a coreferential reading, which was claimed to be impossible in the literature until now.

\subsection{Discussion}

In Section 3.2, two research questions were formulated. First of all, the aim of the experiment was to discover whether coreference is indeed admissible between a possessive name in subject position and a pronoun in object position in Serbian (Q1). Secondly, if the coreferential reading is possible in such constructions, the question is whether there are differences between sentences with the clitic $g a$ and the strong pronoun njega in object position (Q2).

Concerning the first question, the results of the experiment indicate that coreference is actually acceptable in Serbian. All the native speakers that participated in the experiment, except one, ${ }^{6}$ were able to get coreferential interpretation between possessive mod-

\footnotetext{
${ }^{5}$ The numbers in brackets indicate the number of participants.

${ }^{6}$ This participant who always disliked coreference said that she would express the coreferential meaning by putting the name of the boy, i.e. the object, at the first place in the sentence, and the possessive pronoun before the dog: Jovana ${ }_{i}$ je ugrizao njegov ${ }_{i}$ pas., 'John. acc $_{i}$ was bitten by his ${ }_{i}$ dog.'
} 
ifiers and pronouns. The results obtained in this experiment are contradicting the claims in previous literature, in particular to Despić (2013) and LaTerza (2016). According to these authors, the coreferential reading should never be available, neither with the clitic ga nor with the strong pronominal object njega. However, in this experiment, coreference was proven in both conditions, both with the clitic as well as with the strong pronoun. Therefore, no violation of Binding Principle B was observed and the results are in line with my hypothesis that coreference between possessives and pronouns is indeed allowed in Serbian.

Recall that Principle B violations in Serbian have been accounted for by Despić (2013) and LaTerza (2016) on the basis of the assumption that possessive modifiers ccommand out of the noun phrase because they are adjuncts to NP and no DP shell prevents c-command. The findings of my experiment falsify this analysis. The fact that coreference is perfectly acceptable suggests quite the opposite, i.e. that prenominal possessive modifiers do not c-command out of their phrase. Moreover, there should be a functional category above the possessive to prevent the c-command out of the noun phrase. This could be either a DP, which would speak in favour of the Universal DP hypothesis, or another functional projection FP. This will be further discussed in the general discussion in Chapter 5. Whatever this functional projection is, it is important to emphasize that the experimental results corroborate the hypothesis that prenominal possessives are found somewhere lower within the extended nominal phrase, from where they cannot ccommand a bound element in object position. As suggested in Chapter 2, SpecAgrP could be the relevant position to accommodate lexical possessives.

Even though coreference is possible, that does not mean that such an interpretation is always available or preferred. As opposed to the Bulgarian judgments allowing the coreferential reading with the clitic only (cf. Franks 2019), Serbian native speakers chose a coreferential reading with both forms. Although both types of pronouns are in general possible to be interpreted as coreferential with a possessive modifier, the results also reveal that there is a difference between the two types of pronouns. Namely, the participants show an overall tendency for coreference as the preferred interpretation for clitics, and non-coreference as the preferred interpretation in the case of the strong pronoun. Even though clitics in Serbian did not (yet) develop into agreement markers as argued by Franks (2019) for Macedonian, the results pattern with the Macedonian judgments, where both readings are possible with either of the two pronominal forms, implying that the (non)coreference in these structures is rather a matter of preference.

This also has to do with the fact that these two pronominal types take different kinds of discourse antecedents: discourse topics in the case of the clitic, new information (if not stressed) antecedents or contrast (if stressed) in the case of strong pronouns (cf. Zec 2002; Jovović 2020). Therefore, when participants interpret the possessor as given information 
(which is more likely in this kind of test), they show it by allowing coreference with the clitic. On the other hand, when they interpret the possessor in terms of new information or contrast (which is less likely in this test), this provokes non-coreferential reading with the clitic, but a coreferential reading with the strong form.

Even though the participants generally preferred the non-coreferential interpretation with the strong pronoun, a high number of cases was observed for the acceptance of the strong pronoun with a coreferential interpretation, too. As already mentioned, this could be seen as a reflex of the perceived discourse status of the antecedent. It could also be due to the emphatic stress on the strong pronoun form njega that some participants might have produced for themselves. ${ }^{7}$ It is well known that emphatic stress may alter the interpretation of the coreference, since it signals an emphasis or contrast. Despite the fact that the participants heard the test sentences, which were read without emphatic stress on the pronoun, it might be the case that they still implicitly stressed the pronoun and allowed the coreference with the strong pronoun in more cases than expected. Some of the participants actually reported that they perceived the pronoun as stressed when they were asked to explain their choices after the experiment was finished. For this reason, rather than just controlling for the stress of the strong pronoun, there should be 3 conditions that could help clarify this issue in a further study, namely the clitic, the strong pronoun without the stress and the strong pronoun with the stress.

Given all the above, there is no violation of Binding Principle B in Serbian possessive structures. The results suggest that coreference between possessive names and pronouns is possible, and that the availability of coreference could be accounted for if we assume that prenominal possessives do not c-command out of their phrase. This supports my assumption that they are located rather lower in the noun phrase structure than previously assumed, namely in SpecAgrP. Furthermore, if the coreferential reading is not obtained, this is not caused by grammaticality constraints, but other factors that might influence disjoint reading, such as the type of pronominal objects. Preference for the clitic or the strong pronoun also depends on additional factors such as the information structure of the antecedent and the bound element, adjacency, the grammatical role of antecedents, stress on the pronoun etc.

In order to find out more precisely how other factors affect the coreference between possessive names and pronouns in Serbian, further experimental research that systematically includes all those factors is needed.

Having provided an experimental piece of evidence in favour of the acceptability of coreferential interpretation between lexical possessives in subject position and pronouns in object position, I will examine if the same holds true for pronominal possessives and R-expression (Binding Principle C). This configuration is investigated in the upcoming

\footnotetext{
${ }^{7}$ The clitic pronoun $g a$ cannot bear stress on its own.
} 
chapter, and Experiments 2 and 3 provide further experimental evidence on this matter.

\subsection{Chapter summary}

In Chapter 3, I have shown on the basis of experimental evidence from a picture selection task that coreference between a lexical possessive modifying a noun in subject position and a pronominal object is possible in Serbian. Given that Serbian has two different pronominal forms in the accusative, namely the clitic $g a$ 'him.CL' and the strong form njega 'him.STR', the goal was to examine whether there is a difference in binding of these two forms. The results have shown that participants accepted coreference with both forms, but they slightly preferred the coreferential interpretation with clitics more than with strong pronouns. These findings suggest that lexical possessives do not behave like adjectives, since they have referential possibilities that adjectives lack. In addition, the results imply that possessives are not adjoined high within the nominal phrase as specifiers of NP, since they do not c-command out of their phrase and do not violate Binding Principle B. The structure that could account for these facts could be a lower specifier position (SpecAgrP) above which is another projection that bans c-command.

In the following sections, two further experiments will examine pronominal possessives and R-expression objects in order to provide more evidence on the categorial status and syntactic position of prenominal possessive modifiers and the nature of pronominal possessives. 


\section{Chapter 4}

\section{Study II - Binding of R-expressions/ Binding Principle C}

In the previous chapter, I presented Study I that focused on Binding Principle B in possessive constructions. The results revealed that the participants allow for a coreferential reading between the lexical possessive modifying a noun in subject position and the pronoun in object position in Serbian. This shows that Serbian lexical possessives pattern with the behaviour of lexical possessives in English and other DP languages (German, Macedonian, Bulgarian among others), which supports the assumption that possessives do not c-command out of their phrase and that they occupy a position higher than NP but lower than DP.

Given the difference between pronominal and lexical possessives in some languages (Alexiadou 2001), the question arises whether Serbian pronominal possessives behave in the same way as lexical possessives with respect to their binding possibilities. Therefore, Study II addresses coreferential possibilities of pronominal possessives.

In this chapter, I present and discuss the results of two experiments focussing on the question whether coreference is indeed possible between a pronominal possessive modifier in subject position and an R-expression in object position, or whether violations of Binding Principle C arise in Serbian, as suggested by Despić (2013) (see Chapter 2).

Following the methodology in the studies by Kazanina et al. (2007) and Drummer and Felser (2018) on English and German, I compared constructions with a pronominal possessive (modifying a noun) in subject position and an R-expression in object position with structures containing a pronoun in subject position and an $\mathrm{R}$ expression in object position, in order to investigate whether coreference is accepted in the former but not in the latter in Serbian as well. If this was the case, this would provide further evidence that pronominal possessives do not c-command out of the phrase and bind the R-expression, as previously assumed by Despić (2013).

This chapter is structured in the following way: In Section 4.1 I provide an overview 
of the role of c-command in binding structures, and in Section 4.2 I present a literature overview of previous psycholinguistic studies. Then, I present the results from my two experiments in Section 4.3: Experiment 2 - the forced-choice task (Subsection 4.3.1), and Experiment 3 - the self-paced reading task (Subsection 4.3.2).

\subsection{Cataphoric dependencies and Condition $\mathrm{C}$ effect}

As mentioned in Chapter 2, it has been claimed that Serbian does not pattern with English concerning the availability of coreferential interpretation between the possessive pronoun njegov, 'his' and the R-expression Jovana, 'John' in sentences with possessive pronouns modifying a noun in subject position as in (1) (Despić 2013:253).

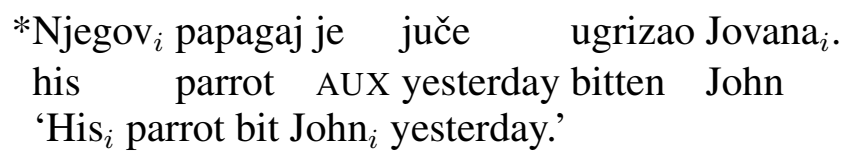

Recall that Despić (2013) assumes that in Serbian, the possessive in (1) is in an adjoined position and since there is no DP to prevent it from c-commanding out of its phrase, binding principle $\mathrm{C}$ is violated (Despić 2013).

As discussed in Chapter 3, LaTerza (2016) questions Despić's (2013) analysis. Based on the alleged parallelism of Serbian with DP languages like Bulgarian and Macedonian, LaTerza (2016) assumes that possessive pronouns raise covertly, in LF, to a high position from which they c-command the entire clause. Her examples for Binding Principle $\mathrm{C}$ are given in (2) for Bulgarian and (3) for Macedonian.

(2) *Negovijat ${ }_{i}$ papagal uxapa $\operatorname{Ivan}_{i}$ včera. (Bulgarian)

his.def parrot bit Ivan yesterday

'His ${ }_{i}$ parrot bit $\operatorname{Ivan}_{i}$ yesterday.'

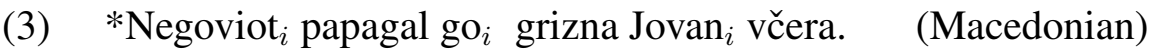

his.def parrot him bit Jovan yesterday

'His $i$ parrot bit $\mathrm{Jovan}_{i}$ yesterday.'

Moreover, LaTerza (2016) states that the acceptability of such sentences does not ameliorate even when a demonstrative precedes the possessives, as illustrated in (4) with tozi, 'this' for Bulgarian and (5) with toj, 'this' for Macedonian.

(4) *Tozi negov ${ }_{i}$ papagal uxapa $\operatorname{Ivan}_{i}$ včera. (Bulgarian)

this his parrot bit Ivan yesterday

'This parrot of his bit $\operatorname{Ivan}_{i}$ yesterday.' 


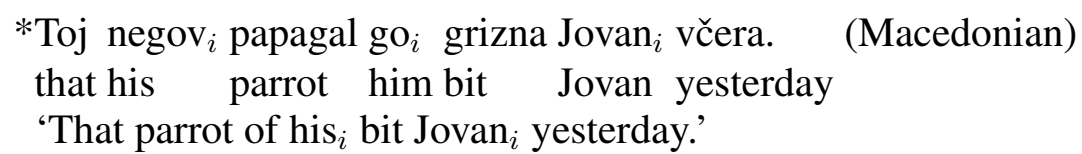

Franks (2019) points out some problems with LaTerza's data and argues that, when these are corrected for, Macedonian and Bulgarian indeed pattern with English. His Macedonian consultants declared that in none of LaTerza's examples disjoint reference is forced. In sentences as (3) and (5), the pronominal possessive negoviot, 'his' is ambiguous, and it can refer either to Jovan, 'John' or somebody else.

Concerning the Bulgarian judgments, Franks (2019) confirms that some Bulgarian speakers do agree with the judgment LaTerza reports for (2). However, when the demonstrative tezi, 'these' is placed before the possessive, as in (6), coreference ameliorates considerably according to Franks (2019:74). Hence, whereas Macedonian seems to pattern with English, Bulgarian shows a mixed behaviour (cf. also Tasseva-Kurktchieva and Dubinsky 2018).

(6) Tezi negovi ${ }_{i}$ papagali uxapaxa $\operatorname{Ivan}_{i}$ včera. (Bulgarian) these his parrots bit Ivan yesterday

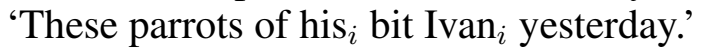

The results from Experiment 1 reported in Chapter 3 have shown that Serbian patterns with Bulgarian and Macedonian (and English) in the acceptability of a coreferential interpretation between a lexical possessive and an object pronoun (no violation of Binding Principle B). In the following sections, I will extend my investigation to the corresponding constructions concerning Principle $\mathrm{C}$ in Serbian and the coreference assignment between pronominal possessives and R-expressions in order to find out whether Serbian patterns with English in this context as well.

Generally speaking, backward anaphora (cataphora) (7) is less common than forward anaphora (8), but it is still productive and acceptable in English sentences such as (7).

When he ${ }_{i}$ was alone, Rick $_{i}$ invited Kate for a drink.

When $\operatorname{Rick}_{i}$ was alone, he ${ }_{i}$ invited Kate for a drink.

However, a sentence is ruled out when a pronoun c-commands its antecedent, because it is constrained by Binding Principle C (Chomsky 1981), which states that R(eferential) expressions have to be free and not bound. When a pronoun c-commands an R-expression and binds it, as in (9), the noun phrases he and John cannot be coreferential, due to the violation of Binding Principle $\mathrm{C}$. 


$$
\mathrm{He}_{\star i / j} \text { likes } \operatorname{David}_{i} \text {. }
$$

Condition $\mathrm{C}$ also applies across a clause boundary and limits the distribution of coreferring R-expressions, see (10).

$$
\mathrm{He}_{* i / j} \text { drank beer, [while David }{ }_{i} \text { watched a football match]. }
$$

On the other hand, in the absence of a potential binding configuration, a coreferential reading is freely available, as in (11). Here, the possessive pronoun his is deeply embedded in the phrase his brother and it does neither c-command nor bind the R-expression David, which then remains free as determined by the definition of Binding Principle C. Thus, the sentence is acceptable.

(11) His $_{i / j}$ brother drank beer, while David $_{i}$ watched a football match.

In Section 4.2, I present a literature overview of the aforementioned psycholinguistic studies by Kazanina et al. (2007) and Drummer and Felser (2018), which provide psycholinguistic evidence showing that structures like (9) and (10) indeed differ from structures like (11).

\subsection{Previous psycholinguistic studies}

There is a number of psycholinguistic studies investigating the effects of syntactic constraints on the processing of backward anaphora (cataphora) for English (Gordon and Hendrick 1997; Kazanina et al. 2007), for Russian (Kazanina and Phillips 2010), for Dutch (Pablos et al. 2015), for German (Drummer and Felser 2018) etc. It is assumed that the resolution of forward anaphora and backward anaphora differ as they employ different mechanisms in language comprehension. Concerning forward anaphora, it is necessary to restore the information about the antecedent at the pronoun position, given that the antecedent precedes the pronoun. This mechanism is linked to memory-retrieval processes (Chow et al. 2014). On the other hand, in the case of cataphoric dependencies, a different kind of process is needed. In such constructions, the pronoun precedes the antecedent which requires a predictive process, such as the active search mechanism. This process was first attested in the interpretation of wh-gap dependencies (Crain and Fodor 1985; Stowe 1986; Frazier and Clifton 1989). The assumption of an active search mechanism predicts for cataphoric pronoun resolution, that immediately after encountering a 
cataphoric pronoun, a search for a suitable referent in the upcoming sentence is triggered. ${ }^{1}$ Previous research indicated that this search is constrained by grammatical principles, such as Binding Principle $\mathrm{C}$, which prohibits coreference between the cataphoric pronoun and the referential expression within its c-command domain (Van Gompel and Liversedge 2003; Kazanina et al. 2007). The experiments conducted in this dissertation aimed at testing Binding Principle $\mathrm{C}$ on Serbian were designed following the offline and online experiments by Kazanina et al. (2007) and Drummer and Felser (2018), which will be presented in this section.

Kazanina et al. (2007) conducted several experiments on the processing of cataphoric dependencies in English. In their Experiment 3, Kazanina et al. (2007) used offline (acceptability rating task) and online (self-paced reading task) tasks to corroborate that the active search mechanism is restricted by syntactic constraints such as Principle C. Their central assumption is that speakers search for an antecedent in upcoming sentence(s) only in positions where the coreference between the pronoun and the R-expression is structurally allowed, i.e. in constructions with possessive pronouns that do not c-command out of their phrase and therefore do not bind the R-expression. In a self-paced reading task, Kazanina et al. (2007) included a gender match/mismatch condition which is a useful method for monitoring active dependency formation in cataphora, and it allowed them to test for a (potential) coreference indirectly. The gender mismatch paradigm is essential in the constructions where coreference is possible. Namely, in cases when the potential antecedent and the preceding pronoun do not match in gender, reading times on the antecedent are longer as opposed to cases with a gender match between these two elements (Van Gompel and Liversedge 2003). This slowdown in reading - the gender mismatch effect - indicates that the speaker actively searches for an antecedent in order to resolve the reference of the pronoun. Crucially, this effect is not found if there is a violation of Binding Principle $\mathrm{C}$, as it is the case if a pronoun in subject position c-commands the $\mathrm{R}$-expression. In other words, the lack of gender mismatch effect in these cases suggests that the R-expression does not qualify as a potential antecedent for the pronoun (Kazanina et al. 2007). Table 4.1 presents a set of stimuli from Kazanina et al.'s (2007) self-paced reading task.

In $\mathrm{C} 1$, the possessive pronoun his does not bind the R-expression quarterback, which qualifies as a potential antecedent, as they also match in gender. Hence, the pronoun his should be resolved at the position of the first upcoming antecedent (quarterback). In C2, the gender of the pronoun her and the potential antecedent quarterback do not match, and a slowdown in the reading time in comparison to $\mathrm{C} 1$ is expected (gender mismatch effect). In $\mathrm{C} 3$, the pronoun he binds the referential expression quarterback causing a Principle $\mathrm{C}$

\footnotetext{
${ }^{1}$ It is of course possible that pronouns can have antecedents outside of the sentence, but it is assumed that the search for an antecedent within the sentence is the default strategy in cases without preceding discourse, or it belongs to world knowledge.
} 
violation. Thus, the R-expression quarterback is not allowed to be the antecedent of the pronoun he. The same syntactic structure is present in $\mathrm{C} 4$, with a difference that the pronoun she mismatches in gender with the noun quarterback. Comparing $\mathrm{C} 3$ and $\mathrm{C} 4$, no slowdown in reading time is expected.

Table 4.1: Conditions from the self-paced reading task (Experiment 3) by Kazanina et al. $(2007: 401)$

\begin{tabular}{|c|c|c|}
\hline & Condition & Item \\
\hline $\mathrm{C} 1$ & $\begin{array}{l}\text { no constraint } \\
\text { gender match }\end{array}$ & $\begin{array}{l}\text { His }_{i} \text { managers chatted amiably with some fans while the tal- } \\
\text { ented, young quarterback }{ }_{i} \text { signed autographs for the kids, but } \\
\text { Steve wished the children's charity event would end soon so } \\
\text { he could go home. }\end{array}$ \\
\hline $\mathrm{C} 2$ & $\begin{array}{l}\text { no constraint } \\
\text { gender mismatch }\end{array}$ & $\begin{array}{l}\text { Her }_{i} \text { managers chatted amiably with some fans while the tal- } \\
\text { ented, young quarterback signed autographs for the kids, but } \\
\text { Carol }_{i} \text { wished the children's charity event would end soon so } \\
\text { she could go home. }\end{array}$ \\
\hline $\mathrm{C} 3$ & $\begin{array}{l}\text { Principle C } \\
\text { gender match }\end{array}$ & $\begin{array}{l}\mathrm{He}_{i} \text { chatted amiably with some fans while the talented, } \\
\text { young quarterback signed autographs for the kids, but Steve } \\
\text { wished the children's charity event would end soon so he } \\
\text { could go home. }\end{array}$ \\
\hline $\mathrm{C} 4$ & $\begin{array}{l}\text { Principle C } \\
\text { gender mismatch }\end{array}$ & $\begin{array}{l}\text { She }_{i} \text { chatted amiably with some fans while the talented, } \\
\text { young quarterback signed autographs for the kids, but Carol } \\
\text { wished the children's charity event would end soon so she } \\
\text { could go home. }\end{array}$ \\
\hline
\end{tabular}

Note. The underlined noun indicates the critical word (first possible antecedent). Subscript indices indicate intended cataphoric dependencies.

Kazanina et al.'s (2007) results suggest that the speakers obey Principle C, given that the gender mismatch effect occurs as expected between the no-constraint conditions only (C1 vs. C2). More precisely, the longer reading time at the critical noun quarterback is visible in $\mathrm{C} 2(\mathrm{M}=402.5 \mathrm{~ms})$ compared to $\mathrm{C} 1(\mathrm{M}=364.6 \mathrm{~ms})$ at the same position. Crucially, no significant difference is detected at the critical region in the Principle $\mathrm{C}$ conditions C3 ( $\mathrm{M}=369.6 \mathrm{~ms})$ and C4 $(\mathrm{M}=376.4 \mathrm{~ms})$. Moreover, the statistical analysis revealed a main effect of congruency (gender) and a significant interaction of constraint and congruency at the critical noun quarterback. Separate pairwise comparisons of the 
Principle $\mathrm{C}$ and no-constraint conditions revealed a strong effect of congruency in the no constraint pair (C1 vs. C2) in the predicted direction. No such effect was observed in the Principle C pair (C3 vs. C4).

Summing up the results from Kazanina et al.'s (2007) self-paced reading task, an active search for an antecedent in cataphoric constructions only occurs when there is no violation of Binding Principle C. After conducting the self-paced reading task, the same participants completed an offline acceptability rating task. Kazanina et al. (2007) used the offline task to confirm that the syntactic structure in the no-constraint and Principle $\mathrm{C}$ conditions has an effect on the acceptability of coreference between the pronoun and the upcoming R-expression. Accordingly, the speakers should accept coreference between the pronoun and the R-expression in the no-constraint condition, but reject it in the Principle $\mathrm{C}$ condition.

The task of this experiment was the following. In each item a pronoun and a noun phrase were highlighted and participants were instructed 'to determine how plausible it is that the pronoun in bold and the noun in bold refer to the same person' on a scale from 1 (impossible) to 5 (absolutely natural) (Kazanina et al. 2007). The stimuli were constructed out of the stimuli from the online experiment with some adjustments and consisted of 24 test items together with 36 filler items. The experiment encompassed 4 conditions: Principle C, no-constraint, forward anaphora and but-condition. An example of each condition is illustrated in Table 4.2.

Table 4.2: Conditions from the offline task (Experiment 3) by Kazanina et al. (2007)

\begin{tabular}{|c|c|}
\hline Condition & Item \\
\hline Principle C & $\begin{array}{l}\mathrm{He}_{i} \text { chatted amiably with some fans while the talented, young } \\
\text { quarterback }_{\star i} \text { signed autographs for the kids. }\end{array}$ \\
\hline no constraint & $\begin{array}{l}\text { His }_{i} \text { managers chatted amiably with some fans while the talented, } \\
\text { young quarterback }{ }_{i} \text { signed autographs for the kids. }\end{array}$ \\
\hline forward anaphora & $\begin{array}{l}\text { The talented, young quarterback }{ }_{i} \text { signed autographs for the kids } \\
\text { while he } e_{i} \text { chatted amiably with some fans. }\end{array}$ \\
\hline but condition & $\begin{array}{l}\mathrm{He}_{i} \text { chatted amiably with some fans while the talented, young } \\
\text { quarterback signed autographs for the kids, but Steve }{ }_{i} \text { wished the } \\
\text { children's charity event would end soon so he could go home. }\end{array}$ \\
\hline
\end{tabular}

Note. Subscript indices indicate intended cataphoric/anaphoric dependencies.

The first two conditions (Principle $\mathrm{C}$, no constraint) were the same as the gender match conditions ( $\mathrm{C} 1$ and $\mathrm{C} 3)$ in the online study, but without the final but-clause. In 
the forward anaphora condition, the position of the pronoun and the second R-expression was switched in comparison to the Principle C-condition. This condition was included in order to avoid that lower ratings in the Principle $\mathrm{C}$ condition might be due to the fact that the events of the main and embedded clauses could not be simultaneously performed by the same agent (e.g. chat and sign can be performed simultaneously by one person). The fourth, but-condition also matched the Principle C/gender match condition (C3) from the online study but was included to test the efficiency of providing another possible antecedent in an additional clause.

The results of this experiment showed that the Principle $\mathrm{C}$ condition received a significantly lower mean rating score than the rating score in the other conditions, as expected. The coreference rating score in the no-constraint condition was considerably lower than in the but-condition and the forward anaphora condition, but this is also expected given that forward anaphora is the preferred way of expressing coreference in this context. The results showed that the judgments of coreference are substantially degraded (only) when a pronoun c-commands its antecedent, as predicted by the Principle C constraint (Kazanina et al. 2007).

The results from Kazanina et al.'s (2007) study support the analysis that syntactic constraints prevent illicit anaphoric relations from being considered. The same results are replicated on Dutch data in the ERP study by Pablos et al. (2015).

Following the design of Kazanina et al.'s (2007) study, Drummer and Felser (2018) investigated cataphoric pronoun resolution in native and proficient non-native speakers of German. They conducted an eye-tracking and an offline judgement task. In the eyetracking experiment (Experiment 4) they also used the two factors: syntactic structure (no-constraint vs. Principle C) and gender manipulation (match/mismatch), whereas in the offline judgment task (Experiment 3 ) they only used gender matching stimuli.

What they found in the offline experiment patterns with the results of Kazanina et al.'s (2007) offline study. The participants disallowed coreference between the cataphoric pronoun and the name in the constraint sentences in $83 \%$ of cases for the native group and $85 \%$ for the non-native group, and they allowed coreference in the no-constraint condition $-78 \%$ (native speakers) and $83 \%$ (non-native speakers).

Contrary to the results of Kazanina et al.'s (2007) self-paced reading task, the results of Drummer and Felser's (2018) eye-tracking study showed that the effect of Principle $\mathrm{C}$ was delayed to later processing measures. More precisely, during the first reading of the critical name, participants initially considered the second clause subject as a potential antecedent in both the no-constraint and the Principle $\mathrm{C}$ conditions, as the interaction between gender and the structural position became significant only later at the rereading stage. The authors suggest that Principle $C$ does not per se prevent illicit antecedents from being considered, but rather acts as a later filter when assigning coreference. 
Summing up, Kazanina et al.'s (2007) and Drummer and Felser's (2018) offline studies came to the same conclusion - that speakers are sensitive to Principle C. Coreference between the cataphoric pronoun and the proper name is disallowed, and a coreferential reading is allowed where Principle $\mathrm{C}$ does not apply (with the possessive modifiers in the no constraint condition). The results corroborate the assumption that pronouns ccommand out of their phrase and bind the R-expression, which is not the case with possessive pronouns. It is not so clear in Kazanina et al.'s (2007) and Drummer and Felser's (2018) online studies whether syntactic constraints immediately restrict active search processes (Kazanina et al. 2007) or act as a relatively late filter on coreference assignment (Drummer and Felser 2018).

Based on the methodology and results of the aforementioned studies, I conducted two experiments to investigate whether Serbian speakers also show a sensitivity to Binding Principle C. Section 4.3 presents the results of these experiments.

\subsection{The study: two experiments investigating the Princi- ple $\mathbf{C}$ effect in Serbian}

In Serbian, sentences such as (12) are clearly ungrammatical as well, and examples with the pronominal possessive as in (13) are also not acceptable according to Despić (2013).

$$
\begin{aligned}
& \mathrm{On}_{* i / j} \text { je pio pivo dok je David } \text { gledao fudbalsku utakmicu. }_{\text {. }} \text { he AUX drank beer while AUX David watched football match } \\
& \text { 'He } \mathrm{H}_{\star i / j} \text { drank beer, while David }{ }_{i} \text { watched a football match.' }
\end{aligned}
$$

\footnotetext{
?Njegov ${ }_{i}$ brat je pio pivo dok je David $_{i}$ gledao fudbalsku his brother AUX drank beer while AUX David watched football utakmicu. match 'His ${ }_{i / j}$ brother drank beer while David $_{i}$ watched a football match.'
}

Examples (12) and (13) differ in the structure of the subject. In (12), the pronoun on, 'he' is in subject position, whereas in (13) the subject is njegov brat, 'his brother', i.e. the pronominal possessive modifies the noun.

On the one hand, the personal pronoun he c-commands out of the phrase and binds the R-expression, which causes the violation of Binding Principle $\mathrm{C}$ both in English and Serbian. On the other hand, under Kayne's (1994) approach, the possessor his should occupy a position lower than SpecDP in English, as discussed in Chapter 2. Section 2.2 outlined why the categorial status and the structural position of Serbian possessives are debatable, and I argued for an analysis along the lines of Kayne's (1994) approach with 
some additional adjustments. The hypotheses I made for Serbian are the following: (a) Serbian prenominal possessives - Poss are of a different category than adjectives, i.e. they are DPs from a categorical point of view, (b) both lexical and pronominal possessives are located in the SpecAgrP, above which there is another projection that can prohibit the ccommand of either lexical or pronominal possessives (see the structure in (108) in Section 2.2.4). This way, the pronominal possessive cannot bind the R-expression and no violation of Principle $\mathrm{C}$ should occur.

Under these assumptions, it would be expected that prenominal possessive pronouns do not c-command out of their phrase, as illustrated in (13), unlike pronouns in subject position, as shown in (12). This suggests that there is no grammaticality constraint in binding with possessives, which is different from 'typical binding' (without possessives). The lack of c-command is significant in the possessive constructions, as the absence of c-command allows for a potential coreferential interpretation between the possessive modifier and the object.

When it comes to English, the lack of c-command also accounts for the fact that possessive binding causes a violation of binding principle A, but no violation of Binding Principle C in English. As shown by Reuland (2001), the anaphor in (15) is not licensed in the same position as the pronoun in (14) because anaphora, unlike pronouns, have to be bound. This shows that binding of anaphora is not possible if there is a non-ccommanding antecedent such as possessive modifier.

(14) $\operatorname{John}_{i}{ }^{\prime}$ s mother loves $\operatorname{him}_{i}$.

(15) $* \mathrm{John}_{i}{ }^{\prime}$ s mother loves himself .

In the same manner, there is no violation of Condition $C$, although example (16) sounds pragmatically over explicit.

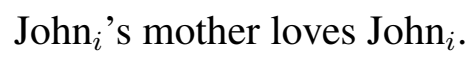

With this in mind, I would like to examine possible differences in the antecedent domain by questioning the existence of c-command in possessive binding by comparing sentences with the pronominal subjects on/ona, 'he/she' (17) and the pronominal possessives njegov/njen, 'his/her' modifying a noun in subject position (18) with respect to binding the R-expression in object position.

* On ${ }_{i}$ je juče ugrizao Jovana ${ }_{i}$. he is yesterday bitten John

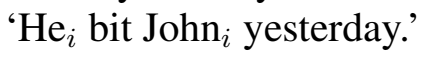




$$
\begin{aligned}
& \text { ?Njegov }_{i} \text { papagaj je juče ugrizao Jovana } \\
& \text { his parrot is yesterday bitten John } \\
& \text { 'His }{ }_{i} \text { parrot bit John }{ }_{i} \text { yesterday.' }
\end{aligned}
$$

However, Despić (2013) assumes that unlike (18), the sentence in (19) is acceptable with coreferential reading, and that there is no violation of Binding Principle $\mathrm{C}$, which would be expected given that the R-expression is not free.

$$
\begin{aligned}
& \text { Jovanov }_{i} \text { papagaj je juče ugrizao Jovana }{ }_{i} \text {. } \\
& \text { John's parrot is yesterday bitten John } \\
& \text { 'John }{ }_{i} \text { 's parrot bit John }{ }_{i} \text { yesterday.' }
\end{aligned}
$$

In spite of Despić's (2013) account, it is unexpected that Serbian does not show a Condition $C$ violation in (19) and that anaphora are not licensed as shown by (20). If the possessor indeed c-commanded out of the noun phrase, one would expect that (19) is ungrammatical because of a violation of Principle C, and (20) is grammatical because the anaphor is properly c-commanded (Srdanović and Rinke 2020).

$$
\begin{aligned}
& \text { *Jovanov }_{i} \text { papagaj je juče ugrizao sebe } \\
& \text { John's parrot is yesterday bitten self } \\
& \text { 'John }{ }_{i} \text { 's parrot bit himself }{ }_{i} \text { yesterday.' }
\end{aligned}
$$

Despić (2013) explains the grammaticality of (19) by employing Safir et al.'s (2004) FTIP, and Lasnik's (1989) definition of Binding Principle C - that an R-expression is pronoun-free, which is illustrated in Section 2.2.5. Following these additional principles, he assumes that (19) is acceptable because all other alternatives are not possible. More precisely, (20) is not available for independent reasons (since the reflexive sebe is strictly subject-oriented and can only be anteceded by a local subject) and a (strong or clitic) object pronoun is also not possible, as it has been claimed to violate binding Principle B according to Despić (2013).

Under Despić's (2013) analysis, it would be expected that no difference exists between (12) and (13) if both the pronoun and the possessive could c-command out of their phrase. However, based on the theoretical conclusions (in Chapter 2) and the results from Experiment 1 (in Chapter 3) showing that lexical possessives do not c-command out of their phrase, I would like to empirically examine whether pronominal possessives also lack the ability to c-command out of the phrase. Therefore, two experiments have been conducted following the studies by Kazanina et al. (2007) for English and Drummer and Felser (2018) for German, which show that speakers of these languages are sensitive to Binding Principle C. Namely, coreference is allowed between the possessive pronoun and the R-expression, but disallowed between the pronoun and the R-expression due to the 
already mentioned syntactic constraint - Principle C.

Experiments 2 and 3 address the question whether Serbian disallows coreference with both the possessive pronoun and the personal pronoun in subject position, or whether coreference is available with possessive constructions as in the case of Principle B (Experiment 1). Study II consists of two experiments, following the design of previous studies conducted in English and German (Kazanina et al. 2007; Drummer and Felser 2018), with some adjustments. Experiment 2 is an offline experiment - a forced-choice task; Experiment 3 is an online experiment - a self-paced reading task.

Based on the findings from Experiment 1 (Chapter 3) which showed that coreference between a lexical possessive and a pronominal object is possible, it is expected that a coreferential interpretation between a pronominal possessive and an R-expression should be allowed. Additionally, Experimental Study 2 aims at investigating not only whether it is possible to get a coreferential reading between pronominal possessives and R-expressions, but also whether the structure of pronominal possessives differs from the structure of personal pronouns in subject position. Following the previous studies on English and German cataphora (Kazanina et al. 2007; Drummer and Felser 2018), the offline study will show whether participants allow for these constructions with coreferential reading or not, while the online study can tell us more about the processing of these structures, i.e. whether people are sensitive to the Principle $\mathrm{C}$ constraint. With respect to the syntactic position, the findings will tell us more about the role of c-command in binding and whether Serbian possessives are able to c-command and bind the object. Concerning the categorial status, the results will show whether possessives bear referential features as discussed in Chapter 2. Experiment 2 is described in detail in Section 4.3.1 and Experiment 3 in Section 4.3.2.

\subsubsection{Experiment 2 - Principle C: an offline study}

Experiment 2 was conducted to examine the possibility of assigning coreference between the R-expression and the possessive pronoun modifying a noun in subject position in Serbian. More concretely, I tested whether there is a difference between structures like (21a) and (21b) with and without c-command with respect to binding possibilities in Serbian.

a. $* \operatorname{Pro}_{i}$ pričao je sa fanovima dok je $\operatorname{Jovan}_{i}$ potpisivao autograme. pro $_{h e}$ talked AUX to fans while AUX John signed autographs *' $\mathrm{He}_{i}$ talked to the fans while $\mathrm{John}_{i}$ signed autographs.'

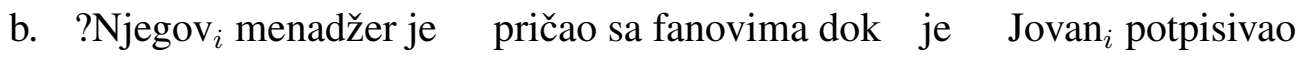
his manager AUX talked to fans while AUX John signed autograme. autographs 'His ${ }_{i}$ manager talked to the fans while John $_{i}$ signed autographs.' 
Hence, the main research question of this study is the following:

Q. Do pronominal possessives modifying noun phrases and pronouns in subject position differ regarding their ability to bind an R-expression in Serbian?

Following the theoretical assumptions from Chapter 2, the results in Chapter 3 on Principle B in Serbian, and the results from previous studies (Drummer and Felser 2018; Kazanina et al. 2007) on languages like English or German, I hypothesize that pronouns, but not possessives, c-command out of their phrase in Serbian.

H. Assuming that pronominal possessives are not adjoined as adjectives but located lower than XP/DP, in a position from which they cannot c-command the antecedent (SpecAgrP), as discussed in Chapter 2, there should be a difference in structure between pronouns and pronominal possessives, as in English. Thus, coreference should be accepted in sentences with possessive noun phrases (no violation of Principle C) and rejected with pronouns (violation of Principle C) because the possessive pronouns do not c-command out of the noun phrase, whereas pronouns do so.

\subsubsection{Methodology}

The method used in Experiment 2 was a Forced-Choice task, because it reveals interpretation patterns that are even more compelling if chosen over an alternative, at first glance more prominent interpretation. The participants' task was to choose one of the given answers regarding to whom something referred. The possible options expressed either a coreferential or non-coreferential interpretation.

Even though the design of my experiments 2 and 3 was based on the previous experimental work by Drummer and Felser (2018) and Kazanina et al. (2007), a different method was used for the offline study. In Kazanina et al. (2007), an offline acceptability rating task was used. In each sentence a pronoun and a noun phrase were highlighted in bold and participants were instructed 'to determine how plausible it is that the pronoun in bold and the noun in bold refer to the same person' on the Likert-scale from 1 to 5. In order to avoid unclear results, i.e. participants' bias in choosing the middle point (3) of this scale which would be difficult to interpret, it was decided to force the participants to make a decision for either coreference or non-coreference. The methodology is more similar to Drummer and Felser (2018), who used a truth-value judgment task where participants had to read sentences for themselves and to decide whether the underlined pronoun referred to the proper name or not by choosing yes or no. The difference was that in this experiment the participants were asked for each item specifically 'Whose ' $\mathrm{X}$ ' is it?' or 'Who did something?', in order to avoid asking for coreference as such, a concept that might be difficult for an ingenious native speaker. 


\subsubsection{Participants}

Thirty-five Serbian native speakers $(n=35)$ with normal or corrected-to-normal vision were recruited for Experiment 2. Their ages ranged from 19 to 42 years, with a mean age of 28.54 years. Twenty-six of the participants were female. All the participants lived in Novi Sad, Serbia, some of them moved there for their studies, and some were born there. All of them were non-linguists. The majority had a university degree (28) and 7 had a high school degree (11 or 12 years of education). All participants gave their consent and agreed to participate in the study.

\subsubsection{Design and Stimuli}

Given that the main research question of this study was whether there was a difference in structure between pronominal possessives and pronouns in connection to the role of c-command for binding R-expressions, C-command was included in the design as an independent variable. Gender was included as a second independent variable. The two factors had two levels each: (1) c-command with 2 levels: (a) no c-command (possessive) and (b) c-command (pro); (2) gender with 2 levels: (a) gender match and (b) gender mismatch. The dependent variable was the choice between 2 options: (1) coreferential: $1^{\text {st }}$ antecedent and (2) non-coreferential interpretation: $2^{\text {nd }}$ antecedent or somebody else.

The design of the experiment was 2-by-2, leading to 4 conditions. The items were distributed across 4 lists using the Latin Square Design, in order for each participant to see only 1 item per condition. In total, there were 48 items per participant: test items $(\mathrm{N}=24)$ and fillers $(\mathrm{N}=24)$. A sample set of test items for all 4 conditions is presented below in Table 4.3 and the full set is available in Appendix B.

The design of the experiment was based on Experiment 3 from Kazanina et al. (2007) but in a modified way. Only C-command and no-constraint were used as test conditions, but with the second clause where another possible antecedent is given (similar to their but-condition). They included the but-condition to test the efficiency of providing an additional antecedent, I concluded that it was indeed effective, and that it would be easier for participants if they were given the possibility to resolve reference of the pronoun by adding another antecedent. To make the conditions more alike, I did this for both $\mathrm{C}$ command and no constraint conditions.

The stimuli consisted of two sentences. In case of no c-command conditions ( $\mathrm{C} 1$ and $\mathrm{C} 2$ ), the possessive pronoun (njegov, 'his', or njen, 'her') was modifying a noun, which was always a name of a profession (e.g. njena frizerka, 'her hairdresser'), whereas in c-command conditions ( $\mathrm{C} 3$ and $\mathrm{C} 4$ ), the subject of the first sentence was pro $_{\text {she/he }}$. The first possible antecedent was given in a while-clause, and the second possible antecedent was in the second sentence. Gender match/mismatch refers to the possessive pronoun/pro 
and the first antecedent in the while-clause, while gender of the second antecedent always matched the gender of the possessive pronoun/pro in the first sentence, in order to always provide a possible antecedent when the first antecedent did not correspond to the subject (gender mismatch cases). This way, it was always possible to resolve a pronoun's reference in some way within the items.

Male-female gender was equally distributed across the items, both for the names and professions. Pro was used instead of the pronoun because it is more natural in these contexts in Serbian and because gender, person and number are marked on the verb, e.g. pisao je, 'pro he wrote'.

Table 4.3: A sample of test items for Experiment 2

\begin{tabular}{|c|c|c|}
\hline & Condition & Item \\
\hline $\mathrm{C} 1$ & $\begin{array}{l}\text { No c-command } \\
\text { gender match }\end{array}$ & $\begin{array}{l}\text { Njegov }_{i} \text { advokat je čitao slučaj dok je } \text { Dejan }_{i} \text { čekao u kance- } \\
\text { lariji. Filip je bio optimističan u vezi sa parnicom. } \\
\text { 'His } \text { lawyer was reading the case while Dejan }_{i} \text { was waiting } \\
\text { in the office. Filip was optimistic about the litigation.' }\end{array}$ \\
\hline $\mathrm{C} 2$ & $\begin{array}{l}\text { No c-command } \\
\text { gender mismatch }\end{array}$ & $\begin{array}{l}\text { Njen }_{i} \text { advokat je čitao slučaj dok je Dejan čekao u kance- } \\
\text { lariji. Elena }{ }_{i} \text { je bila optimistična u vezi sa parnicom. } \\
\text { 'Her }{ }_{i} \text { lawyer was reading the case while Dejan was waiting } \\
\text { in the office. Elena }{ }_{i} \text { was optimistic about the litigation.' }\end{array}$ \\
\hline $\mathrm{C} 3$ & $\begin{array}{l}\text { C-command } \\
\text { gender match }\end{array}$ & $\begin{array}{l}\text { Pro }_{i} \text { čitao je slučaj dok je Dejan čekao u kancelariji. Filip } \\
\text { je bio optimističan u vezi sa parnicom. } \\
\text { 'Pro.he }{ }_{i} \text { was reading the case while Dejan was waiting in } \\
\text { the office. Filip }{ }_{i} \text { was optimistic about the litigation.' }\end{array}$ \\
\hline $\mathrm{C} 4$ & $\begin{array}{l}\text { C-command } \\
\text { gender mismatch }\end{array}$ & $\begin{array}{l}\text { Pro }_{i} \text { čitala je slučaj dok je Dejan čekao u kancelariji. Elena }_{i} \\
\text { je bila optimistična u vezi sa parnicom. } \\
\text { 'Pro.she }{ }_{i} \text { was reading the case while Dejan was waiting in } \\
\text { the office. Elena }{ }_{i} \text { was optimistic about the litigation.' }\end{array}$ \\
\hline
\end{tabular}

Note. Pronominal possessives and pros are given in bold. The underlined name indicates the critical word (first possible antecedent). Subscript indices indicate intended cataphoric dependencies.

Forward anaphora is the preferred way of expressing coreference in this context. It was used for filler items to ensure that lower acceptability ratings in the C-command condition are not due to the implausibility of having the main and embedded clause events simultaneously performed by the same agent. This is shown in the filler items, as it is possible to have coreference in $\mathrm{C} 3$. The same 4 conditions were created for the fillers as 
for the test items by exchanging the position of the pronoun and name from a while-clause, see Table 4.4.

Table 4.4: A sample of filler items for Experiment 2

\begin{tabular}{|c|c|c|}
\hline & Condition & Item \\
\hline $\mathrm{F} 1$ & $\begin{array}{l}\text { No c-command } \\
\text { gender match }\end{array}$ & $\begin{array}{l}\text { Branka }_{i} \text { je čekala da joj se kosa osuši dok je njena }{ }_{i} \text { frizerka } \\
\text { mešala farbu. Nevena je bila zadovoljna bojom. } \\
\text { 'Branka }{ }_{i} \text { was waiting for her hair to dry while her }{ }_{i} \text { hair- } \\
\text { dresser mixed the hair dye. Nevena was satisfied with the } \\
\text { colour.' }\end{array}$ \\
\hline $\mathrm{F} 2$ & $\begin{array}{l}\text { No c-command } \\
\text { gender mismatch }\end{array}$ & $\begin{array}{l}\text { Branka je čekala da joj se kosa osuši dok je njegova } \text { friz- } \text { - } \\
\text { erka mešala farbu. Damjan } \\
\text { je bio zadovoljan bojom. } \\
\text { 'Branka was waiting for her hair to dry while his }{ }_{i} \text { hair- } \\
\text { dresser mixed the hair dye. Damjan }{ }_{i} \text { was satisfied with the } \\
\text { colour.' }\end{array}$ \\
\hline F3 & $\begin{array}{l}\text { C-command } \\
\text { gender match }\end{array}$ & $\begin{array}{l}\text { Branka }_{i} \text { je čekala da joj se kosa osuši dok je pro } \text { prešala }_{i} \\
\text { farbu. Nevena je bila zadovoljna bojom. } \\
\text { 'Branka }{ }_{i} \text { was waiting for her hair to dry while pro.she } \\
\text { mixed the hair dye. Nevena was satisfied with the colour.' }\end{array}$ \\
\hline $\mathrm{F} 4$ & $\begin{array}{l}\text { C-command } \\
\text { gender mismatch }\end{array}$ & $\begin{array}{l}\text { Branka je čekala da joj se kosa osuši dok je pro } \text { pešao }_{i} \\
\text { farbu. Damjan } \\
\text { je bio zadovoljan bojom. } \\
\text { 'Branka was waiting for her hair to dry while pro.he }{ }_{i} \text { mixed } \\
\text { the hair dye. Damjan }{ }_{i} \text { was satisfied with the colour.' }\end{array}$ \\
\hline
\end{tabular}

Note. Pronominal possessives and pros are given in bold. Subscript indices indicate intended anaphoric dependencies.

In the case of the test items, coreference is expected only in $\mathrm{C} 1$, whereas with the fillers, it is possible in $\mathrm{C} 1$ and $\mathrm{C} 3$. As already mentioned, the gender mismatch condition was included in the offline task in order to have a parallel design with the online experiment, but here it served as a control condition. Given that the only option is noncoreferential reading (either referring to the $2^{\text {nd }}$ antecedent or somebody else), gender mismatch sentences will show whether participants paid attention. Thus, the expectancy is that for these conditions the results will show $0 \%$ of the acceptance or at least close to zero.

Each item was introduced by a short sentence that provided a general, neutral context 
about the situation/event, without mentioning any antecedents. ${ }^{2}$ Cataphoric sentences have to start with a pronoun which might sound strange out of the blue, thus in order to diminish this effect, there was a lead-in sentence before each item, see an example in (22).
Uveče je održan rok koncert na trgu. evening AUX held rock concert at square
'A rock concert was held in the square in the evening.'

After each item (test items, but also fillers) there was a question following.

(23) Njegov menadžer je pričao sa fanovima dok je Jovan potpisivao autograme. Petar je bio srećan što je koncert uspešno završen.

'His manager talked to the fans while John signed the autographs. Peter was happy that the concert was over successfully.'

Q: Čiji je menadžer?, 'Whose manager is it?'
a. Jovanov, 'John's'
b. Petrov, 'Peter's'
c. nečijeg drugog, 'somebody else's'

(24) Pričao je sa fanovima dok je Jovan potpisivao autograme. Petar je bio srećan što je koncert uspešno završen.

'He.pro talked to the fans while John signed the autographs. Peter was happy that the concert was over successfully.'

Q: Ko je pričao sa fanovima?, 'Who talked to the fans?'
a. Jovan, 'John'
b. Petar, 'Peter'
c. neko drugi, 'somebody else'

As can be seen in the examples above, the questions referred to the coreferentiality of possessives/pro and proper names. There were 2 types of questions, depending on the condition: (i) for $\mathrm{C} 1$ and $\mathrm{C} 2$ (possessive pronouns modifying professions), the question referred to the possessive pronoun: Whose 'profession' (e.g. doctor) is someone? as illustrated in (23); (ii) for C3 and C4 (pro) - the question referred to the subject of an action - Who was doing something? as in (24). The procedure of the task is explained in detail in the following section.

\footnotetext{
${ }^{2}$ If antecedents were already mentioned that could influence the interpretation and to avoid that, more conditions had to be set up (e.g. vary if only $1^{\text {st }}$ or $2^{\text {nd }}$ antecedent is mentioned or which one is adjacent to the cataphoric pronoun in the items), which would be too many conditions for one experiment.
} 


\subsubsection{Procedure}

As in Experiment 1, the participants were first asked to write their personal information that was needed for the data analysis. They were informed about data privacy and all of them gave their consent. Then, the participants read the description of the experiment and heard the instructions. Before starting with the experiment, there were three practice items to familiarize the participants with the task. When participants understood the task, they clicked on the button to start with the experiment.

After reading each item, the participants' task was to answer to whom something or someone belongs or who did something by choosing only one of three possibilities (see examples of questions in the previous section or the list of stimuli in Appendix B). There were three buttons on the screen and the possible answers were always given in the following order: $1^{\text {st }}$ name (co-referential), $2^{\text {nd }}$ name (non-coreferential) or somebody else (non-coreferential). The presentation of the items was randomized for each participant.

The task was constructed in the online software IBEX farm, using PennController (Zehr and Schwarz 2018). The participants were tested in person. The experiment lasted around 20 minutes.

\subsubsection{Results}

In the gender mismatch conditions ( $\mathrm{C} 2$ and $\mathrm{C} 4)$, the coreferential interpretation was chosen only in $1.90 \%$ (C2) and $1.43 \%$ (C4) of the cases. Since in these conditions pro/pronominal possessive never agreed in gender with the corresponding R-expression (e.g. $\mathrm{He}_{i} / \mathrm{His}_{i}$ manager...while Elena ${ }_{j} \ldots$ ), only non-coreferential reading was expected. Hence, the results confirm the expectations and show that participants paid attention to the task.

Coreference between pronouns and names was also strongly disregarded (selected only in $0.95 \%$ of the cases) in condition $\mathrm{C} 3$ (c-command, gender match; $\mathrm{Pro}_{i} \ldots$ while $\operatorname{Dejan}_{j}{ }^{\prime}$ ). When it comes to the crucial condition - C1 (no c-command, gender match; His ${ }_{i}$ lawyer ... while $\operatorname{Dejan}_{i}$ ), the coreferential interpretation between possessive pronouns and names was chosen in $58.57 \%$. The results are presented visually in Figure 4.1, using the package ggplot2 (Wickham 2011).

The statistical analysis was performed in $\mathrm{R}$ (Team 2013). The results of the test items were introduced in a Generalized Linear Mixed-Effects Regression (GLMER) (Bates et al. 2014) with choice (coreference/no coreference) as the dependent variable and conditions (C-command and Gender) as the independent variables. The trial order was included into the statistical model as a numerical co-variable, and the independent variables and the covariable were treated as fixed effects. Participants and stimuli were included as random factors, in the final GLMER model (Formula: Choice poly(TrialOrder, 2) + Ccommand 
Table 4.5: Experiment2. Generalized Linear Mixed-Effects Regression for the choice of coreferential interpretation

\begin{tabular}{lcccc}
\hline Fixed effects & & & & \\
\hline & Estimate & Std. Error & $\mathrm{Z}$ value & $\operatorname{Pr}(>|\mathrm{z}|)$ \\
\hline (Intercept) & -0.29 & 0.30 & 0.30 & 0.33 \\
Trial Order (order of presentation) & -8.31 & 4.42 & -1.88 & 0.66 \\
$\begin{array}{l}\text { C-command } \\
\text { (possessive vs. pronoun) }\end{array}$ & 4.75 & 0.59 & 7.9 & $2.2 \mathrm{e}-15 * * *$ \\
$\begin{array}{l}\text { Gender } \\
\text { (match vs. mismatch) }\end{array}$ & 4.32 & 0.54 & 7.92 & $2.3 \mathrm{e}-15 * * *$ \\
\hline
\end{tabular}

Note. $* * * \mathrm{p}<.001$.

+ Gender + (1 I Participants $)+(0+$ poly(TrialOrder, 2) I Participants $)+(1 \mid$ Item $))$.

There is a statistically significant effect of both conditions, C-command and Gender $(\mathrm{p}<.001)$. The results of the GLMER model are summarized in Table 4.5.

Figure 4.1: Choice of coreferential/non-coreferential interpretation in 4 conditions

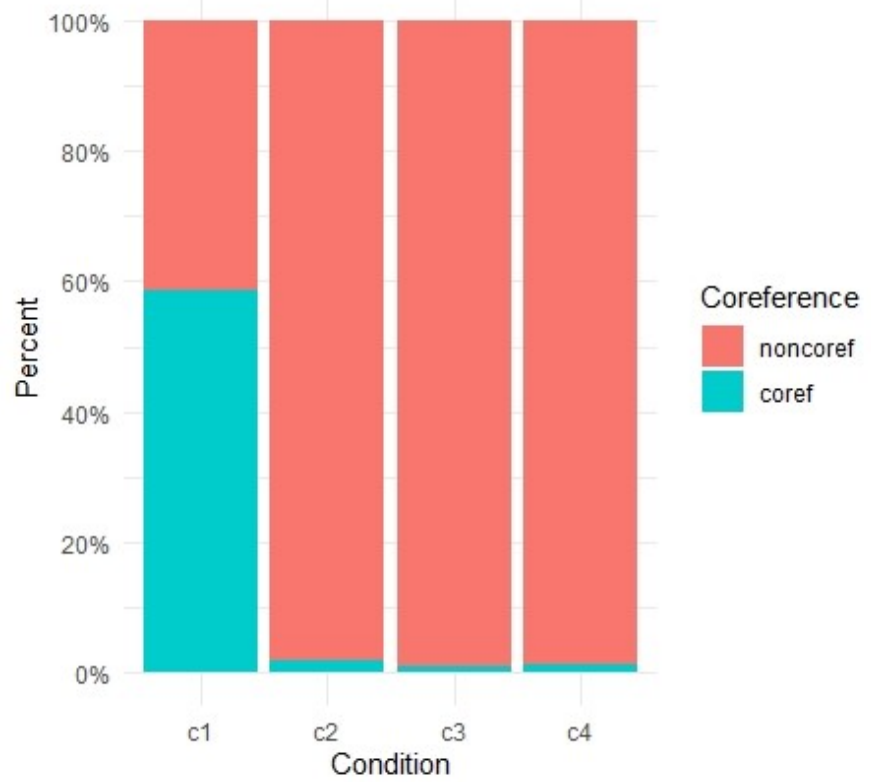

Note. $\mathrm{c} 1=$ possessive match, $\mathrm{c} 2=$ possessive mismatch, $\mathrm{c} 3=$ pronoun match, $\mathrm{c} 4=$ pronoun mismatch

Even though the choice of $\mathrm{C} 1-58.57 \%$ is not very high in comparison to the corresponding sentences in filler items (forward anaphora) -90\%, it is still a remarkable observation that participants opted for coreference at all. According to previous studies, the chances for allowing coreference between pronominal possessives and R-expressions in Serbian were equal to 0. Also, a lower selection of coreference in cataphoric sentences 
(backward anaphora) is expected, since forward anaphora (anaphoric contexts) represent the more common way of expressing coreference. The filler items also show an effect of gender and c-command, which suggests that coreference is available when the positions of R-expressions and pronominal possessives are switched. Unlike in the test items, coreference is here possible in $\mathrm{C} 1$ and $\mathrm{C} 3$, because the position of main and embedded clauses was changed. In addition, this indicates that both actions expressed by verbs could be done by the same agent simultaneously which proves that this was not the reason for lower selection ratings in the $\mathrm{C}$-command condition in the test items, but that there is a grammatical restriction, meaning that the pronoun c-commands the R-expression causing the violation of Principle $\mathrm{C}$. The choice of (non-)coreferential interpretation for forward anaphora/ filler items is shown in Figure 4.2 below.

Figure 4.2: Choice of coreferential/non-coreferential interpretation for fillers

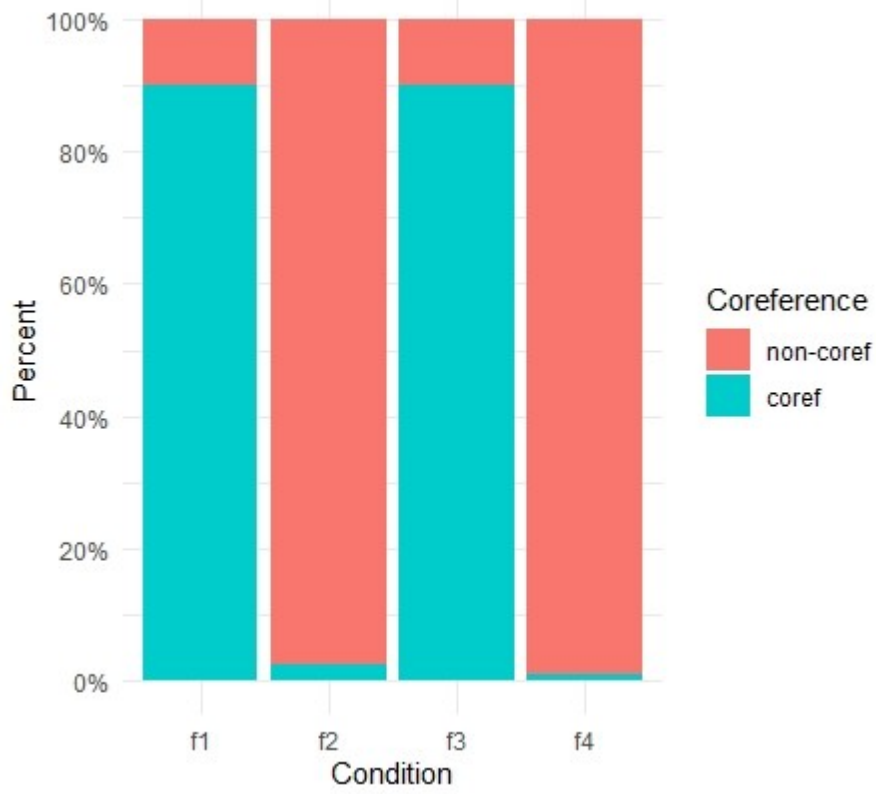

Note. $\mathrm{f} 1=$ possessive match, $\mathrm{f} 2=$ possessive mismatch, $\mathrm{f} 3=$ pronoun match, $\mathrm{f} 4=$ pronoun mis match

After looking at the individual patterns, according to the binomial distribution the participants were above chance if they responded correctly to 5 or 6 out of the 6 test items per condition. For $\mathrm{C} 1$, it was expected by the hypothesis that participants should allow for coreference and 20/35 individuals were above chance (and 3 of them had 4 out of 6 answers). When it comes to the other conditions, almost all the individuals were above chance, namely 32 out of 35 participants.

In my analysis, I merged the "second name" and "somebody else" into a noncoreferential response, since both of these options expressed a non-coreferential interpretation, and my main goal was to find out whether coreference can be obtained in $\mathrm{C} 1$ 
between the pronominal possessive and first antecedent. Nevertheless, I also looked at the distribution of non-coreference responses and noticed that the other referent was always preferred to somebody else-option, see Table 4.6. This was especially the case in C2 (possessive - gender mismatch), where the participants rather chose the other referent - given that coreference was not possible with the first referent as they did not match in gender, they chose the only possible referent that was given in the sentence rather than somebody else who was not mentioned at all. Also in $\mathrm{C} 1$, if they did not match the first coming antecedent as a coreferential one, they rather opted for another referent than somebody else, probably because there were already two possible names with corresponding gender. A slightly higher selection of somebody else choice can be observed in pro conditions, especially in C3. In this condition, it was impossible to match pro with the first coming name, but apparently, the participants then preferred that it was somebody else, and not the second possible name who did the action. The proportion of answers might be different if an overt pronoun was used in $\mathrm{C} 3$ and $\mathrm{C} 4$, but this does not fall under the scope of the dissertation, what matters is that in either way, pro(non) cannot be coreferential with the first antecedent, and the pronominal possessive can be, according to these results.

Table 4.6: The distribution of non-coreferential responses: another referent vs. somebody else

\begin{tabular}{l|l|l}
\hline & another referent & somebody else \\
\hline $\mathrm{C} 1$ & $75.86 \%$ & $24.14 \%$ \\
$\mathrm{C} 2$ & $82.52 \%$ & $17.48 \%$ \\
$\mathrm{C} 3$ & $59.62 \%$ & $40.38 \%$ \\
$\mathrm{C} 4$ & $67.63 \%$ & $32.37 \%$ \\
\hline
\end{tabular}

The results of this experiment will be discussed together with the results from the self-paced reading task in Section 4.3.3.

\subsubsection{Experiment 3 - Principle C: an online study}

The results from Experiment 2 confirm the assumption that a coreferential reading is possible between the possessive pronoun modifying a noun and the R-expression in Serbian. Put differently, even though these possessive constructions are less common than forward anaphora, cataphoric pronoun resolution is possible in this language, like in English. Speakers of Serbian show sensitivity to Principle C violations with pronouns in subject position and R-expressions in object position, but not with possessive modifiers in subject position and an R-expression in object position. 
I conducted a self-paced reading task to corroborate the findings from Experiment 2 and to investigate how Serbian native speakers process cataphoric constructions with and without c-command. Experiment 3 aims at answering the following research questions:

Q1. Is there a gender mismatch effect (slowdown in reading times) at the R-expression in Serbian cataphoric constructions with the pronominal possessive in subject position?

Q2. Is this effect observed in both the no-constraint condition (possessives) and the Principle $\mathrm{C}$ condition (pronouns) or not?

H1. Following previous literature (Kazanina et al. 2007; Drummer and Felser 2018), and given the results of Experiment 2, I expect to find the gender mismatch effect in Serbian cataphoric constructions including a possessive pronoun in subject position and an R-expression in object position.

H2. Given that Experiment 2 has shown that Serbian speakers reject a coreferential reading with a pronoun in subject position and an R-expression in object position (violation of Principle C) as English speakers do, I expect that the gender mismatch influences RTs only in the no constraint conditions ( $\mathrm{C} 1$ and $\mathrm{C} 2)$, but not in the constraint conditions (C3 and C4). If we confirm a gender mismatch effect only in C2 as in Kazanina et al.'s (2007) findings, this would suggest that Principle C immediately restricts the active search in Serbian. On the other hand, if there is a slowdown both in $\mathrm{C} 2$ and $\mathrm{C} 4$, the results would support the analysis that Principle $\mathrm{C}$ acts as a late filter on the coreference assignment in line with Drummer and Felser (2018).

\subsubsection{Methodology}

A self-paced reading task (the moving window technique (Just et al. 1982)) was constructed in the online software IBEX farm, using PennController (Zehr and Schwarz 2018). The participants' task was to read sentences word-by-word at their own pace, and the reading times on each word were measured. By pressing the space bar, the next word appeared on the screen and the previous word disappeared. After having read each item, participants were asked to answer with yes or no to comprehension questions, in order to control that they were reading the sentences carefully.

\subsubsection{Participants}

Forty-six Serbian native speakers $(n=46)$ with normal or corrected-to-normal vision were recruited for Experiment 3. None of them participated in Experiment 2 in order to avoid a bias, since both experiments consisted of almost the same stimuli. Participants' age 
ranged from 18 to 34 years, with a mean age of 22.60 years. Most of the participants were students at the University of Novi Sad, Serbia. Therefore, most of them were from Novi Sad. Thirty-one of the participants were female. All participants gave their consent and they were paid for their participation.

\subsubsection{Design and Stimuli}

The design and stimuli for Experiment 3 were similar to Experiment 2. The design was 2-by-2 which lead to identical 4 conditions as in the previous experiment. There were 2 independent variables: (1) c-command with 2 levels: (a) no c-command (possessive) and (b) c-command (pronoun); (2) gender with 2 levels: (a) gender match and (b) gender mismatch. The dependent variable was reading time (RT) measured in milliseconds (ms). The items were divided into 4 lists using the Latin Square Design, so that each participant saw 1 item per condition. In total, there were 48 items per participant including test items $(\mathrm{N}=24)$ and fillers $(\mathrm{N}=24)$. The presentation sequence was randomized for each participant.

The stimuli consisted of two sentences. The first sentence included a main clause with the pronominal possessive modifying a noun/pronoun in subject position and a whileclause where a first antecedent was given. The second possible antecedent was provided in the second sentence. In case of the no c-command conditions, the possessive pronoun (njegov, 'his', or njen, 'her') modified a subject, which was always a name of a profession; in the c-command conditions, the pronoun on, 'he' or ona, 'she' was the subject of the first sentence, as in (26). This was different from Experiment 2, where sentences were with non-overt pronouns (pro), cf. (25) and (26). In the self-paced reading task, the overt pronoun was used in order to have approximately the same length of the sentences, since there is evidence from other self-paced reading studies showing that word and sentence length can affect reading times (Hopp 2016; Ibáñez et al. 2010 among others).

(25) $\quad$ Pro $_{i}$ čitao je slučaj dok je Dejan čekao u kancelariji. Filip $i$ je bio optimističan u vezi sa parnicom.

'Pro.he ${ }_{i}$ was reading the case while Dejan was waiting in the office. Filip ${ }_{i}$ was optimistic about the litigation.'

(26) $\quad \mathbf{O n}_{i}$ je čitao slučaj dok je Dejan čekao u kancelariji. Filip $i$ je bio optimističan u vezi sa parnicom.

' $\mathrm{He}_{i}$ was reading the case while Dejan was waiting in the office. Filip ${ }_{i}$ was optimistic about the litigation.'

Here in the stimuli, the critical word ( $1^{\text {st }}$ antecedent name) could not be at the same position in the sentence because the two structures (c-command vs. no c-command) differ, 
in $\mathrm{C} 1$ and $\mathrm{C} 2$ the subject is a noun modified by a possessor ( 2 words) as compared to $\mathrm{C} 3$ and $\mathrm{C} 4$ where the subject is a pronoun (1 word). If the pronoun was omitted, there would be a 2-word difference in the sentences, therefore the overt pronoun was included as it is important for the self-paced reading task to have the critical name almost at the same place, and the length of the critical area as close as possible in all conditions. The issue of length is addressed by using mixed-effects models with item as a random factor (Barr 2013; Cunnings 2012), which will be included in the statistical analysis in this study, as well. ${ }^{3}$ In this way, the critical word was at the $8^{\text {th }}$ position in $\mathrm{C} 1$ and $\mathrm{C} 2$ and at the $7^{\text {th }}$ position in $\mathrm{C} 3$ and $\mathrm{C} 4$. A sample of test items in all 4 conditions is given in Table 4.7.

Table 4.7: A sample of test items for Experiment 2

\begin{tabular}{|c|c|c|}
\hline & Condition & Item \\
\hline $\mathrm{C} 1$ & $\begin{array}{l}\text { No c-command } \\
\text { gender match }\end{array}$ & $\begin{array}{l}\operatorname{Njegov}_{i} \text { advokat je čitao slučaj dok je } \operatorname{Dejan}_{i} \check{c ̌ e k a o ~ u ~ k a n c e-} \\
\text { lariji. Filip je bio optimističan u vezi sa parnicom. } \\
\text { 'His }{ }_{i} \text { lawyer was reading the case while Dejan }{ }_{i} \text { was waiting } \\
\text { in the office. Filip was optimistic about the litigation.' }\end{array}$ \\
\hline $\mathrm{C} 2$ & $\begin{array}{l}\text { No c-command } \\
\text { gender mismatch }\end{array}$ & $\begin{array}{l}\text { Njen }_{i} \text { advokat je čitao slučaj dok je Dejan čekao u kance- } \\
\text { lariji. Elena }{ }_{i} \text { je bila optimistična u vezi sa parnicom. } \\
\text { 'Her }{ }_{i} \text { lawyer was reading the case while Dejan was waiting } \\
\text { in the office. Elena }{ }_{i} \text { was optimistic about the litigation.' }\end{array}$ \\
\hline C3 & $\begin{array}{l}\text { C-command } \\
\text { gender match }\end{array}$ & $\begin{array}{l}\text { On }_{i} \text { je čitao slučaj dok je Dejan čekao u kancelariji. Filip } \\
\text { je bio optimističan u vezi sa parnicom. } \\
\text { 'He }{ }_{i} \text { was reading the case while Dejan was waiting in the } \\
\text { office. Filip }{ }_{i} \text { was optimistic about the litigation.' }\end{array}$ \\
\hline $\mathrm{C} 4$ & $\begin{array}{l}\text { C-command } \\
\text { gender mismatch }\end{array}$ & $\begin{array}{l}\text { Ona }_{i} \text { je čitala slučaj dok je Dejan čekao u kancelariji. } \\
\text { Elena }_{i} \text { je bila optimistična u vezi sa parnicom. } \\
\text { 'She }{ }_{i} \text { was reading the case while Dejan was waiting in the } \\
\text { office. Elena }{ }_{i} \text { was optimistic about the litigation.' }\end{array}$ \\
\hline
\end{tabular}

Note. Pronominal possessives and pronouns are given in bold. The underlined name indicates the critical word (first possible antecedent). Subscript indices indicate intended cataphoric dependencies.

The number of antecedents was the same as in Experiment 2: the first possible an-

\footnotetext{
${ }^{3} \mathrm{~A}$ few informants were asked to judge the sentences with overt (not stressed) and non-overt pronouns in subject position in respect to coreferential possibilities with an R-expression, and no crucial differences were observed. Therefore, I decided to use the overt pronoun in the self-paced reading task because of the number of words, even though the non-overt variant was used in the offline study. Still, a further self-paced reading experiment could be conducted with both overt and non-overt pronouns to corroborate this claim.
} 
tecedent appeared in a while-clause, whereas the second one was in the second sentence. Gender match/mismatch is an important factor in the online task, because a slowdown at the critical word in gender mismatch conditions would reveal a difference in the processing of structures with and without a syntactic constraint (C-command). Male-female gender was equally distributed across the items, both with respect to the names and professions to balance the stimuli. All the names in a sentence were of a same length in order to control that potential differences in RTs are not due to the differences in length (Hopp 2016; Ibáñez et al. 2010). Both male and female names were common Serbian names and they consisted of 5 to 7 letters. For professions, it was ensured that they have more or less the same length as well (from 6 to 9 characters) for the same reason. Also, the professions were chosen in a way that it is possible to modify them with a possessive, i.e. 'her hairdresser'. The length of the sentence was always the same up to the first antecedent (the critical word) across the items. After the critical word, the length of the sentences was not uniform, in order to prevent that the sentences sounded too artificial.

Fillers resembled the test items, but they did not include possessive pronouns, see Table 4.8.

Table 4.8: A sample of filler items - Experiment 3

\begin{tabular}{|c|c|c|}
\hline & Condition & Item \\
\hline $\mathrm{F} 1$ & $\begin{array}{l}\text { overt } \\
\text { gender match }\end{array}$ & $\begin{array}{l}\text { Kada je Đorđe došao u bioskop, on je kupio kokice. Marko } \\
\text { je jedva čekao da počne film. } \\
\text { 'When Đorđe came to the cinema, he bought popcorn. } \\
\text { Marko couldn't wait for movie to start.' }\end{array}$ \\
\hline $\mathrm{F} 2$ & $\begin{array}{l}\text { non-overt } \\
\text { gender match }\end{array}$ & $\begin{array}{l}\text { Kada je Đorđe došao u bioskop, kupio je kokice. Marko je } \\
\text { jedva čekao da počne film. } \\
\text { 'When Đorđe came to the cinema, he.pro bought popcorn. } \\
\text { Marko couldn't wait for movie to start.' }\end{array}$ \\
\hline F3 & $\begin{array}{l}\text { overt } \\
\text { gender mismatch }\end{array}$ & $\begin{array}{l}\text { Kada je Đorđe došao u bioskop, ona je kupila kokice. Ivona } \\
\text { je jedva čekala da počne film. } \\
\text { 'When Đorđe came to the cinema, she bought popcorn. } \\
\text { Ivona couldn't wait for movie to start.' }\end{array}$ \\
\hline F4 & $\begin{array}{l}\text { non-overt } \\
\text { gender mismatch }\end{array}$ & $\begin{array}{l}\text { Kada je Đorđe došao u bioskop, kupila je kokice. Ivona je } \\
\text { jedva čekala da počne film. } \\
\text { 'When Đorđe came to the cinema, she.pro bought popcorn. } \\
\text { Ivona couldn't wait for movie to start.' }\end{array}$ \\
\hline
\end{tabular}


The filler items also consisted of two sentences, including two names. The first sentence started with a when-clause, where the first name was mentioned, and the second clause either had an overt or non-overt (gender matching) pronoun. The second sentence included either a male or a female name.

Each item was followed by a yes/no comprehension question. The comprehension questions were not aimed at resolving the coreference, their goal was to ensure that participants read the sentences carefully and understood what they read. Since the purpose of comprehension questions was about keeping the concentration on the reading task, questions were clear and not difficult to answer (see examples in Table 4.9).

Table 4.9: A sample of comprehension questions - Experiment 3

\begin{tabular}{|c|c|c|}
\hline Test item & $\begin{array}{l}\text { Comprehension ques- } \\
\text { tion }\end{array}$ & $\begin{array}{l}\text { Correct } \\
\text { answer }\end{array}$ \\
\hline $\begin{array}{l}\text { Njegov menadžer je pričao sa fanovima dok je Jovan } \\
\text { potpisivao autograme. Petar je bio srećan što je kon- } \\
\text { cert uspešno završen. } \\
\text { His manager talked to the fans while John signed au- } \\
\text { tographs. Peter was happy that the concert ended } \\
\text { successfully. }\end{array}$ & $\begin{array}{l}\text { Da li je Jovan odbio da } \\
\text { potpiše autograme? } \\
\text { Did John refuse to sign } \\
\text { autographs? }\end{array}$ & NE \\
\hline $\begin{array}{l}\text { Ona je slala mejlove dok je Sandra slušala muziku. } \\
\text { Sofija je bila umorna od gledanja u monitor. }\end{array}$ & $\begin{array}{l}\text { Da li je Sofija bila } \\
\text { umorna od trčanja? }\end{array}$ & NE \\
\hline $\begin{array}{l}\text { She was sending emails while Sandra was listening } \\
\text { to music. Sofia was tired from staring at the screen. }\end{array}$ & $\begin{array}{l}\text { Was Sofia tired from } \\
\text { running? }\end{array}$ & NO \\
\hline $\begin{array}{l}\text { On je krečio zid dok je Stojan pevušio melodiju iz } \\
\text { filma. Vedranu se svidela nova boja sobe. }\end{array}$ & $\begin{array}{l}\text { Da li je Stojan pevušio } \\
\text { melodiju iz filma? }\end{array}$ & DA \\
\hline $\begin{array}{l}\text { He was painting the wall while Stojan was singing a } \\
\text { movie theme song. Vedran liked the new room colour. }\end{array}$ & $\begin{array}{l}\text { Was Stojan singigng a } \\
\text { movie theme song? }\end{array}$ & YES \\
\hline $\begin{array}{l}\text { Ona je pregledala dokumentaciju dok je Gordana } \\
\text { razgovarala sa zaposlenima. Dragana se radovala } \\
\text { novom projektu. }\end{array}$ & $\begin{array}{l}\text { Da li se Dragana } \\
\text { radovala novom pro- } \\
\text { jektu? }\end{array}$ & DA \\
\hline $\begin{array}{l}\text { She was checking the documents while Gordana was } \\
\text { talking to the employees. Dragana was looking for- } \\
\text { ward to the new project. }\end{array}$ & $\begin{array}{l}\text { Was Dragana looking } \\
\text { forward to the new } \\
\text { project? }\end{array}$ & YES \\
\hline
\end{tabular}

Note. The clauses in italics represent the parts related to the comprehension questions. 
Half of the questions were about the while-clause, and the other half were related to the second sentence, so that participants did not expect questions about the last sentence or a specific part of the sentence. This way, their attention span was increased and made them read sentences more carefully without skipping certain parts of the sentences. The number of yes/no answers was balanced, i.e. $50 \%$ of correct answers was yes, and $50 \%$ was no.

\subsubsection{Procedure}

As in the previous experiments, the participants were first asked to write their personal information and they were informed about data privacy and all of them gave their consent. Next, the participants were instructed how to do the experiment. There were 6 practice items in order to familiarize the participants with the task. Three items were simple sentences with an aim to accustom them to read word by word (e.g. 'This is a trial sentence to get used to reading sentences like this'). The other three sentences resembled the stimuli and were followed by comprehension questions in order to indicate that there will be a comprehension question after each item and to show how they are supposed to answer the questions. When the trial section ended, the participants clicked on the button to proceed with the experiment. After they conducted the experiment, they signed the sheet with their names, email and that they received money for the participation in the study.

Participants were tested individually in person and the experiment lasted around 20 minutes. The stimuli were presented on a standard PC configuration (Pentium(R) DualCore CPU E6600 processor/3.06GHz/2.00 GB RAM, with a monitor set to $75 \mathrm{~Hz}$ vertical refresh rate and 1920x1080 pixels resolution). The moving window technique, i.e. a noncumulative linear display was used to present the stimuli. All the words in the sentence first appeared on the screen masked by a series of dashes, and when the space bar was pressed, the first word in the sentence appeared. Each time when the space bar was pressed, the next word appeared and the previous word was hidden. Only one word was always visible at a time (see picture (a) in Figure 4.3).

Each test and filler item was followed by a yes/no comprehension question to make sure that the participants were paying attention to the stimuli. Participants answered the questions by pressing 1 or 2 on the keyboard. They were instructed to read the sentences for themselves as quickly as possible, but in a way that they still understand the content. If they answered the question incorrectly, a warning message appeared on the screen, so that the participants would pay more attention to reading the sentences and to answering the questions more carefully (as shown in Figure 4.3). Between the two items the sentence 'Please wait for the next sentence' appeared at the centre of the screen. The order of experimental and filler items was randomized for each participant. 
Figure 4.3: Self-paced reading task procedure

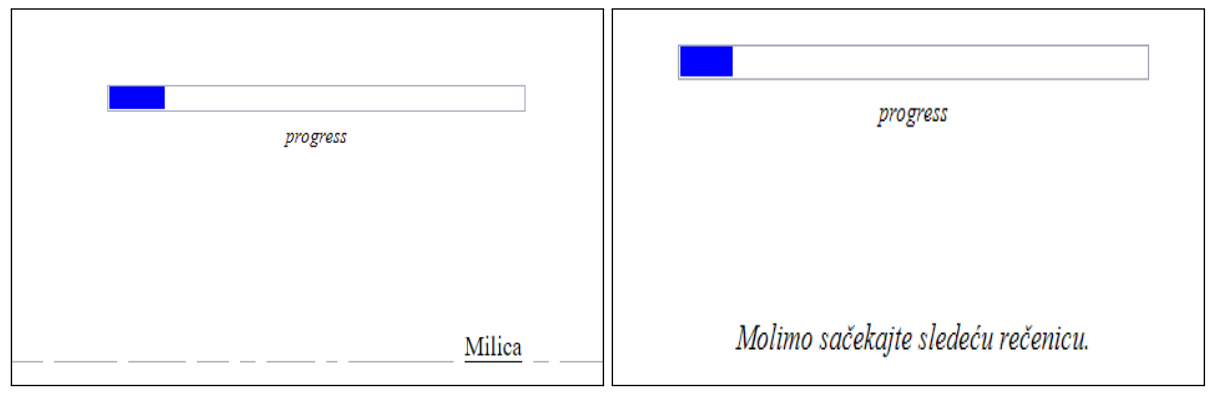

'Please wait for the next sentence.'

(a) Reading word-by-word

(b) The sentence between stimuli

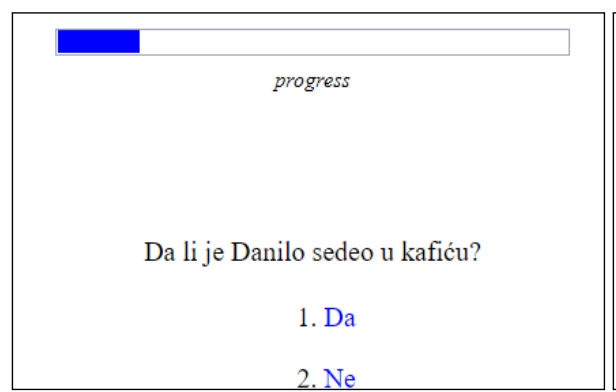

'Was Danilo sitting in the cafe?

1. Yes 2. No'

(c) A comprehension question

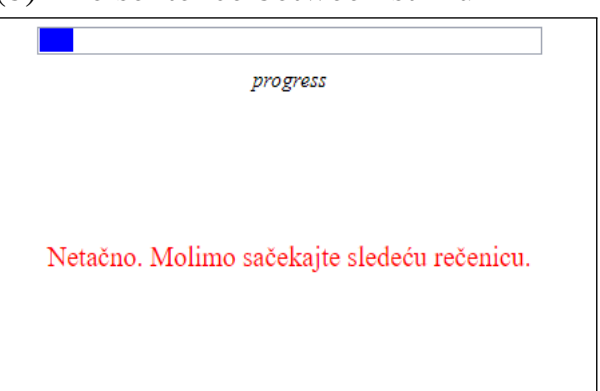

'Incorrect. Please wait for the next sentence.'

(d) A warning message

\subsubsection{Results}

Analyses were carried out in R (Team 2013), using the lme4 package for linear mixedeffects models (Bates et al. 2014) and the lmerTest package (Kuznetsova et al. 2014).

\section{Data preparation.}

The comprehension questions' mean accuracy for test items was $90.8 \%$ and question accuracy did not statistically differ across conditions ( $87 \%-93.8 \%$ for individual conditions). Concerning the accuracy of filler items, the mean accuracy of their comprehension questions was checked in order to confirm if there were any participants with low accuracy that should be removed from the further analysis. ${ }^{4}$ The comprehension questions' mean accuracy of filler items was $93.1 \%$ (range from $92 \%-95.7 \%$ for individual conditions). The data from all participants were included in the analysis, given that the lowest accuracy of one participant was $79.2 \%$ in the comprehension questions, and all others had higher accuracy rates. Therefore, the data from all 46 participants could be analysed. However, due to a mistake in the test item 24 , in which one word was accidentally omitted

\footnotetext{
${ }^{4}$ The accuracy of comprehension questions of fillers, and not of the test items was considered for excluding the possible outliers. If the accuracy of participants was lower for test items, this might suggest that they answered incorrectly because these specific items were more difficult and did not necessarily represent a mistake due to a misunderstanding, lack of effort etc., and this effect and data points should not be lost.
} 
before the critical word, this item was excluded from the analysis. ${ }^{5}$ Reaction times (RTs) that were longer than $3000 \mathrm{~ms}$ or shorter than $150 \mathrm{~ms}$ were excluded after looking at the distribution of the data points, assuming that these are extreme values that occur either because the participant did not pay attention or was interrupted for some reason during the experiment. This means that $0.4 \%$ of the data were excluded.

The Kolmogorov-Smirnov test, used to check for the normality of the distribution, was significant. Since the distribution was not normal, the reaction times needed to be transformed. The reaction times were log-transformed in accordance with the recommendations described in Baayen and Milin (2010). In parallel to previous studies (Kazanina et al. 2007), the region of interest was the first antecedent in the while-clause. More precisely, that was region 8 for $\mathrm{C} 1$ and $\mathrm{C} 2$, and region 7 for $\mathrm{C} 3$ and $\mathrm{C} 4$. In the following examples, the name Dejan is the critical word, and it is illustrated at which position it is in each condition. The reaction times will be calculated for the critical name (N1) and for the word immediately following it (N2).

(27) $\operatorname{Njegov}_{i}$ advokat je čitao slučaj dok je Dejan $_{i}$ čekao u kancelariji. Filip je bio

$\begin{array}{lllllllllllll}1 & 2 & 3 & 4 & 5 & 6 & 7 & 8 & 9 & 10 & 11 & 12 & 1314\end{array}$

optimističan u vezi sa parnicom.

$15 \quad 1617 \quad 1819$

'His ${ }_{i}$ lawyer was reading the case while Dejan ${ }_{i}$ was waiting in the office. Filip was optimistic about the litigation.'

(28) $\quad \mathrm{Njen}_{i}$ advokat je čitao slučaj dok je Dejan čekao u kancelariji. Elena $i$ je bila

$\begin{array}{lllllllllllll}1 & 2 & 3 & 4 & 5 & 6 & 7 & 8 & 9 & 10 & 11 & 12 & 1314\end{array}$

optimistična u vezi sa parnicom.

$15 \quad 1617 \quad 1819$

'Her ${ }_{i}$ lawyer was reading the case while Dejan was waiting in the office. Elena was optimistic about the litigation.'

(29) $\mathrm{On}_{i}$ je čitao slučaj dok je Dejan čekao u kancelariji. Filip $i$ je bio optimističan

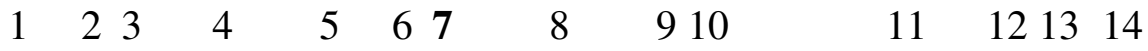

u vezi sa parnicom.

$1516 \quad 1718$

' $\mathrm{He}_{i}$ was reading the case while Dejan was waiting in the office. Filip $i$ was optimistic about the litigation.'

(30) $\quad$ Ona $_{i}$ je čitala slučaj dok je Dejan čekao u kancelariji. Elena ${ }_{i}$ je bila

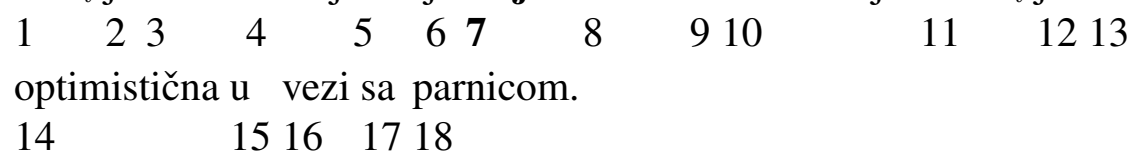

\footnotetext{
${ }^{5}$ This item was excluded because the position of the critical word (R-expression) would not be at the same place anymore, and this would affect the analysis, since the specific regions of interest are compared.
} 
'She ${ }_{i}$ was reading the case while Dejan was waiting in the office. Elena ${ }_{i}$ was optimistic about the litigation.'

Two-way contrasts $(0.5-, 0.5)$ were coded: possessive vs. pronoun for the factor C-command and match vs. mismatch for the factor Gender. Following current psycholinguistics literature (Barr 2013), a maximal model including random intercepts and slopes for all fixed effects and their interaction was constructed first. Given that it failed to converge, the random effects structure was simplified step by step in order to find the best final model. The results from the final model (Formula: m1a $=\operatorname{lmer}(\operatorname{logRT} \sim$ Ccommand * Gender +( 1 I subject $)+(1$ I sentence $)$, control = lmerControl(optimizer="bobyqa"), N1data, REML=FALSE)) are reported in Table 4.10.

Table 4.10: Linear Mixed-Effects Regression - the final model at the critical word region (N1)

\begin{tabular}{lccccc}
\hline Fixed effects & \multicolumn{7}{l}{} \\
\hline & Estimate & Std. Error & df & t value & $\operatorname{Pr}(>|\mathrm{t}|)$ \\
\hline (Intercept) & 6.16 & 0.04 & 49.87 & 145.52 & $<2 \mathrm{e}-16 * * *$ \\
$\begin{array}{l}\text { Ccommand1 } \\
\text { (possessive vs. pronoun) }\end{array}$ & -0.07 & 0.02 & 993.90 & -3.73 & $0.00021^{* * *}$ \\
$\begin{array}{l}\text { Gender1 } \\
\text { (match vs. mismatch) }\end{array}$ & 0.06 & 0.02 & 991.94 & 2.99 & $0.00286 * *$ \\
Ccommand1: Gender1 & -0.10 & 0.04 & 993.58 & -2.56 & $0.01074 *$ \\
\hline
\end{tabular}

Note. $* \mathrm{p}<.05 ; * * \mathrm{p}<.01 ; * * * \mathrm{p}<.001$.

There was a main effect of both conditions, C-command $(\mathrm{p}<.001)$ and Gender $(\mathrm{p}<$ $.01)$, and their interaction was statistically significant $(\mathrm{p}<.05)$.

Because the interaction was significant, I created two further models with pairwise comparisons to analyze for which level the effect holds, i.e. to disentangle the effect of gender and c-command on the interaction.

The first model aimed to examine the role of C-command on each Gender level, i.e. to look closer whether there is a difference between possessive and pronoun for the gender match or mismatch condition. The formula was the following: m1inta $=$ lmer(rt $\sim$ Gender + Gender:Ccommand + $(1$ | subject $)+(1$ I sentence $)$, control = lmerControl(optimizer="bobyqa"), N1data, REML=FALSE). The results are reported in Table 4.11 . 
Table 4.11: The role of C-command on each Gender level (N1)

\begin{tabular}{lccccc}
\hline Fixed effects & \multicolumn{7}{l}{} \\
\hline & Estimate & Std. Error & df & t value & $\operatorname{Pr}(>|\mathrm{t}|)$ \\
\hline (Intercept) & 519.5 & 22.7 & 50.0 & 22.88 & $<2 \mathrm{e}-16 * * *$ \\
Gender1 & 29.9 & 12.7 & 992.2 & 2.35 & $0.0189 *$ \\
(match vs. mismatch) & & & & & \\
Match:Ccommand1 & -17.1 & 18.0 & 994.1 & -0.95 & 0.3421 \\
Mismatch:Ccommand1 & -52.1 & 18.0 & 994.1 & -2.89 & $0.0039 * *$ \\
\hline
\end{tabular}

Note. Match:Ccommand $1=$ possessive match $(\mathrm{C} 1)$ vs. pronoun match $(\mathrm{C} 3)$

Mismatch:Ccommand $1=$ possessive mismatch $(\mathrm{C} 2)$ vs. pronoun mismatch $(\mathrm{C} 4)$

$* \mathrm{p}<.05 ; * * \mathrm{p}<.01 ; * * * \mathrm{p}<.001$.

The difference between possessive and pronoun is not significant for the gender match condition, but it is significant for the gender mismatch condition $(p<.01)$. This means that the RTs for the possessive are significantly higher than those of the pronoun when the gender did not match (C2 vs. $\mathrm{C} 4)$, whereas there is no difference in the gender matching conditions ( $\mathrm{C} 1$ and $\mathrm{C} 3)$.

Next, the difference between match and mismatch for the possessive and pronoun conditions was examined (Formula: $\mathrm{m} 1$ intb $=\operatorname{lmer}(\mathrm{rt} \sim$ Ccommand + Gender:Ccommand + $(1$ । subject $)+(1$ । sentence $)$, control = lmerControl (optimizer="bobyqa"), N1data, REML=FALSE)) in Table 4.12.

Table 4.12: The role of Gender on each C-command level (N1)

\begin{tabular}{lccccc}
\hline Fixed effects & \multicolumn{7}{l}{} \\
\hline & Estimate & Std. Error & df & t value & $\operatorname{Pr}(>|\mathrm{t}|)$ \\
\hline (Intercept) & 519.5 & 22.7 & 50.0 & 22.88 & $<2 \mathrm{e}-16^{* * *}$ \\
Ccommand1 & -34.6 & 12.7 & 994.3 & -2.72 & $0.0067^{* *}$ \\
(possessive vs. pronoun) & & & & & \\
Poss:Gender1 & 47.4 & 18.0 & 992.9 & 2.63 & $0.0086^{* *}$ \\
Pron:Gender1 & 12.4 & 18.0 & 993.2 & 0.69 & 0.4904 \\
\hline
\end{tabular}

Note. Poss:Gender1 = poss match $(\mathrm{C} 1)$ vs. poss mismatch $(\mathrm{C} 2)$;

Pron:Gender1 $=$ pron match $(\mathrm{C} 3)$ vs. pron mismatch $(\mathrm{C} 4)$;

$* \mathrm{p}<.05 ; * * \mathrm{p}<.01 ; * * * \mathrm{p}<.001$.

The results suggest that there is a significant difference between match and mismatch 
for possessives $(\mathrm{p}<.01)$. There is no significant effect of gender for the pronoun condition (C4). This means that the gender mismatch is only influencing RTs in the possessive condition $(\mathrm{C} 2)$, and not in the condition with the pronoun $(\mathrm{C} 4)$.

The same trend is confirmed by a post-hoc Tukey Test. There was a significant difference between possessive mismatch $(\mathrm{C} 2)$ and pronoun mismatch $(\mathrm{C} 4)(\mathrm{t}=4.430$; $\mathrm{p}<.0001$ ) in the expected direction (longer reaction times are observed for $\mathrm{C} 2-\mathrm{M}=$ $558 \mathrm{~ms}$ than for $\mathrm{C} 4-\mathrm{M}=511 \mathrm{~ms}$ ); and a significant difference between possessive gender match $(\mathrm{C} 1-\mathrm{M}=515 \mathrm{~ms})$ and possessive gender mismatch $(\mathrm{C} 2-\mathrm{M}=558 \mathrm{~ms})(\mathrm{t}=-3.920$; $\mathrm{p}<.001)$ in the expected direction. However, there was no significant difference between pronoun gender match and pronoun gender mismatch $-\mathrm{C} 3$ vs. $\mathrm{C} 4(\mathrm{t}=-0.310 ; \mathrm{p}=.99)$. This shows that gender mismatch slows down the reading time of the critical word only in the no-constraint condition, but not when there is a principle $\mathrm{C}$ violation. The Table with all pairwise comparisons is given in Appendix $\mathrm{C}$. The average reading times on the critical word (N1) are illustrated for all 4 conditions in Figure 4.4, using the package ggplot2 (Wickham 2011).

Figure 4.4: Average reading times on the critical word per condition (N1)

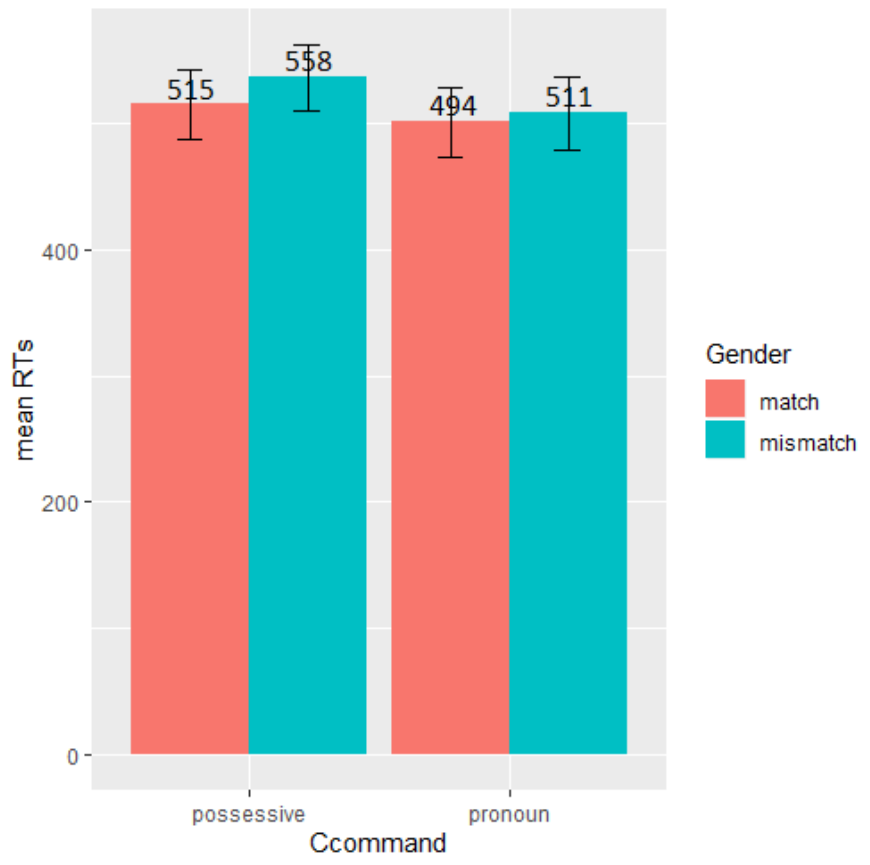

Given that the critical word was a proper name that could either corefer or not corefer with the pronominal possessive or pronoun that occurred at the beginning of the sentence, the surprisal that the pronominal possessive or the pronoun does not match the gender of the certain name, might postpone the gender effect. Thus, the gender mismatch effect could be visible on the words following the critical word as well, so RTs were calculated for the critical word and the word immediately following the name (name +1$)$ to check 
the spillover effect of the factors (N2).

The data were analysed in the same way as in the case of the data on the critical word (N1). The maximal model failed to converge. The final model was the same as for the critical region: $\mathrm{m} 2 \mathrm{a}=\operatorname{lmer}(\log \mathrm{RT} \sim$ Ccommand $*$ Gender $+(1$ I subject $)+(1$ I sentence $)$, control = lmerControl(optimizer="bobyqa"), N2data, REML=FALSE).

Table 4.13: Linear Mixed-Effects Regression - the final model at the spillover region (N2)

\begin{tabular}{lccccc}
\hline Fixed effects & \multicolumn{7}{l}{} \\
\hline & Estimate & Std. Error & df & t value & $\operatorname{Pr}(>|\mathrm{t}|)$ \\
\hline (Intercept) & 6.17 & 0.04 & 51.91 & 162.67 & $<2 \mathrm{e}-16 * * *$ \\
$\begin{array}{l}\text { Ccommand1 } \\
\text { (possessive vs. pronoun) }\end{array}$ & -0.04 & 0.01 & 2051.30 & -2.64 & $0.0083^{* *}$ \\
$\begin{array}{l}\text { Gender1 } \\
\text { (match vs. mismatch) }\end{array}$ & 0.04 & 0.01 & 2048.57 & 2.84 & $0.0045^{* *}$ \\
Ccommand1:Gender1 & -0.07 & 0.03 & 2050.90 & -2.60 & $0.0093^{* *}$ \\
\hline
\end{tabular}

Note. ${ }^{*} \mathrm{p}<.05 ; * * \mathrm{p}<.01 ; * * * \mathrm{p}<.001$.

The statistical analysis revealed a significant main effect for the factors C-command and Gender $(\mathrm{p}<.01)$ (see Table 4.13). The interaction between the factors was statistically significant $(\mathrm{p}<.01)$ as for the analysis at the critical word.

Again, I examined how Gender and C-command influenced the interaction. First, the analysis of the role of C-command on each Gender level $(\mathrm{m} 3 \mathrm{a}=\operatorname{lmer}(\mathrm{rt} \sim \mathrm{Gen}-$ der + Gender:Ccommand + (1 I subject $)+(1$ I sentence $)$, control = lmerControl (optimizer="bobyqa"), N2data, REML=FALSE)) yielded the fixed effect in Table 4.14.

Table 4.14: The role of C-command on each Gender level (N2)

\begin{tabular}{lccccc}
\hline Fixed effects & \multicolumn{7}{l}{} \\
\hline & Estimate & Std. Error & df & t value & $\operatorname{Pr}(>|t|)$ \\
\hline (Intercept) & 526.49 & 20.50 & 52.87 & 25.68 & $<2 \mathrm{e}-16 * * *$ \\
Gender1 & 17.91 & 9.51 & 2048.84 & 1.88 & 0.060. \\
$\begin{array}{l}\text { (match vs. mismatch) } \\
\text { Match:Ccommand1 }\end{array}$ & 1.02 & 13.43 & 2051.49 & 0.08 & 0.940 \\
Mismatch:Ccommand1 & -31.88 & 13.47 & 2051.62 & -2.37 & $0.018 *$ \\
\hline
\end{tabular}

Note. Match:Ccommand $1=$ possessive match $(\mathrm{C} 1)$ vs. pronoun match $(\mathrm{C} 3)$

Mismatch:Ccommand $1=$ possessive mismatch $(\mathrm{C} 2)$ vs. pronoun mismatch $(\mathrm{C} 4)$

$. \mathrm{p}<.1 ; * \mathrm{p}<.05 ; * * * \mathrm{p}<.001$. 
The results show that the effect of $\mathrm{C}$-command (the difference between possessives and pronouns) is significant for Gender mismatch $(\mathrm{p}<.05)$, but not for Gender match.

Next, the difference between match and mismatch for the possessive and pronoun conditions was examined. The formula used was $\mathrm{m} 3 \mathrm{~b}=\operatorname{lmer}(\mathrm{rt} \sim \mathrm{Ccom}-$ mand + Gender:Ccommand + (1 | subject $)+(1$ | sentence $)$, mcontrol = lmerControl(optimizer="bobyqa"), N2data), and the results are illustrated in Table 4.15.

Table 4.15: The role of Gender on each C-command level (N2)

\begin{tabular}{lccccc}
\hline Fixed effects & \multicolumn{7}{l}{} \\
\hline & Estimate & Std. Error & df & t value & $\operatorname{Pr}(>|\mathrm{t}|)$ \\
\hline (Intercept) & 526.49 & 20.70 & 51.82 & 25.44 & $<2 \mathrm{e}-16 * * *$ \\
C-command1 & -15.43 & 9.52 & 2048.84 & -1.62 & 0.105 \\
(possessive vs. pronoun) & & & & & \\
Poss:Gender1 & 34.37 & 13.45 & 2046.98 & 2.56 & $0.011 *$ \\
Pron:Gender1 & 1.46 & 13.46 & 2047.41 & 0.11 & 0.914 \\
\hline
\end{tabular}

Note. Poss:Gender1 = poss match $(\mathrm{C} 1)$ vs. poss mismatch $(\mathrm{C} 2)$;

Pron:Gender $1=$ pron match $(\mathrm{C} 3)$ vs. pron mismatch $(\mathrm{C} 4)$;

$* \mathrm{p}<.05 ; * * * \mathrm{p}<.001$

The results reveal that the difference between match and mismatch is significant for the possessive $(\mathrm{p}<.05)$, but not for the pronoun. This means that the gender mismatch effect is observed only in $\mathrm{C} 2$, where coreference is possible.

Tukey Test supports these results: the same patterns were observed as in the case of the critical word only (N1): there was a significant difference between $\mathrm{C} 2$ and $\mathrm{C} 4$ in the expected direction - possessive mismatch $(\mathrm{C} 2-\mathrm{M}=549 \mathrm{~ms})$ took longer to read than pronoun mismatch $(\mathrm{C} 4-\mathrm{M}=522 \mathrm{~ms})(\mathrm{t}=3.700 ; \mathrm{p}<.001)$; significant difference between $\mathrm{C} 1$ and $\mathrm{C} 2$ as well - lower reading times for possessive gender match $\mathrm{C} 1(\mathrm{M}=518 \mathrm{~ms})$ than for possessive gender mismatch $\mathrm{C} 2(\mathrm{M}=549 \mathrm{~ms})(\mathrm{t}=-3.850 ; \mathrm{p}<.001)$. However, there was no significant difference between pronoun gender match $(\mathrm{C} 3-\mathrm{M}=516)$ and pronoun gender mismatch $(\mathrm{C} 4-\mathrm{M}=522 \mathrm{~ms})(\mathrm{t}=-0.170 ; \mathrm{p}=.99)$. The results reveal that an effect of gender mismatch is present only in the comparison between no-constraint conditions with possessives ( $\mathrm{C} 1$ vs. $\mathrm{C} 2$ ), but not between Principle $\mathrm{C}$ conditions with pronouns (C3 vs. C4). The table with the results from the post-hoc Tukey Test is provided in Appendix C.

The average reading times (RTs) of N2data (critical word +1 word) are illustrated in Figure 4.5 below, using the package ggplot2 (Wickham 2011). 
Figure 4.5: Average reading times at the spillover region per condition (N2)

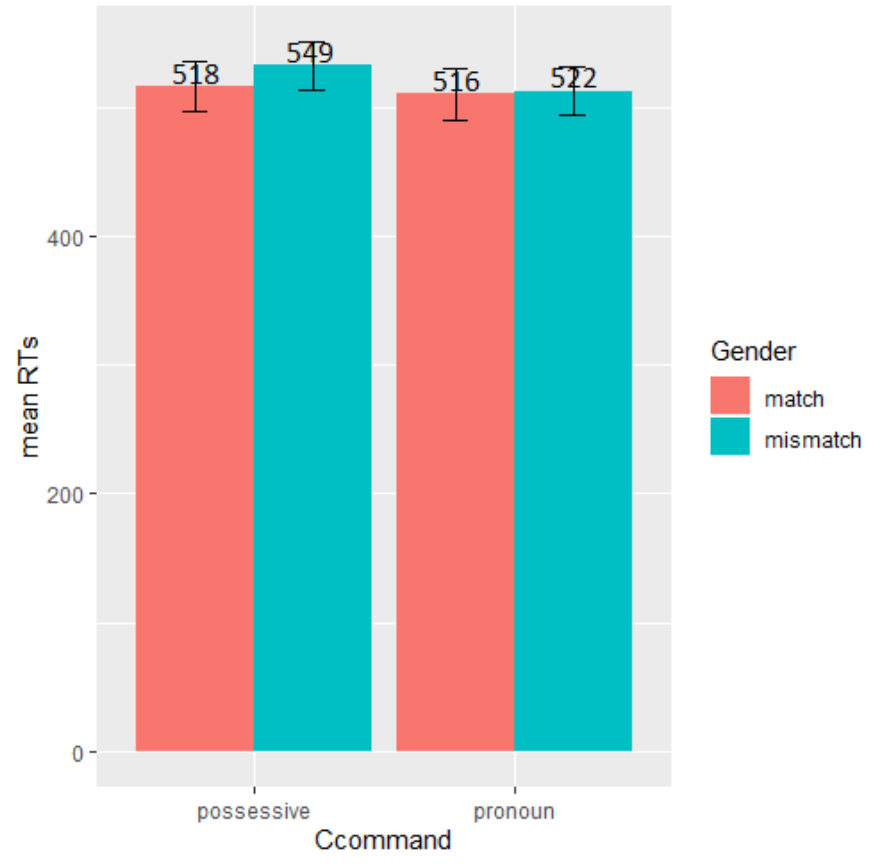

In the next section, the result of both offline and online experiments are discussed.

\subsubsection{Summary of the results of Experiments 2 and 3}

Experiment 2 addressed the question whether coreference is possible between a pronominal possessive modifying a noun in subject position and an R-expression in a ForcedChoice task.

As expected, coreference between pronouns and names was strongly disregarded (chosen only in $0.95 \%$ of cases) in condition C3 (c-command, gender match 'Pro.he ${ }_{i} \ldots$ while $\operatorname{Dejan}_{i}{ }^{\prime}$ ). However, in the crucial condition with the pronominal possessive - $\mathrm{C} 1$ (no c-command, gender match, 'His ${ }_{i}$ lawyer... while Dejan $_{i}$ '), the coreferential interpretation between possessives and names was an option in $58.57 \%$.

It could be expected that the number of choices was even higher, but the result was probably affected by the presence of forward anaphora which are a more common way to express coreference because the referent is recovered from memory, while backward anaphora include a search for an upcoming antecedent (Kazanina et al. 2007). In addition, it is also more natural to start a sentence with a (possessive) name than with a (possessive) pronoun out of the blue. However, the results confirm that it is still possible to match the cataphoric possessive pronoun with the corresponding antecedent and to get a coreferential relation between them. Recall that under the judgments from previous studies (Despić 2013; LaTerza 2016) the coreferential reading in C1 should be ruled out as in C3. Hence, the results of Experiment 2 show that the participants chose coreferential reading only in 
case of $\mathrm{C} 1$, between the R-expression and the gender matching possessive pronoun. The finding is in line with the hypothesis that there is a clear difference between the structure of possessives modifying a noun and pronouns in subject position and their ability to bind the R-expression in object position which results from the position of the possessive within the noun phrase structure, as discussed in Chapter 2.

The results from Experiment 2 are in line with previous offline studies for English and German (Kazanina et al. 2007; Drummer and Felser 2018), but not consistent with Despić's (2013) analysis of Serbian. The findings suggest that there is an effect of ccommand on the choice of coreference in Serbian. The fact that the structure with the possessive modifier in subject position is indeed selected with the coreferential reading, contrary to the structure with the pronoun in subject position further indicates that they have different structures in Serbian. It suggests that the possessive does not reach the (outmost) specifier position of the noun phrase, that it cannot c-command nor bind the $\mathrm{R}$-expression, and that there is no violation of Principle $\mathrm{C}$ in Serbian. Hence, Serbian patterns with English and German, where it is assumed that the possessive pronoun 'his' is located below the DP (Kayne 1994). Ultimately, the assumption of an intervening DP projection or another functional projection XP would support Serbian data as well, if we assume that the pronominal possessive occupies a lower specifier position such as SpecAgrP, as assumed for lexical possessives (see the structure in (108) in Section 2.2.4).

In order to add more experimental evidence from online processing, a self-paced reading test was conducted, following the methodology by Kazanina et al. (2007). Fortysix Serbian native speakers participated in this experiment in order to examine if they engage in an active search following the encounter of a cataphoric pronoun in the same way as in English, and whether Principle $\mathrm{C}$ restricts this search. Experiment 3 aimed at answering whether a gender mismatch effect can be observed at the R-expression in Serbian cataphoric constructions when the pronominal possessive or the pronoun is in subject position; and whether such an effect can be observed in the case of both the noconstraint condition (possessives) and the Principle $\mathrm{C}$ condition (pronouns).

The results from Experiment 3 show that both at the critical word region (N1) and at the spillover region (N2) both factors - C-command and Gender - were statistically significant, as well as their interaction. The interaction was only significant between gender mismatch and $\mathrm{C}$-command, but not between gender match and $\mathrm{C}$-command. This finding suggests that a gender mismatch effect is observed in Serbian cataphoric constructions. In the case of the effect of C-command on the interaction between c-command and gender, the factor was significant for N1, but not for N2 data, which indicates that the effect was weaker at the spillover region. At both regions, the interaction between possessives and gender was statistically significant, but the interaction between pronouns and gender was not. The results show that there is an effect of gender mismatch only with possessives and 
only when coreference is possible. The results of Experiment 3 have shown that there is a difference between subjects consisting of the pronominal possessive modifying a noun (no constraint) and pronouns (constraint) in Serbian. This means that the results are in line with previous studies for English (Kazanina et al. 2007). Therefore, given that the gender mismatch effect was found in these structures and assuming that it relates to a syntactic constraint, it can be concluded that possessives do not c-command out of the noun phrase and do not cause a violation of Binding Principle $\mathrm{C}$.

The self-paced reading task shows that participants slowed down at the critical word only when they encountered gender mismatch in the no-constraint condition because they were searching for a possible antecedent, which matched the possessive 'his' or 'her' at the beginning of the sentence. This finding goes in line with Kazanina et al.'s (2007) conclusion that Principle $\mathrm{C}$ immediately restricts active search processes, but not with Drummer and Felser's (2018) results showing that this effect is found at the later stage of processing. One of the reasons for the discrepancy of the results could be the fact that in their online study, Drummer and Felser (2018) used a different methodology - eyetracking, a method by which more fine-grained details and observations are available, as it is possible for participants to reread parts of the sentences. In the self-paced reading task as used here and in Kazanina et al.'s (2007) study, only one word is visible at the time, and the other words are hidden, so it is impossible to go back to previous words.

The findings from both experiments are compatible with the noun phrase structure assumed in Chapter 2, namely with the assumption that possessives are located in the Spec of AgrP below a higher projection XP/DP, which 'bans' c-command out of this phrase. As a result, coreference between the pronominal possessive and the R-expression in object position is possible because no violation of Principle $\mathrm{C}$ arises.

All of this will be discussed in more detail in the General Discussion in Chapter 5, in which all pieces of the conclusion are summed up together. 


\section{Chapter 5}

\section{General discussion}

The results of both experimental studies show that coreference between lexical possessives in subject position and pronouns in object position is possible, as well as between pronominal possessives in subject position and R-expressions. Recall that according to Despić (2013) and LaTerza (2016) structures like (1) and (2) were ruled out with coreferential reading in Serbian.
a. Jovanov $_{i}$ papagaj ga $_{i}$ je ugrizao.
Jovan's parrot him.CL AUX bitten
'John $i$ 's parrot has bitten $\operatorname{him}_{i}$ '.
b. Jovanov $_{i}$ papagaj je ugrizao njega . $_{i}$.
Jovan's parrot AUX bitten him.STR
'John $i$ 's parrot has bitten $\operatorname{him}_{i}$.'

(2) $\operatorname{Njegov}_{i}$ papagaj je ugrizao Jovana ${ }_{i}$.

His parrot AUX bitten John

'His ${ }_{i}$ parrot has bitten $\mathrm{John}_{i}$.'

Given that these constructions proved to be possible with coreferential reading in Serbian, the main aim of this chapter is to discuss the consequences of the empirical results on the theoretical assumptions. Particularly, I will disentangle how the new findings influence the controversial theoretical aspects of prenominal possessive modifiers concerning their categorial status and the syntactic position of possessives within the nominal phrase in Serbian. I will also discuss how to accommodate the new findings concerning the possibility of coreference into the overall analysis of noun phrases in Serbian.

The chapter is organized as follows: Section 5.1 addresses the issue of the categorial status of possessives. I will address the question how the empirical data reconcile the opposing views claiming that Serbian possessives are either adjectives or exponents of $\mathrm{D}$ (presented in Chapter 2). The category of possessives directly pertains to their syntactic position within the nominal phrase, which is discussed in Section 5.2. Contrary to 
previous accounts of Serbian, the experimental findings corroborate the assumption that possessives occupy a position from where they do not c-command out of their phrase, implying the presence of an XP/DP layer above NP. Section 5.3 contributes to the debate on NP vs. DP structure in Serbian, and discusses which of the analyses is more appropriate to accommodate the new findings. In Section 5.4, it is explained how to account for the possibility of both coreferential and non-coreferential interpretations, and which factors can influence the preference for one or the other reading. This section provides an alternative analysis to account for the availability of different readings in these structures in terms of covaluation instead of binding.

\subsection{Coming back to the categorial status of possessives}

Recall from Chapter 2 that Serbian belongs to the group of AG-languages according to the DG/AG parameter (Lyons 1986; Giorgi and Longobardi 1991). This is assumed because possessives function as modifiers and behave like adjectives in a number of aspects. The fact that possessives morphologically agree with nouns in number, case and gender substantiate this claim (additional arguments for treating possessives on a par with adjectives are provided in Section 2.2.3.1). The proponents of the NP analysis used the categorial status of possessives as evidence against the DP hypothesis in an articleless language like Serbian. However, there are counterarguments suggesting that Serbian possessives should rather be treated as exponents of D. For instance, Bašić (2004) and Šarić (2018) argue that possessives do pattern with adjectives in some characteristics, but nevertheless, they do not show the definite/indefinite distinction of Serbian adjectives and they are able to bind an anaphor unlike adjectives etc. (see Section 2.2.3.2 for more arguments). The argumentation provides some motivation to analyse possessives as exponents of $\mathrm{D}$, but they are also not D-elements in the sense of articles. This is clear given that in Serbian possessives do co-occur with d-like elements as in ta moja knjiga, 'that my book' parallel to possessives in other AG languages with articles, where possessives can be combined with articles and demonstratives, e.g. il mio libro, 'the my book'. On the contrary, the combination of demonstratives and possessives before a noun is not possible in DG languages like English: *this my book.

Given the mixed behaviour of Serbian possessives, it is difficult to group them in one of the two types of languages exclusively. Both of the analyses provide valid argumentation in favour of possessives being either adjectives or D elements, which calls the DG/AG parameter into question. This is not an issue just in Serbian, but the problem of the division into DG or AG languages can be observed cross-linguistically, given that in a number of languages possessive pronouns behave in between the two categories. For instance, Latin and old Romance languages pose a problem for this parameter. Latin has 
been analysed as an AG language by Giorgi and Longobardi (1991) although it does not have articles. Possessives can combine with numerals (e.g. tres tui libri, 'three books of yours'), showing that possessives have indefinite reading, which is in line with the characteristics of AG languages. However, according to Lyons (1986), Latin has DG properties as well, as prenominal possessives are interpreted as definite (e.g. meus liber, 'my book'). Hence, this casts doubt on the DG/AG parameter and whether the properties of both groups can co-occur within a language. Possessives in some other languages are treated in between adjectives and determiners, and analysed to belong to both the AG and DG group (Old French, Modern Spanish). Some issues occur even in languages with articles that are treated as typical DG languages, such as in English, which will be discussed in more detail in Section 5.2. Therefore, this division is not so clear and it should be modified for languages with articles and languages without articles alike.

After considering both proposals in favour of adjectives and exponents of $D$, it can be concluded that there are reasonable arguments for both analyses and that Serbian possessives belong to neither of the two categories exclusively. Such a negative definition of the categorial status is unsatisfactory, because we would like to know what they are, and not what they are not. The findings from the experimental studies can contribute to the discussion of the categorial status and offer a more elegant solution than assuming that possessives are in between the two categories. In Chapter 2, it was already demonstrated that in Serbian both lexical and pronominal possessives express the ability to bind reflexives as in (3) (Bašić 2004; Zlatić 1997).
a. $\operatorname{Petar}_{i}$ je slušao Marijino $_{j}$ opisivanje svoje si/j majke. Peter AUX listened Mary's description self's mother 'Peter ${ }_{i}$ listened to Mary ${ }_{j}$ 's description of her ${ }_{\star i / j}$ mother.'

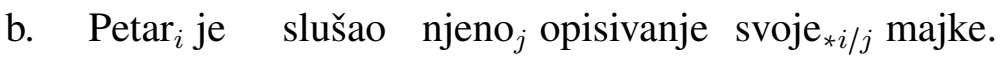 Peter AUX listened her description self's mother 'Peter ${ }_{i}$ listened to her ${ }_{j}$ 's description of her ${ }_{\star i / j}$ mother.'

Experiment 2 shows that pronominal possessives can be coreferential with an Rexpression. This indicates that, unlike adjectives, possessives have referential properties. Pronominal possessives behave like pronouns depending on whether they are in a c-commanding or non-c-commanding position.

Lexical possessives are also referential, given that the coreference was allowed between lexical possessives and pronominal objects in Experiment 1. The referential features of lexical possessives can be captured by the nature of their formation. Zlatić (2000) explains that possessives have both nominal and adjectival behaviour, arguing that they are syntactically adjectives, but semantically nouns. Possessives show concord with the noun they modify in the same fashion as modifying adjectives do, but they also carry a set 
of index features from the underlying noun. Theoretical assumptions and the empirical results from both studies show that both lexical and pronominal possessives have referential properties.

Another piece of evidence showing that possessives are referential comes from the derivation of deverbal nominals. It has been argued that complex deverbal nominals involve verbal functional projections embedded within their structure, with possessives acting as subjects (Alexiadou 2001; Bašić 2010; Schoorlemmer 1998). At some point in the derivation, the possessive functions as a subject binding the reflexive (e.g. ' $\mathrm{John}_{i}$ 's description of himself ${ }_{i}{ }^{\prime}$ ). On the contrary, adjectives cannot function as syntactic subjects in this respect (e.g. * 'the italian $_{i}$ description of themselves $_{i}$ ').

The theoretical assumptions of referential properties of possessives presented in Chapter 2 are supported by the experimental results. Hence, given that possessives have such distinctive features including index which allows for coreference, I label them as Poss to differentiate possessives from adjectives and determiners, which differ in several aspects. However, since they are represented by either a noun or a proper name, they are full noun phrases, namely DPs from a categorial point of view.

\subsection{The non-c-commanding position of possessives within the nominal phrase}

As already shown, the DG/AG distinction is problematic for the categorial status and this has significant consequences for the syntactic position of possessives. Crosslinguistically, depending on the type of possessives, the positions they typically occupy have been proposed to be SpecDP or D for DG languages, and SpecAgrP or SpecnP for AG languages (Alexiadou et al. 2007). This is proposed because in DG languages, possessives behave like determiners, which explains possessives being in a complementary distribution with determiners in these languages. Hence they are assumed to occupy D, unlike in AG languages where possessives pattern with adjectives and are analysed as being located lower than D. According to Alexiadou et al. (2007), possessives occupy SpecAgrP in AG languages, which is associated with possessive agreement.

The assumption that possessives are located very high in DP in a DG language like English cannot account for the binding facts in this language, because in such a position the possessive would be able to c-command out of DP and violate binding principles (Kayne 1994). This is another issue for the DG/AG parameter for languages with articles, in which possessives are analysed as determiner-like and as occupying SpecDP or D. To solve this problem, Kayne (1994) following Szabolcsi (1983), proposes that an independent empty D-head should be assumed above the possessor. This means that in English, 
possessives cannot be located in D as previously assumed, but in a lower position from where they do not c-command out of the DP. Kayne (1994) proposes that possessives are located in the specifier of a PossP, which is dominated by a DP with a null D head. Similarly, Bernstein and Tortora (2005) assume a structure for English that can accommodate binding data. In addition, they address the difference between lexical and pronominal possessives in the language. According to their structure, pronominal possessives occupy a lower position than lexical possessives in the DP, along the lines of Alexiadou et al. (2007), but they are both still below DP in the vein of Kayne's (1994) approach. Namely, pronominal possessives occupy a SpecFP which is projected above NP and dominated by AgrP where the lexical possessive is located (a lexical element occupies SpecAgrP, whereas 's is in Agr head). In contrast to the structure proposed by Alexiadou et al. (2007), Bernstein and Tortora's (2005) structure (repeated here as (4)) accounts for the lack of ability of possessives to c-command out of DP.

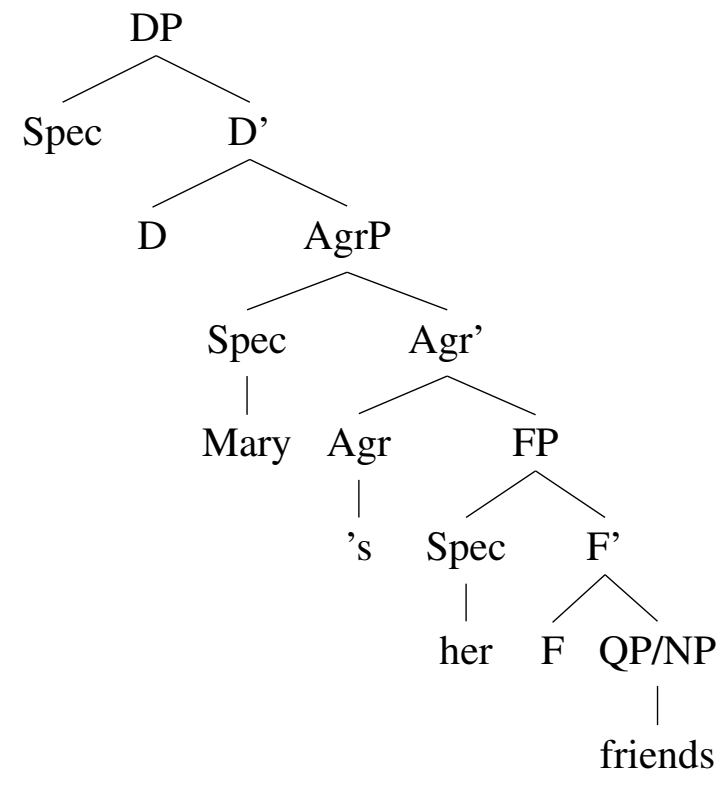

How can these arguments be applied to Serbian? Similarly to Kayne's (1994) proposal, Bašić (2004) assumes that possessives in Serbian occupy the specifier of PossP. According to Bašić's (2004) analysis, possessives are generated as subjects within complex nominals, and they subsequently move to SpecPossP. The possessor phrase is projected above adjectives, but below demonstratives which appear in DP. One argument for this structure comes from word order. As shown in Chapter 2, Bašić (2004) argues that Serbian has a more rigid word order than typically assumed, and that only one default word order within the nominal phrase is neutral (e.g. Igorovi smešni drugovi, 'Igor's funny friends'), and others are derived, which alters the semantic meaning (e.g. smešni Igorovi drugovi, 'funny Igor's friends' indicating contrastive topic, meaning that not all of his friends are funny so this is just a subset of his friends, while Igorovi smešni drugovi, 'Igor's funny 
friends' represents an exhaustive set.). This shows that possessives generally precede adjectives, but they follow demonstratives (e.g. oni Igorovi drugovi, 'those friends of Igor') and if they change their positions the outcome is ungrammatical (e.g. *Igorovi oni drugovi, 'Igor's those friends'). From this follows that possessives occupy a lower specifier position within the DP-spine - below demonstratives. This way, Bašić (2004) treats SpecPossP as a structural licensing position, equivalent to SpecIP in the clausal domain. The possessive marking (the suffix -ov/-in on the noun), can be seen as a morphological reflex of this formal licensing. This is similar to the structure presented in Alexiadou et al. (2007), where possessives are base generated in SpecnP (or sometimes labelled as PossP as well) and they move to SpecAgrP in order to get their case and agreement. Correspondingly, I also assume that Serbian possessives move up from their base position, SpecnP to SpecAgrP to get their agreement with the noun they modify.

Essentially, the outcome of both Bašić's (2004) and Alexiadou et al.'s (2007) analysis is the same in terms of word order: determiners are above possessives, whereas adjectives are in a lower projection. This structure is necessary despite of binding facts, as it accounts for how possessives get their case ${ }^{1}$ and agreement with the noun they modify. In addition, the assumption that possessives occupy the position in SpecAgrP within the extended nominal phrase accounts for the word order, adjectives follow possessives, co-occurrence with d-like elements which precede them, and other relevant structures that have been discussed in Chapter 2. The fact that both pronominal and lexical possessives agree with the noun they modify is another argument for their position within AgrP. Importantly, it captures the controversial issue related to the binding facts: From this position, possessives cannot c-command out of their phrase like in English, and they do not bind the object. Therefore, no violation of Binding Principles B and C occurs, contrary to what has been claimed by Despić (2013). Based on the characteristics of possessives presented in Chapter 2, no differences between lexical and pronominal possessives have been observed in Serbian. Moreover, the experimental studies show that both lexical and pronominal possessives have the same referential features. For the purpose of this study, it is not crucial to differentiate between the two types of possessives regarding their structural position, but I concluded that there was not enough motivation to treat them separately with respect to the syntactic position they occupy as in English (cf. Alexiadou et al. 2007; Bernstein and Tortora 2005), so both types of possessives are located in SpecAgrP. Another argument that both pronominal and lexical possessives occupy this position is that case marking on pronominal possessives is identical like on nominal ones, contrary

\footnotetext{
${ }^{1}$ For the purpose of this study I do not go into detail regarding the morphology of possessive suffix -ov/-in and the debate whether it is derivational or inflectional. For an alternative analysis of how Serbian possessives get case in Pesetsky's framework, see Šaric (2018), who argues that the traditional possessive suffix is actually an allomorphic realization of the genitive case morpheme, which appears only in case stacking environments.
} 
to English. Even if there were differences between lexical and pronominal possessives with respect to their syntactic position, that would not affect the analysis. Then, it could be assumed that pronominal possessives are located lower than lexical possessives, and they could occupy a specifier position of FP lower than AgrP, as suggested by Bernstein and Tortora (2005). What is important is that both types of possessives are not able to c-command out of their phrase from either of the positions, which is important to explain the findings observed in the experimental studies.

Even though Despić $(2011,2013)$ claims that only disjoint reference is forced in the possessive configurations in question, he also provides examples when this is not the case. For instance, in example (5) Despić (2011:37) asserts that the coreference is possible and there is no violation of binding principles, as the possessive is deeper embedded and it does not c-command the element coindexed with it.

a. Film koji je Kusturica ${ }_{i}$ snimao tri godine u Veneciji ga ga $_{i}$ na Film which AUX Kusturica shot three years in Venice him.CL on kraju nije u potpunosti zadovoljio.

end not in completeness satisfied.

'The movie that Kusturica ${ }_{i}$ shot for three years in Venice at the end didn't satisfy $\operatorname{him}_{i}$ completely.'

b. Onaj ko voli njegove ${ }_{i}$ filmove voli i Kusturicu . $_{\text {. }}$ That who loves his films loves and Kusturica

'The one who loves his ${ }_{i}$ movies loves Kusturica ${ }_{i}$ too.'

Based on the arguments presented above, I suggest that no c-command is in force even in examples where possessive is not embedded as in (5), but modifies a noun in subject position as in examples (1) and (2). Therefore, it was necessary to confirm the judgments of native speakers in a more rigid and controlled way, such as by the means of carefully designed experiments. Experiments 1 and 2 have shown that coreference is possible: this means that the same analysis as for English must apply. In other words, a lower position of possessives should be assumed and as already discussed, SpecAgrP classifies to be a good position. Otherwise, if possessives c-commanded out of their phrase, the participants would not accept them with a coreferential interpretation, as they did not accept coreference between pronouns in subject position and R-expression in Experiment 2.

To sum up, based on the categorial status of possessives, the two similar approaches have been discussed, both assuming that possessives occupy a different specifier position than adjectives and are in a position higher than adjectives, but lower the projection which determines occupy. Following Bašić's (2004) arguments for strict word order (demonstratives before possessives), possessives are in SpecPossP. In line with the cross-linguistic structure suggested for AG languages (Alexiadou et al. 2007), possessives move higher 
due to the agreement reasons and occupy SpecAgrP, which I assume for Serbian as well. To account for the availability of coreference, there should be a projection above possessives that bans c-command, similarly as in English which leads to the discussion in Section 5.3. Put differently, I will discuss whether the NP analysis of Serbian can account for the new findings (Bošković 2005, 2008; Despić 2013) or whether the NP-analysis of Serbian must be rejected in favour of the Universal DP Hypothesis (Bašić 2004; Progovac 1998).

\subsection{DP or NP in Serbian?}

The question arises whether the experimental data speak against Despić's (2013) NP analysis of Serbian noun phrases or not. The availability of coreference at least shows that the assumption that possessives represent unambiguous evidence in favour of an NP-analysis as proposed by Despić (2013) is much too strong. Nevertheless, there is one option to accommodate the new findings within his model which will in turn be discussed.

Despić (2011:71) shows that a possessive modifier in a noun phrase including a quantifier like mnogo, 'many' (6) can be coreferential with a pronoun in object position. According to the author, this is possible because the quantifier is the head of a QP projected above NP. According to Despić (2011), a coreferential interpretation with a pronoun is allowed, because this QP blocks c-command, and thus there is no violation of Binding Principle B.

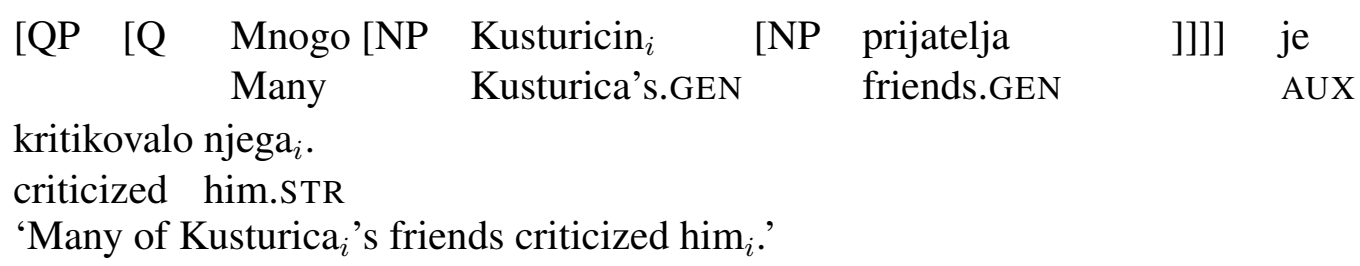

Given the fact that, as shown in Experiment 1, a possessive modifier can be interpreted as being coreferential with a pronoun in object position also in the absence of a quantifier, it could be assumed that the realization of a possessive modifier always exceptionally leads to the projection of a functional category above NP in Serbian (see (7)). Further, the possessor covertly moves to this position at LF, and this could explain how c-command out of the noun phrase in these constructions is prevented (cf. LaTerza's (2016) analysis for Serbian, Bulgarian and Macedonian).

$[\mathrm{FP} \quad[\mathrm{F}$

\section{$[\mathrm{NP}$} Kusturica's najnoviji [NP latest film]]] $\mathrm{ga}_{i} \quad$ je zaista film him.CL AUX really

razočarao. disappointed 
'Kusturica's latest film has really disappointed him.'

This structure in (7) is actually very similar to the proposed structure for English, where a DP with an empty D-head is projected above PossP (cf. Kayne 1994). Calling this position FP above NP is an ad hoc solution to avoid the term DP and actually speaks against the "pure NP analysis". What is the nature of FP and what kind of features does it have? Is this position a potential structural position or landing site for determinerlike elements such as demonstratives as suggested by the word order facts discussed in Chapter 2? Another point concerns the position of the possessive. It has been argued in the previous section that possessives differ from adjectives when it comes to their categorial status. Hence, possessives occupy different specifier positions as suggested within the DP analysis (cf. Bašić 2004) and should not simply be analysed as adjoined to NP as one of multiple specifiers.

The results of the empirical studies, together with other arguments presented in Chapter 2 on the categorial status and syntactic structure, speak for a parallel structure of possessive noun phrases in Serbian and English and ultimately in favour of the Universal DP Hypothesis. First of all, based on Hungarian data, the hierarchy of functional projections within the nominal phrase is such that possessives are not in the same position as adjectives, but they occupy a specifier position above them, namely a SpecAgrP, which is associated with possessive agreement. This position is lower than DP which is projected above AgrP. Such a configuration accounts for the Serbian data as well, following Bašićs (2004) claim on the unmarked order of constituents within Serbian nominal phrase, where determiners precede possessives.

Additionally, the observations concerning the binding of anaphora (8b) in comparison to the non-binding of R-expressions (8a) support this assumption.
a. Jovanov ${ }_{i}$ papagaj je juče ugrizao Jovana ${ }_{i}$.
John's parrot AUX yesterday bitten John
'John ${ }_{i}$ 's parrot bit John ${ }_{i}$ yesterday.'
b. *Jovanov ${ }_{i}$ papagaj je juče ugrizao sebe ${ }_{i}$.
John's parrot AUX yesterday bitten self
'John ${ }_{i}$ 's parrot bit himself ${ }_{i}$ yesterday.'

Recall from Section 2.2.5 that Despić (2013:256) explains the grammaticality of structures as in (8a) by employing Safir et al.'s (2004) Form to Interpretation Principle (FTIP). According to this principle, $(8 \mathrm{a})$ is grammatical because neither a reflexive, nor a (clitic or strong) pronoun are possible in such a context. Similar economy principles are assumed to explain pronoun choice in different pragmatic contexts (Cardinaletti and Starke 1994; Montalbetti 1984). However, this presupposes that different pronouns are in principal 
grammatical in this context and it is problematic to assume that such a principle would overrule a core structural configuration such as c-command. Additionally, the reflexive is undeniably felicitous in object position if it refers to the subject papagaj, 'parrot' (9), showing that papagaj, 'parrot' indeed c-commands the reflexive.

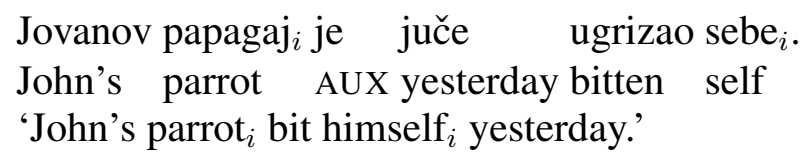

The grammaticality of (8a) and the ungrammaticality of (8b) prevail without any additional postulations, under the assumption that the possessive does not c-command out of the noun phrase, indicating that Serbian patterns with DP languages with respect to binding possibilities (Srdanović and Rinke 2020).

To sum up, the findings of the experimental studies can be explained more easily by assuming the DP analysis, since the availability of coreference in possessive nominal phrases patterns with other languages in which this layer is assumed. Also, no additional principles need to be postulated (FTIP, Lasnik's condition C) to account for the possibility of coreference, it comes with no costs if assumed that possessives do not c-command out of DP, as in English and other DP languages.

\subsection{The explanation of the variability of coreference and non-coreference}

Based on the theoretical argumentation and the results from both experimental studies, I claim that the configurations under scrutiny are not a consequence of grammaticality restrictions, such as binding principles. The fact that coreference is allowed in configurations with possessive modifiers in subject position, suggests that there is no c-command, like in English or German. It is important to take into account the lack of c-command in possessive noun phrases, because this is reflected on the syntactic structure of possessives within a nominal phrase. In comparison to pronominal possessives modifying a noun in subject position, personal pronouns do c-command out of their phrase as demonstrated in Chapter 4 . The difference between the two structures is supported by the fact that speakers categorically rejected coreference between pronominal subjects and R-expressions, but highly accepted it between pronominal possessives and R-expressions in Experiment 2. This finding speaks in favour of the existence of c-command of the pronoun and its relevance for binding in case of typical binding configurations, as a result of the antecedent's structural position. Therefore, configurations with pronouns violate binding principles when they bind R-expressions which are supposed to be free. Another argument that we 
are not dealing with grammatical constraints is that typical binding principles cannot be repaired even when the type of pronoun is changed or when other pragmatic factors are varied. On the other hand, additional factors could influence the likelihood of coreferential interpretation in sentences with possessives (as shown in Chapter 3). Hence, we can conclude that constructions with possessive modifiers are not instances of violation of Binding Principles B and C as claimed by Despić (2013). In other words, the structure of possessives within a nominal phrase is such that it enables a possible coreferential interpretation, as there are no grammaticality restrictions that could prohibit coreference.

Having shown that the structure of possessives modifying a noun in subject allows for coreference to be established, I will now address the question how to account for the variability of the two possible interpretations observed in the experiments. The fact that coreference is possible, does not imply that this interpretation is always employed or preferred. Since these configurations involve a pronoun, either a pronominal object or a pronominal possessive modifying a subject, the variability is a result of the fact that the reference of this pronoun should be resolved. As it is the case in other pronoun resolution constructions, where additional pragmatic factors influence to whom the pronoun refers, I assume that the same applies to these possessive constructions. Pronouns can be ambiguous, i.e. refer to more than one referent if a rigid discourse context is not provided. Therefore, when talking about these structures, one should take into account different factors, such as the type of pronoun (if multiple forms are available in a language), as they differ in their use, or the information structure of antecedent(s). There are different strategies if more than one referent is introduced in the discourse context, so speakers could prefer the last mentioned or more adjacent referent, or they resolve the reference depending on the grammatical role antecedents have in the previous sentence etc.

In my study the type of pronoun in object position was systematically manipulated. The results from Experiment 1 indicate that strong and clitic pronouns in object position show differences regarding their referential properties. A preference for coreferential reading is observed with clitics, and for non-coreferential reading with strong pronouns. This can be explained by the theoretical principles dealing with pronoun choice which claim that the deficient form is preferred over the strong one if both forms are an option. In contrast to Bulgarian where a coreferential reading is exclusively possible with the clitic but not with strong pronouns (cf. Franks 2019), Serbian speakers chose a coreferential reading with the strong pronoun, as well. The choice patterns with the Macedonian judgments reported by Franks (2019), where both coreferential and non-coreferential readings are possible with both pronominal forms. The availability of coreference with both types of pronouns suggests that the (non-)coreference in these structures entails preference and cannot be related to grammaticality constraints such as Binding Principle B.

Even though both forms are in principle acceptable with a coreferential reading, the 
results suggest that clitics allow for a coreferential interpretation more easily, whereas strong pronouns are preferred with disjoint reference. This preference may be conditioned by a number of factors, such as a specific context or a type of antecedent available in the discourse. Cross-linguistically, topic continuity is preferred with weaker elements (the clitic in this case) and topic shift with stronger elements (the strong pronoun). The context of the Experiment 1 was such that the protagonists were given in the context and the possessive modifier occurred in subject position, so the participants could assume that the possessor was the discourse topic. In this case, to resolve the reference of the clitic leads to a coreferential interpretation because they are associated with given information (Zec 2002; Jovović 2020). If the participants do not attribute a topic status to the possessor, a non-coreferential interpretation with the clitic would be chosen. Concerning the strong pronoun, the coreferential reading is plausible if the speakers assume a contrast between the protagonists given in the introduction, which is also possible in this experimental setting because the two participants were mentioned together. Jovović (2020) also claims that the strong pronoun needs to be contrastively focused to be coreferential with the possessor if the antecedent is already mentioned in the discourse. Despite the fact that the participants heard the test sentences which were read without emphatic stress on the strong pronoun, it might be the case that they still implicitly stressed the pronoun for themselves and allowed for coreference with the strong pronoun in more cases than expected, which some of them actually did as came out when they were asked to explain their choices after the experiment was finished. Thus, future studies should control more carefully for the discursive context by manipulating the information status of the antecedents, and for stress on the pronoun in a stricter way. This empirical evidence could reveal more information on which factors actually determine the interpretation of the strong and clitic pronouns in these configurations.

Having shown that coreference does not relate to syntactic binding restrictions, the possible analysis that could account for the coreference could be covaluation in the sense of Reinhart (2006), as we argued in Srdanović and Rinke (2020). Covaluation represents a mechanism of anaphora resolution by which the value of a discourse antecedent is assigned to a pronoun. Reinhart (2006) explains the difference between binding and covaluation in the following way: she assumes that in the case of binding, the variable gets bound by the $\alpha$-operator in binding configurations, as in (11b), explaining that "the predicate denotes the set of individuals who think that they have got the flu, and the sentence asserts that Lili is in this set." (Reinhart 2006:165). On the other hand, in the case of covaluation as in (11c) "the free variable is assigned a value from the discourse storage." (Reinhart 2006:165).

a. Lucie didn't show up today. 
b. Lili thinks she's gotten the flu.
a. Lili $(\alpha \mathrm{x}(\mathrm{x}$ thinks $\mathrm{z}$ has gotten the flu $))$
b. Binding: Lili ( $\alpha \mathrm{x}$ ( $\mathrm{x}$ thinks $\mathrm{x}$ has gotten the flu))
c. Covaluation: Lili ( $\alpha \mathrm{x}$ ( $\mathrm{x}$ thinks $\mathrm{z}$ has gotten the flu) \& $\mathrm{z}=$ Lucie)

Under the assumption that a storage of discourse entities (which can be potential antecedents of anaphoric expressions) is created while processing sentences in context (Prince 1981; Heim 1982), Reinhart (2006) proposes that in (11c) an entry for Lucie has been stored, and when encountering the pronoun this value is assigned to she. This becomes more evident in elliptical constructions. In (12b) the example (12a) can be interpreted as a 'sloppy reading', which corresponds to (11b), whereas in (12c), the 'strict reading' corresponds to (11c) (Reinhart 2006:165).
a. Lili thinks she has gotten the flu, and Max does, too.
b. sloppy reading: Max thinks that he himself has gotten the flu.
c. strict reading: Max thinks that Lili has gotten the flu.

Applying this analysis to the availability of coreference in possessive configurations in Serbian can explain some additional examples from Despić (2013:264). Despić (2013) illustrates that a pronoun can be coreferential with a possessive modifier in Serbian in (13).

(13) $\operatorname{Jovan}_{i}$ je razočaran. Njegov $_{i}$ omiljeni papagaj ga ${ }_{i}$ je juče John is disappointed his favourite parrot him.CL AUX yesterday ugrizao. bitten ' $\mathrm{John}_{i}$ is disappointed. His ${ }_{i}$ favourite parrot bit him $i$ yesterday.'

In (13), Jovan, njegov and ga can refer to the same person. According to Despić (2013), if the sentence is embedded in an ellipsis context, only a strict reading but not a sloppy reading is possible, showing that a bound interpretation is not available. ${ }^{2}$

(14) $\operatorname{Jovan}_{i}$ je razočaran. Njegov $_{i}$ papagaj ga $_{i}$ je juče ugrizao, dok John is disappointed his parrot him.CL AUX yesterday bitten while Markov papagaj nije. Marko's papagaj is.not ' $\mathrm{John}_{i}$ is disappointed. His $i$ parrot bit him $i$ yesterday, while Marko's parrot did

\footnotetext{
${ }^{2}$ According to Despić (2013), the single interpretation in the sentence is that Marko's parrot did not bite John, which corresponds to a strict reading. The sentence cannot be interpreted as a sloppy identity reading, i.e. that Marko's parrot did not bite Marko.
} 
not.'

If bound interpretation is not an option in examples like (14), then only covaluation is possible. Following Reinhart (2006:165) who argues that covaluation is free in such contexts in English because of the lack of c-command, it follows that there is also no c-command in these configurations in Serbian.

The differences between strong and weak pronouns observed in Experiment 1 can also be easily accounted for by assuming covaluation. We can notice that clitics and pronouns exhibit a differential behaviour if structures with possessive antecedents are compared to binding configurations with a (non-possessive) R-expression as antecedent and a pronoun in a non c-command position (subordinate clause). Namely, clitics allow for both strict and sloppy identity readings, while strong pronouns impose a ban on sloppy readings (cf. Runić 2014 for Serbian, Stegovec 2019 for Slovenian). In example (15) both the sloppy and the strict readings are allowed with the clitic, i.e. Mary either thinks that the police saw John (strict) or her (sloppy).

Jovan misli da ga je policija videla i Marija misli takođe. John thinks that him.CL AUX police saw and Mary thinks same 'John thinks that the police saw him and Mary thinks the same.'

In contrast, as shown in (16), the strong pronoun in the same contexts allows for the strict reading only ('Mary thinks that the police saw John'), but not for the sloppy reading ('Mary thinks that the police saw her'). This indicates that there is only covaluation, but no binding available for this type of pronoun.

Jovan misli da je policija videla njega i Marija misli takođe. John thinks that AUX police saw him.STR and Mary thinks same 'John thinks that the police saw him and Mary thinks the same.'

Supposing that the difference between Serbian ga and njega in (15) vs. (16) is related to the internal structure of pronouns, we may conclude that the structural difference between the strong form njega and the morphologically reduced form ga may result in the difference in their interpretation. Following more recent minimalist accounts of binding, differences between structurally different types of pronouns are not unexpected. The complementary distribution of anaphora and pronouns is attributed to derivational economy instead of independent binding principles whose status has been challenged by minimalist theory (Hicks 2009; Reuland 2001).

In cases where a pronominal possessive modifies a noun in subject position, only one form - njegov is available (in contrast to object position where svog, 'self's is also accessible). In Experiment 2, the participants chose coreferential reading between the 
pronominal possessive and R-expression in a high number of cases, but the results also show that it is possible to interpret the sentences with a disjoint reference. The variability of coreference with pronominal possessive constructions can be also accounted for with covaluation, as it is clearly shown that these configurations cannot be considered as cases of grammatical constraint - Binding Principle $\mathrm{C}$ because there is no c-command. What is important is that the structure allows for the possibility of coreference, but then the coindexation depends on the discourse antecedents available or other factors.

This analysis accounts for the variability of coreference in possessive constructions and it brings together syntactic structure and discourse factors. Firstly, no c-command is assumed as in binding, and secondly, the value of a discourse antecedent is assigned to a pronoun, which provides an explanation for the variability of coreferential and noncoreferential readings. 


\section{Chapter 6}

\section{Conclusion}

This thesis investigated the referential properties of prenominal possessive modifiers in Serbian. Particularly, it focused on the configurations that have been claimed to violate Binding Principles B and C: lexical or pronominal possessives modifying a noun in subject position binding a pronoun or an R-expression in object position. Such configurations have been claimed to be ungrammatical in Serbian due to the categorial status of the possessive as adjectives and its presumed syntactic position as adjoined to NP (Despić 2013).

The aim of the thesis was threefold. First, I re-examined binding with possessives in comparison to 'typical binding' constructions without possessives in order to provide empirical evidence showing that the coreferential interpretation between possessive modifiers and objects is available in Serbian. Second, I wanted to examine the categorial status of prenominal possessives in Serbian, as it has been disputed whether they are adjectives or determiners. Third, I wanted to investigate the position of the possessives within the Serbian noun phrase. Based on the theoretical arguments and experimental evidence, I propose a structural position that would accommodate the binding facts and the referential possibilities in these configurations.

The thesis encompassed two empirical studies: Study I focused on the Principle B constructions, which had a pronominal object and a lexical possessive modifying a noun in subject position; whereas Study II addressed Principle C constructions, including Rexpressions in object position and pronominal possessives modifying a noun in subject position. Both of the studies aimed at answering the question whether it is possible to establish coreference between possessive modifiers and objects in Serbian. The findings from the experiments contribute to the bigger picture of the nature and behaviour of Serbian possessives with respect to the categorial status and syntactic position of possessives.

Concerning the categorial status of Serbian possessives, the traditional analysis is that they belong to the group of AG languages. However, based on the number of arguments and the results reached in both experimental studies, I conclude that their behaviour pertains to full noun phrases, namely DPs from a categorial point of view. It is true that 
possessives show a mixed behaviour in between adjectives and d-like modifiers: On the one hand, possessives show morphological agreement in gender, number and case like adjectives, but on the other hand, unlike adjectives, they can bind anaphora. Having discussed both analyses, I reached the conclusion that possessives are neither typical adjectives nor typical determiners, and I label them as Poss. Because Poss shares properties with both adjectives and determiners, this casts doubt on the DG/AG parameter. Additional evidence from other languages such as Spanish or Old French which behave in the similar manner also questions the subdivision of languages into adjectival genitives and determinative genitives exclusively. This parameter seems to be problematic even for apparently clear DG languages with articles such as English, because possessives, although they have been analysed as determiners, do not occupy the D head (cf. Kayne 1994).

This is clearly shown by the binding facts with possessives, relevant to the data examined in this dissertation. According to Kayne's (1994) analysis, possessives occupy SpecPossP which is governed by DP and includes an empty D-head. Bernstein and Tortora (2005) propose a structure similar to Kayne's (1994) with the difference that according to their analysis pronominal possessives occupy a lower position than lexical possessives in the DP, along the lines of Alexiadou et al. (2007), but they are both below DP in the vein of Kayne's (1994) approach. According to Bernstein and Tortora (2005), pronominal possessives occupy a SpecFP which is projected above NP and dominated by AgrP where the lexical possessive is located in SpecAgrP. In contrast to the structure proposed by Alexiadou et al. (2007), this structure can explain the lack of ability of possessives to c-command out of DP. I adopted the analysis in line with Kayne (1994); Bernstein and Tortora (2005) and Alexiadou et al. (2007), and assume that possessives should occupy a SpecAgrP in Serbian as well, to which they move from SpecPossP which is their base position. Being in this position, they agree with the noun phrase and are assigned their case. Importantly, from this position the possessive is not able to c-command and bind the object, because there must be another phrase dominating AgrP. I have argued in Section 5.3 that proposing a functional projection XP above NP would be an ad hoc solution and taken together with the argument that they are a different category from adjectives, possessives should not be adjoined to NP as multiple specifiers, but rather occupy different specifier positions as suggest in the DP analysis. Essentially, this structure actually patterns with a proposal that there is a DP with an empty D-head, as assumed for English for the same constructions (cf. Kayne 1994). The empirical results of the study, together with other arguments presented in Chapter 2 on the categorial status and syntactic structure, rather speak for a parallel structure of possessive noun phrases in Serbian and English and ultimately in favour of the Universal DP Hypothesis.

The results from Experiment 1 have shown that coreference between a lexical possessive and a (clitic or strong pronoun) is allowed in Serbian. Further, there is a difference 
in a (non-)coreferential interpretation depending on the type of pronoun used in object position. The coreferential reading is preferred with clitics, while the disjoint reference is preferred with strong pronouns. This tendency to give preference to clitics is expected following that more deficient pronouns are chosen over stronger forms when both forms are available. Additionally, not only the type of pronoun can influence the reading, but also the discourse context. In my experiment, both characters were mentioned in a lead-in sentence, meaning that possessive had a topic-like status which selects the weaker form, the clitic in this case. The fact that coreference is possible, does not necessarily mean that it is always available as the only interpretation.

The same finding is observed in Experiments 2 and 3 as coreference was accepted between pronominal possessives modifying a noun in subject position and R-expressions. This structure was compared to sentences with pronouns in subject position which lead to a Binding Principle $\mathrm{C}$ violation. These results reveal that coreference is rejected between pronouns and R-expressions, but allowed between possessives and R-expressions, suggesting a structural difference - no c-command - in the latter case. The results from the self-paced reading task corroborate this finding, as the gender mismatch effect was exclusively found in the possessive but not in the pronominal condition signalling that c-command restricts the active search process in reading comprehension and that Serbian speakers are sensitive to Binding Principle C. This is another piece of evidence showing that possessive configurations are not violating Binding Principles B and C, and it implies the lack of c-command in Serbian possessives which pertains to their syntactic structure. The existence of coreference observed in the experiments substantiates the suggestion that possessives cannot be adjectives as they bear referential properties and index features, unlike adjectives.

In my dissertation, I focused on specific constructions with possessives modifying a noun in subject position, but the experimental results could be extended to similar configurations with possessives. Given what we know from theory the results could be replicated for similar constructions involving object pronouns in dative (with verbs that take indirect objects) and similar results could be expected for a different type of possession. I leave this matter open for some future research, where semantics of different types of possession can be experimentally investigated.

In this thesis, I have shown that these possessive constructions do not violate binding principles. An alternative explanation is that we are dealing with covaluation and not binding. This analysis brings together structure and discourse factors. No c-command is assumed like in binding configurations, and the value of a discourse antecedent is assigned to a pronoun, which also accounts for the variability of coreferential and non-coreferential readings.

What still remains open to be inquired in future work is examining possessives more 
closely with respect to their categorial status cross-linguistically in order to modify the existing bipartite DG/AG division. Additionally, a lot of work still needs to be done regarding the structure of Serbian nominal phrases, and to provide additional evidence for the presence of the Universal DP Hypothesis. Although it has been controlled for many factors in the current experiments, a follow-up is needed to inspect how the discourse context or information structure would influence the results. Moreover, using different methods such as eye-tracking could reveal more interesting conclusions on the phenomenon, both in the case of visual paradigm and reading comprehension. 


\section{Bibliography}

Abney, S. P. (1987). The English noun phrase in its sentential aspect. PhD thesis, Massachusetts Institute of Technology.

Alexiadou, A. (2001). Functional structure in nominals: Nominalization and ergativity, volume 42. John Benjamins Publishing.

Alexiadou, A., Haegeman, L., and Stavrou, M. (2007). Noun Phrase in the Generative Perspective, volume 71. Walter de Gruyter.

Ariel, M. (1990). Accessing Noun-Phrase Antecedents. London: Routlege.

Arnold, J. E. and Griffin, Z. M. (2007). The effect of additional characters on choice of referring expression: Everyone counts. Journal of memory and language, 56(4),521536.

Baayen, R. H. and Milin, P. (2010). Analyzing reaction times. International Journal of Psychological Research, 3(2),12-28.

Baker, M. C. (2003). Lexical categories: Verbs, nouns and adjectives, volume 102. Cambridge University Press.

Barr, D. J. (2013). Random effects structure for testing interactions in linear mixed-effects models. Frontiers in psychology, 4,328.

Bašić, M. (2004). Nominal subextractions and the structure of NPs in Serbian and English. Master's thesis, Universitetet i Troms $\varnothing$. 
Bašić, M. (2010). On the morphological make-up of nominalizations in Serbian. The syntax of nominalizations across languages and frameworks, 39,66.

Bates, D., Mächler, M., Bolker, B., and Walker, S. (2014). Fitting linear mixed-effects models using lme4. arXiv preprint arXiv:1406.5823.

Bernstein, J. B. and Tortora, C. (2005). Two types of possessive forms in English. Lingua, 115(9),1221-1242.

Borer, H. (1993). Parallel morphology. Ms., University of Massachusetts at Amherst.

Bošković, Ž. (2005). On the locality of left branch extraction and the structure of NP. Studia linguistica, 59(1),1-45.

Bošković, Ž. (2008). What will you have, DP or NP? In Proceedings of NELS, volume 37, pages $101-114$.

Bošković, Ž. (2009). More on the no-DP analysis of article-less languages. Studia linguistica, 63(2), 187-203.

Bošković, Ž. (2012). On NPs and clauses. Discourse and grammar: From sentence types to lexical categories, 179,242.

Calabrese, A. (1986). Pronomina: some properties of the Italian pronominal system. Mit working papers in linguistics, 8,1-46.

Cardinaletti, A. (1998). On the deficient/strong opposition in possessive systems. Possessors, predicates and movement in the determiner phrase, 22,17-53.

Cardinaletti, A. and Starke, M. (1994). The typology of structural deficiency: On the three grammatical classes. Working Papers in Linguistics, 4(2),41-109.

Cardinaletti, A. and Starke, M. (1999). Responses and demonstratives. Clitics in the Languages of Europe, pages 280-289. 
Carminati, M. N. (2002). The processing of Italian subject pronouns. PhD thesis, University of Massachusetts at Amherst.

Chierchia, G. (1998). Reference to kinds across language. Natural language semantics, 6(4),339-405.

Chomsky, N. (1981). Lectures on binding and government. Foris, Dordrecht.

Chomsky, N. (1995). The minimalist program. Cambridge, Massachusetts: MIT Press.

Chomsky, N. (2000). Minimalist inquiries: The framework. In R. Martin, et al. (Eds.), Step by step: Essays on minimalist syntax in honor of Howard Lasnik, pages 89-156. Cambridge, Mass.: MIT Press.

Chomsky, N. (2001). Derivation by phase. In M. Kenstowicz (Ed.), Ken Hale: A life in language, pages 1-50. Cambridge, Mass.: MIT Press.

Chomsky, N. and Lasnik, H. (1977). Filters and control. Linguistic inquiry, 8(3),425-504.

Chow, W.-Y., Lewis, S., and Phillips, C. (2014). Immediate sensitivity to structural constraints in pronoun resolution. Frontiers in Psychology, 5,630.

Cinque, G. (1994). On the evidence for partial N-movement in the Romance DP. In Paths towards universal grammar. Studies in honor of Richard S. Kayne. Georgetown University Press.

Corbett, G. G. (1987). The morphology/syntax interface: evidence from possessive adjectives in Slavonic. Language, 63(2),299-345.

Corbett, G. G. (1995). Slavonic's closest approach to suffixaufnahme: The possessive adjective. Double Case: Agreement by Suffixaufnahme. Oxford University Press, New York.

Corver, N. (1992). Left branch extraction. In Proceedings of NELS, volume 22, pages $67-84$. 
Crain, S. and Fodor, J. (1985). How can grammars help parsers? In D.R. Dowty and L. Karttunen, and A.M. Zwicky (Eds.), Natural language parsing. Psychological, Computational, and Theoretical Perspectives, pages 94-128. Cambridge University Press.

Cunnings, I. (2012). An overview of mixed-effects statistical models for second language researchers. Second Language Research, 28(3),369-382.

den Dikken, M. (1995). Particles: On the syntax of verb-particle, triadic, and causative constructions. New York: Oxford University Press.

Despić, M. (2011). Syntax in the absence of Determiner Phrase. PhD thesis, University of Connecticut.

Despić, M. (2013). Binding and the structure of NP in Serbo-Croatian. Linguistic inquiry, 44(2),239-270.

Dimitrova-Vulchanova, M. and Giusti, G. (1995). Quantified noun phrase structure in Bulgarian. Working Papers in Linguistics, 5(1),43-65.

Dimitrova-Vulchanova, M. and Tomić, O. M. (2009). The structure of the Bulgarian and Macedonian nominal expression: Introduction. Investigations in the Bulgarian and Macedonian nominal expression, pages 1-23.

Drummer, J.-D. and Felser, C. (2018). Cataphoric pronoun resolution in native and nonnative sentence comprehension. Journal of Memory and Language, 101,97-113.

Flores, C., Rinke, E., and Sopata, A. (2020). Acquiring the distribution of null and overt direct objects in European Portuguese. Journal of Portuguese Linguistics, 19(5),1-20.

Franks, S. (2009). Macedonian pronominal clitics as object agreement markers. A linguist's linguist: Studies in South Slavic linguistics in honor of E. Wayles Browne, pages $189-221$.

Franks, S. (2019). Binding and phasehood in South Slavic revisited. Studies in Polish Linguistics, 14(2),61-80. 
Frazier, L. and Clifton, C. (1989). Successive cyclicity in the grammar and the parser. Language and cognitive processes, 4(2),93-126.

Giorgi, A. and Longobardi, G. (1991). The syntax of noun phrases: Configuration, parameters and empty categories, volume 57. Cambridge University Press.

Gordon, P. C. and Hendrick, R. (1997). Intuitive knowledge of linguistic co-reference. Cognition, 62(3),325-370.

Grimshaw, J. (1990). Argument structure. the MIT Press.

Guéron, J. (1985). Inalienable possession, PRO-inclusion and lexical chains. In H.-G. Obenauer, J.-Y. Pollock, and J. Guéron (Eds.), Grammatical representation, pages 4386. Dordrecht: Foris.

Gundel, J. K., Hedberg, N., and Zacharski, R. (1993). Cognitive status and the form of referring expressions in discourse. Language, pages 274-307.

Halpern, A. (1995). On the placement and morphology of clitics. Stanford: CSLI Publications.

Heim, I. (1982). File change semantics and the familiarity theory of definiteness. In Baurle, R., Schwarze, C., and Von Stechow, A., (Eds.), Meaning, Use, and the Interpretation of Language, pages 164-89. Berlin: de Gruyter.

Hicks, G. (2009). The derivation of anaphoric relations, volume 139. Amsterdam/Philadelphia: John Benjamins Publishing Company.

Hoekstra, T. (1994). HAVE as BE plus or minus. Paths towards Universal Grammar: Studies in Honor of Richard S. Kayne, pages 199-215.

Hopp, H. (2016). The timing of lexical and syntactic processes in second language sentence comprehension. Applied Psycholinguistics, 37(5),1253.

Ibáñez, A. J., Macizo, P., and Bajo, M. T. (2010). Language access and language selection in professional translators. Acta psychologica, 135(2),257-266. 
Jovović, I. (2020). On discourse licensing of co-indexed readings of pronouns: SerboCroatian strong pronouns as topic-shift anaphors. Paper presented at Formal Approaches to Slavic Linguistics 29, online.

Julien, M. (2002). Determiners and word order in Scandinavian DPs. Studia Linguistica, $56(3), 265-315$.

Just, M. A., Carpenter, P. A., and Woolley, J. D. (1982). Paradigms and processes in reading comprehension. Journal of experimental psychology: General, 111(2),228238.

Kayne, R. S. (1984). Connectedness and Binary Branching. Foris, Dordrecht.

Kayne, R. S. (1994). The antisymmetry of syntax, volume 25. MIT press.

Kazanina, N., Lau, E. F., Lieberman, M., Yoshida, M., and Phillips, C. (2007). The effect of syntactic constraints on the processing of backwards anaphora. Journal of Memory and Language, 56(3),384-409.

Kazanina, N. and Phillips, C. (2010). Differential effects of constraints in the processing of Russian cataphora. The Quarterly Journal of Experimental Psychology, 63(2),371400.

Koster, J. (1997). Anaphora and the Uniformity of Grammar. In H. Bennis, P. Pica, and J. Rooryck (Eds.), Atomism and binding, pages 235-250. Dordrecht:Foris.

Kupisch, T. and Rinke, E. (2011). The diachronic development of article possessor complementarity in the history of Italian and Portuguese. Linguistic universals and language variation, pages 92-127.

Kuznetsova, A., Brockhoff, P. B., and Christensen, R. H. B. (2014). lmertest: Tests for random and fixed effects for linear mixed effect models. $\mathrm{R}$ package version 2.0-11. http://CRAN.R-project.org/package=lmerTest. 
Larson, R. and Cho, S. (2003). Temporal adjectives and the structure of possessive DPs. Natural Language Semantics, 11(3),217-247.

Lasnik, H. (1989). Essays on anaphora. Dordrecht: Kluwer.

LaTerza, I. (2015). Adjectives and determiners. Lingua, 168,85-103.

LaTerza, I. (2016). Binding in English and South Slavic and the parameterized DP hypothesis. Linguistic inquiry, 47(4),741-753.

Lee-Schoenfeld, V. (2008). Binding, phases, and locality. Syntax, 11(3),281-298.

Lobo, M. and Silva, C. (2016). Ambiguidade pronominal em orações adverbiais do Português Europeu. Revista da Associação Portuguesa de Linguística 2, pages 319-338.

Lyons, C. (1986). The syntax of English genitive constructions. Journal of Linguistics, 22(1),123-143.

Montalbetti, M. (1984). After binding: On the interpretation of pronouns. PhD thesis, Massachusetts Institute of Technology.

Pablos, L., Doetjes, J., Ruijgrok, B., and Cheng, L. L.-S. (2015). Active search for antecedents in cataphoric pronoun resolution. Frontiers in psychology, 6,1638.

Plank, F. (1990). Suffix copying as a mirror-image phenomenon. Linguistics, 28(5),1039_ 1045.

Portele, Y. and Bader, M. (2016). Accessibility and referential choice: Personal pronouns and d-pronouns in written German. Discours. Revue de linguistique, psycholinguistique et informatique, 18,1-41.

Prince, E. F. (1981). Towards a taxonomy of given-new information. In Peter Cole (Ed.), Radical pragmatics, pages 223-255. New York: Academic Press.

Progovac, L. (1998). Determiner phrase in a language without determiners. Journal of linguistics, 34(1),165-179. 
Radford, A. (2000). NP shells. Essex research reports in linguistics, 33,2-20.

Rappaport, G. (1998). The Slavic noun phrase. Position paper for Comparative Slavic Morphosyntax. Available at http://www.indiana.edu/slavconf/linguistics/download.

Rappaport, G. C. (2000). Extraction from nominal phrases in Polish and the theory of determiners. Journal of Slavic linguistics, pages 159-198.

Reinhart, T. (2006). Interface strategies: Optimal and costly computations. The MIT Press.

Reuland, E. (2001). Primitives of binding. Linguistic inquiry, 32(3),439-492.

Rinke, E. and Flores, C. (2018). Another look at the interpretation of overt and null pronominal subjects in bilingual language acquisition: Heritage Portuguese in contact with German and Spanish. Glossa: a journal of general linguistics, 3(1),68,1-24.

Runić, J. (2014). A new look at clitics, clitic doubling, and argument ellipsis: Evidence from Slavic. PhD thesis, University of Connecticut.

Safir, K. et al. (2004). The syntax of anaphora. Oxford University Press.

Šarić, A. (2018). Nominalizations, Double Genitives and Possessives: Evidence for the DP-Hypothesis in Serbian. Berlin, Boston: De Gruyter.

Schoorlemmer, M. (1998). Possessors, articles, and definiteness. In A. Alexiadou \& $C$. Wilder (Eds.), Possessors, predicates, and movement in the DP., pages 55-86. Amsterdam: John Benjamins.

Smyth, R. (1994). Grammatical determinants of ambiguous pronoun resolution. Journal of psycholinguistic research, 23(3),197-229.

Sproat, R. and Shih, C. (1991). The cross-linguistic distribution of adjective ordering restrictions. In Interdisciplinary approaches to language, pages 565-593. Springer. 
Srdanović, S. and Rinke, E. (2020). Possessive Modifiers in Serbian: Coreference with Clitics and Strong Pronouns. Journal of Slavic Linguistics, 28(2),161-181.

Stanković, B. (2013). DP or NP? the case of Serbian southeastern dialects and Macedonian language. Presented at SinFonIJa 6, University of Niš.

Stegovec, A. (2019). Crop to fit: Pronoun size and its relation to strict/sloppy identity and animacy. Handout at Linguistic Society of America 2019, New York City.

Stowe, L. A. (1986). Parsing wh-constructions: Evidence for on-line gap location. Language and cognitive processes, 1(3),227-245.

Szabolcsi, A. (1981). The possessive construction in Hungarian: A configurational category in a non-configurational language. Acta Linguistica Academiae Scientiarum Hungaricae, 31(1/4),261-289.

Szabolcsi, A. (1983). The possessor that ran away from home. The linguistic review, $3(1), 89-102$.

Szabolcsi, A. (1994). The noun phrase. In Franz Kiefer and Katalin Kiss, (Eds.), The syntactic structure of Hungarian, pages 179-274. San Diego: Academic Press.

Tasseva-Kurktchieva, M. and Dubinsky, S. (2018). On the NP/DP frontier: Bulgarian as a Transitional Case. Katerino Mome, pages 287-312.

Team, R. C. (2013). R: A language and environment for statistical computing. R Foundation for Statistical Computing, Vienna, Austria.

Tsimpli, I., Sorace, A., Heycock, C., and Filiaci, F. (2004). First language attrition and syntactic subjects: A study of Greek and Italian near-native speakers of English. International Journal of Bilingualism, 8(3),257-277.

Van Gompel, R. P. and Liversedge, S. P. (2003). The influence of morphological information on cataphoric pronoun assignment. Journal of Experimental Psychology: Learning, Memory, and Cognition, 29(1),128-139. 
Veselovská, L. (2014). Possessives and Their Equivalents in English and Czech: A Comparative Study. Nominal Structures: All in Complex DPs, pages 110-33.

Wechsler, S. and Zlatić, L. (1998). Agreement in discourse. In Proceedings of the Conference on the Structure of Non-narrative Texts.

Wechsler, S. and Zlatić, L. (2000). A theory of agreement and its application to SerboCroatian. Language, pages 799-832.

Wickham, H. (2011). ggplot2. Wiley Interdisciplinary Reviews: Computational Statistics, $3(2), 180-185$.

Zec, D. (2002). On the prosodic status of function words. Working Papers of the Cornell Phonetics Laboratory, 14,207-249.

Zehr, J. and Schwarz, F. (2018). PennController for Internet Based Experiments (IBEX).

Zlatić, L. (1997). The structure of the Serbian Noun Phrase. PhD thesis, University of Texas at Austin.

Zlatić, L. (1998). Slavic noun phrases are NPs not DPs. In Workshop on Comparative Slavic Morphosyntax, Bloomington, Indiana.

Zlatić, L. (2000). The morpho-syntax of Slavic possessives. In The Proceedings from the Panels of the Chicago Linguistic Society's Thirty-Sixth Meeting, volume 2, pages 179-190. 


\section{Appendix A}

\section{Experiment 1}

\section{Intro sentences and pictures}

Each test and control item was preceded by an introductory sentence and a picture showing two boys and an animal. The introductory items are given in the Table below, items are labelled with $\mathrm{T}$ for test items, $\mathrm{C}$ for controls, and $\mathrm{P}$ for practice items. English translations for all the items are provided under the items, or next to them.

Table A.1: Experiment 1: Intro sentences and pictures

\begin{tabular}{|c|c|c|c|}
\hline $\begin{array}{l}\text { Item } \\
\text { num }\end{array}$ & $\begin{array}{l}\text { Introductory item } \\
\text { English translation }\end{array}$ & $\begin{array}{l}\text { Item } \\
\text { num }\end{array}$ & $\begin{array}{l}\text { Introductory item } \\
\text { English translation }\end{array}$ \\
\hline $\mathrm{T} 1$ & $\begin{array}{l}\text { Na slici su Jovan, Jovanov papagaj i Petar. } \\
\text { Pogledajte šta se desilo. } \\
\text { There are John, John's parrot and Peter. } \\
\text { Look what happened. }\end{array}$ & $\mathrm{T} 2$ & $\begin{array}{l}\text { Na slici su Jovan, Jovanov hrčak i Petar. } \\
\text { Pogledajte šta se desilo. } \\
\text { There are John, John's hamster and Peter. } \\
\text { Look what happened. }\end{array}$ \\
\hline $\begin{array}{l}\mathrm{T} 3 \\
\mathrm{P} 2\end{array}$ & $\begin{array}{l}\text { Na slici su Jovan, Jovanov konj i Petar. } \\
\text { Pogledajte šta se desilo. } \\
\text { There are John, John's horse and Peter. } \\
\text { Look what happened. }\end{array}$ & & $\begin{array}{l}\text { Na slici su Jovan, Jovanov magarac i } \\
\text { Petar. Pogledajte šta se desilo. } \\
\text { There are John, John's donkey and Peter. } \\
\text { Look what happened. }\end{array}$ \\
\hline T5 & $\begin{array}{l}\text { Na slici su Jovan, Jovanov patak i Petar. } \\
\text { Pogledajte šta se desilo. }\end{array}$ & T6 & $\begin{array}{l}\text { Na slici su Jovan, Jovanovo prase i Petar. } \\
\text { Pogledajte šta se desilo. }\end{array}$ \\
\hline
\end{tabular}




\begin{tabular}{|c|c|c|c|}
\hline $\begin{array}{l}\text { Item } \\
\text { num }\end{array}$ & $\begin{array}{l}\text { Introductory item } \\
\text { English translation } \\
\text { There are John, John's duck and Peter. } \\
\text { Look what happened. }\end{array}$ & $\begin{array}{l}\text { Item } \\
\text { num }\end{array}$ & $\begin{array}{l}\text { Introductory item } \\
\text { English translation } \\
\text { There are John, John's pig and Peter. } \\
\text { Look what happened. }\end{array}$ \\
\hline $\mathrm{C} 4$ & $\begin{array}{l}\text { Na slici su Jovan, Jovanov bik i Petar. } \\
\text { Pogledajte šta se desilo. } \\
\text { There are John, John's bull and Peter. } \\
\text { Look what happened. }\end{array}$ & T8 & $\begin{array}{l}\text { Na slici su Jovan, Jovanov mačak i Petar. } \\
\text { Pogledajte šta se desilo. } \\
\text { There are John, John's tomcat and Peter. } \\
\text { Look what happened. }\end{array}$ \\
\hline T9 & $\begin{array}{l}\text { Na slici su Jovan, Jovanov pas i Petar. } \\
\text { Pogledajte šta se desilo. } \\
\text { There are John, John's dog and Peter. } \\
\text { Look what happened. }\end{array}$ & $\mathrm{T} 10$ & $\begin{array}{l}\text { Na slici su Jovan, Jovanov petao i Petar. } \\
\text { Pogledajte šta se desilo. } \\
\text { There are John, John's rooster and Peter. } \\
\text { Look what happened. }\end{array}$ \\
\hline $\begin{array}{l}\text { T11 } \\
\text { C8 }\end{array}$ & $\begin{array}{l}\text { Na slici su Jovan, Jovanov jež i Petar. } \\
\text { Pogledajte šta se desilo. } \\
\text { There are John, John's hedgehog and Pe- } \\
\text { ter. Look what happened. }\end{array}$ & $\mathrm{T} 12$ & $\begin{array}{l}\text { Na slici su Jovan, Jovanov majmun i } \\
\text { Petar. Pogledajte šta se desilo. } \\
\text { There are John, John's monkey and Peter. } \\
\text { Look what happened. }\end{array}$ \\
\hline $\mathrm{T} 13$ & $\begin{array}{l}\text { Na slici su Petar, Petrov papagaj i Jovan. } \\
\text { Pogledajte šta se desilo. } \\
\text { There are Peter, Peter's parrot and John. } \\
\text { Look what happened. }\end{array}$ & $\mathrm{T} 14$ & $\begin{array}{l}\text { Na slici su Petar, Petrov hrčak i Jovan. } \\
\text { Pogledajte šta se desilo. } \\
\text { There are Peter, Peter's hamster and John. } \\
\text { Look what happened. }\end{array}$ \\
\hline
\end{tabular}




\begin{tabular}{|c|c|c|c|}
\hline $\begin{array}{l}\text { Item } \\
\text { num }\end{array}$ & $\begin{array}{l}\text { Introductory item } \\
\text { English translation }\end{array}$ & $\begin{array}{l}\text { Item } \\
\text { num }\end{array}$ & $\begin{array}{l}\text { Introductory item } \\
\text { English translation }\end{array}$ \\
\hline $\begin{array}{l}\mathrm{T} 15 \\
\mathrm{C} 5\end{array}$ & $\begin{array}{l}\text { Na slici su Petar, Petrov konj i Jovan. } \\
\text { Pogledajte šta se desilo. } \\
\text { There are Peter, Peter's horse and John. } \\
\text { Look what happened. }\end{array}$ & T16 & $\begin{array}{l}\text { Na slici su Petar, Petrov magarac i Jovan. } \\
\text { Pogledajte šta se desilo. } \\
\text { There are Peter, Peter's donkey and John. } \\
\text { Look what happened. }\end{array}$ \\
\hline $\mathrm{T} 17$ & $\begin{array}{l}\text { Na slici su Petar, Petrov patak i Jovan. } \\
\text { Pogledajte šta se desilo. } \\
\text { There are Peter, Peter's duck and John. } \\
\text { Look what happened. }\end{array}$ & $\begin{array}{l}\mathrm{T} 18 \\
\mathrm{C} 3\end{array}$ & $\begin{array}{l}\text { Na slici su Petar, Petrovo prase i Jovan. } \\
\text { Pogledajte šta se desilo. } \\
\text { There are Peter, Peter's pig and John. } \\
\text { Look what happened. }\end{array}$ \\
\hline T19 & $\begin{array}{l}\text { Na slici su Petar, Petrov bik i Jovan. } \\
\text { Pogledajte šta se desilo. } \\
\text { There are Peter, Peter's bull and John. } \\
\text { Look what happened. }\end{array}$ & $\begin{array}{l}\mathrm{T} 20 \\
\text { C10 } \\
\text { P1 }\end{array}$ & $\begin{array}{l}\text { Na slici su Petar, Petrov mačak i Jovan. } \\
\text { Pogledajte šta se desilo. } \\
\text { There are Peter, Peter's tomcat and John. } \\
\text { Look what happened. }\end{array}$ \\
\hline $\begin{array}{l}\mathrm{T} 21 \\
\mathrm{C} 9\end{array}$ & $\begin{array}{l}\text { Na slici su Petar, Petrov pas i Jovan. } \\
\text { Pogledajte šta se desilo. } \\
\text { There are Peter, Peter's dog and John. } \\
\text { Look what happened. }\end{array}$ & & $\begin{array}{l}\text { Na slici su Petar, Petrov petao i Jovan. } \\
\text { Pogledajte šta se desilo. } \\
\text { There are Peter, Peter's rooster and John. } \\
\text { Look what happened. }\end{array}$ \\
\hline
\end{tabular}




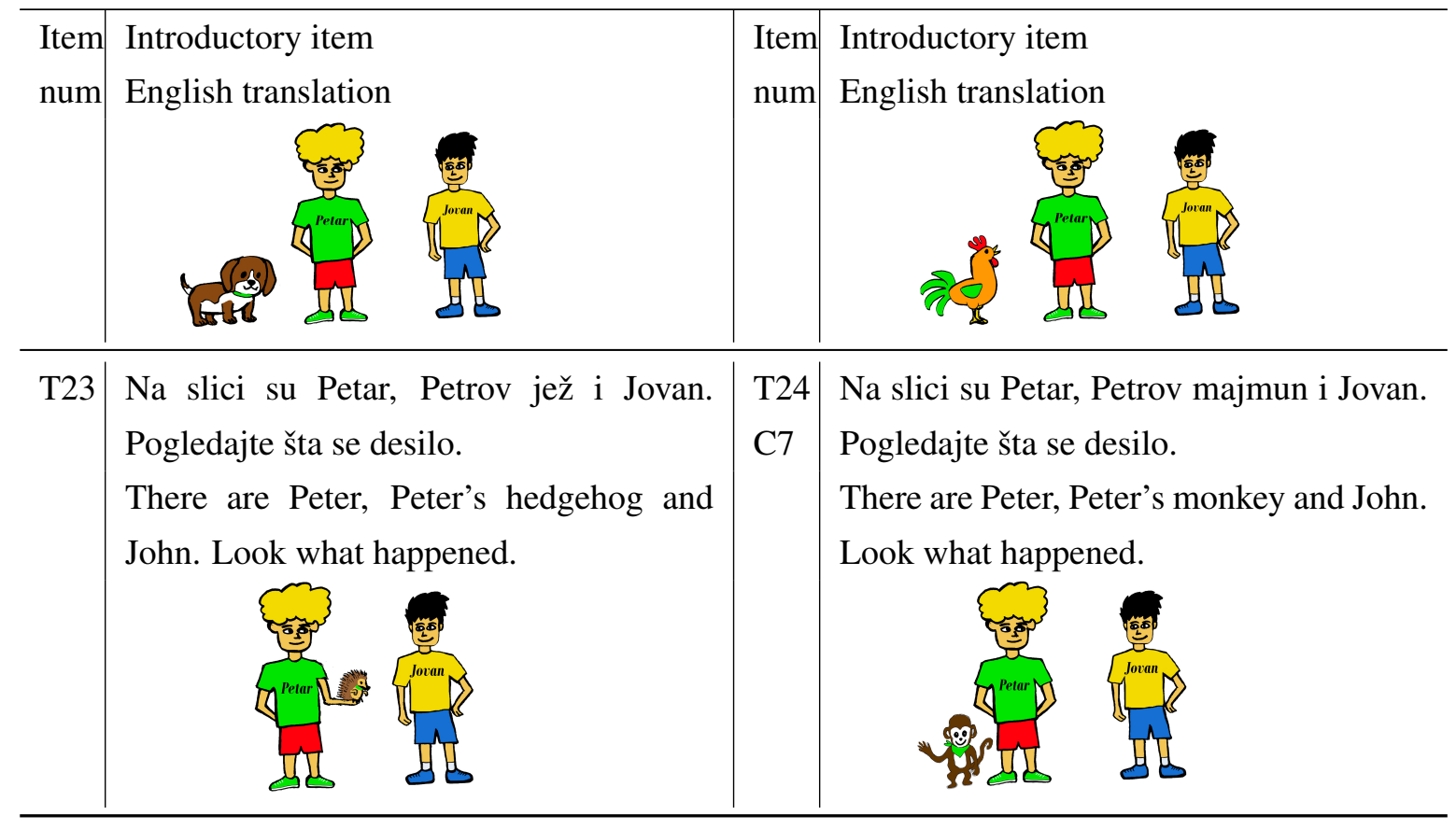

Test items: test sentences and pictures

Table A.2: Experiment 1: Test sentences and pictures

\begin{tabular}{lcc}
\hline Item number & Test item & English translation \\
\hline $1 \mathrm{a}$ & Jovanov papagaj ga je ugrizao. & 'John's parrot has bitten him.CL.' \\
1b & Jovanov papagaj je ugrizao njega. & 'John's parrot has bitten him.STR.' \\
\hline 2a & Jovanov hrčak ga je ogrebao. & 'John's hamster has scratched him.CL.' \\
& Jovanov hrčak je ogrebao njega. & 'John's hamster has scratched him.STR.' \\
\hline $3 \mathrm{~b}$ & Jovanov konj ga je srušio. & 'John's horse has knocked him.CL down.' \\
& Jovanov konj je srušio njega. & 'John's horse has knocked him.STR down.'
\end{tabular}




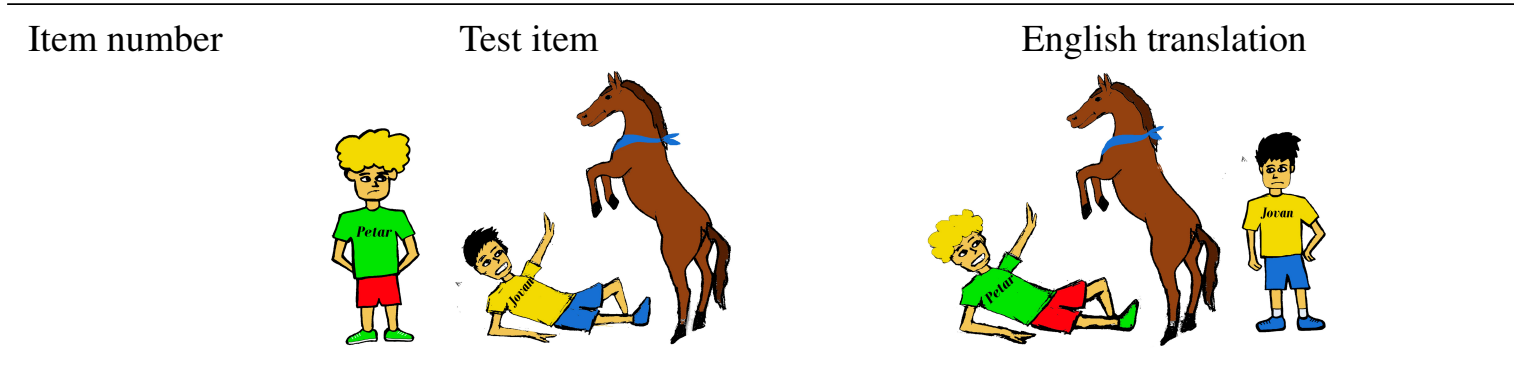

\begin{tabular}{|c|c|c|}
\hline $4 a$ & Jovanov magarac ga je gurnuo. & 'John's donkey has pushed him.CL.' \\
\hline $4 b$ & Jovanov magarac je gurnuo njega. & 'John's donkey has pushed him.STR.' \\
\hline $5 a$ & Jovanov patak ga je isprskao. & 'John's duck has splashed him.CL.' \\
\hline $5 b$ & Jovanov patak je isprskao njega. & 'John's duck has splashed him.STR.' \\
\hline $6 a$ & Jovanovo prase ga je isprljalo. & 'John's pig has made him.CL dirty.' \\
\hline $6 b$ & Jovanovo prase je isprljalo njega. & 'John's pig has made him.STR dirty.' \\
\hline $7 a$ & Jovanov bik ga je pojurio. & 'John's bull has chased him.CL.' \\
\hline $7 b$ & Jovanov bik je pojurio njega. & 'John's bull has chased him.STR.' \\
\hline $8 \mathrm{a}$ & Jovanov mačak ga je udario. & 'John's tomcat has hit him.CL.' \\
\hline $8 b$ & Jovanov mačak je udario njega. & 'John's tomcat has hit him.STR.' \\
\hline
\end{tabular}


Item number

$9 \mathrm{a}$

$9 b$

Jovanov pas ga je nagazio.

Jovanov pas je nagazio njega.
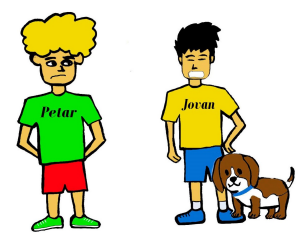

English translation

'John's dog has stepped on him.CL.'

'John's dog has stepped on him.STR.'

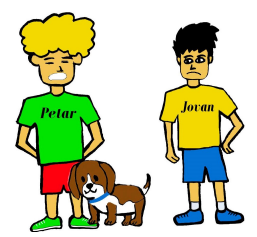

10a Jovanov petao ga je gledao. 'John's rooster has looked at him.CL.'
$10 \mathrm{~b}$ Jovanov petao je gledao njega.

$11 \mathrm{a}$
$11 \mathrm{~b}$
Jovanov jež ga je onjušio.
Jovanov jež je onjušio njega.

$13 \mathrm{a}$

Petrov papagaj ga je posmatrao.

'Peter's parrot has observed him.CL.'

$13 b$

Petrov papagaj je posmatrao njega.

'Peter's parrot has observed him.STR.'
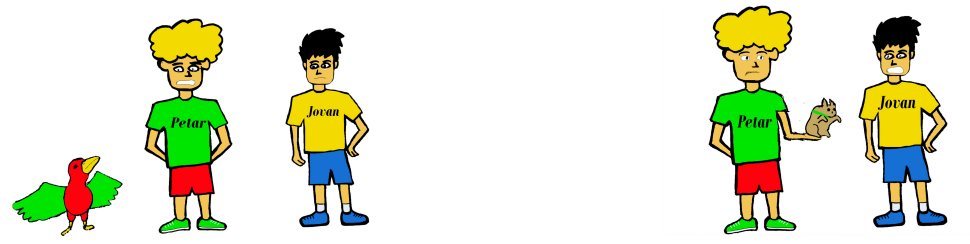

'Peter's hamster has scared him.CL.'

'Peter's hamster has scared him.STR.' 


Item number

$15 \mathrm{a}$

$15 b$

Petrov konj ga je napao.

Petrov konj je napao njega.

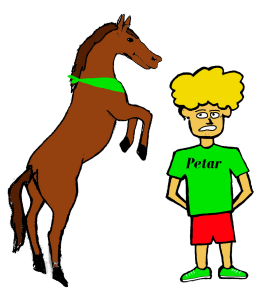

Petrov magarac ga je polizao.

$16 b$

Petrov magarac je polizao njega.
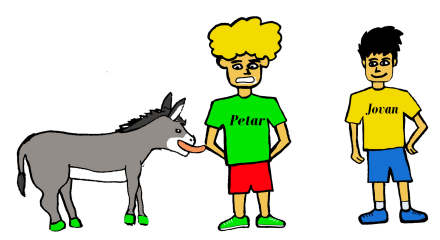

Petrov patak ga je pokvasio.

Petrov patak je pokvasio njega.

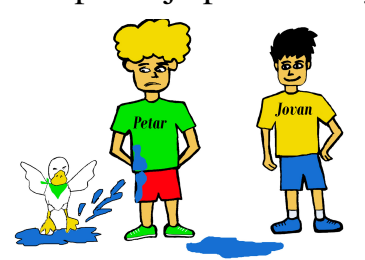

Petrovo prase ga je poljubilo.

$18 \mathrm{~b} \quad$ Petrovo prase je poljubilo njega.
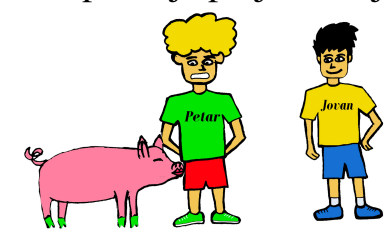

Petrov bik ga je povredio.

$19 b$
Petrov bik je povredio njega.

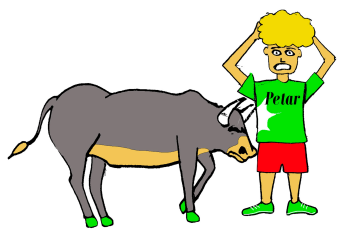

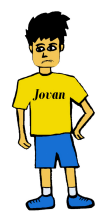

'Peter's horse has attacked him.CL.'

'Peter's horse has attacked him.STR.'
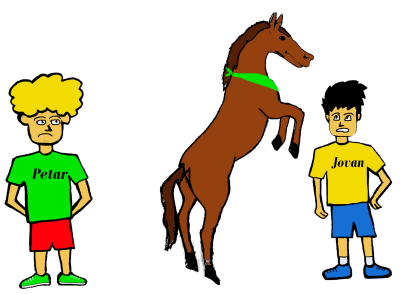

'Peter's donkey has licked him.CL.'

'Peter's donkey has licked him.STR.'

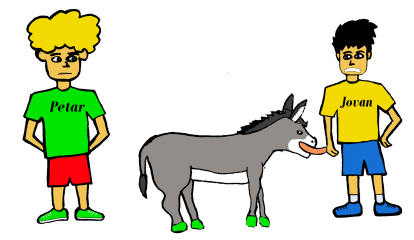

'Peter's duck has splashed him.CL.'

'Peter's duck has splashed him.STR.'

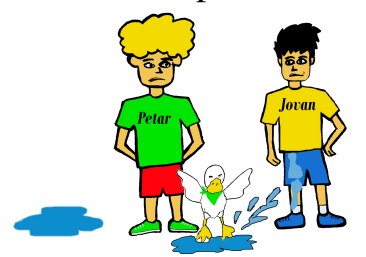

'Peter's pig has kissed him.CL.'

'Peter's pig has kissed him.STR.'

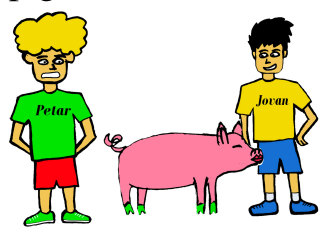

'Peter's bull has hurt him.CL.'

'Peter's bull has hurt him.STR.'

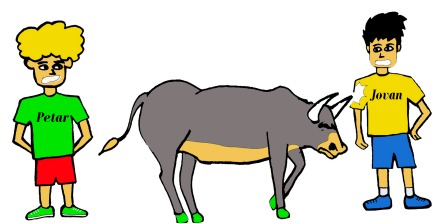


Item number

$20 \mathrm{a}$

$20 \mathrm{~b}$
Test item

Petrov mačak ga je zagrlio.

Petrov mačak je zagrlio njega.
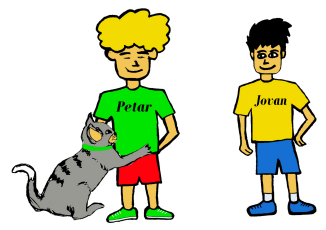

Petrov pas ga je pozdravio.

$21 b$

Petrov pas je pozdravio njega.
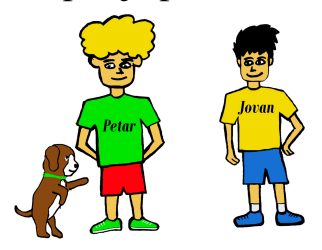

Petrov petao ga je kljucnuo.

Petrov petao je kljucnuo njega.
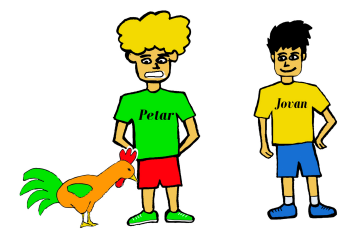

$22 \mathrm{a}$

$22 b$

\section{English translation}

'Peter's tomcat has hugged him.CL.'

'Peter's tomcat has hugged him.STR.'

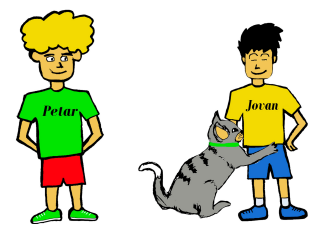

Petrov jež ga je ubo.

Petrov jež je ubo njega.
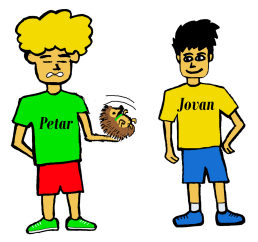

'Peter's dog has greeted him.CL.'

'Peter's dog has greeted him.STR.'

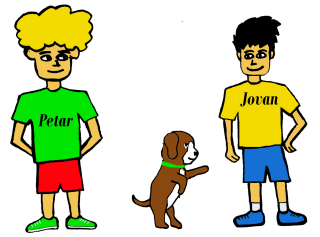

$23 \mathrm{a}$

$23 b$
Petrov majmun ga je imitirao.

Petrov majmun je imitirao njega.

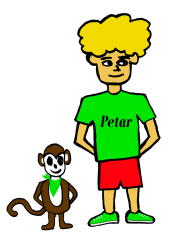

'Peter's rooster has pecked him.CL.'

'Peter's rooster has pecked him.STR.'

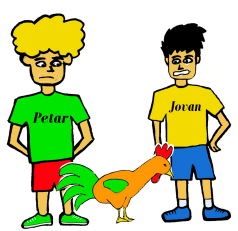

'Peter's hedgehog has pricked him.CL.'

'Peter's hedgehog has pricked him.STR.'

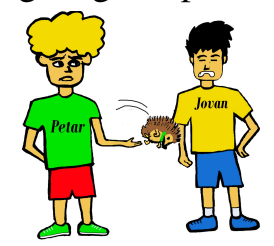

'Peter's monkey has imitated him.CL.'

'Peter's monkey has imitated him.STR.'

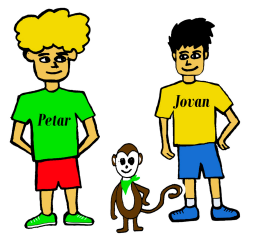




\section{Control items}

Table A.3: Experiment 1: Control sentences and pictures

\begin{tabular}{ll}
\hline Item Control item & English translation \\
\hline 1 Jovanov pas je nagazio Petra. & 'John's dog has stepped on Peter.'
\end{tabular}

2 Petrov petao je kljucnuo Jovana.

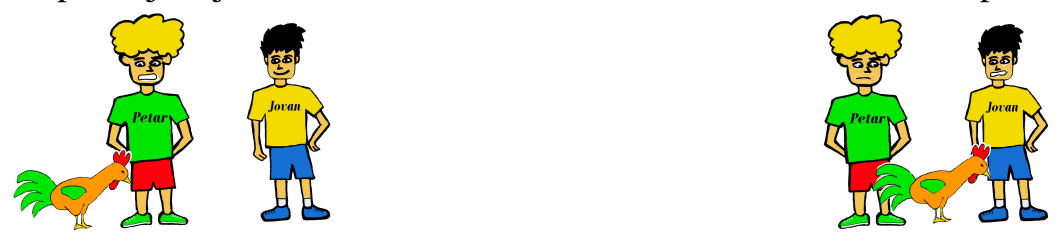

3 Petrovo prase je poljubilo Jovana.

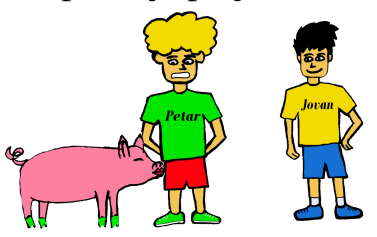

'Peter's pig has kissed John.'

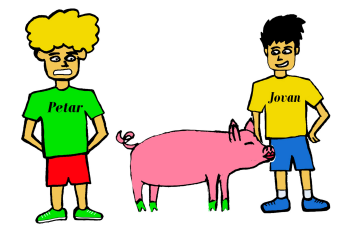

4 Jovanov bik je jurio Petra.

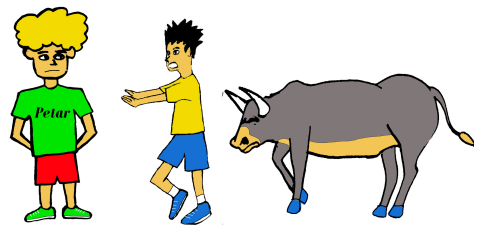

'John's bull has chased Peter.'

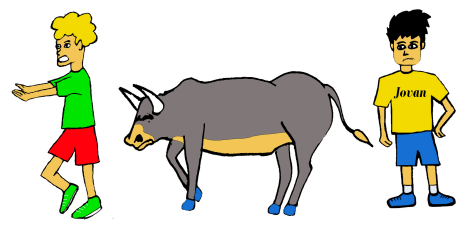

5 Petrov konj je napao Jovana.

'Peter's horse has attacked John.'
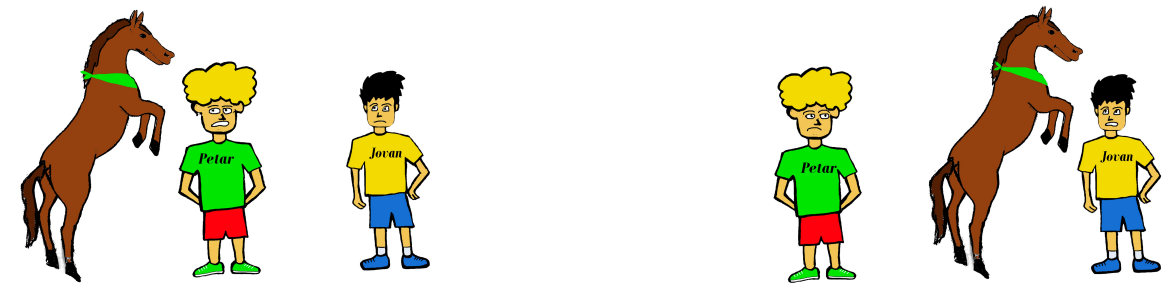

6 Jovanov magarac je gurnuo Petra.
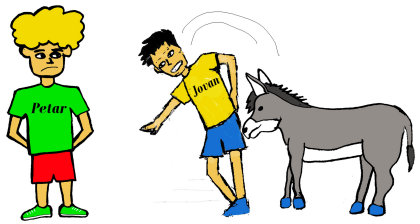

'John's donkey has pushed Peter.'

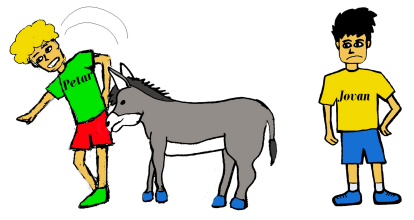

$7 \quad$ Petrov majmun je imitirao Jovana.

'Peter's monkey has imitated John.' 


\section{Item Control item}

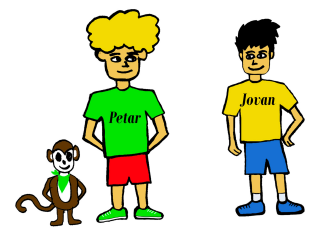

English translation

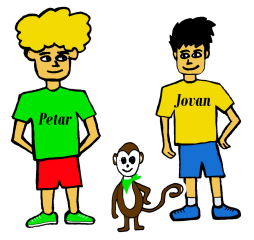

'John's hedgehog has sniffed Peter.'

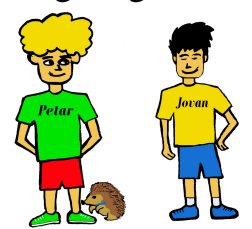

9 Petrov pas je pozdravio Jovana.

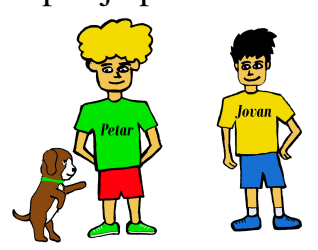

'Peter's dog has greeted John.'

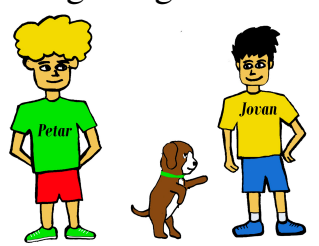

10 Petrov mačak je zagrlio Jovana.

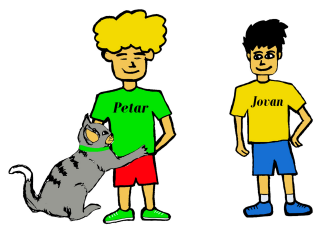

'Peter's tomcat has hugged John.'

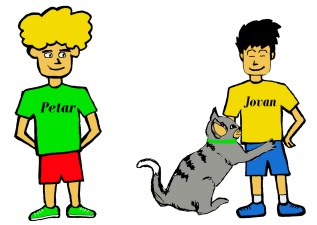

\section{Practice items}

Table A.4: Experiment 1: Practice sentences and pictures

\begin{tabular}{lcc}
\hline Item & Practice item & English translation \\
\hline 1 & Petrov pas je pozdravio Jovana. & 'Peter's dog has greeted John.'
\end{tabular}

2 Jovanov konj je srušio Petra. 'John's horse has knocked Peter down.'
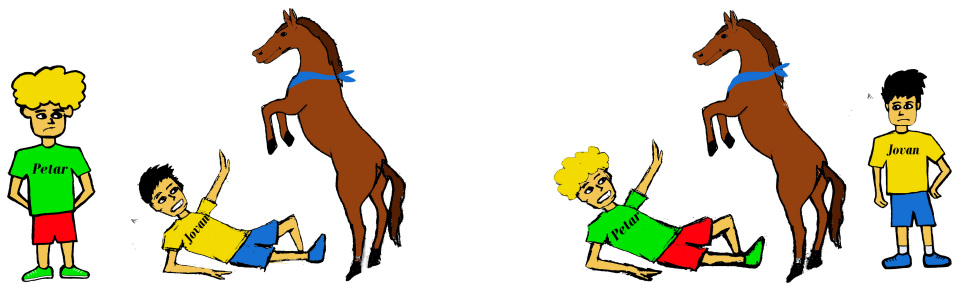


\section{Appendix B}

\section{Experiment 2}

Experiment 2 consists of 24 test items and 24 filler items. All items have 4 versions. The conditions are labelled in the following way for each test item:

a- $\mathrm{C} 1$ : possessive/ gender match

b- C2: possessive/ gender mismatch

c- C3: pro(noun)/ gender match

d- C4: pro(noun)/ gender mismatch

After each item, the corresponding question is given, and 3 options participants were supposed to choose from. English translations are provided in the column on the right. There were 3 practice items.

\section{Practice items}

Table B.1: Experiment 2: Practice items

\begin{tabular}{|l|l|}
\hline Practice item & English translation \\
\hline $\begin{array}{l}\text { Njena menadžerka je pričala sa novinarima dok } \\
\text { se Dajana slikala za novine. Jelena se radovala } \\
\text { dolazećem koncertu. }\end{array}$ & $\begin{array}{l}\text { Her manager was talking to reporters while Da- } \\
\text { jana posed for newspapers. Jelena was looking } \\
\text { forward to the coming concert. } \\
\text { Čija je menadžerka? }\end{array}$ \\
Dajanina / Jelenina / od nekog drugog & $\begin{array}{l}\text { Whanager is it? } \\
\text { Djana's / Jelena's /somebody else's }\end{array}$ \\
\hline $\begin{array}{l}\text { Dušan je čitao novine dok je pio kafu. Bojan se } \\
\text { već uveliko razbudio. }\end{array}$ & $\begin{array}{l}\text { Dusan was reading newspapers while he was } \\
\text { drinking coffee. Bojan was already awake. }\end{array}$ \\
Ko je pio kafu? & $\begin{array}{l}\text { Who was drinking coffee? } \\
\text { Dušan / Bojan / neko drugi }\end{array}$ \\
\hline $\begin{array}{l}\text { Razgovarao je telefonom dok je Darko potpisi- } \\
\text { vao naloge. Dejan je bio ubeđen da će dogovoriti } \\
\text { posao. }\end{array}$ & $\begin{array}{l}\text { (He) was talking on the phone while Darko } \\
\text { signed orders. Dejan was sure that he would ar- } \\
\text { Ko je razgovarao telefonom? } \\
\text { Darko / Dejan / neko drugi }\end{array}$ \\
\hline
\end{tabular}




\section{Test items}

Table B.2: Experiment 2: Test items with questions

\begin{tabular}{|c|c|c|}
\hline Item & Test item & English translation \\
\hline $1 \mathrm{a}$ & $\begin{array}{l}\text { Njegov menadžer je pričao fanovima dok je } \\
\text { Jovan potpisivao autograme. Petar je bio } \\
\text { srećan što je koncert uspešno završen. } \\
\text { Čiji je menadžer? } \\
\text { Jovanov / Petrov / od nekog drugog }\end{array}$ & $\begin{array}{l}\text { His manager talked to the fans while Jovan } \\
\text { signed autographs. Peter was happy that the } \\
\text { concert was successfully finished. } \\
\text { Whose manager is it? } \\
\text { Jovan's / Petar's / somebody else's }\end{array}$ \\
\hline $1 b$ & $\begin{array}{l}\text { Njen menadžer je pričao fanovima dok je } \\
\text { Jovan potpisivao autograme. Ivana je bila } \\
\text { srećna što je koncert uspešno završen. } \\
\text { Čiji je menadžer? } \\
\text { Jovanov / Ivanin / od nekog drugog }\end{array}$ & $\begin{array}{l}\text { Her manager talked to the fans while Jovan } \\
\text { signed autographs. Ivana was happy that the } \\
\text { concert was successfully finished. } \\
\text { Whose manager is it? } \\
\text { Jovan's / Ivana's / somebody else's }\end{array}$ \\
\hline $1 \mathrm{c}$ & $\begin{array}{l}\text { Pričao je fanovima dok je Jovan potpisivao } \\
\text { autograme. Petar je bio srećan što je koncert } \\
\text { uspešno završen. } \\
\text { Ko je pričao fanovima? } \\
\text { Jovan / Petar / neko drugi }\end{array}$ & $\begin{array}{l}\text { (He) talked to the fans while Jovan signed au- } \\
\text { tographs. Peter was happy that the concert } \\
\text { was successfully finished. } \\
\text { Who talked to the fans? } \\
\text { Jovan / Petar / somebody else }\end{array}$ \\
\hline $1 d$ & $\begin{array}{l}\text { Pričala je fanovima dok je Jovan potpisivao } \\
\text { autograme. Ivana je bila srećna što je koncert } \\
\text { uspešno završen. } \\
\text { Ko je pričao fanovima? } \\
\text { Jovan / Ivana / neko drugi }\end{array}$ & $\begin{array}{l}\text { (She) talked to the fans while Jovan signed au- } \\
\text { tographs. Ivana was happy that the concert } \\
\text { was successfully finished. } \\
\text { Who talked to the fans? } \\
\text { Jovan / Ivana / somebody else }\end{array}$ \\
\hline $\begin{array}{l}2 \mathrm{a} \\
2 \mathrm{~b}\end{array}$ & $\begin{array}{l}\text { Njegov/Njen doktor je čitao rezultate dok je } \\
\text { Danilo sedeo u ordinaciji. Maksim je bio } \\
\text { zadovoljan/Bojana je bila zadovoljna dijagno- } \\
\text { zom. Čiji je doktor? } \\
\text { Danilov Maksimov/Bojanin od nekog } \\
\text { drugog }\end{array}$ & $\begin{array}{l}\text { His/Her doctor examined the results while } \\
\text { Danilo was sitting in the doctor's practice. } \\
\text { Maksim/Bojana was satisfied with the diag- } \\
\text { nosis. Whose doctor is it? } \\
\text { Danilo's Maksim's/Bojana's somebody } \\
\text { else's }\end{array}$ \\
\hline $\begin{array}{l}2 \mathrm{c} \\
2 \mathrm{~d}\end{array}$ & $\begin{array}{l}\text { Čitao/Čitala je rezultate dok je Danilo sedeo u } \\
\text { ordinaciji. Maksim je bio zadovoljan/Bojana } \\
\text { je bila zadovoljna dijagnozom. } \\
\text { Ko je čitao rezultate? } \\
\text { Danilo Maksim/Bojana neko drugi }\end{array}$ & $\begin{array}{l}\text { (He)/(She) examined the results while Danilo } \\
\text { was sitting in the doctor's practice. Mak- } \\
\text { sim/Bojana was satisfied with the diagnosis. } \\
\text { Who examined the results? } \\
\text { Danilo Maksim/Bojana somebody else }\end{array}$ \\
\hline
\end{tabular}




\begin{tabular}{|c|c|c|}
\hline Item & Test item & English translation \\
\hline $3 a, b$ & $\begin{array}{l}\text { Njegov/Njen frizer je pravio frizuru dok je } \\
\text { Miloš čekao red. Lazar je bio zadovol- } \\
\text { jan/Jasna je bila zadovoljna izgledom. } \\
\text { Ćiji je frizer? } \\
\text { Milošev Lazarev/Jasnin od nekog drugog }\end{array}$ & $\begin{array}{l}\text { His/Her hairdresser was making a hairstyle } \\
\text { while Milos was waiting. Lazar/Jasna was } \\
\text { satisfied with the look. } \\
\text { Whose hairdresser is it? } \\
\text { Milos's Lazar's/Jasna's somebody else's }\end{array}$ \\
\hline $3 \mathrm{c}, \mathrm{d}$ & $\begin{array}{l}\text { Pravio/Pravila je frizuru dok je Miloš čekao } \\
\text { red. Lazar je bio zadovoljan/Jasna je bila } \\
\text { zadovoljna izgledom. } \\
\text { Ko je pravio frizuru? } \\
\text { Miloš Lazar/Jasna neko drugi }\end{array}$ & $\begin{array}{l}\text { (He)/(She) was making a hairstyle while Mi- } \\
\text { los was waiting. Lazar/Jasna was satisfied } \\
\text { with the look. } \\
\text { Who was making a hairstyle? } \\
\text { Milos Lazar/Jasna somebody else }\end{array}$ \\
\hline $4 a, b$ & $\begin{array}{l}\text { Njegov/Njen učitelj je pisao zadatke na tabli } \\
\text { dok je Milan nestrpljivo čekao početak testa. } \\
\text { Bojan je bio ubeđen/Vesna je bila ubeđena da } \\
\text { će svi učenici dobiti dobre ocene. } \\
\text { Čiji je učitelj? } \\
\text { Milanov Bojanov/Vesnin od nekog drugog }\end{array}$ & $\begin{array}{l}\text { His/Her teacher was writing assignments on } \\
\text { the blackboard while Milan was impatiently } \\
\text { waiting for the test to begin. Bojan/Vesna was } \\
\text { sure that all the students will get good marks. } \\
\text { Whose teacher is it? } \\
\text { Milan's Bojan's/Vesna's somebody else's }\end{array}$ \\
\hline $4 \mathrm{c}, \mathrm{d}$ & $\begin{array}{l}\text { Pisao/Pisala je zadatke na tabli dok je Mi- } \\
\text { lan nestrpljivo čekao početak testa. Bojan je } \\
\text { bio ubeđen/Vesna je bila ubeđena da će svi } \\
\text { učenici dobiti dobre ocene. } \\
\text { Ko je pisao zadatke na tabli? } \\
\text { Milan Bojan/Vesna neko drugi }\end{array}$ & $\begin{array}{l}\text { (He)/(She) was writing assignments on the } \\
\text { blackboard while Milan was impatiently wait- } \\
\text { ing for the test to begin. Bojan/Vesna was sure } \\
\text { that all the students will get good marks. } \\
\text { Who was writing assignments on the black- } \\
\text { board? } \\
\text { Milan Bojan/Vesna somebody else }\end{array}$ \\
\hline $5 \mathrm{a}, \mathrm{b}$ & $\begin{array}{l}\text { Njegov/Njen trener je objašnjavao napad } \\
\text { dok je Zoran oblačio dres. Marko je bio } \\
\text { ubeđen/Milka je bila ubeđena da će pobediti. } \\
\text { Čiji je trener? } \\
\text { Zornov Markov/Milkin od nekog drugog }\end{array}$ & $\begin{array}{l}\text { His/Her coach was explaining the attack } \\
\text { while Zoran was putting his jersey on. } \\
\text { Marko/Milka was conviced that they will win. } \\
\text { Whose coach is it? } \\
\text { Zoran's Marko's/Milka's somebody else's }\end{array}$ \\
\hline $5 \mathrm{c}, \mathrm{d}$ & $\begin{array}{l}\text { Objašnjavao/Objašnjavala je napad dok je Zo- } \\
\text { ran oblačio dres. Marko je bio ubeđen/Milka } \\
\text { je bila ubeđena da će pobediti. } \\
\text { Ko je objašnjavao napad? } \\
\text { Zoran Marko/Milka neko drugi }\end{array}$ & $\begin{array}{l}\text { (He)/(She) was explaining the attack while } \\
\text { Zoran was putting his jersey on. Marko/Milka } \\
\text { was conviced that they will win. } \\
\text { Who was explaining the attack? } \\
\text { Zoran Marko/Milka somebody else }\end{array}$ \\
\hline $6 \mathrm{a}, \mathrm{b}$ & $\begin{array}{l}\text { Njegov/Njen advokat je čitao slučaj dok je } \\
\text { Dejan čekao u kancelariji. Filip je bio opti- } \\
\text { mističan/Elena je bila optimistična u vezi sa } \\
\text { parnicom. Čiji je advokat? } \\
\text { Dejanov Filipov/Elenin od nekog drugog }\end{array}$ & $\begin{array}{l}\text { His/Her lawyer was reading the case while } \\
\text { Dejan was sitting in the office. Filip/Elena } \\
\text { was optimistic about the litigation. } \\
\text { Whose lawyer is it? } \\
\text { Dejan's Filip's/Elena's somebody else's }\end{array}$ \\
\hline
\end{tabular}




\begin{tabular}{|c|c|c|}
\hline Item & Test item & English translation \\
\hline $6 \mathrm{c}, \mathrm{d}$ & $\begin{array}{l}\text { Čitao/Čitala je slučaj dok je Dejan čekao u } \\
\text { kancelariji. Filip je bio optimističan/Elena je } \\
\text { bila optimistična u vezi sa parnicom. } \\
\text { Ko je čitao slučaj? } \\
\text { Dejan Filip/Elena neko drugi }\end{array}$ & $\begin{array}{l}(\mathrm{He}) /(\mathrm{She}) \text { was reading the case while Dejan } \\
\text { was sitting in the office. Filip/Elena was opti- } \\
\text { mistic about the litigation. } \\
\text { Who was reading the case? } \\
\text { Dejan Filip/Elena somebody else }\end{array}$ \\
\hline $7 \mathrm{a}, \mathrm{b}$ & $\begin{array}{l}\text { Njegov/Njen sekretar je razgovorao tele- } \\
\text { fonom dok je Boris potpisivao ugovore. } \\
\text { Dušan je upravo ugovorio/Marta je upravo } \\
\text { ugovorila sastanak sa sponzorima. } \\
\text { Čiji je sekretar? } \\
\text { Borisov Dušanov/Martin od nekog drugog }\end{array}$ & $\begin{array}{l}\text { His/Her secretary was talking on the phone } \\
\text { while Boris was signing contracts. Du- } \\
\text { san/Marta has just arranged a meeting with } \\
\text { sponsors. } \\
\text { Whose secretary is it? } \\
\text { Boris's Dusan's/Marta's somebody else's }\end{array}$ \\
\hline $7 \mathrm{c}, \mathrm{d}$ & $\begin{array}{l}\text { Razgovorao/Razgovarala je telefonom dok je } \\
\text { Boris potpisivao ugovore. Dušan je upravo } \\
\text { ugovorio/Marta je upravo ugovorila sastanak } \\
\text { sa sponzorima. } \\
\text { Ko je razgovarao telefonom? } \\
\text { Boris Dušan/Marta neko drugi }\end{array}$ & $\begin{array}{l}\text { (He)/(She) was talking on the phone while } \\
\text { Boris was signing contracts. Dusan/Marta has } \\
\text { just arranged a meeting with sponsors. } \\
\text { Who was talking on the phone? } \\
\text { Boris Dusan/Marta somebody else }\end{array}$ \\
\hline $8 \mathrm{a}, \mathrm{b}$ & $\begin{array}{l}\text { Njegov/Njen profesor je pregledao zadatke } \\
\text { dok je Nikola slušao muziku. Stefan je bio } \\
\text { zadovoljan/Jovana je bila zadovoljna rešen- } \\
\text { jima. Čiji je profesor? } \\
\text { Nikolin Stefanov/Jovanin od nekog drugog }\end{array}$ & $\begin{array}{l}\text { His/Her professor was grading assignments } \\
\text { while Nikola was listening to music. Ste- } \\
\text { fan/Jovana was satisfied with the results. } \\
\text { Whose professor is it? } \\
\text { Nikola's Stefan's/Jovana's somebody else's }\end{array}$ \\
\hline $8 \mathrm{c}, \mathrm{d}$ & $\begin{array}{l}\text { Pregledao/Pregledala je zadatke dok je Nikola } \\
\text { slušao muziku. Stefan je bio zadovol- } \\
\text { jan/Jovana je bila zadovoljna rešenjima. } \\
\text { Ko je pregledao zadatke? } \\
\text { Nikola Stefan/Jovana neko drugi }\end{array}$ & $\begin{array}{l}\text { (He)/(She) was grading assignments while } \\
\text { Nikola was listening to music. Stefan/Jovana } \\
\text { was satisfied with the results. } \\
\text { Who was grading assignments? } \\
\text { Nikola Stefan/Jovana somebody else }\end{array}$ \\
\hline $9 \mathrm{a}, \mathrm{b}$ & $\begin{array}{l}\text { Njegov/Njen radnik je čistio alat dok je } \\
\text { Aleksa pričao o narednom poslu. Bogdan je } \\
\text { bio srećan/Marija je bila srećna da se bliži kraj } \\
\text { radnog vremena. Čiji je radnik? } \\
\text { Aleksin Bogdanov/Marijin od nekog drugog }\end{array}$ & $\begin{array}{l}\text { His/Her worker was cleaning the tools while } \\
\text { Aleksa was talking about the next job. Bog- } \\
\text { dan/Marija was happy that it is soon the end } \\
\text { of the working day. Whose worker is it? } \\
\text { Aleksa's Bogdan's/Marija's somebody else's }\end{array}$ \\
\hline $9 \mathrm{c}, \mathrm{d}$ & $\begin{array}{l}\text { Čistio/Čistila je alat dok je Aleksa pričao o } \\
\text { narednom poslu. Bogdan je bio srećan/Marija } \\
\text { je bila srećna da se bliži kraj radnog vremena. } \\
\text { Ko je čistio alat? } \\
\text { Aleksa Bogdan/Marija neko drugi }\end{array}$ & $\begin{array}{l}\text { (He)/(She) was cleaning the tools while } \\
\text { Aleksa was talking about the next job. Bog- } \\
\text { dan/Marija was happy that it is soon the end } \\
\text { of the working day. } \\
\text { Who was cleaning the tools? } \\
\text { Aleksa Bogdan/Marija somebody else }\end{array}$ \\
\hline
\end{tabular}




\begin{tabular}{|c|c|c|}
\hline Item & Test item & English translation \\
\hline $\begin{array}{l}10 a \\
b\end{array}$ & $\begin{array}{l}\text { Njegov/Njen mehaničar je pregledao auto dok } \\
\text { je Dragan razmišljao o godišnjem odmoru. } \\
\text { Mladen je znao/Tijana je znala da je kvar oz- } \\
\text { biljan. Čiji je mehaničar? } \\
\text { Draganov Mladenov/Tijanin od nekog drugog }\end{array}$ & $\begin{array}{l}\text { His/Her mechanic was checking the car } \\
\text { while Dragan was thinking about the holiday. } \\
\text { Mladen/Tijana knew that the damage was se- } \\
\text { rious. Whose mechanic is it? } \\
\text { Dragan's Mladen's/Tijana's somebody else's }\end{array}$ \\
\hline $\begin{array}{l}10 \mathrm{c}, \\
\mathrm{d}\end{array}$ & $\begin{array}{l}\text { Pregledao/Pregledala je auto dok je Dragan } \\
\text { razmišljao o godišnjem odmoru. Mladen je } \\
\text { znao/Tijana je znala da je kvar ozbiljan. } \\
\text { Ko je pregledao auto? } \\
\text { Dragan Mladen/Tijana neko drugi }\end{array}$ & $\begin{array}{l}(\mathrm{He}) /(\mathrm{She}) \text { was checking the car while } \\
\text { Dragan was thinking about the holiday. } \\
\text { Mladen/Tijana knew that the damage was se- } \\
\text { rious. Who was checking the car? } \\
\text { Dragan Mladen/Tijana somebody else }\end{array}$ \\
\hline $\begin{array}{l}11 \mathrm{a}, \\
\mathrm{b}\end{array}$ & $\begin{array}{l}\text { Njegov/Njen savetnik je predlagao rešenja } \\
\text { dok je Stevan čitao katalog. Branko nije bio } \\
\text { zadovoljan/Milica nije bila zadovoljna sug- } \\
\text { estijama. Čiji je savetnik? } \\
\text { Stevanov Brankov/Milicin od nekog drugog }\end{array}$ & $\begin{array}{l}\text { His/Her adviser was suggesting solutions } \\
\text { while Stevan was reading a catalogue. } \\
\text { Branko/Milica wasn't satisfied with the ideas. } \\
\text { Whose adviser is it? } \\
\text { Stevan's Branko's/Milica's somebody else's }\end{array}$ \\
\hline $\begin{array}{l}11 \mathrm{c}, \\
\mathrm{d}\end{array}$ & $\begin{array}{l}\text { Predlagao/Predlagala je rešenja dok je Stevan } \\
\text { čitao katalog. Branko nije bio zadovoljan/ } \\
\text { Milica nije bila zadovoljna sugestijama. } \\
\text { Ko je predlagao rešenja? } \\
\text { Stevan Branko/Milica neko drugi }\end{array}$ & $\begin{array}{l}(\mathrm{He}) /(\mathrm{She}) \text { was suggesting solutions } \\
\text { while Stevan was reading a catalogue. } \\
\text { Branko/Milica wasn't satisfied with the ideas. } \\
\text { Who was suggesting solutions? } \\
\text { Stevan Branko/Milica somebody else }\end{array}$ \\
\hline $\begin{array}{l}12 \mathrm{a} \\
\mathrm{b}\end{array}$ & $\begin{array}{l}\text { Njegov/Njen majstor je krečio zid dok je Sto- } \\
\text { jan pevušio melodiju iz filma. Vedranu/Milici } \\
\text { se svidela nova boja sobe. } \\
\text { Čiji je majstor? } \\
\text { Stojanov Vedranov/Milicin od nekog drugog }\end{array}$ & $\begin{array}{l}\text { His/Her worker was painting the wall while } \\
\text { Stojan was singing a melody from a movie. } \\
\text { Vedran/Milica liked the new colour of the } \\
\text { room. Whose worker is it? } \\
\text { Stojan's Vedran's/Milica's somebody else's }\end{array}$ \\
\hline $\begin{array}{l}12 \mathrm{c}, \\
\mathrm{d}\end{array}$ & $\begin{array}{l}\text { Krečio/Krečila je zid dok je Stojan pevušio } \\
\text { melodiju iz filma. Vedranu/Milici se svidela } \\
\text { nova boja sobe. } \\
\text { Ko je krečio zid? } \\
\text { Stojan Vedran/Milica neko drugi }\end{array}$ & $\begin{array}{l}\text { (He)/(She) was painting the wall while Sto- } \\
\text { jan was singing a melody from a movie. Ve- } \\
\text { dran/Milica liked the new colour of the room. } \\
\text { Who was painting the wall? } \\
\text { Stojan Vedran/Milica somebody else }\end{array}$ \\
\hline $\begin{array}{l}13 \mathrm{a}, \\
\mathrm{b}\end{array}$ & $\begin{array}{l}\text { Njena/Njegova frizerka je mešala farbu dok je } \\
\text { Branka čekala da joj se kosa osuši. Nevena je } \\
\text { bila zadovoljna/Damjan je bio zadovoljan bo- } \\
\text { jom. Čija je frizerka? } \\
\text { Brankina Nevenina/Damjanova od nekog dru- } \\
\text { gog }\end{array}$ & $\begin{array}{l}\text { Her/his hairdresser was mixing the dye while } \\
\text { Branka was waiting her hair to get dry. } \\
\text { Nevena/Damjan was satisfied with the colour. } \\
\text { Whose hairdresser is it? } \\
\text { Branka's Nevena's/Damjan's somebody } \\
\text { else's }\end{array}$ \\
\hline
\end{tabular}




\begin{tabular}{|c|c|c|}
\hline Item & Test item & English translation \\
\hline $\begin{array}{l}13 \mathrm{c}, \\
\mathrm{d}\end{array}$ & $\begin{array}{l}\text { Mešala/Mešao je farbu dok je Branka čekala } \\
\text { da joj se kosa osuši. Nevena je bila zado- } \\
\text { voljna/Damjan je bio zadovoljan bojom. } \\
\text { Ko je mešao farbu? } \\
\text { Branka Nevena/Damjan neko drugi }\end{array}$ & $\begin{array}{l}\text { (She)/(He) was mixing the dye while } \\
\text { Branka was waiting her hair to get dry. } \\
\text { Nevena/Damjan was satisfied with the colour. } \\
\text { Who was mixing the dye? } \\
\text { Branka Nevena/Damjan somebody else }\end{array}$ \\
\hline $\begin{array}{l}14 a \\
b\end{array}$ & $\begin{array}{l}\text { Njena/Njegova knjigovođa je sabirala račune } \\
\text { dok je Dušica računala u Excel-u. Zorana } \\
\text { nije bila zadovoljna/Tadija nije bio zadovol- } \\
\text { jan brojkama. Čija je knjigovođa? } \\
\text { Dušicina Zoranina/Tadijina od nekog drugog }\end{array}$ & $\begin{array}{l}\text { Her/His accountant was working on the bills } \\
\text { while Dusica was working in Excel. Zo- } \\
\text { rana/Tadija was not happy with the numbers. } \\
\text { Whose accountant is it? } \\
\text { Dusica's Zorana's/Tadija's somebody else's }\end{array}$ \\
\hline $\begin{array}{l}14 \mathrm{c}, \\
\mathrm{d}\end{array}$ & $\begin{array}{l}\text { Sabirala/Sabirao je račune dok je Dušica } \\
\text { računala u Excel-u. Zorana nije bila zado- } \\
\text { voljna/Tadija nije bio zadovoljan brojkama. } \\
\text { Ko je sabirao račune? } \\
\text { Dušica Zorana/Tadija neko drugi }\end{array}$ & $\begin{array}{l}\text { (She)/(He) was working on the bills while } \\
\text { Dusica was working in Excel. Zorana/Tadija } \\
\text { was not happy with the numbers. } \\
\text { Who was working on the bills? } \\
\text { Dusica Zorana/Tadija somebody else }\end{array}$ \\
\hline $\begin{array}{l}15 \mathrm{a}, \\
\mathrm{b}\end{array}$ & $\begin{array}{l}\text { Njena/Njegova krojačica je uzimala mere dok } \\
\text { je Danica razmišljala o bojama i materijalima. } \\
\text { Zorica je bila takođe veoma uzbuđena/Siniša } \\
\text { je bio takođe veoma uzbuđen zbog venčanja. } \\
\text { Čija je krojačica? } \\
\text { Danicina Zoricina/Sinišina od nekog drugog }\end{array}$ & $\begin{array}{l}\text { Her/His tailor was getting the measurements } \\
\text { while Danica was thinking about the decora- } \\
\text { tion. Zorica/Sinisa was excited because of the } \\
\text { wedding. } \\
\text { Whose tailor is it? } \\
\text { Danica's Zorica's/Sinisa's somebody else's }\end{array}$ \\
\hline $\begin{array}{l}15 \mathrm{c}, \\
\mathrm{d}\end{array}$ & $\begin{array}{l}\text { Uzimala/Uzimao je mere dok je Danica } \\
\text { razmišljala o bojama i materijalima. Zorica } \\
\text { je bila takođe veoma uzbuđena/Siniša je bio } \\
\text { takođe veoma uzbuđen zbog venčanja. } \\
\text { Ko je uzimao mere? } \\
\text { Danica Zorica/Siniša neko drugi }\end{array}$ & $\begin{array}{l}(\mathrm{She}) /(\mathrm{He}) \text { was getting the measurements } \\
\text { while Danica was thinking about the decora- } \\
\text { tion. Zorica/Sinisa was excited because of the } \\
\text { wedding. } \\
\text { Who was getting the measurements? } \\
\text { Danica Zorica/Sinisa somebody else }\end{array}$ \\
\hline $\begin{array}{l}16 a \\
b\end{array}$ & $\begin{array}{l}\text { Njena/Njegova pomoćnica je kuvala sarmu } \\
\text { dok je Lidija gledala youtube. Milena je bila } \\
\text { srećna/Sreten je bio srećan kako je ručak is- } \\
\text { pao. Čija je pomoćnica? } \\
\text { Lidijina Milenina/Sretenova od nekog } \\
\text { drugog }\end{array}$ & $\begin{array}{l}\text { Her/His chef was cooking sarma while Lidija } \\
\text { was watching youtube. Milena/Sreten was } \\
\text { happy how the lunch turned out. } \\
\text { Whose chef is it? } \\
\text { Lidija's Milena's/Sreten's somebody } \\
\text { else's }\end{array}$ \\
\hline $\begin{array}{l}16 \mathrm{c} \\
\mathrm{d}\end{array}$ & $\begin{array}{l}\text { Kuvala je sarmu dok je Lidija gledala } \\
\text { youtube. Milena je bila srećna/Sreten je bio } \\
\text { srećan kako je ručak ispao. } \\
\text { Ko je kuvao sarmu? } \\
\text { Lidija Milena/Sreten neko drugi }\end{array}$ & $\begin{array}{l}\text { (She)/(He) was cooking sarma while Lidija } \\
\text { was watching youtube. Milena/Sreten was } \\
\text { happy how the lunch turned out. } \\
\text { Who was cooking sarma? } \\
\text { Lidija Milena/Sreten somebody else }\end{array}$ \\
\hline
\end{tabular}




\begin{tabular}{|c|c|c|}
\hline Item & Test item & English translation \\
\hline $\begin{array}{l}17 \mathrm{a}, \\
\mathrm{b}\end{array}$ & $\begin{array}{l}\text { Njena/Njegova dadilja je čuvala bebu dok se } \\
\text { Olivera spremala za posao. Tatjana je bila } \\
\text { srećna/Miodrag je bio srećan što je beba u do- } \\
\text { brim rukama. Čija je dadilja? } \\
\text { Oliverina Tatjanina/Miodragova od nekog } \\
\text { drugog }\end{array}$ & $\begin{array}{l}\text { Her/His nanny was looking after the baby } \\
\text { while Olivera was getting ready for work. } \\
\text { Tatjana/Miodrag was happy that the baby was } \\
\text { in good hands. Whose nanny is it? } \\
\text { Olivera's Tatjana's/Miodrag's somebody } \\
\text { else's }\end{array}$ \\
\hline $\begin{array}{l}17 \mathrm{c}, \\
\mathrm{d}\end{array}$ & $\begin{array}{l}\text { Čuvala/Čuvao je bebu dok se Olivera spre- } \\
\text { mala za posao. Tatjana je bila srećna/Miodrag } \\
\text { je bio srećan što je beba u dobrim rukama. } \\
\text { Ko je čuvao bebu? } \\
\text { Olivera Tatjana/Miodrag neko drugi }\end{array}$ & $\begin{array}{l}\text { (She)/(He) was looking after the baby while } \\
\text { Olivera was getting ready for work. Tat- } \\
\text { jana/Miodrag was happy that the baby was in } \\
\text { good hands. Who was looking after the baby? } \\
\text { Olivera Tatjana/Miodrag somebody else }\end{array}$ \\
\hline $\begin{array}{l}18 \mathrm{a}, \\
\mathrm{b}\end{array}$ & $\begin{array}{l}\text { Njena/Njegova šefica je radila za kom- } \\
\text { pjuterom dok je Sandra slušala muziku. Sofija } \\
\text { je bila umorna/Rastko je bio umoran od } \\
\text { gledanja u monitor. Čija je šefica? } \\
\text { Sandrina Sofijina/Rastkova od nekog drugog }\end{array}$ & $\begin{array}{l}\text { Her/his boss was working on the com- } \\
\text { puter while Sandra was listening to music. } \\
\text { Sofija/Rastko was tired from looking at the } \\
\text { screen. Whose boss is it? } \\
\text { Sandra's Sofija's/Rastko's somebody else's }\end{array}$ \\
\hline $\begin{array}{l}18 \mathrm{c}, \\
\mathrm{d}\end{array}$ & $\begin{array}{l}\text { Radila/Radio je za kompjuterom dok je } \\
\text { Sandra slušala muziku. Sofija je bila } \\
\text { umorna/Rastko je bio umoran od gledanja u } \\
\text { monitor. Ko je radio za kompjuterom? } \\
\text { Sandra Sofija/Rastko neko drugi }\end{array}$ & $\begin{array}{l}\text { (She)/(He) was working on the computer } \\
\text { while Sandra was listening to music. } \\
\text { Sofija/Rastko was tired from looking at the } \\
\text { screen. Who was working on the computer? } \\
\text { Sandra Sofija/Rastko somebody else }\end{array}$ \\
\hline $\begin{array}{l}19 a, \\
b\end{array}$ & $\begin{array}{l}\text { Njena/Njegova zubarka je čistila instrumente } \\
\text { dok je Suzana još sedela na zubarskoj } \\
\text { stolici. Helena je bila zabrinuta/Vladan je bio } \\
\text { zabrinut zbog popravke zuba. } \\
\text { Čija je zubarka? } \\
\text { Suzanina Helenina/Vladanova od nekog } \\
\text { drugog }\end{array}$ & $\begin{array}{l}\text { Her/His dentist was cleaning the instruments } \\
\text { while Sandra was sitting in the praxis. He- } \\
\text { lena/Vladan was worried because of the tooth } \\
\text { intervention. } \\
\text { Whose dentist is it? } \\
\text { Suzana's Helena's/Vladan's somebody } \\
\text { else's }\end{array}$ \\
\hline $\begin{array}{l}19 \mathrm{c} \\
\mathrm{d}\end{array}$ & $\begin{array}{l}\text { Čistila/Čistio je instrumente dok je Suzana } \\
\text { još sedela na zubarskoj stolici. Helena je } \\
\text { bila zabrinuta/Vladan je bio zabrinut zbog } \\
\text { popravke zuba. } \\
\text { Ko je čistio instrumente? } \\
\text { Suzana Helena/Vladan neko drugi }\end{array}$ & $\begin{array}{l}\text { (She)/(He) was cleaning the instruments } \\
\text { while Sandra was sitting in the praxis. He- } \\
\text { lena/Vladan was worried because of the tooth } \\
\text { intervention. } \\
\text { Who was cleaning the instruments? } \\
\text { Suzana Helena/Vladan somebody else }\end{array}$ \\
\hline
\end{tabular}




\begin{tabular}{|c|c|c|}
\hline Item & Test item & English translation \\
\hline $\begin{array}{l}20 a \\
b\end{array}$ & $\begin{array}{l}\text { Njena/Njegova doktorica je prepisivala recept } \\
\text { dok je Teodora pričala o simptomima. Slav- } \\
\text { ica je znala/Andrija je znao koji će lek biti od } \\
\text { pomoći. Čija je doktorica? } \\
\text { Teodorina Slavicina/Andrijina od nekog } \\
\text { drugog }\end{array}$ & $\begin{array}{l}\text { Her/His doctor was prescribing a prescription } \\
\text { while Teodora was talking about the symp- } \\
\text { toms. Slavica/Andrija knew which medicine } \\
\text { will be helpful. Whose doctor is it? } \\
\text { Teodora's Slavica's/Andrija's somebody } \\
\text { else's }\end{array}$ \\
\hline $\begin{array}{l}20 \mathrm{c}, \\
\mathrm{d}\end{array}$ & $\begin{array}{l}\text { Prepisivala/Prepisivao je recept dok je } \\
\text { Teodora pričala o simptomima. Slavica je } \\
\text { znala/Andrija je znao koji ce lek biti od } \\
\text { pomoći. } \\
\text { Ko je prepisivao recept? } \\
\text { Teodora Slavica/Andrija neko drugi }\end{array}$ & $\begin{array}{l}\text { (She)/(He) was prescribing a prescription } \\
\text { while Teodora was talking about the symp- } \\
\text { toms. Slavica/Andrija knew which medicine } \\
\text { will be helpful. } \\
\text { Who was prescribing a prescription? } \\
\text { Teodora Slavica/Andrija somebody else }\end{array}$ \\
\hline $\begin{array}{l}21 \mathrm{a}, \\
\mathrm{b}\end{array}$ & $\begin{array}{l}\text { Njena/Njegova sluškinja je peglala košulje } \\
\text { dok je Snežana gledala seriju. Violeta je bila } \\
\text { srećna/Dalibor je bio srećan što je kuća skoro } \\
\text { spremljena. Čija je sluškinja? } \\
\text { Snežanina Violetina/Daliborova od nekog } \\
\text { drugog }\end{array}$ & $\begin{array}{l}\text { Her/His cleaning lady was ironing the shirts } \\
\text { while Snezana was watching the series. Vi- } \\
\text { oleta/Dalibor was satisfied that the house is } \\
\text { almost tidy. Whose cleaning lady is it? } \\
\text { Snezana's Violeta's/Dalibor's somebody } \\
\text { else's }\end{array}$ \\
\hline $\begin{array}{l}21 \mathrm{c}, \\
\mathrm{d}\end{array}$ & $\begin{array}{l}\text { Peglala/Peglao je košulje dok je Snežana } \\
\text { gledala seriju. Violeta je bila srećna/Dalibor } \\
\text { je bio srećan što je kuća skoro spremljena. } \\
\text { Ko je peglao košulje? } \\
\text { Snežana Violeta/Dalibor neko drugi }\end{array}$ & $\begin{array}{l}\text { (She)/(He) was ironing the shirts while } \\
\text { Snezana was watching the series. Vio- } \\
\text { leta/Dalibor was satisfied that the house is al- } \\
\text { most tidy. Who was ironing the shirts? } \\
\text { Snezana Violeta/Dalibor somebody else }\end{array}$ \\
\hline $\begin{array}{l}22 \mathrm{a}, \\
\mathrm{b}\end{array}$ & $\begin{array}{l}\text { Njena/Njegova direktorica je pregledala } \\
\text { dokumentaciju dok je Gordana razgovarala } \\
\text { sa zaposlenima. Dragana se radovala/Milorad } \\
\text { se radovao novom projektu. } \\
\text { Čija je direktorica? } \\
\text { Gordanina Draganina/Miloradova od } \\
\text { nekog drugog }\end{array}$ & $\begin{array}{l}\text { Her/His director was checking the documen- } \\
\text { tation while Gordana was talking to the em- } \\
\text { ployees. Dragana/Milorad was looking for- } \\
\text { ward to the new project. } \\
\text { Whose director is it? } \\
\text { Gordana's Dragana's/ Milorad's some- } \\
\text { body else's }\end{array}$ \\
\hline $\begin{array}{l}22 \mathrm{c}, \\
\mathrm{d}\end{array}$ & $\begin{array}{l}\text { Pregledala/Pregledao je dokumentaciju dok je } \\
\text { Gordana razgovarala sa zaposlenima. Dra- } \\
\text { gana se radovala/Milorad se radovao novom } \\
\text { projektu. } \\
\text { Ko je pregledao dokumentaciju? } \\
\text { Gordana Dragana/Milorad neko drugi }\end{array}$ & $\begin{array}{l}\text { (She)/(He) was checking the documentation } \\
\text { while Gordana was talking to the employees. } \\
\text { Dragana/Milorad was looking forward to the } \\
\text { new project. } \\
\text { Who was checking the documentation? } \\
\text { Gordana Dragana/Milorad somebody else }\end{array}$ \\
\hline
\end{tabular}




\begin{tabular}{|c|c|c|}
\hline Item & Test item & English translation \\
\hline $\begin{array}{l}23 a \\
b\end{array}$ & $\begin{array}{l}\text { Njena/Njegova dizajnerka je crtala skice dok } \\
\text { je Mirjana gledala slike nameštaja. Isidora je } \\
\text { bila srećna/Nebojša je bio srećan da može da } \\
\text { pomogne u uređenju stana. } \\
\text { Čija je dizajnerka? } \\
\text { Mirjanina Isidorina/Nebojšina od nekog } \\
\text { drugog }\end{array}$ & $\begin{array}{l}\text { Her/His designer was sketching a design } \\
\text { while Mirjana was looking at photos of furni- } \\
\text { ture. Isidora/Nebojsa was happy to help with } \\
\text { the apartment decoration. } \\
\text { Whose designer is it? } \\
\text { Mirjana's Isidora's/Nebojsa's somebody } \\
\text { else's }\end{array}$ \\
\hline $\begin{array}{l}23 \mathrm{c} \\
\mathrm{d}\end{array}$ & $\begin{array}{l}\text { Crtala/Crtao je skice dok je Mirjana } \\
\text { gledala slike nameštaja. Isidora je bila } \\
\text { srećna/Nebojša je bio srećan da može da } \\
\text { pomogne u uređenju stana. } \\
\text { Ko je crtao skice? } \\
\text { Mirjana Isidora/Nebojša neko drugi }\end{array}$ & $\begin{array}{l}\text { (She)/(He) was sketching a design while } \\
\text { Mirjana was looking at photos of furniture. } \\
\text { Isidora/Nebojsa was happy to help with the } \\
\text { apartment decoration. } \\
\text { Who was sketching a design? } \\
\text { Mirjana Isidora/Nebojša somebody else }\end{array}$ \\
\hline $\begin{array}{l}24 a \\
b\end{array}$ & $\begin{array}{l}\text { Njena/Njegova učiteljica je svirala klavir dok } \\
\text { je Milana pevala pesmicu. Tamari/Oliveru se } \\
\text { svidelo izvođenje kompozicije. } \\
\text { Čija je učiteljica? } \\
\text { Milanina Tamarina/Oliverova od nekog } \\
\text { drugog }\end{array}$ & $\begin{array}{l}\text { Her/His teacher was playing the piano while } \\
\text { Milana was singing a song. Tamara/Oliver } \\
\text { liked the performance. } \\
\text { Whose teacher is it? } \\
\text { Milana's Tamara's/Oliver's somebody } \\
\text { else's }\end{array}$ \\
\hline $\begin{array}{l}24 \mathrm{c}, \\
\mathrm{d}\end{array}$ & $\begin{array}{l}\text { Svirala/Svirao je klavir dok je Milana pevala } \\
\text { pesmicu. Tamari/Oliveru se svidelo izvođenje } \\
\text { kompozicije. } \\
\text { Ko je svirao klavir? } \\
\text { Milana Tamara/Oliver neko drugi }\end{array}$ & $\begin{array}{l}\text { (She)/(He) was playing the piano while Mi- } \\
\text { lana was singing a song. Tamara/Oliver liked } \\
\text { the performance. } \\
\text { Who was playing the piano? } \\
\text { Milana Tamara/Oliver somebody else }\end{array}$ \\
\hline
\end{tabular}

\section{Filler items}

Filler items are presented in the same form like the test items in the Table below.

Table B.3: Experiment 2: Filler items with questions

\begin{tabular}{l|l|l}
\hline Item & Filler item & English translation \\
\hline 1a & Jovan je potpisivao autograme dok je nje- & Jovan signed autographs while his manager \\
& gov menadžer pričao fanovima. Petar je bio & talked to the fans. Peter was happy that the \\
& srećan što je koncert uspešno završen. & concert was successfully finished. \\
& Čiji je menadžer? & Whose manager is it? \\
& Jovanov / Petrov / od nekog drugog & Jovan's / Petar's / somebody else's \\
\hline
\end{tabular}




\begin{tabular}{|c|c|c|}
\hline Item & Filler item & English translation \\
\hline $1 b$ & $\begin{array}{l}\text { Jovan je potpisivao autograme dok je njen } \\
\text { menadžer pričao fanovima. Ivana je bila } \\
\text { srećna što je koncert uspešno završen. } \\
\text { Čiji je menadžer? } \\
\text { Jovanov / Ivanin / od nekog drugog }\end{array}$ & $\begin{array}{l}\text { Jovan signed autographs while her manager } \\
\text { talked to the fans. Ivana was happy that the } \\
\text { concert was successfully finished. } \\
\text { Whose manager is it? } \\
\text { Jovan's / Ivana's / somebody else's }\end{array}$ \\
\hline $1 \mathrm{c}$ & $\begin{array}{l}\text { Jovan je potpisivao autograme dok je pričao } \\
\text { fanovima. Petar je bio srećan što je koncert } \\
\text { uspešno završen. } \\
\text { Ko je pričao fanovima? } \\
\text { Jovan / Petar / neko drugi }\end{array}$ & $\begin{array}{l}\text { Jovan signed autographs while (he) talked to } \\
\text { the fans. Peter was happy that the concert was } \\
\text { successfully finished. } \\
\text { Who talked to the fans? } \\
\text { Jovan / Petar / somebody else }\end{array}$ \\
\hline $1 d$ & $\begin{array}{l}\text { Jovan je potpisivao autograme dok je pričala } \\
\text { fanovima. Ivana je bila srećna što je koncert } \\
\text { uspešno završen. } \\
\text { Ko je fanovima? } \\
\text { Jovan / Ivana / neko drugi }\end{array}$ & $\begin{array}{l}\text { Jovan signed autographs while (she) talked to } \\
\text { the fans. Ivana was happy that the concert was } \\
\text { successfully finished. } \\
\text { Who talked to the fans? } \\
\text { Jovan / Ivana / somebody else }\end{array}$ \\
\hline & $\begin{array}{l}\text { Danilo je sedeo u ordinaciji dok je nje- } \\
\text { gov/njen doktor čitao rezultate. Maksim je } \\
\text { bio zadovoljan/Bojana je bila zadovoljna di- } \\
\text { jagnozom. Čiji je doktor? } \\
\text { Danilov Maksimov/Bojanin od nekog drugog }\end{array}$ & $\begin{array}{l}\text { Danilo was sitting in the doctor's practice } \\
\text { while his/her doctor examined the results. } \\
\text { Maksim/Bojana was satisfied with the diag- } \\
\text { nosis. Whose doctor is it? } \\
\text { Danilo's Maksim's/Bojana's somebody else's }\end{array}$ \\
\hline $\begin{array}{l}2 \mathrm{c}, \\
\mathrm{d}\end{array}$ & $\begin{array}{l}\text { Danilo je sedeo u ordinaciji dok je čitao/čitala } \\
\text { rezultate. Maksim je bio zadovoljan/Bojana } \\
\text { je bila zadovoljna dijagnozom. Ko je čitao } \\
\text { rezultate? } \\
\text { Danilo Maksim/Bojana neko drugi }\end{array}$ & $\begin{array}{l}\text { Danilo was sitting in the doctor's practice } \\
\text { while (he)/(she) examined the results. Mak- } \\
\text { sim/Bojana was satisfied with the diagnosis. } \\
\text { Who examined the results? } \\
\text { Danilo Maksim/Bojana somebody else }\end{array}$ \\
\hline $\begin{array}{l}3 a, \\
b\end{array}$ & $\begin{array}{l}\text { Miloš je čekao red dok je njegov/njen frizer } \\
\text { pravio frizuru. Lazar je bio zadovoljan/Jasna } \\
\text { je bila zadovoljna izgledom. } \\
\text { Čiji je frizer? } \\
\text { Milošev Lazarev/Jasnin od nekog drugog }\end{array}$ & $\begin{array}{l}\text { Milos was waiting while his/her hairdresser } \\
\text { was making a hairstyle. Lazar/Jasna was sat- } \\
\text { isfied with the look. } \\
\text { Whose hairdresser is it? } \\
\text { Milos's Lazar's/Jasna's somebody else's }\end{array}$ \\
\hline $\begin{array}{l}3 \mathrm{c}, \\
\mathrm{d}\end{array}$ & $\begin{array}{l}\text { Miloš je čekao red dok je pravio/pravila } \\
\text { frizuru. Lazar je bio zadovoljan/Jasna je bila } \\
\text { zadovoljna izgledom. } \\
\text { Ko je pravio frizuru? } \\
\text { Miloš Lazar/Jasna neko drugi }\end{array}$ & $\begin{array}{l}\text { Milos was waiting while (he)/(she) was mak- } \\
\text { ing a hairstyle. Lazar/Jasna was satisfied with } \\
\text { the look. } \\
\text { Who was making a hairstyle? } \\
\text { Milos Lazar/Jasna somebody else }\end{array}$ \\
\hline
\end{tabular}




\begin{tabular}{|c|c|c|}
\hline Item & & \\
\hline , b & $\begin{array}{l}\text { Milan je nestrpljivo čekao početak testa dok je } \\
\text { njegov/njen učitelj pisao zadatke na tabli. Bo- } \\
\text { jan je bio ubeđen/Vesna je bila ubeđena da će } \\
\text { svi učenici dobiti dobre ocene. Čiji je učitelj? } \\
\text { Milanov Bojanov/Vesnin od nekog drugog }\end{array}$ & $\begin{array}{l}\text { begin while his/her teacher was writing as- } \\
\text { signments on the blackboard. Bojan/Vesna } \\
\text { was sure that all the students will get good } \\
\text { marks. Whose teacher is it? } \\
\text { Milan's Bojan's/Vesna's somebody else's }\end{array}$ \\
\hline $\begin{array}{l}4 \mathrm{c} \\
\mathrm{d}\end{array}$ & $\begin{array}{l}\text { Milan je nestrpljivo čekao početak testa dok } \\
\text { je pisao/pisala zadatke na tabli. Bojan je } \\
\text { bio ubeđen/Vesna je bila ubeđena da će svi } \\
\text { učenici dobiti dobre ocene. } \\
\text { Ko je pisao zadatke na tabli? } \\
\text { Milan Bojan/Vesna neko drugi }\end{array}$ & $\begin{array}{l}\text { Milan was impatiently waiting for the test } \\
\text { to begin while (he)/(she) was writing assign- } \\
\text { ments on the blackboard. Bojan/Vesna was } \\
\text { sure that all the students will get good marks. } \\
\text { Who was writing assignments on the black- } \\
\text { board? } \\
\text { Milan Bojan/Vesna somebody else }\end{array}$ \\
\hline $5 a$, & $\begin{array}{l}\text { Zoran je oblačio dres dok je njegov/njen } \\
\text { trener objašnjavao napad. Marko je bio } \\
\text { ubeđen/Milka je bila ubeđena da će pobediti. } \\
\text { Čiji je trener? } \\
\text { Zornov Markov/Milkin od nekog drugog }\end{array}$ & $\begin{array}{l}\text { Zoran was putting his jersey on while } \\
\text { his/her coach was explaining the attack. } \\
\text { Marko/Milka was conviced that they will win. } \\
\text { Whose coach is it? } \\
\text { Zoran's Marko's/Milka's somebody else's }\end{array}$ \\
\hline $5 c$ & $\begin{array}{l}\text { Zoran je oblačio dres dok je objašn- } \\
\text { javao/objašnjavala napad. Marko je bio } \\
\text { ubeđen/Milka je bila ubeđena da će pobediti. } \\
\text { Ko je objašnjavao napad? } \\
\text { Zoran Marko/Milka neko drugi }\end{array}$ & $\begin{array}{l}\text { Zoran was putting his jersey on while } \\
\text { (he)/(she) was explaining the attack. } \\
\text { Marko/Milka was conviced that they will } \\
\text { win. Who was explaining the attack? } \\
\text { Zoran Marko/Milka somebody else }\end{array}$ \\
\hline 6a, & $\begin{array}{l}\text { Dejan je čekao u kancelariji dok je nje- } \\
\text { gov/njen advokat čitao slučaj. Filip je bio op- } \\
\text { timističan/Elena je bila optimistična u vezi sa } \\
\text { parnicom. Čiji je advokat? } \\
\text { Dejanov Filipov/Elenin od nekog drugog }\end{array}$ & $\begin{array}{l}\text { Dejan was sitting in the office while his/her } \\
\text { lawyer was reading the case. Filip/Elena was } \\
\text { optimistic about the litigation. } \\
\text { Whose lawyer is it? } \\
\text { Dejan's Filip's/Elena's somebody else's }\end{array}$ \\
\hline & $\begin{array}{l}\text { Dejan je čekao u kancelariji dok je čitao/čitala } \\
\text { slučaj. Filip je bio optimističan/Elena je bila } \\
\text { optimistična u vezi sa parnicom. Ko je čitao } \\
\text { slučaj? } \\
\text { Dejan Filip/Elena neko drugi }\end{array}$ & $\begin{array}{l}\text { Dejan was sitting in the office while (he)/(she) } \\
\text { was reading the case. Filip/Elena was opti- } \\
\text { mistic about the litigation. } \\
\text { Who was reading the case? } \\
\text { Dejan Filip/Elena somebody else }\end{array}$ \\
\hline
\end{tabular}




\begin{tabular}{|c|c|c|}
\hline Item & Filler item & English translation \\
\hline $\begin{array}{l}7 \mathrm{a}, \\
\mathrm{b}\end{array}$ & $\begin{array}{l}\text { Boris je potpisivao ugovore dok je nje- } \\
\text { gov/njen sekretar razgovorao telefonom. } \\
\text { Dušan je upravo ugovorio/Marta je upravo } \\
\text { ugovorila sastanak sa sponzorima. } \\
\text { Čiji je sekretar? } \\
\text { Borisov Dušanov/Martin od nekog drugog }\end{array}$ & $\begin{array}{l}\text { Boris was signing contracts while his/her sec- } \\
\text { retary was talking on the phone. Dusan/Marta } \\
\text { has just arranged a meeting with sponsors. } \\
\text { Whose secretary is it? } \\
\text { Boris's Dusan's/Marta's somebody else's }\end{array}$ \\
\hline $\begin{array}{l}7 \mathrm{c} \\
\mathrm{d}\end{array}$ & $\begin{array}{l}\text { Boris je potpisivao ugovore dok je razgovo- } \\
\text { rao/razgovarala telefonom. Dušan je upravo } \\
\text { ugovorio/Marta je upravo ugovorila sastanak } \\
\text { sa sponzorima. Ko je razgovarao telefonom? } \\
\text { Boris Dušan/Marta neko drugi }\end{array}$ & $\begin{array}{l}\text { Boris was signing contracts while (he)/(she) } \\
\text { was talking on the phone. Dusan/Marta has } \\
\text { just arranged a meeting with sponsors. } \\
\text { Who was talking on the phone? } \\
\text { Boris Dusan/Marta somebody else }\end{array}$ \\
\hline $\begin{array}{l}8 \mathrm{a}, \\
\mathrm{b}\end{array}$ & $\begin{array}{l}\text { Nikola je slušao muziku dok je njegov/njen } \\
\text { profesor pregledao zadatke. Stefan je bio } \\
\text { zadovoljan/Jovana je bila zadovoljna rešen- } \\
\text { jima. Čiji je profesor? } \\
\text { Nikolin Stefanov/Jovanin od nekog drugog }\end{array}$ & $\begin{array}{l}\text { Nikola was listening to music while his/her } \\
\text { professor was grading assignments. Ste- } \\
\text { fan/Jovana was satisfied with the results. } \\
\text { Whose professor is it? } \\
\text { Nikola's Stefan's/Jovana's somebody else's }\end{array}$ \\
\hline $\begin{array}{l}8 \mathrm{c} \\
\mathrm{d}\end{array}$ & $\begin{array}{l}\text { Nikola je slušao muziku dok je pre- } \\
\text { gledao/pregledala zadatke. Stefan je bio } \\
\text { zadovoljan/Jovana je bila zadovoljna rešen- } \\
\text { jima. Ko je pregledao zadatke? } \\
\text { Nikola Stefan/Jovana neko drugi }\end{array}$ & $\begin{array}{l}\text { Nikola was listening to music while (he)/(she) } \\
\text { was grading assignments. Stefan/Jovana was } \\
\text { satisfied with the results. } \\
\text { Who was grading assignments? } \\
\text { Nikola Stefan/Jovana somebody else }\end{array}$ \\
\hline $\begin{array}{l}9 \mathrm{a}, \\
\mathrm{b}\end{array}$ & $\begin{array}{l}\text { Aleksa je pričao o narednom poslu dok je nje- } \\
\text { gov/njen radnik čistio alat. Bogdan je bio } \\
\text { srećan/Marija je bila srećna da se bliži kraj } \\
\text { radnog vremena. Čiji je radnik? } \\
\text { Aleksin Bogdanov/Marijin od nekog drugog }\end{array}$ & $\begin{array}{l}\text { Aleksa was talking about the next job while } \\
\text { his/her worker was cleaning the tools. Bog- } \\
\text { dan/Marija was happy that it is soon the end } \\
\text { of the working day. Whose worker is it? } \\
\text { Aleksa's Bogdan's/Marija's somebody else's }\end{array}$ \\
\hline $\begin{array}{l}9 \mathrm{c}, \\
\mathrm{d}\end{array}$ & $\begin{array}{l}\text { Aleksa je pričao o narednom poslu dok je čis- } \\
\text { tio/čistila alat. Bogdan je bio srećan/Marija je } \\
\text { bila srećna da se bliži kraj radnog vremena. } \\
\text { Ko je čistio alat? } \\
\text { Aleksa Bogdan/Marija neko drugi }\end{array}$ & $\begin{array}{l}\text { Aleksa was talking about the next job while } \\
\text { (he)/(she) was cleaning the tools. Bog- } \\
\text { dan/Marija was happy that it is soon the end } \\
\text { of the working day. Who was cleaning the } \\
\text { tools? } \\
\text { Aleksa Bogdan/Marija somebody else }\end{array}$ \\
\hline $\begin{array}{l}10 \mathrm{a}, \\
\mathrm{b}\end{array}$ & $\begin{array}{l}\text { Dragan je razmišljao o godišnjem odmoru } \\
\text { dok je njegov/njen mehaničar pregledao auto. } \\
\text { Mladen je znao/Tijana je znala da je kvar oz- } \\
\text { biljan. Čiji je mehaničar? } \\
\text { Draganov Mladenov/Tijanin od nekog } \\
\text { drugog }\end{array}$ & $\begin{array}{l}\text { Dragan was thinking about the holiday while } \\
\text { his/her mechanic was checking the car. } \\
\text { Mladen/Tijana knew that the damage was se- } \\
\text { rious. Whose mechanic is it? } \\
\text { Dragan's Mladen's/Tijana's somebody } \\
\text { else's }\end{array}$ \\
\hline
\end{tabular}




\begin{tabular}{|c|c|c|}
\hline Item & Filler item & English translation \\
\hline $\begin{array}{l}10 \mathrm{c}, \\
\mathrm{d}\end{array}$ & $\begin{array}{l}\text { Dragan je razmišljao o godišnjem odmoru } \\
\text { dok je pregledao/Tijana auto. Mladen/Tijana } \\
\text { je znao da je kvar ozbiljan. } \\
\text { Ko je pregledao auto? } \\
\text { Dragan Mladen/Tijana neko drugi }\end{array}$ & $\begin{array}{l}\text { Dragan was thinking about the holiday } \\
\text { while (he)/(she) was checking the car. } \\
\text { Mladen/Tijana knew that the damage was se- } \\
\text { rious. Who was checking the car? } \\
\text { Dragan Mladen/Tijana somebody else }\end{array}$ \\
\hline $\begin{array}{l}11 \mathrm{a}, \\
\mathrm{b}\end{array}$ & $\begin{array}{l}\text { Stevan je čitao katalog dok je njegov/njen } \\
\text { savetnik predlagao rešenja. Branko nije bio } \\
\text { zadovoljan/Milica nije bila zadovoljna sug- } \\
\text { estijama. Čiji je savetnik? } \\
\text { Stevanov Brankov/Milicin od nekog drugog }\end{array}$ & $\begin{array}{l}\text { Stevan was reading a catalogue while } \\
\text { his/her adviser was suggesting solutions. } \\
\text { Branko/Milica wasn't satisfied with the ideas. } \\
\text { Whose adviser is it? } \\
\text { Stevan's Branko's/Milica's somebody else's }\end{array}$ \\
\hline $\begin{array}{l}11 \mathrm{c} \\
\mathrm{d}\end{array}$ & $\begin{array}{l}\text { Stevan je čitao katalog dok je predla- } \\
\text { gao/predlagala rešenja. Branko nije bio zado- } \\
\text { voljan/Milica nije bila zadovoljna sugesti- } \\
\text { jama. Ko je predlagao rešenja? } \\
\text { Stevan Branko/Milica neko drugi }\end{array}$ & $\begin{array}{l}\text { Stevan was reading a catalogue while } \\
\text { (he)/(she) was suggesting solutions. } \\
\text { Branko/Milica wasn't satisfied with the } \\
\text { ideas. Who was suggesting solutions? } \\
\text { Stevan Branko/Milica somebody else }\end{array}$ \\
\hline $\begin{array}{l}12 \mathrm{a} \\
\mathrm{b}\end{array}$ & $\begin{array}{l}\text { Stojan je pevušio melodiju iz filma dok je nje- } \\
\text { gov/njen majstor krečio zid. Vedranu/Milici } \\
\text { se svidela nova boja sobe. Čiji je majstor? } \\
\text { Stojanov Vedranov/Milicin od nekog drugog }\end{array}$ & $\begin{array}{l}\text { Stojan was singing a melody from a movie } \\
\text { while his.her worker was painting the wall. } \\
\text { Vedran/Milica liked the new colour of the } \\
\text { room. Whose worker is it? } \\
\text { Stojan's / Vedran's/Milica's somebody else's }\end{array}$ \\
\hline $\begin{array}{l}12 \mathrm{c} \\
\mathrm{d}\end{array}$ & $\begin{array}{l}\text { Stojan je pevušio melodiju iz filma dok je } \\
\text { krečio/krečila zid. Vedranu/Milici se svidela } \\
\text { nova boja sobe. } \\
\text { Ko je krečio zid? } \\
\text { Stojan Vedran/Milica neko drugi }\end{array}$ & $\begin{array}{l}\text { Stojan was singing a melody from a movie } \\
\text { while (he)/(she) was painting the wall. Ve- } \\
\text { dran/Milica liked the new colour of the room. } \\
\text { Who was painting the wall? } \\
\text { Stojan Vedran/Milica somebody else }\end{array}$ \\
\hline $\begin{array}{l}13 a \\
b\end{array}$ & $\begin{array}{l}\text { Branka je čekala da joj se kosa osuši dok je } \\
\text { njena/njegova frizerka mešala farbu. Nevena } \\
\text { je bila zadovoljna/Damjan je bio zadovoljan } \\
\text { bojom. Čija je frizerka? } \\
\text { Brankina Nevenina/Damjanova od nekog } \\
\text { drugog }\end{array}$ & $\begin{array}{l}\text { Branka was waiting her hair to get dry } \\
\text { while her/his hairdresser was mixing the dye. } \\
\text { Nevena/Damjan was satisfied with the colour. } \\
\text { Whose hairdresser is it? } \\
\text { Branka's Nevena's/Damjan's somebody } \\
\text { else's }\end{array}$ \\
\hline $\begin{array}{l}13 \mathrm{c} \\
\mathrm{d}\end{array}$ & $\begin{array}{l}\text { Branka je čekala da joj se kosa osuši dok je } \\
\text { mešala/mešao farbu. Nevena je bila zado- } \\
\text { voljna/Damjan je bio zadovoljan bojom. } \\
\text { Ko je mešao farbu? } \\
\text { Branka Nevena/Damjan neko drugi }\end{array}$ & $\begin{array}{l}\text { Branka was waiting her hair to get dry } \\
\text { while (she)/(he) was mixing the dye. } \\
\text { Nevena/Damjan was satisfied with the colour. } \\
\text { Who was mixing the dye? } \\
\text { Branka Nevena/Damjan somebody else }\end{array}$ \\
\hline
\end{tabular}




\begin{tabular}{|c|c|c|}
\hline & & \\
\hline $14 a$, & $\begin{array}{l}\text { Dušica je računala u Excel-u dok je } \\
\text { njena/njegova knjigovođa sabirala račune. } \\
\text { Zorana nije bila zadovoljna/Tadija nije bio } \\
\text { zadovoljan brojkama. Čija je knjigovođa? } \\
\text { Dušicina Zoranina/Tadijina od nekog } \\
\text { drugog }\end{array}$ & $\begin{array}{l}\text { Dusica was working in Excel while her/his } \\
\text { accountant was working on the bills. Zo- } \\
\text { rana/Tadija was not happy with the numbers. } \\
\text { Whose accountant is it? } \\
\text { Dusica's Zorana's/Tadija's somebody } \\
\text { else's }\end{array}$ \\
\hline $14 \mathrm{c}$ & $\begin{array}{l}\text { Dušica je računala u Excel-u dok je sabi- } \\
\text { rala/sabirao račune. Zorana nije bila zado- } \\
\text { voljna/Tadija nije bio zadovoljan brojkama. } \\
\text { Ko je sabirao račune? } \\
\text { Dušica Zorana/Tadija neko drugi }\end{array}$ & $\begin{array}{l}\text { Dusica was working in Excel while (she)/(he) } \\
\text { was working on the bills. Zorana/Tadija was } \\
\text { not happy with the numbers. } \\
\text { Who was working on the bills? } \\
\text { Dusica Zorana/Tadija somebody else }\end{array}$ \\
\hline $15 \mathrm{a}$ & $\begin{array}{l}\text { Danica je razmišljala o bojama i materijalima } \\
\text { dok je njena/njegova krojačica uzimala mere. } \\
\text { Zorica je bila veoma uzbuđena/Siniša je bio } \\
\text { uzbuđen zbog venčanja. Čija je krojačica? } \\
\text { Danicina Zoricina/Sinišina od nekog drugog }\end{array}$ & $\begin{array}{l}\text { Danica was thinking about the decoration } \\
\text { while her/his tailor was getting the measure- } \\
\text { ments. Zorica/Sinisa was excited because of } \\
\text { the wedding. Whose tailor is it? } \\
\text { Danica's Zorica's/Sinisa's somebody else's }\end{array}$ \\
\hline $15 \mathrm{c}$ & $\begin{array}{l}\text { Danica je razmišljala o bojama i materijalima } \\
\text { dok je uzimala/uzimao mere. Zorica je bila } \\
\text { veoma uzbuđena/Siniša je bio uzbuđen zbog } \\
\text { venčanja. } \\
\text { Ko je uzimao mere? } \\
\text { Danica Zorica/Siniša neko drugi }\end{array}$ & $\begin{array}{l}\text { (Danica was thinking about the decoration } \\
\text { while (she)/(he) was getting the measure- } \\
\text { ments. Zorica/Sinisa was excited because of } \\
\text { the wedding. } \\
\text { Who was getting the measurements? } \\
\text { Danica Zorica/Sinisa somebody else }\end{array}$ \\
\hline 16a, & $\begin{array}{l}\text { Lidija je gledala youtube dok je njena/njegova } \\
\text { pomoćnica kuvala sarmu. Milena je bila } \\
\text { srećna/Sreten je bio srećan kako je ručak is- } \\
\text { pao. Čija je pomoćnica? } \\
\text { Lidijina Milenina/Sretenova od nekog } \\
\text { drugog }\end{array}$ & $\begin{array}{l}\text { Lidija was watching youtube while her/his } \\
\text { chef was cooking sarma. Milena/Sreten was } \\
\text { happy how the lunch turned out. } \\
\text { Whose chef is it? } \\
\text { Lidija's Milena's/Sreten's somebody } \\
\text { else's }\end{array}$ \\
\hline $\begin{array}{l}16 \mathrm{c}, \\
\mathrm{d}\end{array}$ & $\begin{array}{l}\text { Lidija je gledala youtube dok je kuvala/kuvao } \\
\text { sarmu. Milena je bila srećna/Sreten je bio } \\
\text { srećan kako je ručak ispao. Ko je kuvao } \\
\text { sarmu? } \\
\text { Lidija Milena/Sreten neko drugi }\end{array}$ & $\begin{array}{l}\text { Lidija was watching youtube while (she)/(he) } \\
\text { was cooking sarma. Milena/Sreten was happy } \\
\text { how the lunch turned out. } \\
\text { Who was cooking sarma? } \\
\text { Lidija Milena/Sreten somebody else }\end{array}$ \\
\hline
\end{tabular}




\begin{tabular}{|c|c|c|}
\hline Item & Filler item & English translation \\
\hline $\begin{array}{l}17 a, \\
b\end{array}$ & $\begin{array}{l}\text { Olivera se spremala za posao dok je } \\
\text { njena/njegova dadilja čuvala bebu. Tatjana je } \\
\text { bila srećna/Miodrag je bio srećan što je beba } \\
\text { u dobrim rukama. Čija je dadilja? } \\
\text { Oliverina Tatjanina/Miodragova od nekog } \\
\text { drugog }\end{array}$ & $\begin{array}{l}\text { Olivera was getting ready for work while } \\
\text { her/his nanny was looking after the baby. Tat- } \\
\text { jana/Miodrag was happy that the baby was in } \\
\text { good hands. Whose nanny is it? } \\
\text { Olivera's Tatjana's/Miodrag's somebody } \\
\text { else's }\end{array}$ \\
\hline $\begin{array}{l}17 \mathrm{c}, \\
\mathrm{d}\end{array}$ & $\begin{array}{l}\text { Olivera se spremala za posao dok je } \\
\text { čuvala/čuvao bebu. Tatjana je bila } \\
\text { srećna/Miodrag je bio srećan što je beba } \\
\text { u dobrim rukama. Ko je čuvao bebu? } \\
\text { Olivera Tatjana/Miodrag neko drugi }\end{array}$ & $\begin{array}{l}\text { Olivera was getting ready for work while } \\
\text { (she)/(he) was looking after the baby. Tat- } \\
\text { jana/Miodrag was happy that the baby was in } \\
\text { good hands. Who was looking after the baby? } \\
\text { Olivera Tatjana/Miodrag somebody else }\end{array}$ \\
\hline $\begin{array}{l}18 \mathrm{a}, \\
\mathrm{b}\end{array}$ & $\begin{array}{l}\text { Sandra je slušala muziku dok je njena/njegova } \\
\text { šefica radila za kompjuterom. Sofija je bila } \\
\text { umorna/Rastko je bio umoran od gledanja u } \\
\text { monitor. Čija je šefica? } \\
\text { Sandrina Sofijina/Rastkova od nekog drugog }\end{array}$ & $\begin{array}{l}\text { Sandra was listening to music while } \\
\text { her/his boss was working on the com- } \\
\text { puter. Sofija/Rastko was tired from looking } \\
\text { at the screen. Whose boss is it? } \\
\text { Sandra's Sofija's/Rastko's somebody else's }\end{array}$ \\
\hline $\begin{array}{l}18 \mathrm{c}, \\
\mathrm{d}\end{array}$ & $\begin{array}{l}\text { Sandra je slušala muziku dok je } \\
\text { radila/radio za kompjuterom. Sofija je bila } \\
\text { umorna/Rastko je bio umoran od gledanja u } \\
\text { monitor. Ko je radio za kompjuterom? } \\
\text { Sandra Sofija/Rastko neko drugi }\end{array}$ & $\begin{array}{l}\text { Sandra was listening to music while (she)/(he) } \\
\text { was working on the computer. Sofija/Rastko } \\
\text { was tired from looking at the screen. } \\
\text { Who was working on the computer? } \\
\text { Sandra Sofija/Rastko somebody else }\end{array}$ \\
\hline $\begin{array}{l}19 a, \\
b\end{array}$ & $\begin{array}{l}\text { Suzana je još sedela na zubarskoj stolici } \\
\text { dok je njena/njegova zubarka čistila instru- } \\
\text { mente. Helena je bila zabrinuta/Vladan je } \\
\text { bio zabrinut zbog popravke zuba. Čija je } \\
\text { zubarka? } \\
\text { Suzanina Helenina/Vladanova od nekog } \\
\text { drugog }\end{array}$ & $\begin{array}{l}\text { Sandra was sitting in the praxis while her/his } \\
\text { dentist was cleaning the instruments. He- } \\
\text { lena/Vladan was worried because of the tooth } \\
\text { intervention. Whose dentist is it? } \\
\text { Suzana's Helena's/Vladan's somebody } \\
\text { else's }\end{array}$ \\
\hline $\begin{array}{l}19 \mathrm{c}, \\
\mathrm{d}\end{array}$ & $\begin{array}{l}\text { Suzana je još sedela na zubarskoj stolici } \\
\text { dok je čistila/čistio instrumente. Helena je } \\
\text { bila zabrinuta/Vladan je bio zabrinut zbog } \\
\text { popravke zuba. Ko je čistio instrumente? } \\
\text { Suzana Helena/Vladan neko drugi }\end{array}$ & $\begin{array}{l}\text { Sandra was sitting in the praxis while } \\
\text { (she)/(he) was cleaning the instruments. He- } \\
\text { lena/Vladan was worried because of the tooth } \\
\text { intervention. Who was cleaning the instru- } \\
\text { ments? } \\
\text { Suzana Helena/Vladan somebody else }\end{array}$ \\
\hline
\end{tabular}




\begin{tabular}{|c|c|c|}
\hline Item & & \\
\hline $\begin{array}{l}20 a, \\
b\end{array}$ & $\begin{array}{l}\text { Teodora je pričala o simptomima dok je } \\
\text { njena/njegova doktorica prepisivala recept. } \\
\text { Slavica je znala/Andrija je znao koji će lek } \\
\text { biti od pomoći. Čija je doktorica? } \\
\text { Teodorina Slavicina/Andrijina od nekog } \\
\text { drugog }\end{array}$ & $\begin{array}{l}\text { Teodora was talking about the symptoms } \\
\text { while her/his doctor was prescribing a pre- } \\
\text { scription. Slavica/Andrija knew which } \\
\text { medicine will be helpful. Whose doctor is it? } \\
\text { Teodora's Slavica's/Andrija's somebody } \\
\text { else's }\end{array}$ \\
\hline $\begin{array}{l}20 c, \\
d\end{array}$ & $\begin{array}{l}\text { Teodora je pričala o simptomima dok je } \\
\text { prepisivala/prepisivao recept. Slavica je } \\
\text { znala/Andrija je znao koji će lek biti od po- } \\
\text { moći. Ko je prepisivao recept? } \\
\text { Teodora Slavica/Andrija neko drugi }\end{array}$ & $\begin{array}{l}\text { Teodora was talking about the symptoms } \\
\text { while (she)/(he) was prescribing a prescrip- } \\
\text { tion. Slavica/Andrija knew which medicine } \\
\text { will be helpful. Who was prescribing a pre- } \\
\text { scription? } \\
\text { Teodora Slavica/Andrija somebody else }\end{array}$ \\
\hline 21a, & $\begin{array}{l}\text { Snežana je gledala seriju dok je njena/njegova } \\
\text { sluškinja peglala košulje. Violeta je bila } \\
\text { srećna/Dalibor je bio srećan što je kuća skoro } \\
\text { spremljena. Čija je sluškinja? } \\
\text { Snežanina Violetina/Daliborova od nekog } \\
\text { drugog }\end{array}$ & $\begin{array}{l}\text { Snezana was watching the series while her/his } \\
\text { cleaning lady was ironing the shirts. Vio- } \\
\text { leta/Dalibor was satisfied that the house is al- } \\
\text { most tidy. Whose cleaning lady is it? } \\
\text { Snezana's Violeta's/Dalibor's somebody } \\
\text { else's }\end{array}$ \\
\hline $21 \mathrm{c}$ & $\begin{array}{l}\text { Snežana je gledala seriju dok je } \\
\text { peglala/peglao košulje. Violeta je bila } \\
\text { srećna/Dalibor je bio srećan što je kuća skoro } \\
\text { spremljena. Ko je peglao košulje? } \\
\text { Snežana Violeta/Dalibor neko drugi }\end{array}$ & $\begin{array}{l}\text { Snezana was watching the series while } \\
\text { (she)/(he) was ironing the shirts. Vio- } \\
\text { leta/Dalibor was satisfied that the house is al- } \\
\text { most tidy. Who was ironing the shirts? } \\
\text { Snezana Violeta/Dalibor somebody else }\end{array}$ \\
\hline $22 \mathrm{a}$ & $\begin{array}{l}\text { Gordana je razgovarala sa zaposlenima dok } \\
\text { je njena/njegova direktorica pregledala doku- } \\
\text { mentaciju. Dragana se radovala/Milorad se } \\
\text { radovao novom projektu. Čija je direktorica? } \\
\text { Gordanina Draganina/Miloradova od } \\
\text { nekog drugog }\end{array}$ & $\begin{array}{l}\text { Gordana was talking to the employees while } \\
\text { her/his director was checking the documenta- } \\
\text { tion. Dragana/Milorad was looking forward } \\
\text { to the new project. Whose director is it? } \\
\text { Gordana's Dragana's/Milorad's some- } \\
\text { body else's }\end{array}$ \\
\hline $\begin{array}{l}22 \mathrm{c}, \\
\mathrm{d}\end{array}$ & $\begin{array}{l}\text { Gordana je razgovarala sa zaposlenima dok } \\
\text { je pregledala/pregledao dokumentaciju. Dra- } \\
\text { gana/Milorad se radovala novom projektu. } \\
\text { Ko je pregledao dokumentaciju? } \\
\text { Gordana Dragana/Milorad neko drugi }\end{array}$ & $\begin{array}{l}\text { Gordana was talking to the employees while } \\
\text { (she)/(he) was checking the documentation. } \\
\text { Dragana/Milorad was looking forward to the } \\
\text { new project. } \\
\text { Who was checking the documentation? } \\
\text { Gordana Dragana/Milorad somebody else }\end{array}$ \\
\hline
\end{tabular}




\begin{tabular}{|c|c|c|}
\hline Item & Filler & Englis \\
\hline $\begin{array}{l}23 \mathrm{a}, \\
\mathrm{b}\end{array}$ & $\begin{array}{l}\text { Mirjana je gledala slike nameštaja dok je } \\
\text { njena/njegova dizajnerka crtala skice. Isidora } \\
\text { je bila srećna/Nebojša je bio srećan da može } \\
\text { da pomogne u uređenju stana. } \\
\text { Čija je dizajnerka? } \\
\text { Mirjanina Isidorina/Nebojšina od nekog } \\
\text { drugog }\end{array}$ & $\begin{array}{l}\text { Mirjana was looking at photos of furniture } \\
\text { while her/his designer was sketching a design. } \\
\text { Isidora/Nebojsa was happy to help with the } \\
\text { apartment decoration. } \\
\text { Whose designer is it? } \\
\text { Mirjana's Isidora's/Nebojsa's somebody } \\
\text { else's }\end{array}$ \\
\hline $\begin{array}{l}23 \mathrm{c}, \\
\mathrm{d}\end{array}$ & $\begin{array}{l}\text { Mirjana je gledala slike nameštaja dok je cr- } \\
\text { tala/crtao skice. Isidora je bila srećna/Nebojša } \\
\text { je bio srećan da može da pomogne u uređenju } \\
\text { stana. Ko je crtao skice? } \\
\text { Mirjana Isidora/Nebojša neko drugi }\end{array}$ & $\begin{array}{l}\text { Mirjana was looking at photos of furni- } \\
\text { ture while (she)/(he) was sketching a design. } \\
\text { Isidora/Nebojsa was happy to help with the } \\
\text { apartment decoration. Who was sketching a } \\
\text { design? } \\
\text { Mirjana Isidora/Nebojsa somebody else }\end{array}$ \\
\hline $\begin{array}{l}24 \mathrm{a}, \\
\mathrm{b}\end{array}$ & $\begin{array}{l}\text { Milana je pevala pesmicu dok je } \\
\text { njena/njegova učiteljica svirala klavir. } \\
\text { Tamari/Oliveru se svidelo izvođenje kom- } \\
\text { pozicije. Čija je učiteljica? } \\
\text { Milanina Tamarina/Oliverova od nekog } \\
\text { drugog }\end{array}$ & $\begin{array}{l}\text { Milana was singing a song while her/his } \\
\text { teacher was playing the piano. Tamara/Oliver } \\
\text { liked the performance. } \\
\text { Whose teacher is it? } \\
\text { Milana's Tamara's/Oliver's somebody } \\
\text { else's }\end{array}$ \\
\hline $\begin{array}{l}24 \mathrm{c} \\
\mathrm{d}\end{array}$ & $\begin{array}{l}\text { Milana je pevala pesmicu dok je svi- } \\
\text { rala/svirao klavir. Tamari/Oliveru se svidelo } \\
\text { izvođenje kompozicije. } \\
\text { Ko je svirao klavir? } \\
\text { Milana Tamara/Oliver neko drugi }\end{array}$ & $\begin{array}{l}\text { Milana was singing a song while (she)/(he) } \\
\text { was playing the piano. Tamara/Oliver liked } \\
\text { the performance. } \\
\text { Who was playing the piano? } \\
\text { Milana Tamara/Oliver somebody else }\end{array}$ \\
\hline
\end{tabular}




\section{Appendix C}

\section{Experiment 3}

Experiment 3 consists of 24 test items and 24 filler items. All items have 4 versions. The conditions are labelled in the following way for each test item:

a- $\mathrm{C} 1$ : possessive/ gender match

b- C2: possessive/ gender mismatch

c- C3: pronoun/gender match

d- C4: pronoun/ gender mismatch

After each set of items, the corresponding yes/no question is given. English translations are provided in the column on the right. There were 6 practice items.

\section{Practice items}

Table C.1: Experiment 3: Practice items

\begin{tabular}{|c|c|}
\hline Practice item & English translation \\
\hline $\begin{array}{l}\text { Ovo je primer rečenice da se naviknete da čitate } \\
\text { rečenice na ovaj način. }\end{array}$ & $\begin{array}{l}\text { This is an example sentence for you to get used } \\
\text { to read sentences like this. }\end{array}$ \\
\hline $\begin{array}{l}\text { Ovo je još jedan primer rečenice posle koje sledi } \\
\text { pitanje. Kako biste voleli da odgovorite na ovo } \\
\text { pitanje? Pritisnite } 1 \text { / Pritisnite } 2\end{array}$ & $\begin{array}{l}\text { This is another example followed by a question. } \\
\text { How would you like to answer to this question? } \\
\text { Click } 1 \text { / Click } 2\end{array}$ \\
\hline $\begin{array}{l}\text { Njena menadžerka je pričala sa novinarima dok } \\
\text { se Dajana slikala za novine. Jelena se radovala } \\
\text { dolazećem koncertu. } \\
\text { Da li se Dajana slikala za novine? }\end{array}$ & $\begin{array}{l}\text { Her manager was talking to reporters while Da- } \\
\text { jana posed for newspapers. Jelena was looking } \\
\text { forward to the coming concert. } \\
\text { Did Dajana pose for newspapers? }\end{array}$ \\
\hline $\begin{array}{l}\text { Dušan je čitao novine dok je pio kafu. Bojan se } \\
\text { već uveliko razbudio. } \\
\text { Da li je Bojan spavao? }\end{array}$ & $\begin{array}{l}\text { Dusan was reading newspapers while he was } \\
\text { drinking coffee. Bojan was already awake. } \\
\text { Was Bojan asleep? }\end{array}$ \\
\hline
\end{tabular}




\begin{tabular}{|c|c|}
\hline Practi & English translation \\
\hline $\begin{array}{l}\text { Razgovarao je telefonom dok je Darko potpisi- } \\
\text { vao naloge. Dejan je bio ubeđen da će dogovoriti } \\
\text { posao. } \\
\text { Da li je Darko potpisivao autograme? }\end{array}$ & $\begin{array}{l}\text { (He) was talking on the phone while Darko } \\
\text { signed orders. Dejan was sure that he would ar- } \\
\text { range the job. } \\
\text { Did Darko sign autographs? }\end{array}$ \\
\hline $\begin{array}{l}\text { Ovo je poslednja probna rečenica nakon koje } \\
\text { eksperiment počinje. }\end{array}$ & $\begin{array}{l}\text { This is the last trial sentence after which the ex- } \\
\text { periment begins. }\end{array}$ \\
\hline
\end{tabular}

\section{Test items}

Table C.2: Experiment 3: Test items and comprehension questions

\begin{tabular}{|c|c|c|}
\hline Item & em & nglish translation \\
\hline $1 \mathrm{a}$ & $\begin{array}{l}\text { Njegov menadžer je pričao fanovima dok je } \\
\text { Jovan potpisivao autograme. Petar je bio } \\
\text { srećan što je koncert uspešno završen. }\end{array}$ & $\begin{array}{l}\text { signed autographs. Peter was happy that the } \\
\text { concert was successfully finished. }\end{array}$ \\
\hline $1 b$ & $\begin{array}{l}\text { Njen menadžer je pričao fanovima dok je } \\
\text { Jovan potpisivao autograme. Ivana je bila } \\
\text { srećna što je koncert uspešno završen. }\end{array}$ & $\begin{array}{l}\text { Her manager talked to the fans while Jovan } \\
\text { signed autographs. Ivana was happy that the } \\
\text { concert was successfully finished. }\end{array}$ \\
\hline $1 \mathrm{c}$ & $\begin{array}{l}\text { je pričao fanovima dok je Jovan potpisivao } \\
\text { tograme. Petar je bio srećan što je koncert } \\
\text { pešno završen. }\end{array}$ & $\begin{array}{l}\text { He talked to the fans while Jovan signed auto- } \\
\text { graphs. Peter was happy that the concert was } \\
\text { successfully finished. }\end{array}$ \\
\hline $1 d$ & $\begin{array}{l}\text { cala fanovima dok je Jovan potpi- } \\
\text { rrame. Ivana je bila srećna što je } \\
\text { eešno završen. }\end{array}$ & $\begin{array}{l}\text { s while Jovan signed au- } \\
\text { happy that the concert } \\
\text { shed. }\end{array}$ \\
\hline Q1 & & Did Luraf rofuch \\
\hline $\begin{array}{l}2 \mathrm{a}, \\
\mathrm{b}\end{array}$ & $\begin{array}{l}\text { Njegov/Njen doktor je čitao rezultate dok je } \\
\text { Danilo sedeo u ordinaciji. Maksim je bio } \\
\text { zadovoljan/ Bojana je bila zadovoljna dijag- } \\
\text { nozom. }\end{array}$ & $\begin{array}{l}\text { His/Her doctor examined the results while } \\
\text { Danilo was sitting in the doctor's practice. } \\
\text { Maksim/Bojana was satisfied with the diag- } \\
\text { nosis. }\end{array}$ \\
\hline $\begin{array}{l}2 \mathrm{c}, \\
\mathrm{d}\end{array}$ & $\begin{array}{l}\text { /Ona je čitao/la rezultate dok je Danilo } \\
\text { leo u ordinaciji. Maksim je bio zadovol- } \\
\text { /Bojana je bila zadovoljna dijagnozom. }\end{array}$ & $\begin{array}{l}\text { He/She examined the results while Danilo } \\
\text { was sitting in the doctor's practice. Mak- } \\
\text { sim/Bojana was satisfied with the diagnosis. }\end{array}$ \\
\hline Q2 & & \\
\hline $\begin{array}{l}3 \mathrm{a}, \\
\mathrm{b}\end{array}$ & $\begin{array}{l}\text { Njegov/Njen frizer je pravio frizuru dok je } \\
\text { Miloš čekao red. Lazar je bio zadovol- } \\
\text { jan/Jasna je bila zadovoljna izgledom. }\end{array}$ & $\begin{array}{l}\text { His/Her hairdresser was making a hairstyle } \\
\text { while Milos was waiting. Lazar/Jasna was } \\
\text { satisfied with the look. }\end{array}$ \\
\hline $\begin{array}{l}3 \mathrm{c}, \\
\mathrm{d}\end{array}$ & $\begin{array}{l}\text { On/Ona je pravio/la frizuru dok je Miloš } \\
\text { čekao red. Lazar je bio zadovoljan/Jasna je } \\
\text { bila zadovoljna izgledom. }\end{array}$ & $\begin{array}{l}\text { He/She was making a hairstyle while Milos } \\
\text { was waiting. Lazar/Jasna was satisfied with } \\
\text { the look. }\end{array}$ \\
\hline
\end{tabular}




\begin{tabular}{|c|c|c|}
\hline Item & Test item & English translation \\
\hline Q3 & Da li je Miloš čekao u pošti? & Was Milos waiting at the post office? \\
\hline $\begin{array}{l}4 a \\
b\end{array}$ & $\begin{array}{l}\text { Njegov/Njen učitelj je pisao zadatke na tabli } \\
\text { dok je Milan nestrpljivo čekao početak testa. } \\
\text { Bojan je bio ubeđen/Vesna je bila ubeđena da } \\
\text { će svi učenici dobiti dobre ocene. }\end{array}$ & $\begin{array}{l}\text { His/Her teacher was writing assignments on } \\
\text { the blackboard while Milan was impatiently } \\
\text { waiting for the test to begin. Bojan/Vesna was } \\
\text { sure that all the students will get good marks. }\end{array}$ \\
\hline $\begin{array}{l}4 \mathrm{c} \\
\mathrm{d}\end{array}$ & $\begin{array}{l}\text { On/Ona je pisao/la zadatke na tabli dok je Mi- } \\
\text { lan nestrpljivo čekao početak testa. Bojan je } \\
\text { bio ubeđen/Vesna je bila ubeđena da će svi } \\
\text { učenici dobiti dobre ocene. }\end{array}$ & $\begin{array}{l}\text { He/She was writing assignments on the black- } \\
\text { board while Milan was impatiently waiting } \\
\text { for the test to begin. Bojan/Vesna was sure } \\
\text { that all the students will get good marks. }\end{array}$ \\
\hline Q4 & Da li je Milan već položio test? & Has Milan already passed the test? \\
\hline $\begin{array}{l}5 \mathrm{a}, \\
\mathrm{b}\end{array}$ & $\begin{array}{l}\text { Njegov/Njen trener je objašnjavao napad } \\
\text { dok je Zoran oblačio dres. Marko je bio } \\
\text { ubeđen/Milka je bila ubeđena da će pobediti. }\end{array}$ & $\begin{array}{l}\text { His/Her coach was explaining the attack } \\
\text { while Zoran was putting his jersey on. } \\
\text { Marko/Milka was conviced that they will win. }\end{array}$ \\
\hline $\begin{array}{l}5 \mathrm{c} \\
\mathrm{d}\end{array}$ & $\begin{array}{l}\text { On/Ona je objašnjavao/la napad dok je Zoran } \\
\text { oblačio dres. Marko je bio ubeđen/Milka je } \\
\text { bila ubeđena da će pobediti. }\end{array}$ & $\begin{array}{l}\text { He/She was explaining the attack while Zoran } \\
\text { was putting his jersey on. Marko/Milka was } \\
\text { conviced that they will win. }\end{array}$ \\
\hline Q5 & Da li je Zoran skidao dres? & Was Zoran taking off his jersey? \\
\hline $\begin{array}{l}6 \mathrm{a}, \\
\mathrm{b}\end{array}$ & $\begin{array}{l}\text { Njegov/Njen advokat je čitao slučaj dok je } \\
\text { Dejan čekao u kancelariji. Filip je bio opti- } \\
\text { mističan/Elena je bila optimistična u vezi sa } \\
\text { parnicom. }\end{array}$ & $\begin{array}{l}\text { His/Her lawyer was reading the case while } \\
\text { Dejan was sitting in the office. Filip/Elena } \\
\text { was optimistic about the litigation. }\end{array}$ \\
\hline $\begin{array}{l}6 \mathrm{c} \\
\mathrm{d}\end{array}$ & $\begin{array}{l}\text { On/Ona je čitao/la slučaj dok je Dejan čekao } \\
\text { u kancelariji. Filip je bio optimističan/Elena } \\
\text { je bila optimistična u vezi sa parnicom. }\end{array}$ & $\begin{array}{l}\text { He/She was reading the case while Dejan was } \\
\text { sitting in the office. Filip/Elena was opti- } \\
\text { mistic about the litigation. }\end{array}$ \\
\hline Q6 & Da li je Dejan čekao napolju? & Was Dejan waiting outside? \\
\hline $\begin{array}{l}7 \mathrm{a}, \\
\mathrm{b}\end{array}$ & $\begin{array}{l}\text { Njegov/Njen sekretar je razgovorao tele- } \\
\text { fonom dok je Boris potpisivao ugovore. } \\
\text { Dušan je upravo ugovorio/Marta je ugovorila } \\
\text { sastanak sa sponzorima. }\end{array}$ & $\begin{array}{l}\text { His/Her secretary was talking on the phone } \\
\text { while Boris was signing contracts. Du- } \\
\text { san/Marta has just arranged a meeting with } \\
\text { sponsors. }\end{array}$ \\
\hline $\begin{array}{l}7 \mathrm{c} \\
\mathrm{d}\end{array}$ & $\begin{array}{l}\text { On/Ona je razgovorao/la telefonom dok je } \\
\text { Boris potpisivao ugovore. Dušan je upravo } \\
\text { ugovorio/Marta je ugovorila sastanak sa spon- } \\
\text { zorima. }\end{array}$ & $\begin{array}{l}\text { He/She was talking on the phone while Boris } \\
\text { was signing contracts. Dusan/Marta has just } \\
\text { arranged a meeting with sponsors. }\end{array}$ \\
\hline Q7 & Da li je Boris potpisivao ugovore? & Was Boris signing contracts? \\
\hline
\end{tabular}




\begin{tabular}{|c|c|c|}
\hline Item & $\mathrm{m}$ & inglish translation \\
\hline $\begin{array}{l}8 \mathrm{a}, \\
\mathrm{b}\end{array}$ & $\begin{array}{l}\text { Njegov/Njen profesor je pregledao zadatke } \\
\text { dok je Nikola slušao muziku. Stefan je bio } \\
\text { zadovoljan/Jovana je bila zadovoljna rešen- } \\
\text { jima. }\end{array}$ & $\begin{array}{l}\text { His/Her professor was grading assignments } \\
\text { while Nikola was listening to music. Ste- } \\
\text { fan/Jovana was satisfied with the results. }\end{array}$ \\
\hline $\begin{array}{l}8 \mathrm{c}, \\
\mathrm{d}\end{array}$ & $\begin{array}{l}\text { On/Ona je pregledao/la zadatke dok je Nikola } \\
\text { slušao muziku. Stefan je bio zadovol- } \\
\text { jan/Jovana je bila zadovoljna rešenjima. }\end{array}$ & $\begin{array}{l}\text { He/She was grading assignments while } \\
\text { Nikola was listening to music. Stefan/Jovana } \\
\text { was satisfied with the results. }\end{array}$ \\
\hline Q8 & Da li je Nikola slušao muziku? & Was Nikola listening to music? \\
\hline $\begin{array}{l}9 \mathrm{a}, \\
\mathrm{b}\end{array}$ & $\begin{array}{l}\text { Njegov/Njen radnik je čistio alat dok je } \\
\text { Aleksa pričao o narednom poslu. Bogdan je } \\
\text { bio srećan/Marija je bila srećna da se bliži kraj } \\
\text { radnog vremena. }\end{array}$ & $\begin{array}{l}\text { His/Her worker was cleaning the tools while } \\
\text { Aleksa was talking about the next job. Bog- } \\
\text { dan/Marija was happy that it is soon the end } \\
\text { of the working day. }\end{array}$ \\
\hline $\begin{array}{l}9 \mathrm{c}, \\
\mathrm{d}\end{array}$ & $\begin{array}{l}\text { On/Ona je čistio/la alat dok je Aleksa pričao o } \\
\text { narednom poslu. Bogdan je bio srećan/Marija } \\
\text { je bila srećna da se bliži kraj radnog vremena. }\end{array}$ & $\begin{array}{l}\text { He/She was cleaning the tools while Aleksa } \\
\text { was talking about the next job. Bog- } \\
\text { dan/Marija was happy that it is soon the end } \\
\text { of the working day. }\end{array}$ \\
\hline Q9 & & Was Aleksa talking about the next job? \\
\hline $\begin{array}{l}10 a, \\
b\end{array}$ & $\begin{array}{l}\text { Njegov/Njen mehaničar je pregledao auto dok } \\
\text { je Dragan razmišljao o godišnjem odmoru. } \\
\text { Mladen je znao/Tijana je znala da je kvar oz- } \\
\text { biljan. }\end{array}$ & $\begin{array}{l}\text { His/Her mechanic was checking the car } \\
\text { while Dragan was thinking about the holiday. } \\
\text { Mladen/Tijana knew that the damage was se- } \\
\text { rious. }\end{array}$ \\
\hline $\begin{array}{l}10 \mathrm{c}, \\
\mathrm{d}\end{array}$ & $\begin{array}{l}\text { On/Ona je pregledao/la auto dok je Dragan } \\
\text { razmišljao o godišnjem odmoru. Mladen je } \\
\text { znao/Tijana je znala da je kvar ozbiljan. }\end{array}$ & $\begin{array}{l}\text { He/She was checking the car while Dra- } \\
\text { gan was thinking about the holiday. } \\
\text { Mladen/Tijana knew that the damage } \\
\text { was serious. }\end{array}$ \\
\hline Q10 & $\begin{array}{l}\text { Da li je Dragan razmišljao o godišnjem } \\
\text { odmoru? }\end{array}$ & Was Dragan thinking about the holiday? \\
\hline $\begin{array}{l}11 \mathrm{a}, \\
\mathrm{b}\end{array}$ & $\begin{array}{l}\text { Njegov/Njen savetnik je predlagao rešenja } \\
\text { dok je Stevan čitao katalog. Branko nije bio } \\
\text { zadovoljan/Milica nije bila zadovoljna sug- } \\
\text { estijama. }\end{array}$ & $\begin{array}{l}\text { His/Her adviser was suggesting solutions } \\
\text { while Stevan was reading a catalogue. } \\
\text { Branko/Milica wasn't satisfied with the ideas. }\end{array}$ \\
\hline $\begin{array}{l}11 \mathrm{c}, \\
\mathrm{d}\end{array}$ & $\begin{array}{l}\text { On/Ona je predlagao/la rešenja dok je Ste- } \\
\text { van čitao katalog. Branko nije bio zadovol- } \\
\text { jan/Milica nije bila zadovoljna sugestijama. }\end{array}$ & $\begin{array}{l}\text { He/She was suggesting solutions while Ste- } \\
\text { van was reading a catalogue. Branko/Milica } \\
\text { wasn't satisfied with the ideas. }\end{array}$ \\
\hline Q11 & Da li je Stevan čitao katalog? & Was Stevan reading a catalogue? \\
\hline
\end{tabular}




\begin{tabular}{|c|c|c|}
\hline Item & Test item & English translation \\
\hline $\begin{array}{l}12 \mathrm{a}, \\
\mathrm{b}\end{array}$ & $\begin{array}{l}\text { Njegov/Njen majstor je krečio zid dok je Sto- } \\
\text { jan pevušio melodiju iz filma. Vedranu/Milici } \\
\text { se svidela nova boja sobe. }\end{array}$ & $\begin{array}{l}\text { His/Her worker was painting the wall while } \\
\text { Stojan was singing a melody from a movie. } \\
\text { Vedran/Milica liked the new colour of the } \\
\text { room. }\end{array}$ \\
\hline $\begin{array}{l}12 \mathrm{c}, \\
\mathrm{d}\end{array}$ & $\begin{array}{l}\text { On/Ona je krečio/la zid dok je Stojan pevušio } \\
\text { melodiju iz filma. Vedranu/Milici se svidela } \\
\text { nova boja sobe. }\end{array}$ & $\begin{array}{l}\text { He/She was painting the wall while Stojan } \\
\text { was singing a melody from a movie. Ve- } \\
\text { dran/Milica liked the new colour of the room. }\end{array}$ \\
\hline Q12 & Da li je Stojan pevušio melodiju iz filma? & Was Stojan singing a melody from a movie? \\
\hline $\begin{array}{l}13 \mathrm{a}, \\
\mathrm{b}\end{array}$ & $\begin{array}{l}\text { Njena/Njegova frizerka je mešala farbu dok je } \\
\text { Branka čekala da joj se kosa osuši. Nevena } \\
\text { je bila zadovoljna/Damjan je bio zadovoljan } \\
\text { bojom. }\end{array}$ & $\begin{array}{l}\text { Her/His hairdresser was mixing the dye while } \\
\text { Branka was waiting her hair to get dry. } \\
\text { Nevena/Damjan was satisfied with the colour. }\end{array}$ \\
\hline $\begin{array}{l}13 \mathrm{c}, \\
\mathrm{d}\end{array}$ & $\begin{array}{l}\text { Ona/On je mešala/o farbu dok je Branka } \\
\text { čekala da joj se kosa osuši. Nevena je bila } \\
\text { zadovoljna/Damjan je bio zadovoljan bojom. }\end{array}$ & $\begin{array}{l}\text { She/He was mixing the dye while Branka was } \\
\text { waiting her hair to get dry. Nevena/Damjan } \\
\text { was satisfied with the colour. }\end{array}$ \\
\hline Q13 & $\begin{array}{l}\text { Da li je Nevena/Damjan bila/o nezado- } \\
\text { voljna/an bojom? }\end{array}$ & $\begin{array}{l}\text { Was Nevena/Damjana unhappy with the } \\
\text { colour? }\end{array}$ \\
\hline $\begin{array}{l}14 \mathrm{a}, \\
\mathrm{b}\end{array}$ & $\begin{array}{l}\text { Njena/Njegova knjigovođa je sabirala račune } \\
\text { dok je Dušica računala u Excel-u. Zorana } \\
\text { nije bila zadovoljna/Tadija nije bio zadovol- } \\
\text { jan brojkama. }\end{array}$ & $\begin{array}{l}\text { Her/His accountant was working on the bills } \\
\text { while Dusica was working in Excel. Zo- } \\
\text { rana/Tadija was not happy with the numbers. }\end{array}$ \\
\hline $\begin{array}{l}14 \mathrm{c}, \\
\mathrm{d}\end{array}$ & $\begin{array}{l}\text { Ona/Ona je sabirala/o račune dok je Dušica } \\
\text { računala u Excel-u. Zorana nije bila zado- } \\
\text { voljna/Tadija nije bio zadovoljan brojkama. }\end{array}$ & $\begin{array}{l}\text { She/He was working on the bills while Dusica } \\
\text { was working in Excel. Zorana/Tadija was not } \\
\text { happy with the numbers. }\end{array}$ \\
\hline Q14 & $\begin{array}{l}\text { Da li je Zorana/Tadija bila/o zadovoljnalan } \\
\text { brojkama? }\end{array}$ & Was Zorana/Tadija happy with the numbers? \\
\hline $\begin{array}{l}15 \mathrm{a}, \\
\mathrm{b}\end{array}$ & $\begin{array}{l}\text { Njena/Njegova krojačica je uzimala mere dok } \\
\text { je Danica razmišljala o bojama i materijalima. } \\
\text { Zorica je bila takođe veoma uzbuđena/Siniša } \\
\text { je bio uzbuđen zbog venčanja. }\end{array}$ & $\begin{array}{l}\text { Her/His tailor was getting the measurements } \\
\text { while Danica was thinking about the decora- } \\
\text { tion. Zorica/Sinisa was excited because of the } \\
\text { wedding. }\end{array}$ \\
\hline $\begin{array}{l}15 \mathrm{c}, \\
\mathrm{d}\end{array}$ & $\begin{array}{l}\text { Ona/On je uzimala/o mere dok je Danica } \\
\text { razmišljala o bojama i materijalima. Zorica } \\
\text { je bila takođe veoma uzbuđena/Siniša je bio } \\
\text { uzbuđen zbog venčanja. }\end{array}$ & $\begin{array}{l}\text { She/He was getting the measurements while } \\
\text { Danica was thinking about the decoration. } \\
\text { Zorica/Sinisa was excited because of the wed- } \\
\text { ding. }\end{array}$ \\
\hline Q15 & Da li je venčanje prošlo? & Was the wedding over? \\
\hline
\end{tabular}




\begin{tabular}{|c|c|c|}
\hline Item & Test $\mathrm{i}$ & English translation \\
\hline $16 a$ & $\begin{array}{l}\text { Njena/Njegova pomoćnica je kuvala sarmu } \\
\text { dok je Lidija gledala youtube. Milena je bila } \\
\text { srećna/Sreten je bio srećan kako je ručak is- } \\
\text { pao. }\end{array}$ & $\begin{array}{l}\text { Her/His chef was cooking sarma while Lidija } \\
\text { was watching youtube. Milena/Sreten was } \\
\text { happy how the lunch turned out. }\end{array}$ \\
\hline $16 \mathrm{c}$ & $\begin{array}{l}\text { Ona/On je kuvala/o sarmu dok je Lidija } \\
\text { gledala youtube. Milena je bila srećna/Sreten } \\
\text { je bio srećan kako je ručak ispao. }\end{array}$ & $\begin{array}{l}\text { She/He was cooking sarma while Lidija was } \\
\text { watching youtube. Milena/Sreten was happy } \\
\text { how the lunch turned out. }\end{array}$ \\
\hline Q16 & $\begin{array}{l}\text { Da li je Milena/Sreten bilalo srećna/an kako } \\
\text { je večera ispala? }\end{array}$ & $\begin{array}{l}\text { Was Milena/Sreten happy how the dinner } \\
\text { turned out? }\end{array}$ \\
\hline $\begin{array}{l}17 \mathrm{a}, \\
\mathrm{b}\end{array}$ & $\begin{array}{l}\text { Njena/Njegova dadilja je čuvala bebu dok se } \\
\text { Olivera spremala za posao. Tatjana je bila } \\
\text { srećna/Miodrag je bio srećan što je beba u do- } \\
\text { brim rukama. }\end{array}$ & $\begin{array}{l}\text { Her/His nanny was looking after the baby } \\
\text { while Olivera was getting ready for work. } \\
\text { Tatjana/Miodrag was happy that the baby was } \\
\text { in good hands. }\end{array}$ \\
\hline $\begin{array}{l}17 \mathrm{c} \\
\mathrm{d}\end{array}$ & $\begin{array}{l}\text { Ona/On je čuvala/o bebu dok se Olivera spre- } \\
\text { mala za posao. Tatjana je bila srećna/Miodrag } \\
\text { je bio srećan što je beba u dobrim rukama. }\end{array}$ & $\begin{array}{l}\text { She/He was looking after the baby while } \\
\text { Olivera was getting ready for work. Tat- } \\
\text { jana/Miodrag was happy that the baby was in } \\
\text { good hands. }\end{array}$ \\
\hline Q17 & Da li je Tatjana/ Miodrag bila/o nesrećna/an? & Was Tatjana/ Miodrag unhappy? \\
\hline $\begin{array}{l}18 \mathrm{a}, \\
\mathrm{b}\end{array}$ & $\begin{array}{l}\text { Njena/Njegova šefica je radila za kom- } \\
\text { pjuterom dok je Sandra slušala muziku. Sofija } \\
\text { je bila umorna/Rastko je bio umoran od } \\
\text { gledanja u monitor. }\end{array}$ & $\begin{array}{l}\text { Her/His boss was working on the com- } \\
\text { puter while Sandra was listening to music. } \\
\text { Sofija/Rastko was tired from looking at the } \\
\text { screen. }\end{array}$ \\
\hline $\begin{array}{l}18 \mathrm{c}, \\
\mathrm{d}\end{array}$ & $\begin{array}{l}\text { Ona/On je radila/o za kompjuterom dok } \\
\text { je Sandra slušala muziku. Sofija je bila } \\
\text { umorna/Rastko je bio umoran od gledanja u } \\
\text { monitor. }\end{array}$ & $\begin{array}{l}\text { She/He was working on the computer while } \\
\text { Sandra was listening to music. Sofija/Rastko } \\
\text { was tired from looking at the screen. }\end{array}$ \\
\hline Q18 & $\begin{array}{l}\text { Da li je Sofija/ Rastko bilalo umornalan od } \\
\text { trčanja? }\end{array}$ & Was Sofija/ Rastko tired from running? \\
\hline $\begin{array}{l}19 \mathrm{a}, \\
\mathrm{b}\end{array}$ & $\begin{array}{l}\text { Njena/Njegova zubarka je čistila instrumente } \\
\text { dok je Suzana još sedela na zubarskoj } \\
\text { stolici. Helena je bila zabrinuta/Vladan je bio } \\
\text { zabrinut zbog popravke zuba. }\end{array}$ & $\begin{array}{l}\text { Her/His dentist was cleaning the instruments } \\
\text { while Sandra was sitting in the praxis. He- } \\
\text { lena/Vladan was worried because of the tooth } \\
\text { intervention. }\end{array}$ \\
\hline $\begin{array}{l}19 \mathrm{c}, \\
\mathrm{d}\end{array}$ & $\begin{array}{l}\text { Ona/On je čistila/o instrumente dok je Suzana } \\
\text { još sedela na zubarskoj stolici. Helena je } \\
\text { bila zabrinuta/Vladan je bio zabrinut zbog } \\
\text { popravke zuba. }\end{array}$ & $\begin{array}{l}\text { She/He was cleaning the instruments while } \\
\text { Sandra was sitting in the praxis. He- } \\
\text { lena/Vladan was worried because of the tooth } \\
\text { intervention. }\end{array}$ \\
\hline
\end{tabular}




\begin{tabular}{|c|c|c|}
\hline Item & Test item & English translation \\
\hline Q19 & $\begin{array}{l}\text { Da li je Helena/Vladan bila/o zabrinut(a) } \\
\text { zbog popravke zuba? }\end{array}$ & $\begin{array}{l}\text { Was Helena/Vladan worried because of the } \\
\text { tooth intervention? }\end{array}$ \\
\hline $\begin{array}{l}20 a, \\
b\end{array}$ & $\begin{array}{l}\text { Njena/Njegova doktorica je prepisivala recept } \\
\text { dok je Teodora pričala o simptomima. Slav- } \\
\text { ica je znala/Andrija je znao koji će lek biti od } \\
\text { pomoći. }\end{array}$ & $\begin{array}{l}\text { Her/His doctor was prescribing a prescription } \\
\text { while Teodora was talking about the symp- } \\
\text { toms. Slavica/Andrija knew which medicine } \\
\text { will be helpful }\end{array}$ \\
\hline $\begin{array}{l}20 \mathrm{c}, \\
\mathrm{d}\end{array}$ & $\begin{array}{l}\text { Ona/Ona je prepisivala/o recept dok je } \\
\text { Teodora pričala o simptomima. Slavica je } \\
\text { znala/Andrija je znao koji će lek biti od po- } \\
\text { moći. }\end{array}$ & $\begin{array}{l}\text { She/He was prescribing a prescription while } \\
\text { Teodora was talking about the symptoms. } \\
\text { Slavica/Andrija knew which medicine will be } \\
\text { helpful. }\end{array}$ \\
\hline Q20 & $\begin{array}{l}\text { Da li je Slavica/Andrija znalalo koji će lek po- } \\
\text { moći? }\end{array}$ & $\begin{array}{l}\text { Did Slavica/Andrija know which medicine } \\
\text { will be helpful? }\end{array}$ \\
\hline $\begin{array}{l}21 \mathrm{a}, \\
\mathrm{b}\end{array}$ & $\begin{array}{l}\text { Njena/Njegova sluškinja je peglala košulje } \\
\text { dok je Snežana gledala seriju. Violeta je bila } \\
\text { srećna/Dalibor je bio srećan što je kuća skoro } \\
\text { spremljena. }\end{array}$ & $\begin{array}{l}\text { Her/His cleaning lady was ironing the shirts } \\
\text { while Snezana was watching the series. Vi- } \\
\text { oleta/Dalibor was satisfied that the house is } \\
\text { almost tidy. }\end{array}$ \\
\hline $\begin{array}{l}21 \mathrm{c}, \\
\mathrm{d}\end{array}$ & $\begin{array}{l}\text { Ona/On je peglala/o košulje dok je Snežana } \\
\text { gledala seriju. Violeta je bila srećna/Dalibor } \\
\text { je bio srećan što je kuća skoro spremljena. }\end{array}$ & $\begin{array}{l}\text { She/He was ironing the shirts while Snezana } \\
\text { was watching the series. Violeta/Dalibor was } \\
\text { satisfied that the house is almost tidy. }\end{array}$ \\
\hline Q21 & $\begin{array}{l}\text { Da li je Violeta/Dalibor bila/o srećna/an jer } \\
\text { je kuća skoro spremljena? }\end{array}$ & $\begin{array}{l}\text { Was Violeta/Dalibor satisfied that the house is } \\
\text { almost tidy? }\end{array}$ \\
\hline $\begin{array}{l}22 \mathrm{a}, \\
\mathrm{b}\end{array}$ & $\begin{array}{l}\text { Njena/Njegova direktorica je pregledala } \\
\text { dokumentaciju dok je Gordana razgovarala } \\
\text { sa zaposlenima. Dragana se radovala/Milorad } \\
\text { se radovao novom projektu. }\end{array}$ & $\begin{array}{l}\text { Her/His director was checking the documen- } \\
\text { tation while Gordana was talking to the em- } \\
\text { ployees. Dragana/Milorad was looking for- } \\
\text { ward to the new project. }\end{array}$ \\
\hline $\begin{array}{l}22 \mathrm{c} \\
\mathrm{d}\end{array}$ & $\begin{array}{l}\text { Ona/On je pregledala/o dokumentaciju dok je } \\
\text { Gordana razgovarala sa zaposlenima. Dra- } \\
\text { gana se radovala/Milorad se radovao novom } \\
\text { projektu. }\end{array}$ & $\begin{array}{l}\text { She/He was checking the documentation } \\
\text { while Gordana was talking to the employees. } \\
\text { Dragana/Milorad was looking forward to the } \\
\text { new project. }\end{array}$ \\
\hline Q22 & $\begin{array}{l}\text { Da li se Dragana/Milorad radovala/o novom } \\
\text { projektu? }\end{array}$ & $\begin{array}{l}\text { Was Dragana/Milorad looking forward to the } \\
\text { new project? }\end{array}$ \\
\hline $\begin{array}{l}23 \mathrm{a}, \\
\mathrm{b}\end{array}$ & $\begin{array}{l}\text { Njena/Njegova dizajnerka je crtala skice dok } \\
\text { je Mirjana gledala slike nameštaja. Isidora je } \\
\text { bila srećna/Nebojša je bio srećan da može da } \\
\text { pomogne u uređenju stana. }\end{array}$ & $\begin{array}{l}\text { Her/His designer was sketching a design } \\
\text { while Mirjana was looking at photos of furni- } \\
\text { ture. Isidora/Nebojsa was happy to help with } \\
\text { the apartment decoration. }\end{array}$ \\
\hline
\end{tabular}




\begin{tabular}{l|l|l}
\hline Item & Test item & English translation \\
\hline $23 \mathrm{c}$ & $\begin{array}{l}\text { Ona/On je crtala/o skice dok je Mirjana } \\
\text { gledala slike nameštaja. Isidora je bila } \\
\text { srećna/Nebojša je bio srećan da može da po- } \\
\text { mogne u uređenju stana. }\end{array}$ & $\begin{array}{l}\text { She/He was sketching a design while Mir- } \\
\text { jana was looking at photos of furniture. } \\
\text { Isidora/Nebojsa was happy to help with the } \\
\text { apartment decoration. }\end{array}$ \\
\hline Q23 & $\begin{array}{l}\text { Da li je Isidora/Nebojša bila/o srećna/an da } \\
\text { može pomoći pri uređenju stana? }\end{array}$ & $\begin{array}{l}\text { Was Isidora/Nebojsa happy to help with the } \\
\text { apartment decoration? }\end{array}$ \\
\hline 24a, & $\begin{array}{l}\text { Njena/Njegova učiteljica je svirala klavir dok } \\
\text { je Milana pevala pesmicu. Tamari/Oliveru se } \\
\text { b }\end{array}$ & $\begin{array}{l}\text { Her/His teacher was playing the piano while } \\
\text { Milana was singing a song. Tamara/Oliver } \\
\text { liked the performance. }\end{array}$ \\
\hline $\begin{array}{l}\text { 24c, }, \\
\mathrm{d}\end{array}$ & $\begin{array}{l}\text { Ona/On je svirala/o klavir dok je Milana } \\
\text { pevala pesmicu. Tamari/Oliveru se svidelo } \\
\text { izvođenje kompozicije. }\end{array}$ & $\begin{array}{l}\text { She/He was playing the piano while Milana } \\
\text { was singing a song. Tamara/Oliver liked the } \\
\text { performance. }\end{array}$ \\
\hline Q24 & $\begin{array}{l}\text { Da li se Tamari/Oliveru svidelo izvođenje } \\
\text { kompozicije? }\end{array}$ & \begin{tabular}{l} 
Did Tamara/Oliver like the performance? \\
\hline
\end{tabular}
\end{tabular}

\section{Fillers}

Filler items are presented in the same manner as the test items in the Table below.

Table C.3: Experiment 3: Filler items and comprehension questions

\begin{tabular}{l|l|l}
\hline Item & Filler item & English translation \\
\hline 1a & $\begin{array}{l}\text { Kada je Dejan ušao u kuću, on je pričao tele- } \\
\text { fonom. Miloš se obradovao pozivu. }\end{array}$ & $\begin{array}{l}\text { When Dejan entered the house, he was talking } \\
\text { on the phone. Milos was happy about the call. }\end{array}$ \\
\hline 1b & $\begin{array}{l}\text { Kada je Dejan ušao u kuću, pričao je tele- } \\
\text { fonom. Miloš se obradovao pozivu. }\end{array}$ & $\begin{array}{l}\text { When Dejan entered the house, (he) was talk- } \\
\text { ing on the phone. Milos was happy about the } \\
\text { call. }\end{array}$ \\
\hline 1c & $\begin{array}{l}\text { Kada je Dejan ušao u kuću, ona je pričala tele- } \\
\text { fonom. Anica se obradovala pozivu. }\end{array}$ & $\begin{array}{l}\text { When Dejan entered the house, she was talk- } \\
\text { ing on the phone. Anica was happy about the } \\
\text { call. }\end{array}$ \\
\hline 1d & $\begin{array}{l}\text { Kada je Dejan ušao u kuću, pričala je tele- } \\
\text { fonom. Anica se obradovala pozivu. }\end{array}$ & $\begin{array}{l}\text { When Dejan entered the house, (she) was } \\
\text { talking on the phone. Anica was happy about } \\
\text { the call. }\end{array}$ \\
\hline Q1 & Da li je Dejan izašao iz kuće? & Did Dejan leave the house? \\
\hline $\begin{array}{l}\text { 2a, } \\
\text { b }\end{array}$ & $\begin{array}{l}\text { Kada je Milan završio posao, (on) je otišao u } \\
\text { prodavnicu. Darko je kupio čips i sok. }\end{array}$ & $\begin{array}{l}\text { When Milan finished his work, (he) went to } \\
\text { the store. Darko bought chips and juice. }\end{array}$ \\
\hline 2c, & $\begin{array}{l}\text { Kada je Milan završio posao, (ona) je otišla u } \\
\text { prodavnicu. Milica je kupila čips i sok. }\end{array}$ & $\begin{array}{l}\text { When Milan finished his work, (she) went to } \\
\text { the store. Milica bought chips and juice. }\end{array}$ \\
\hline Q2 & Da li je Milan tek započeo posao? & Has Milan just started to work? \\
\hline
\end{tabular}




\begin{tabular}{|c|c|c|}
\hline Item & Filler item & English translation \\
\hline $\begin{array}{l}3 \mathrm{a}, \\
\mathrm{b}\end{array}$ & $\begin{array}{l}\text { Kada je Bojan stigao u školu, (on) je ušao u } \\
\text { učionicu. Boško je pozdravio drugove. }\end{array}$ & $\begin{array}{l}\text { When Bojan came to school, (he) entered the } \\
\text { classroom. Bosko greeted his friends. }\end{array}$ \\
\hline $\begin{array}{l}3 \mathrm{c}, \\
\mathrm{d}\end{array}$ & $\begin{array}{l}\text { Kada je Bojan stigao u školu, (ona) je ušla u } \\
\text { učionicu. Elena je pozdravila drugove. }\end{array}$ & $\begin{array}{l}\text { When Bojan came to school, (she) entered the } \\
\text { classroom. Elena greeted his friends. }\end{array}$ \\
\hline Q3 & Da li se Bojan vratio iz škole? & Did Bojan come back from school? \\
\hline $\begin{array}{l}4 a, \\
b\end{array}$ & $\begin{array}{l}\text { Kada je Đorđe došao u bioskop, (on) je kupio } \\
\text { kokice. Marko je jedva čekao da počne film. }\end{array}$ & $\begin{array}{l}\text { When Djordje came to the cinema, (he) } \\
\text { bought popcorns. Marko could hardly wait } \\
\text { for the movie to start. }\end{array}$ \\
\hline $\begin{array}{l}4 \mathrm{c}, \\
\mathrm{d}\end{array}$ & $\begin{array}{l}\text { Kada je Đorđe došao u bioskop, (ona) je } \\
\text { kupila kokice. Ivona je jedva čekala da počne } \\
\text { film. }\end{array}$ & $\begin{array}{l}\text { When Djordje came to the cinema, (she) } \\
\text { bought popcorns. Ivona could hardly wait for } \\
\text { the movie to start. }\end{array}$ \\
\hline Q4 & Da li je Đorđe došao u pozorište? & Did Djordje come to the theater? \\
\hline $\begin{array}{l}5 \mathrm{a}, \\
\mathrm{b}\end{array}$ & $\begin{array}{l}\text { Kada je Zoran došao s posla, (on) je skuvao } \\
\text { špagete. Lazar je već bio gladan. }\end{array}$ & $\begin{array}{l}\text { When Zoran came home from work, (he) } \\
\text { cooked spaghetti. Lazar was already hungry. }\end{array}$ \\
\hline $\begin{array}{l}5 \mathrm{c}, \\
\mathrm{d}\end{array}$ & $\begin{array}{l}\text { Kada je Zoran došao s posla, (ona) je skuvala } \\
\text { špagete. Lenka je već bila gladna. }\end{array}$ & $\begin{array}{l}\text { When Zoran came home from work, (she) } \\
\text { cooked spaghetti. Lenka was already hungry. }\end{array}$ \\
\hline Q5 & Da li je Zoran tek otišao na posao? & Has Zoran just gone to work? \\
\hline $\begin{array}{l}6 a, \\
b\end{array}$ & $\begin{array}{l}\text { Kada je Mladen završio sa ispitom, (on) je } \\
\text { proverio tačne odgovore. Stefan je sve dobro } \\
\text { uradio. }\end{array}$ & $\begin{array}{l}\text { When Mladen finished the exam, (he) } \\
\text { checked the correct answers. Stefan did ev- } \\
\text { erything well. }\end{array}$ \\
\hline $6 \mathrm{c}, \mathrm{d}$ & $\begin{array}{l}\text { Kada je Mladen završio sa ispitom, (ona) je } \\
\text { proverila tačne odgovore. Jelena je sve dobro } \\
\text { uradila. }\end{array}$ & $\begin{array}{l}\text { When Mladen finished the exam, (she) } \\
\text { checked the correct answers. Jelena did ev- } \\
\text { erything well. }\end{array}$ \\
\hline Q6 & Da li je Mladen tek počeo ispit? & Has Mladen just started the exam? \\
\hline $\begin{array}{l}7 \mathrm{a}, \\
\mathrm{b}\end{array}$ & $\begin{array}{l}\text { Kada je Jovan pročitao tekst, (on) je upalio } \\
\text { televizor. Vlada je gledao neku krimi seriju. }\end{array}$ & $\begin{array}{l}\text { When Jovan read the text, (he) turned on the } \\
\text { TV. Vlada was watching some crime series. }\end{array}$ \\
\hline $\begin{array}{l}7 \mathrm{c}, \\
\mathrm{d}\end{array}$ & $\begin{array}{l}\text { Kada je Jovan pročitao tekst, (ona) je upalila } \\
\text { televizor. Vesna je gledala neku krimi seriju. }\end{array}$ & $\begin{array}{l}\text { When Jovan read the text, (she) turned on the } \\
\text { TV. Vesna was watching some crime series. }\end{array}$ \\
\hline Q7 & Da li je Jovan pročitao tekst? & Did Jovan read the text? \\
\hline $\begin{array}{l}8 \mathrm{a}, \\
\mathrm{b}\end{array}$ & $\begin{array}{l}\text { Kada je Aleksa pokvario mobilni, (on) je ku- } \\
\text { pio novi telefon. Vladan je platio svojom kar- } \\
\text { ticom. }\end{array}$ & $\begin{array}{l}\text { When Aleksa broke his cell phone, (he) } \\
\text { bought a new one. Vladan paid with his card. }\end{array}$ \\
\hline $\begin{array}{l}8 \mathrm{c}, \\
\mathrm{d}\end{array}$ & $\begin{array}{l}\text { Kada je Aleksa pokvario mobilni, (ona) je } \\
\text { kupila novi telefon. Dušica je platila svojom } \\
\text { karticom. }\end{array}$ & $\begin{array}{l}\text { When Aleksa broke his cell phone, (she) } \\
\text { bought a new one. Dusica paid with her card. }\end{array}$ \\
\hline Q8 & Da li je Aleksa pokvario mobilni? & Did Aleksa break the cell phone? \\
\hline
\end{tabular}




\begin{tabular}{|c|c|c|}
\hline Item & Filler item & English translation \\
\hline $\begin{array}{l}9 a, \\
b\end{array}$ & $\begin{array}{l}\text { Kada je Danilo stigao u stan, (on) je otključao } \\
\text { vrata. Maksim je već bio kod kuće. }\end{array}$ & $\begin{array}{l}\text { When Danilo arrived to the apartment, (he) } \\
\text { unlocked the door. Maxim was already at } \\
\text { home. }\end{array}$ \\
\hline $\begin{array}{l}9 \mathrm{c}, \\
\mathrm{d}\end{array}$ & $\begin{array}{l}\text { Kada je Danilo stigao u stan, (ona) je } \\
\text { otključala vrata. Tijana je već bila kod kuće. }\end{array}$ & $\begin{array}{l}\text { When Danilo arrived to the apartment, (she) } \\
\text { unlocked the door. Tijana was already at } \\
\text { home. }\end{array}$ \\
\hline Q9 & Da li je Danilo stigao u stan? & Did Danilo arrive to the apartment? \\
\hline $\begin{array}{l}10 \mathrm{a}, \\
\mathrm{b}\end{array}$ & $\begin{array}{l}\text { Kada je Filip ušao u avion, (on) je bio up- } \\
\text { lašen. Momir je već sedeo na sedištu. }\end{array}$ & $\begin{array}{l}\text { When Filip got on the plane, (he) was scared. } \\
\text { Momir was already sitting on the seat. }\end{array}$ \\
\hline $\begin{array}{l}10 \mathrm{c}, \\
\mathrm{d}\end{array}$ & $\begin{array}{l}\text { Kada je Filip ušao u avion, (ona) je bila up- } \\
\text { lašena. Milka je već sedela na sedištu. }\end{array}$ & $\begin{array}{l}\text { When Filip got on the plane, (she) was scared. } \\
\text { Milka was already sitting on the seat. }\end{array}$ \\
\hline Q10 & Da li je Filip ušao u avion? & Did Filip got on the plane? \\
\hline $\begin{array}{l}11 \mathrm{a}, \\
\mathrm{b}\end{array}$ & $\begin{array}{l}\text { Kada je Željko započeo sastank, (on) je pode- } \\
\text { lio dokumenta. Damjan je objasnio protokol. }\end{array}$ & $\begin{array}{l}\text { When Zeljko started the meeting, (he) dis- } \\
\text { tributed the documents. Damjan explained } \\
\text { the protocol. }\end{array}$ \\
\hline $\begin{array}{l}\text { 11c, } \\
\mathrm{d}\end{array}$ & $\begin{array}{l}\text { Kada je Željko započeo sastank, (ona) je } \\
\text { podelila dokumenta. Bojana je objasnila pro- } \\
\text { tokol. }\end{array}$ & $\begin{array}{l}\text { When Zeljko started the meeting, (she) dis- } \\
\text { tributed the documents. Bojana explained the } \\
\text { protocol. }\end{array}$ \\
\hline Q11 & Da li je Željko započeo sastanak? & Did Zeljko start the meeting? \\
\hline $\begin{array}{l}12 \mathrm{a}, \\
\mathrm{b}\end{array}$ & $\begin{array}{l}\text { Kada je Viktor izašao u dvorište, (on) je čistio } \\
\text { sneg. Dmitar je već bio umoran. }\end{array}$ & $\begin{array}{l}\text { When Victor went out into the yard, (he) was } \\
\text { clearing the snow. Dmitar was already tired. }\end{array}$ \\
\hline $\begin{array}{l}12 \mathrm{c}, \\
\mathrm{d}\end{array}$ & $\begin{array}{l}\text { Kada je Viktor izašao u dvorište, (ona) je čis- } \\
\text { tila sneg. Jovana je već bila umorna. }\end{array}$ & $\begin{array}{l}\text { When Victor went out into the yard, (she) was } \\
\text { clearing the snow. Jovana was already tired. }\end{array}$ \\
\hline Q12 & Da li je Viktor izašao u dvorište? & Did Viktor go out into the yard? \\
\hline $\begin{array}{l}13 \mathrm{a}, \\
\mathrm{b}\end{array}$ & $\begin{array}{l}\text { Kada je Violeta oprala ruke, (ona) je spremila } \\
\text { večeru. Dragana je bila gladna. }\end{array}$ & $\begin{array}{l}\text { When Violeta washed her hands, (she) pre- } \\
\text { pared dinner. Dragana was hungry. }\end{array}$ \\
\hline $\begin{array}{l}13 \mathrm{c}, \\
\mathrm{d}\end{array}$ & $\begin{array}{l}\text { Kada je Violeta oprala ruke, (on) je spremio } \\
\text { večeru. Miodrag je bio gladan. }\end{array}$ & $\begin{array}{l}\text { When Violeta washed her hands, (he) pre- } \\
\text { pared dinner. Miodrag was hungry. }\end{array}$ \\
\hline Q13 & Da li je Dragana/Miodrag bio/la sit? & Was Dragana/Miodrag full? \\
\hline $\begin{array}{l}14 \mathrm{a}, \\
\mathrm{b}\end{array}$ & $\begin{array}{l}\text { Kada je Đurđica uključila TV, (ona) je pre- } \\
\text { bacila na vesti. Anđelka je čekala vremensku } \\
\text { prognozu. }\end{array}$ & $\begin{array}{l}\text { When Djurdjica turned on the TV, (she) } \\
\text { switched to the news. Andjelka was waiting } \\
\text { for the weather forecast. }\end{array}$ \\
\hline $\begin{array}{l}14 \mathrm{c}, \\
\mathrm{d}\end{array}$ & $\begin{array}{l}\text { Kada je Đurđica uključila TV, (on) je prebacio } \\
\text { na vesti. Anđelko je čekao vremensku prog- } \\
\text { nozu. }\end{array}$ & $\begin{array}{l}\text { When Djurdjica turned on the TV, (he) } \\
\text { switched to the news. Andjelko was waiting } \\
\text { for the weather forecast. }\end{array}$ \\
\hline
\end{tabular}




\begin{tabular}{|c|c|c|}
\hline Item & Filler item & English translation \\
\hline Q14 & $\begin{array}{l}\text { Da li je Anđelka/Anđelko čekao/la sportske } \\
\text { vesti? }\end{array}$ & $\begin{array}{l}\text { Was Andjelko/Andjelka waiting for the sports } \\
\text { news? }\end{array}$ \\
\hline $\begin{array}{l}15 \mathrm{a}, \\
\mathrm{b}\end{array}$ & $\begin{array}{l}\text { Kada je Olivera skuvala kafu, (ona) je izašla } \\
\text { na terasu. Isidora je gledala izlazak sunca. }\end{array}$ & $\begin{array}{l}\text { When Olivera made coffee, (she) went out to } \\
\text { the balcony. Isidora watched the sunrise. }\end{array}$ \\
\hline $\begin{array}{l}15 \mathrm{c}, \\
\mathrm{d}\end{array}$ & $\begin{array}{l}\text { Kada je Olivera skuvala kafu, (on) je izašao } \\
\text { na terasu. Milorad je gledao izlazak sunca. }\end{array}$ & $\begin{array}{l}\text { When Olivera made coffee, (he) went out to } \\
\text { the balcony. Milorad watched the sunrise. }\end{array}$ \\
\hline Q15 & $\begin{array}{l}\text { Da li je Isidora/Milorad gledao/la kišu mete- } \\
\text { ora? }\end{array}$ & $\begin{array}{l}\text { Did Isidoral Milorad watch the meteor } \\
\text { shower? }\end{array}$ \\
\hline $\begin{array}{l}16 a, \\
b\end{array}$ & $\begin{array}{l}\text { Kada je Mirjana došla u centar, (ona) je sedela } \\
\text { u kafeteriji. Teodora je pila kapućino. }\end{array}$ & $\begin{array}{l}\text { When Mirjana came to the city center, (she) } \\
\text { was sitting in the cafeteria. Theodora was } \\
\text { drinking cappuccino. }\end{array}$ \\
\hline $\begin{array}{l}16 \mathrm{c}, \\
\mathrm{d}\end{array}$ & $\begin{array}{l}\text { Kada je Mirjana došla u centar, (on) je sedeo } \\
\text { u kafeteriji. Siniša je pio kapućino. }\end{array}$ & $\begin{array}{l}\text { When Mirjana came to the city center, (he) } \\
\text { was sitting in the cafeteria. Sinisa was drink- } \\
\text { ing cappuccino. }\end{array}$ \\
\hline Q16 & Da li je Teodora/Siniša pio/la vino? & Was Teodora/Sinisa drinking wine? \\
\hline $\begin{array}{l}17 \mathrm{a}, \\
\mathrm{b}\end{array}$ & $\begin{array}{l}\text { Kada je Zorica oprala posuđe, (ona) je brisala } \\
\text { čaše. Suzana je razbila šarenu čašu. }\end{array}$ & $\begin{array}{l}\text { When Zorica washed the dishes, (she) wiped } \\
\text { the glasses. Suzana broke the colorful glass. }\end{array}$ \\
\hline $\begin{array}{l}17 \mathrm{c} \\
\mathrm{d}\end{array}$ & $\begin{array}{l}\text { Kada je Zorica oprala posuđe, (on) je brisao } \\
\text { čaše. Nikola je razbio šarenu čašu. }\end{array}$ & $\begin{array}{l}\text { When Zorica washed the dishes, (he) wiped } \\
\text { the glasses. Nikola broke the colorful glass. }\end{array}$ \\
\hline Q17 & Da li je Suzana/Nikola razbio/la zeleni tanjir? & Did Suzana/ Nikola break the green plate? \\
\hline $\begin{array}{l}18 \mathrm{a}, \\
\mathrm{b}\end{array}$ & $\begin{array}{l}\text { Kada je Zorana usisala stan, (ona) je prala } \\
\text { prozore. Milana je već oprala veš. }\end{array}$ & $\begin{array}{l}\text { When Zorana vacuumed the apartment, (she) } \\
\text { was cleaning the windows. Milana has al- } \\
\text { ready done the laundry. }\end{array}$ \\
\hline $\begin{array}{l}18 \mathrm{c}, \\
\mathrm{d}\end{array}$ & $\begin{array}{l}\text { Kada je Zorana usisala stan, (on) je prao pro- } \\
\text { zore. Mladen je već oprao veš. }\end{array}$ & $\begin{array}{l}\text { When Zorana vacuumed the apartment, (he) } \\
\text { was cleaning the windows. Mladen has al- } \\
\text { ready done the laundry. }\end{array}$ \\
\hline Q18 & $\begin{array}{l}\text { Da li je Milana/Mladen odbio/la da opere } \\
\text { vešs? }\end{array}$ & Did Milana/ Mladen refuse to do the laundry? \\
\hline $\begin{array}{l}19 a \\
b\end{array}$ & $\begin{array}{l}\text { Kada je Tamara došla u kancelariju, (ona) je } \\
\text { radila za kompjuterom. Simona je završila } \\
\text { izveštaj. }\end{array}$ & $\begin{array}{l}\text { When Tamara came to the office, (she) was } \\
\text { working at the computer. Simona finished the } \\
\text { report. }\end{array}$ \\
\hline $\begin{array}{l}19 \mathrm{c} \\
\mathrm{d}\end{array}$ & $\begin{array}{l}\text { Kada je Tamara došla u kancelariju, (on) je ra- } \\
\text { dio za kompjuterom. Stevan je završio izveš- } \\
\text { taj. }\end{array}$ & $\begin{array}{l}\text { When Tamara came to the office, (he) was } \\
\text { working at the computer. Stevan finished the } \\
\text { report. }\end{array}$ \\
\hline Q19 & Da li je Simona/Stevan završio/la izveštaj? & Did Simona/Stevan finish the report? \\
\hline
\end{tabular}




\begin{tabular}{|c|c|c|}
\hline Item & Filler & English translation \\
\hline $\begin{array}{l}20 \mathrm{a}, \\
\mathrm{b}\end{array}$ & $\begin{array}{l}\text { Kada je Helena stigla na more, (ona) je otišla } \\
\text { na plažu. Julija je uživala u sunčanju. }\end{array}$ & $\begin{array}{l}\text { When Helena arrived at the seaside, (she) } \\
\text { went to the beach. Julia enjoyed sunbathing. }\end{array}$ \\
\hline $\begin{array}{l}20 \mathrm{c}, \\
\mathrm{d}\end{array}$ & $\begin{array}{l}\text { Kada je Helena stigla na more, (on) je otišao } \\
\text { na plažu. Teodor je uživao u sunčanju. }\end{array}$ & $\begin{array}{l}\text { When Helena arrived at the seaside, (he) went } \\
\text { to the beach. Teodor enjoyed sunbathing. }\end{array}$ \\
\hline Q20 & Da li je Julija/Teodor uživao/la u sunčanju? & Did Julija/Teodor enjoy sunbathing? \\
\hline $\begin{array}{l}21 \mathrm{a}, \\
\mathrm{b}\end{array}$ & $\begin{array}{l}\text { Kada se Ivana vratila kući, (ona) je ispekla } \\
\text { picu. Petra je postavila sto. }\end{array}$ & $\begin{array}{l}\text { When Ivana returned home, (she) baked a } \\
\text { pizza. Petra set the table. }\end{array}$ \\
\hline $\begin{array}{l}21 \mathrm{c}, \\
\mathrm{d}\end{array}$ & $\begin{array}{l}\text { Kada se Ivana vratila kući, (on) je ispekao } \\
\text { picu. Petar je postavio sto. }\end{array}$ & $\begin{array}{l}\text { When Ivana returned home, (he) baked a } \\
\text { pizza. Petar set the table. }\end{array}$ \\
\hline Q21 & Da li je $P$ & $\operatorname{Did} P$ \\
\hline $\begin{array}{l}22 \mathrm{a}, \\
\mathrm{b}\end{array}$ & $\begin{array}{l}\text { Kada se Tatjana istuširala, (ona) je ispeglala } \\
\text { košulju. Gordana je bila spremna za izlazak. }\end{array}$ & $\begin{array}{l}\text { When Tatjana took a shower, (she) ironed her } \\
\text { shirt. Gordana was ready to go out. }\end{array}$ \\
\hline $\begin{array}{l}22 \mathrm{c}, \\
\mathrm{d}\end{array}$ & $\begin{array}{l}\text { Kada se Tatjana istuširala, (on) je ispeglao } \\
\text { košulju. Radomir je bio spreman za izlazak. }\end{array}$ & $\begin{array}{l}\text { When Tatjana took a shower, (he) ironed her } \\
\text { shirt. Radomir was ready to go out. }\end{array}$ \\
\hline Q22 & $\begin{array}{l}\text { Da li je Gordana/Radomir bio/la spremna/an } \\
\text { za izlazak? }\end{array}$ & Was Gordana/Radomir ready to \\
\hline $\begin{array}{l}23 a \\
b\end{array}$ & $\begin{array}{l}\text { Kada je Jelica završila smenu, (ona) je otišla } \\
\text { u teretanu. Jagoda je trčala na traci. }\end{array}$ & $\begin{array}{l}\text { When Jelica finished her shift, (she) went to } \\
\text { the gym. Jagoda was running on the tread- } \\
\text { mill. }\end{array}$ \\
\hline $\begin{array}{l}23 \mathrm{c}, \\
\mathrm{d}\end{array}$ & $\begin{array}{l}\text { Kada je Jelica završila smenu, (on) je otišao u } \\
\text { teretanu. Branko je trčao na traci. }\end{array}$ & $\begin{array}{l}\text { When Jelica finished her shift, (he) went to } \\
\text { the gym. Branko was running on the tread- } \\
\text { mill. }\end{array}$ \\
\hline Q23 & Da li je Jagoda/Branko trčao/la na traci? & $\begin{array}{l}\text { Was Jagoda/Branko running on the tread- } \\
\text { mill? }\end{array}$ \\
\hline $\begin{array}{l}24 a, \\
b\end{array}$ & $\begin{array}{l}\text { Kada je Marija počela s kursom, (ona) nije } \\
\text { imala nikakvo predznanje. Lidija se nadala } \\
\text { da će dosta naučiti. }\end{array}$ & $\begin{array}{l}\text { When Marija started the course, (she) had no } \\
\text { prior knowledge. Lydia hoped to learn a lot. }\end{array}$ \\
\hline $\begin{array}{l}24 \mathrm{c}, \\
\mathrm{d}\end{array}$ & $\begin{array}{l}\text { Kada je Marija počela s kursom, (on) nije } \\
\text { imao nikakvo predznanje. Jovica se nadao da } \\
\text { će dosta naučiti. }\end{array}$ & $\begin{array}{l}\text { When Marija started the course, (he) had no } \\
\text { prior knowledge. Jovica hoped to learn a lot. }\end{array}$ \\
\hline Q24 & $\begin{array}{l}\text { Da li se Lidija/Jovica nadao/la da će dosta } \\
\text { naučiti? }\end{array}$ & Did Lidija/Jovica hope to learn a lot? \\
\hline
\end{tabular}


The post-hoc Tukey Test

Table C.4: The post-hoc Tukey Test - Pairwise comparison at the critical word region (N1)

\begin{tabular}{llccccc} 
Ccommand & Gender & lsmean & SE & df & lower.CL & upper.CL \\
\hline possessive & match & 6.14 & 0.0460 & 68.8 & 6.05 & 6.23 \\
pronoun & match & 6.12 & 0.0461 & 69.0 & 6.02 & 6.21 \\
possessive & mismatch & 6.25 & 0.0461 & 69.1 & 6.16 & 6.34 \\
pronoun & mismatch & 6.13 & 0.0461 & 68.9 & 6.03 & 6.22 \\
\hline
\end{tabular}

\begin{tabular}{lccccc} 
contrast & estimate & SE & df & t.ratio & p.value \\
\hline possessive,match -pronoun,match & 0.0232 & 0.0281 & 997 & 0.830 & 0.8420 \\
possessive,match -possessive,mismatch & -0.1100 & 0.0281 & 996 & -3.920 & 0.0010 \\
possessive,match -pronoun,mismatch & 0.0146 & 0.0280 & 996 & 0.520 & 0.9540 \\
pronoun,match -possessive,mismatch & -0.1332 & 0.0281 & 996 & -4.730 & $<.0001$ \\
pronoun,match -pronoun,mismatch & -0.0086 & 0.0281 & 996 & -0.310 & 0.9900 \\
possessive,mismatch -pronoun,mismatch & 0.1246 & 0.0281 & 997 & 4.430 & $<.0001$ \\
\hline
\end{tabular}

Note. twowayl $=$ lsmeans (mla, pairwise Ccommand ${ }^{*}$ Gender, adjust="tukey") 
Table C.5: The post-hoc Tukey Test - Pairwise comparison at the spillover region (N2)

\begin{tabular}{llccccc} 
Ccommand & Gender & lsmean & SE & df & lower.CL & upper.CL \\
\hline possessive & match & 6.15 & 0.0404 & 65.3 & 6.07 & 6.23 \\
pronoun & match & 6.15 & 0.0404 & 65.4 & 6.07 & 6.23 \\
possessive & mismatch & 6.23 & 0.0404 & 65.5 & 6.15 & 6.31 \\
pronoun & mismatch & 6.16 & 0.0404 & 65.4 & 6.08 & 6.24
\end{tabular}

\begin{tabular}{lccccc} 
contrast & estimate & SE & df & t.ratio & p.value \\
\hline possessive,match -pronoun,match & 0.0006 & 0.0208 & 2054 & 0.030 & 1.0000 \\
possessive,match -possessive,mismatch & -0.0800 & 0.0208 & 2053 & -3.850 & 0.0010 \\
possessive,match -pronoun,mismatch & -0.0029 & 0.0208 & 2053 & -0.140 & 0.9990 \\
pronoun,match -possessive,mismatch & -0.0806 & 0.0208 & 2053 & -3.870 & 0.0010 \\
pronoun,match -pronoun,mismatch & -0.0035 & 0.0208 & 2053 & -0.170 & 0.9980 \\
possessive,mismatch -pronoun,mismatch & 0.0771 & 0.0208 & 2054 & 3.700 & 0.0010 \\
\hline
\end{tabular}

Note. twoway $1=l$ smeans $\left(m 2 a\right.$, pairwise Ccommand ${ }^{*}$ Gender, adjust="tukey") 